\title{
The Life and Demography of the Side-Blotched Lizard, Uta stansburiana
}

\author{
BY \\ DONALD W. TINKLE \\ Museum of Zoology, University of Michigan
}




\section{MisCELLANEOUS PUBLICATIONS \\ MUSEUM OF ZOOLOGY, UNIVERSITY OF MICHIGAN}

The publications of the Museum of Zoology, University of Michigan, consist of two series-the Occasional Papers and the Miscellaneous Publications. Both series were founded by Dr. Bryant Walker, Mr. Bradshaw H. Swales, and Dr. W. W. Newcomb.

The Occasional Papers, publication of which was begun in 1913, serve as a medium for original studies based principally upon the collections in the Museum. They are issued separately. When a sufficient number of pages has been printed to make a volume, a title page, table of contents, and an index are supplied to libraries and individuals on the mailing list for the series.

The Miscellaneous Publications, which include papers on field and museum techniques, monographic studies, and other contributions not within the scope of the Occasional Papers, are published separately. It is not intended that they be grouped into volumes. Each number has a title page and, when necessary, a table of contents.

A complete list of publications on Birds, Fishes, Insects, Mammals, Mollusks, and Reptiles and Amphibians is available. Address nnquiries to the Director, Museum of Zoology, Ann Arbor, Michigan.

\section{List of Mrscellaneous Publications on Reptiles and Amphibians}

No. 8. The amphibians and reptiles of the Sierra Nevada de Santa Marta, Colombia. By Alexander G. Ruthven. (1922) 69 pp., 12 pls., 2 figs., 1 map ... $\$ 1.00$

No. 29. A contribution to a knowledge of the herpetology of a portion of the Savanna Region of Central Petén, Guatemala. By L. C. Stuart. (1935) 56 pp., 4 pls., 1 fig., 1 map ............................ $\$ 0.50$

No. 47. A contribution to the herpetology of the Isthmus of Tehuantepec. IV. An annotated list of the amphibians and reptiles collected on the Pacific slope during the summer of 1936. By NoRman Hartweg aND JAmes A. Oliver. (1940) 31 pp. ........................ $\$ 0.35$

No. 49. Studies of Neotropical Colubrinae. VIII. A revision of the genus Dryadophis Stuart. 1939. By L. C. Stuart. (1941) 106 pp., 4 pls., 13 figs.,

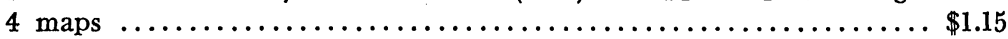

No. 50. A contribution to the knowledge of variation in Opheodrys vernalis (Harlan), with the description of a new subspecies. By ARNold B. GroBMAN. (1941) 38 pp., 2 figs., 1 map ....................... $\$ 0.35$

No. 56. Taxonomic and geographic comments on Guatemalan salamanders of the genus Oedipus. By L. C. Stuart. (1943) 33 pp., 2 pls., 1 map ... $\$ 0.35$

No. 61. Home range, homing behavior, and migration in turtles. By Fred R. CAGLE. (1944) 34 pp., 2 pls., 4 figs., 1 map .................... $\$ 0.35$

No. 69. The amphibians and reptiles of Alta Verapaz, Guatemala. By L. C. StUART. (1948) 109 pp., 10 figs., 1 map ...................... $\$ 1.50$

No. 76. Studies of the black swamp snake, Seminatrix pygaea (Cope), with descriptions of two new subspecies. By Herndon G. Dowling. (1950) 38 pp., 6 figs., 1 map ............................... $\$ 1.25$

No. 91. A brief review of the Guatemalan lizards of the genus Anolis. By L. C.

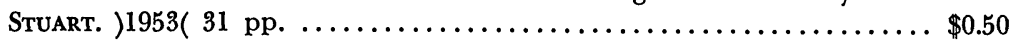

No. 94. The anatomy of the head of Ctenosaura pectinata (Iguanidae). By Thomas M. Oelrich. (1956) 122 pp., 59 figs. .................. $\$ 1.85$

No. 96. The frogs of the hylid genus Phrynohyas Fitzinger, 1843. By William E. Duellman. (1956) 47 pp., 6 pls., 10 figs., 4 maps . .............. $\$ 0.70$

No. 97. Variation and relative growth in the plastral scutes of the turtle Kinosternon integrum Leconte. By James E. Mosimann. (1956) 43 pp., 1 pl., 24 figs. 


\section{The Life and Demography of the Side-Blotched Lizard, Uta stansburiana}

BY

DONALD W. TINKLE

Museum of Zoology, University of Michigan 


\section{CONTENTS}

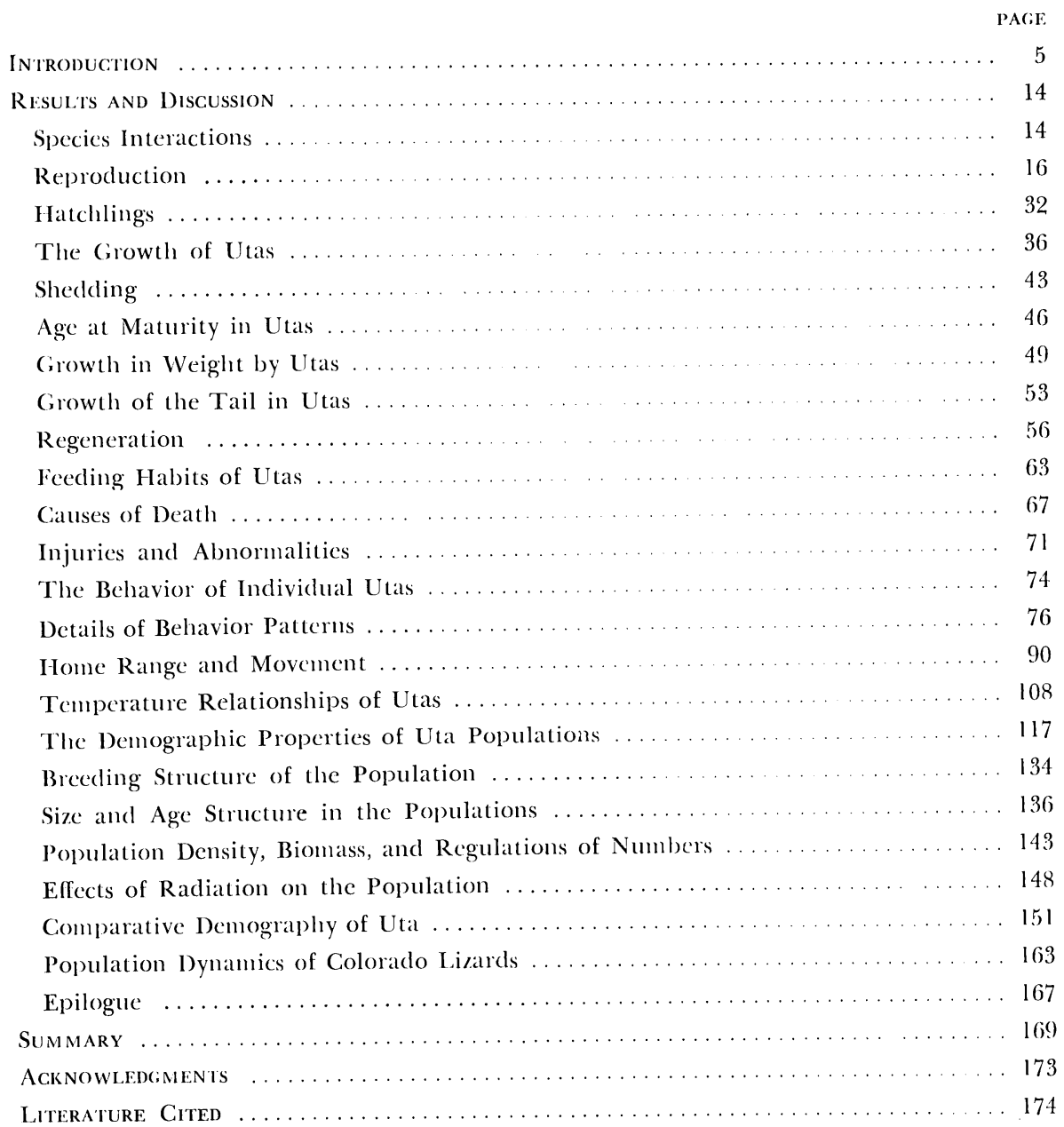




\section{ILLUSTRATIONS}

PI.ATE

PAGE

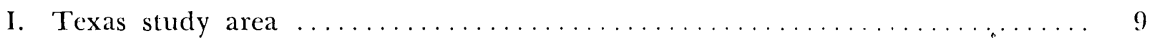

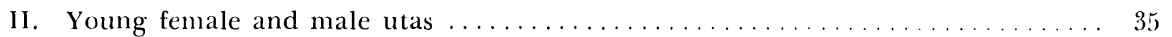

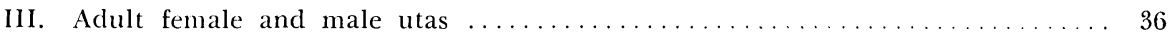

IV. Adult female and male uta from Colorado . . . . . . . . . . . . . . . . . . . 153

FIGURE

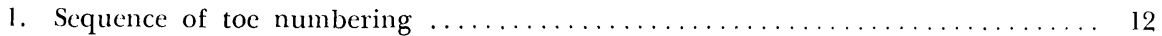

2. Insignia used for individual recognition $\ldots \ldots \ldots \ldots \ldots \ldots$

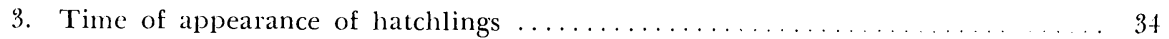

4. Correlation of weight with snout-vent length $\ldots \ldots \ldots \ldots \ldots \ldots$

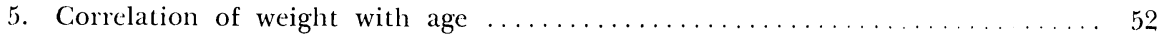

6. Length of tail plotted against snout-vent length $\ldots \ldots \ldots \ldots \ldots$

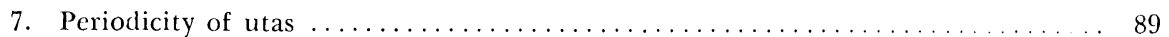

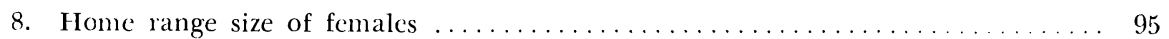

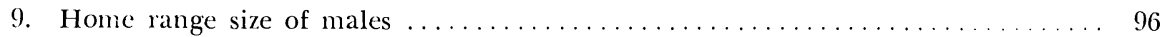

10. Mean temperatures of cloaca, substrate, and air $\ldots \ldots \ldots \ldots \ldots \ldots 11$

11. Air temperatures in unshaded portion of study area $\ldots \ldots \ldots \ldots \ldots$

12. Temperatures at surface in shade of yuccas and 6 inches beneath surface ... . . 116

13. Temperatures in sum and in shade of mesquite $\ldots \ldots \ldots \ldots \ldots \ldots \ldots$

14. Air temperature and temperature 1 inch below surface $\ldots \ldots \ldots \ldots$

15. Air temperature above ground and in artificial burrow . . . . . . . . . . . 119

16. Air temperature above ground and inside packrat nest .............. 120

17. Survivorship curve for male and female utas . . . . . . . . . . . . . . . . 129

18. Age structure of males in uta population $\ldots \ldots \ldots \ldots \ldots \ldots \ldots$

19. Age structure of females in uta population $\ldots \ldots \ldots \ldots \ldots \ldots$

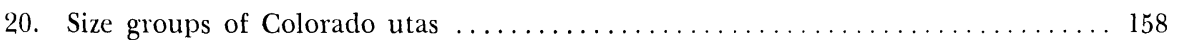





\section{INTRODUCTION}

DFTAIIfD Studifs of natural populations, particularly of reptiles, are rare. Such studies are essential to disclose what ecological differences exist at the individual and population level in response to the environmental conditions prevailing in the area of study. These differences are generally quantitative and, at least for this reason, population studies must be quantitative. It is not sufficient, and perhaps not significant, to know the form of a growth curve for single individuals or to know its longevity. The average rate of growth of a large sample of a local population and the life expectancy of its members are of greater interest.

Most studies of life histories suffer from a lack of quantitative results; this fault exists in some aspects of this study. Consequently, meaningful comparisons of different species or of different populations of the same species cannot be made because the ecological parameters of the populations are inexactly known. The principal aim of this study has been to quantify as many aspects of the life history of the side-blotched lizard as possible.

Apart from the importance of such a descriptive study of the autecology of a species, it should also generate testable predictions concerning the demography of the same species in different parts of its range. The study should suggest laboratory and field experiments that may be of more importance in answering specific questions than is post facto descriptive ecology. Finally, quantitative data may be useful to those interested in the theoretical aspects of population ecology and of microevolution. I can do no better than to paraphrase the statement of Cole (1954) that such things as birth rate, death rate, and the age composition of a population as well as its ability to reproduce were consequences of the life history features of the individual organism. Natural selection will be influential in shaping life history patterns to correspond to efficient populations. Comparative studies of life history appear to be fully as meaningful as studies of comparative morphology, comparative psychology, or comparative physiology, but have been neglected from the evolutionary point of view.

The present study had its inception in 1957 , but intensive field studies were begun in 1960 and continued through 1966. During this period I conducted numerous experiments in the field and laboratory, but the majority of the information has come from 3729 lizards marked in the field, from which we have obtained 12,927 captures. Several thousand additional lizards have been collected for studies ranging from the determination of clutch 
size to experiments with the extrinsic factors responsible for initiating estrous. The results have been a fairly complete knowledge of the biology of this species.

Throughout the ensuing discussions I have drawn heavily from my own previous publications and those of my students. Because I have been aided in this research by a large number of students, it has become difficult for me to distinguish their ideas from my own. I trust it will be clear to each of them where such has been the case and that they will accept credit for the idea and forgive my usurpation of it.

Taxonomic Relationships of Uta.-The genus Uta contains perhaps a half dozen generally recognized species of iguanid lizards. For many years the genus was a larger and probably unnatural one until Mittleman (1942) suggested that it be divided into four genera, viz. Uta, Urosaurus, Streptosaurus, and Petrosaurus. The taxonomic position and validity of these have been variously regarded by Lowe (1955), Savage (1958), Carpenter (1962), and Etheridge (1964); the genus Uta has been recognized by all of these authors, but with obviously close relationship to Urosaurus.

Only one species in the genus (U. stansburiana) has a wide range, which encompasses that of the genus. The other species in the genus, with the exception of the problematical Uta taylori of mainland Mexico, are exclusively insular in the Gulf of California or in the Pacific adjacent to Baja California.

Just when the genus Uta evolved in North America is a matter for conjecture. Auffenberg and Milstead (1965) have pointed to the common conclusion that little speciation has occurred in reptiles since the Pliocene, at least as indicated by the meager fossil record. It seems reasonable to conclude that $U$ ta was present in the Pliocene, but possibly much earlier. The only fossil Uta are recorded from the very late Pleistocene or sub-Recent from the La Brea tar pits (Brattstrom, 1953). Inasmuch as neither Uta nor its close relatives are mesically adapted, it seems unnecessary to look beyond the time of the origin of the western deserts to determine the maximum age of the genus in North America. Utas are essentially Sonoran species. However, outside of this ecological restriction they are abundant in a great variety of semi-arid to arid habitats. Savage (1960) pointed out that Uta stansburiana is one of the few lizard species that is found in all of the four recognized faunal zones of Baja California. Banta (1962) in his consideration of the zoogeography of the lizards of the Great Basin suggested that the extensive range and climatic tolerance of $U t a$ indicate that it may have occupied the basin for a long time with its range simply expanding and contracting with changes in aridity. 
Distribution and Habitat Prefrerinci.-Uta stansburiana ranges from northern Durango and northern Zacatecas north and west through Coahuila, Chihuahua, and Sonora, Mexico (including islands throughout the length of the Gulf of California), and the peninsula of Baja California. From these areas the range extends northward through parts of southern California, Arizona, most of Nevada, eastern Oregon and southeastern Washington. From this northern extreme, the range passes southward and eastward on the western side of the Rocky Mountains and Great Plains through parts of Idaho, Utah, extreme western Colorado, and most of New Mexico to the western quarter of Texas. I am familiar with this species throughout most of its range and have been continually impressed by its ecological amplitude. It occurs on hillsides and boulder rocks, in desert washes, in sand dune areas, sagebrush flats, and in areas of sparse grass cover. It is difficult to discern the preferred habitat, but the species seems to reach its greatest density in sandy areas of western Texas, where most of our studies have been conducted, and on certain sandy beaches (e.g. Carmen Island) in the Gulf of California. In some areas it is restricted primarily to single microhabitats, probably because of competitive interactions with other species. Utas will seldom move far when disturbed, so close proximity of rocks, mammal burrows, or shrubs is always a common leature of uta habitat.

Throughout their range, utas are relatively abundant. They are seldom exceeded in numbers wherever they occur, and in many localities may be by far the most abundant species of lizard. In fact, this great abundance and conspicuousness first attracted my attention.

Some of the gross factors that limit the geographic distribution of Uta are the Great Plains and mountains much above 6000 feet. Grasslands are generally a barrier, and the low cold tolerance of the species restricts it altitudinally and latitudinally. Within apparently suitable areas, competition with other species may be an important factor limiting utas. In western Texas, Holbrookia maculata, another small iguanid lizard, is the dominant species of the High Plains grasslands; it and Uta are almost always ecologically exclusive, though broadly sympatric. In the western United States, Sceloporus graciosus is the dominant lizard in the dry plains. This species, too, is broadly sympatric with $U t a$, but it is an exceptional situation where they occur together in nearly equal abundance. Within the broad habitat limits of utas, there are some associations in which they are rarely found. These include rocky areas with little vegetation and heavily shaded or wooded areas. Utas are strongly heliothermic and avoid shaded areas even in cleserts, where they are uncommon in dense thickets. Although no experimental studies of habitat preference in this lizard (or any other) have been 
made, I think that such would demonstrate the avoidance of thick vegetation by the lizards.

Description of the Species.-Uta stansburiana is a small lizard. Adult males may occasionally reach $60 \mathrm{~mm}$ snout-vent; females are always somewhat smaller. Sexual dimorphism in color is variable. In the eastern populations of the species (subspecies stejnegeri) the males are generally unstriped, with numerous blue flecks over the dorsal surface and tail. There may be a suffusion of orange or yellow along the flanks, colors which are particularly pronounced during the breeding season. The female, in contrast, is a drab gray or brown with two dorsolateral stripes that may be broken. Both sexes have a prominent blotch behind the forearm in the axillary region. In the northwest (subspecies stansburiana) there is little sexual dimorphism and both sexes are unstriped and generally without any obvious pattern to break the ground color. Such differences doubtlessly have an adaptive basis and offer excellent material for a study of its nature.

Another characteristic of some Uta populations is a high degree of polymorphism in pattern. In western Texas, this is exhibited by both sexes, but more obviously in the female, which may have unbroken dorsolateral stripes, stripes that are intersected at intervals by short oblique lines, or stripes broken into a pattern of chevron-like markings. Some females lack a dorsal pattern entirely. The frequencies of these types vary from one locality to another, but usually occur well above the frequency expected from recurrent mutation. Hence, they offer excellent material for a study of adaptive polymorphism (Ballinger and McKinney, 1967).

Description of the Study Areas.-Most of the information presented here was collected from the area around Kermit, Winkler County, Texas, at an elevation of 2900 feet. Two study areas located two miles apart in similar habitat were gridded with lettered and numbered stakes set at intervals of 20 feet. Each area was a square 100 yards on a side, about 2 acres. The type of habitat is shown in Plate I. Short mesquite trees (Prosopis juliflora), yuccas (Yucca sp), sandsage (Artemisia filifolia), broomweed (Xanthocephalum sarothrae), and shinoak (Quercus sp.) are the dominant plants. There are few native grasses remaining in the area, but this was undoubtedly the original dominant vegetation. Overgrazing coupled with an unstable sandy soil has led to deterioration of the habitat. However, before the demise of the grasslands it seems likely that $U t a$ was scarce in this area just as it is in the less disturbed grasslands that still exist in part of wetern Texas. In any event, Uta certainly occurred in the nearby Chihuahuan desert from which it may have been a recent invader. 

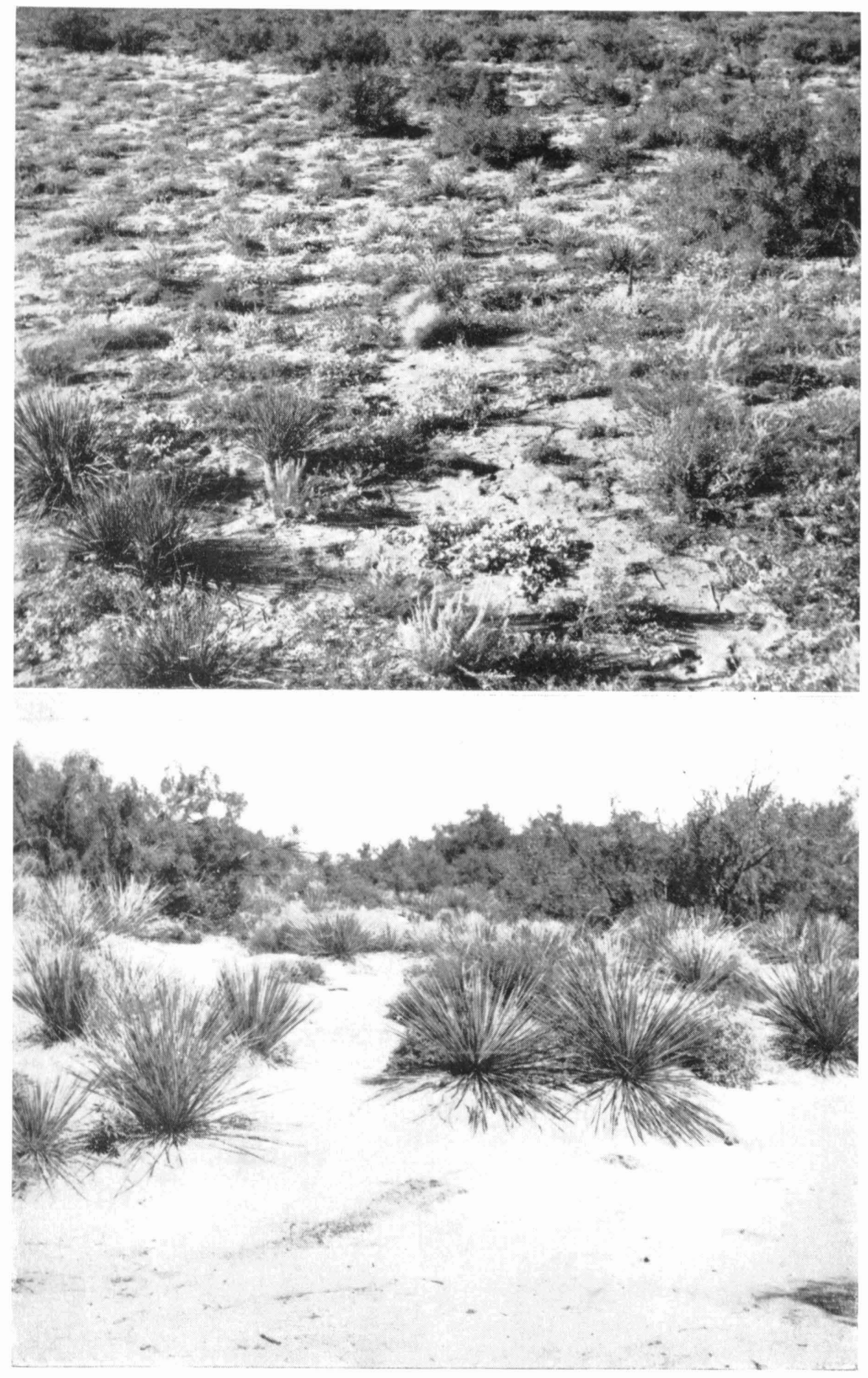

PLATE I

Texas study area. The top photo was taken after summer rains and shows numerous annual weeds in the bare sand between the scattered sages, yuccas, and mesquites. The lower photo shows the large yuccas that are a favored resting, and presumably nesting, site for utas. 
The plant cover has been estimated (I inkle et al., 1962) at about 20 per cent of the ground area, so that much of the study areas is bare aeolian sancl. Following summer rains there is a great increase in plant cover by a variety of annual weeds and, seemingly, a concommitant increase in the quantity of insects.

The area is characterized by hot summers and mild winters with freezing temperatures primarily at night. However, the geographic position of this area at the southern end of the Great Plains, the low humidity, and the moderate altitude make possible very sudden and rather extreme temperature changes as high pressure systems force cold air southward down the Great Plains. During this study I have recorded temperatures down to $-12^{\circ} \mathrm{F}$ and as high as $120^{\circ}$. The rainfall averages about 15 inches annually, mostly in spring and summer; snowfall usually occurs each year, but is a negligible source of moisture. High wind velocities are characteristic of this area and result in considerable blowing and clrifting of the unstable sand so that high dunes exist in several places near the study areas.

Mrtholns of Working thl: Study Arfas and Capturing Lizards.-The study areas were worked in a systematic fashion. Each person chose one row of quadrats and walked slowly across the entire area remaining at all times between two rows of stakes. Each bush and other hiding place was agitated when necessary to locate each lizard.

The areas were worked at every hour of the day. When a lizard was seen a stake was set in the sand to mark the position. The lizard was often captured a considerable distance from where it was first seen, but its capture location was always recorded at the point of first sighting and this is where the lizard was released after all pertinent data were collected. Determination of the lizard's exact position at each capture was made by two coordinate measurements to the nearest quadrat stake.

The time required to go through an area completely was dependent on the number of persons involved, the number of lizards to be handled, and the amount of clata taken. Sometimes as little as one hour was required, sometimes ten hours or longer were spent getting through the area.

The areas were intensively studied. We have gone through them as many as three times in a single day, though twice a day was more usual. We found it effective to work each area intensively for several days and then leave it alone for a variable period of time.

Another method of obtaining data was frequently used. Each person would choose an individual lizard and follow it continuously, making notes of its movements and activities. Uta is not easily clisturbed by close observation provided the observer does not make distracting movements. It was 
frequently possible to watch such things as mating and courtship from a vantage point only a few feet from the animal.

On numerous occasions we worked to distances of several hundred feet beyond the margins of the study areas to cletermine the extent of emigration from the areas.

Several methods have been employed in capturing lizards. We first tried to use stationary drift fences along which pitfall cans were buried at regular intervals. Over a two-week period, only 2 utas were caught during continuous operation of 600 feet of fence. A more successful technique was the use of a section of 18" hardware cloth 10-12 feet long as a portable drift fence into which lizards were driven from their retreats in bushes or packrat nests.

After only a few weeks of such technique we discovered that the lizards were easy to catch by hand if they were properly approached, and this technique was used almost exclusively throughout the study, being partially supplanted only in the last year or so by noosing. However, nooses are generally effective for only a short time because the lizards become wary of them after a few experiences. For sampling purposes, blowguns (Tinkle and Lawrence, 1956) were used almost exclusively. We have found them effective in almost every type of situation from open areas to heavy brush, accurate and less clamaging to the lizards than dust shot or rubber bands. Samples of 50 lizards were frequently collected in a few hours with this device. For obtaining live lizards, hand capture or noosing was employed. Some of our largest samples, of 200 or more animals, were taken during the winter months from beneath boards and debris in the oil fields surrounding the study areas. The lizards take refuge beneath these surface covers during cold or wet weather and are often torpid and easily caught simply by visiting sufficient oilfields over a one- or two-day period. On a few occasions lizards were dug from the sand around the rims of packrat nests; they frequently burrowed there during extremely cold weather.

Trfatment of the Lizaris after Capturl.-Each lizard was permanently marked by clipping up to four toes. Never were adjacent toes clipped, nor more than two on a single foot. The system used was a simple one requiring no previous experience to read the toe-clip numbers (Figure 1). The numbers were read as the actual numbers of the toes removed. Thus, removal of toes 2, 7, and 11 would result in number 2-7-11. All adult lizards were painted with a distinctive insignia (Fig. 2) with one of three easily visible colors. Shedding resulted in confusion of insignias in some cases, but usually the animal's number could be determined by sighting the insignia without the necessity of continuously chasing and recapturing it. 

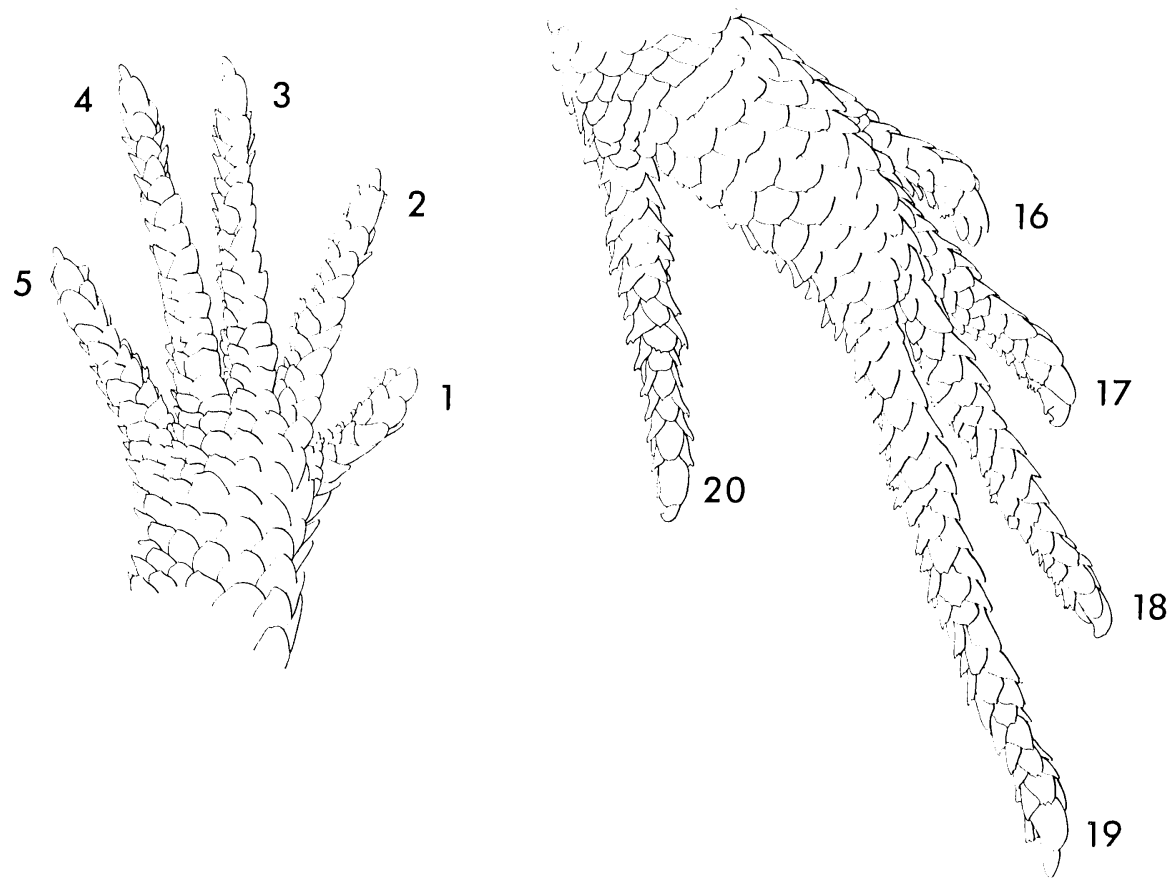

Fic. 1. Left hand and right foot of uta to show sequence of toe numbering. Note that the toes are numbered from the inside out on the front foot and from outside in on the rear. Thus, the right front foot would bear toes $6-10$, the left rear 11-15.

Young lizards were not given individually distinctive insignia, but were painted with a small dot on the dorsum between the thighs. Each time the area was worked, only the unpainted young were captured. Then, at about two-week intervals, all young were captured regardless of color and repainted with a clifferent color. In this way the recaptures of young animals could be better spaced in time to provide information on growth rates, movements, and shedding frequency.

The date, time of day, position, snout-vent length, tail length (both regenerated and unregenerated parts), and shedding condition were recorded at each capture on printed data sheets. In addition, during some periods the reproductive condition of each female was determined by careful palpation of her abdomen. Finally, weights were recorded for each lizard at periodic intervals. For this purpose, lizards were placed in numbered vials after capture and taken to a sheltered place in a wet cloth bag. The lizards were weighed to the nearest $.01 \mathrm{gm}$ and returned to their original location.

Temperatures were taken of numerous lizards during this study, all of 


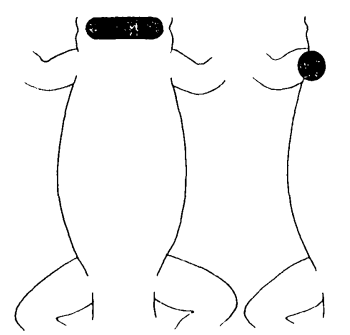

1

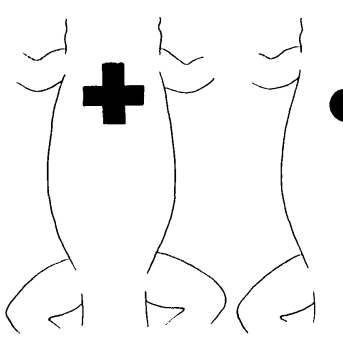

6

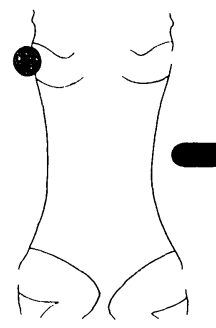

2

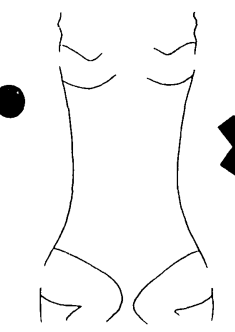

7

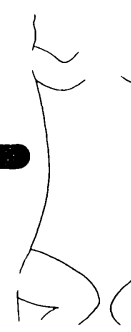

3

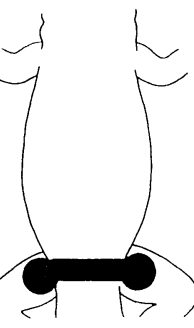

4

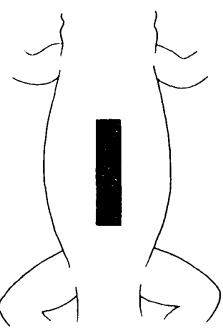

5

FIG. 2. Insignia used to paint adult lizards for individual recognition. Many other patterns were used, but all were multiples of one or more of these 10 basic patterns. For example, number 2 and number 5 on the same animal would be read as shoulder-stripe.

them with a Schultheis cloacal thermometer. Nearly simultaneous temperatures were recorded of the air and substrate at the lizards position of capture.

In all of the above, I occasionally felt that my own disturbance of the animals must have an effect on the results. If so, it is a criticism that can be leveled at almost any study. I have no objective evidence that any aspect of the biology of the animal was being modified. However, we did sometimes damage the study areas themselves in capturing the lizards. To compensate for this, on several occasions we laboriously replanted yuccas and other plants that we had damaged, using a detailed vegetation map of the study areas made prior to the study as a guide to the severity and location of damaged areas.

Metions of Laboratory Study.-One purpose of my study was to ascertain the effects of radiation on the populations, using one of the study areas as an experimental one and the other as a control after both had been studied for a period of at least one year prior to radiation.

In March, 1962, just prior to the breeding season, all adult lizards were removed from the experimental area and given $450 \mathrm{r}$ of gonadal x-radiation 
and returned to the field. In a 1964 replication of this experiment, the former experimental area was used as a control and the former control area as an experimental one. The cletails of the laboratory radiation procedures have been clescribed by Tinkle (1965a).

In most of our laboratory experiments we found that utas did best in plastic wading pools, about 8 feet in diameter, in which there was sufficient sand for traction, a sand bank for egg deposition, and some rocks or plants for concealment. Because of their aggressive nature it was seldom practical to maintain more than a dozen or so in a single terrarium.

The ambient temperature of the laboratory varied between $25-37^{\circ} \mathrm{C}$. However, each terrarium was provided with infra-red lamps so that, by basking, lizards could maintain body temperatures higher than ambient. In addition, fluorescent lamps were used to light each terrarium, and ultraviolet lamps were lighted periodically. Photoperiods varied from 8-12 hours, but could be maintained exactly in specially enclosed, light-proof terraria. Water sprinklers over each terrarium provided water for drinking as well as for maintaining a higher humidity.

Lizards were fed on mealworms (Tenebrio larvae) and on curly-mutant Drosophila. The mealworms were fed a special vitamin enriched chicken mash prior to being fed to the lizards. In addition, vitamin supplements were sometimes provided in the water for the lizards.

\section{RESULTS ANI) IDISCUSSION}

\section{SPECIES INTERACTIONS}

Only three species of lizards, other than Uta, were common on the Texas study areas. In order of relative abundance, these were the whiptail (Cnemidophorus tigris), the horned lizard (Phrynosoma cornutum), and the leopard lizard (Crotaphytus wislizeni). The only other lizards encountered were occasional Eumeces obsoletus and Holbrookia maculata.

The leopard lizard is a large predatory species which we know eats utas on occasion, though the bulk of its diet consists of large arthropods, principally grasshoppers and walking sticks. There were usually two adults and several young leopard lizards seen on the study areas during each summer, but not at other seasons.

The whiptail lizard is also a large species that, while active, is almost continuously foraging, sometimes in groups. This species appears in the spring (usually April) and has a very short above-ground existence; most of the adults disappear by mid- to late summer and the juveniles are gone by October. 
The horned lizard is fairly abundant, but is seldom seen. It is much more common in the short-grass plains, so the habitat near Kermit is probably ecologically marginal for this species. It is seldom encountered far from the cooler parts of the study areas-the dense mesquite thickets and packrat nests. It is seldom seen moving about in the area.

None of these species, I think, represents a serious competitor of Uta, except the whiptail lizard when young, but such competition would exist only for a short period of time not only because of the short activity season of the whiptail, but because it rapidly attains a large size. The leopard lizard is an effective predator on both juvenal and adult utas.

Several snakes in the area are lizard predators. These include the coachwhip (Masticophis flagellum), a large and active diurnal species; the prairie rattlesnake (Crotalus viridis), primarily crepuscular and nocturnal; the night snake (Hypsiglena torquata), a small rear-fanged and semifossorial species; and two semi-fossorial species of medium size which are abundant in most sancly areas of western Texas and active primarily at night. These are the glossy snake (Arizona elegans) and the long-nosed snake (Rhinocheilus lecontei). All of these species have been taken in the study areas.

Detailed records of predation will be discussed in the section on mortality, but it should be noted here that there are numerous predators present in abundance on the area and that various ones are active throughout the day and night renclering utas vulnerable to predation at all times.

Avian predators such as shrikes, roadrunners, and hawks were rarely seen around the study areas. The behavior of utas is such that they would probably seldom be caught by birds. They rarely venture into the open and on such occasions they rapidly traverse the open ground to reach sheltering vegetation. Even when basking, utas choose locations in which they would be relatively invulnerable to aerial predators. Finally, to be discussed later, is the inverse relation between body temperature and wariness in utas. When they are cool, and presumably more vulnerable to predation, they are also more wary than when they are warmer.

One of the most important interactions is an indirect one. The most common mammals on the study areas are the packrat (Neotoma micropus) and the kangaroo rat (I)ipodomys ordi). The packrats cover their nests with enormous piles of debris, usually in mesquite thickets. The kangaroo rats dig extensive tumncls throughout the study areas. Both the tunnels and packrat nests provide excellent protective shelters for utas. There is no question that the lizards quickly learn the locations of the nests and tunnel openings, and will take shelter in them when disturbed, particularly during 
the winter months. In winter, we have dug large numbers of utas from temporary hibernacula in the sandy rims of the packrat nests. Not only does the activity of the mammals loosen the sand and make penetration by utas simple, but the adjacent nest provides shelter for the lizard that is still somewhat torpid after emerging from the sand on warm days. I think that these nests and tunnel systems are also important as food reservoirs for the lizards, for concentrations of insects may sometimes be found in them even during the winter.

\section{REPRODUCTION}

The Reproductive Cyclf.-The reproductive cycle of Uta stansburiana in western Texas was studied by Tinkle (1961), so only a brief description of the cycle and new information collected since the previous paper will be presented here. The cycle in the female has been studied in far greater detail than that of the male and this is reflected in the following discussions.

The first signs of the beginning of the reproductive cycle in females are changes in appearance of the ovarian follicles. These are small $(1.0-1.5 \mathrm{~mm})$ and translucent in non-reproductive females, but in the early spring the follicles lose their transparency and become somewhat milky in appearance. This change is soon followed by a progressively yellower coloration as the follicles undergo vitellogenesis and rapidly enlarge to a diameter of $7-8 \mathrm{~mm}$ at the time of ovulation. After ovulation, a corpus luteum forms and remains distinct until oviposition, but degenerates rapidly thereafter. Immediately following oviposition, another set of follicles undergoes vitellogenesis preparatory to the development of the next clutch of eggs. Reproduction continues until August at which time the ovaries become quiescent, or at least show no further evidence of vitellogenesis. At this time only small, translucent follicles are present in the ovary, and the females begin to store quantities of fat in the paired corpora adiposa.

The cycle in the male was treated on a gross and superficial level by Tinkle (1961), but in much greater cletail by Hahn (1964) from whose paper much of the following discussion is drawn. Hahn sampled male utas from the area around Kermit in all months of the year except October, and used thin sections of the gonads to study the details of the reproductive cycle. Spermatogenic activity commences in September. By November the seminiferous tubules contain 3 or 4 layers of primary spermatocytes and clusters of transforming spermatids. By December, small numbers of sperm may be found in the epididymis. Thus, an enormous population of cells is built up during the fall and early winter so that the elaboration of many spermatozoa takes place rapidly in early spring, actually by February. From this month 
until late summer, spermatogenesis declines and testicular regression is essentially complete by mid-August.

The Onset of Reproduction in Utas.-Tinkle (1961) reported that the majority of female utas near Kermit had yolked follicles by February 13 in 1959, but not until early March in 1960. Additional information is now available. In 1963 only one of 15 females had yolked follicles on February 2, but 20 of 21 had them by February 16. In 1964, vitellogenesis occurred between February 9, when no females carried yolked follicles, and February 22, when the majority did so. Thus, it appears that there is little variation from year to year in the onset of reproduction.

Over a period of several years, Tinkle and Irwin (1965) studied the effects of photoperiod and temperatures on utas under laboratory conditions. Because of our familiarity with the activity of the species in the field, we could estimate accurately the number of hours of daylight to which the lizards were exposed at different seasons, and in the laboratory could shorten or lengthen this period beyond that to which the lizards were exposed in nature. We were primarily working with females taken from the field during times of the year when they were normally non-reproductive. Follicular vitellogenesis was considered a positive response to our artificial light and temperature regimes. Under high ambient temperatures (continuously above $27^{\circ} \mathrm{C}$ ) utas were brought into reproductive condition at any time after early December regardless of the length of the photoperiod. For example, on a photoperiod averaging only one-half hour daily, many times shorter than that received by the lizards in the field at the same time, the majority of females showed a positive reproductive response. It was further demonstrated that the majority of females could not be brought into a reproductive state prior to December, so there is a period in the fall and early winter when the females are refractory to experimental manipulation of their cycle.

The: Relation of Fat Storage to Reproduction.-Utas of both sexes, but particularly the females, store fat in the fall and early winter. This fat amounts to 3-4 per cent of the body weight during the winter, a proportion that remains constant through the winter, indicating that the fat reserves are not being used to meet metabolic demands. These fat bodies are very rapidly depleted in the early spring concommitant with vitellogenesis of the ovarian follicles. By appropriate experiments involving ablation of fat bodies in some females and sham operations on others, Hahn and Tinkle (1965) demonstrated that females deprived of their fat reserves either were unable to produce yolked follicles or, if vitellogenesis had begun prior to 
the operations, showed a higher proportion of atretic follicles and a lowered reproductive potential compared with either the field controls or the shamoperated animals. Therefore, to the list of variables such as size and season that are known to affect the clutch size of Uta stansburiana (Tinkle, 1961) must be adcled the amount of fat storage.

After depletion of the stored fat reserves during the early spring, there is no further recrudescence of the fat bodies until the end of the reproductive season. The females will lay 2 or more clutches during the season in spite of the absence of a fat reserve. I think it likely that the lat storage is important in insuring that sufficient lipid reserves will be available to make early reproduction possible at a time of the year (early spring) when food resources in the environment may be limited. A trait of this sort has obvious selective value because it affects the reproductive rate. After the first clutch, resources in the enviromment are eviclently sufficient for reproduction; however, late season chutches are smaller than early ones and the absence of fat storage cluring the later clutches coupled with a dwindling food supply may be partly responsible.

Two facts are of further interest in the study of fat cycles and reproduction. The fat bodies are 90-93 per cent extractable lipid by weight; nearly the same as that in an average clutch of four eggs. Hahn (pers. comm.) has definitely implicated estrogens as important in the rapid mobilization of the fat bodies in female Uta stansburiana, a fact that explains the close inverse relationship between follicle growth (when estrogen production is presumably high) and (lepletion of fat bodies.

Rreproductive Potrential.-Reproductive potential as I have used it here and in previous papers does not mean biotic potential and is not a measure of $r$. Rather, I use it to designate the number of eggs that a f male lizard is capable of producing under a given set of environmental conditions.

Estimating the clutch size is the first step in determining the reproductive potential and this may be done accurately in one of three ways from samples of lizards: (1) by counting all of the obviously enlarged ovarian follicles that contain yolk; (2) by counting the number of corpora lutea that are present in the ovary after egg deposition and before another cycle of vitellogenesis begins; or (3) by counting the number of oviducal eggs. Tinkle (1961) has shown that there is no significant difference in the clutch size estimated by any of these methods.

The size of the females comprising the sample and the month during which the samples are taken influence the estimate of clutch size as the limires below demonstrate: 


$\begin{array}{crc}\text { Snout-vent length }(\mathrm{mm}) & \mathrm{N} & \text { Mean clutch size } \\ 40-44 & 23 & 3.48 \\ 45-49 & 228 & 4.03 \\ 50-54 & 89 & 4.37 \\ & & \\ \text { Season } & & 4.43 \\ \text { Feb.-March } & 98 & 4.35 \\ \text { April-May } & 77 & 3.67 \\ \text { June-July } & 211 & 2.88 \\ \text { August-Sept. } & 32 & \end{array}$

Taking the data of all 418 females examined, the average clutch size is 3.91 , but the mean clutch size is greater in larger females and larger early in the reproductive season than later. The latter is true regardless of size, for the average clutch size for all of the size groups declines during the summer. Reasons for this decline have already been suggested, but it should be noted here that the frequency of follicular atresia is not high enough to account for this decline in clutch size.

TABLE 1

A Comparison of the Average Clutch Size Estimated from Samples of Utas of Various Sizes in Three Different Years. The Proportions of Each Sample Falling into Three Size Classes are also Shown

\begin{tabular}{lccccc}
\hline \multirow{2}{*}{ Date } & N females & \multicolumn{2}{c}{ Percent of females in size classes } & X clutch size \\
\cline { 3 - 5 } & & $40-44 \mathrm{~mm}$ & $45-49 \mathrm{~mm}$ & $50-54 \mathrm{~mm}$ & \\
\hline 1959-60 & 363 & 10 & 69 & 21 & 4.0 \\
June, 1962 & 15 & 7 & 86 & 7 & 3.3 \\
July, 1962 & 35 & 11 & 67 & 22 & 3.2 \\
Aug., 1962 & 13 & 14 & 86 & 0 & 2.8 \\
Feb., 1963 & 20 & & & & \\
March, 1963 & 48 & 5 & 81 & 14 & 4.7 \\
June, 1963 & 21 & 0 & 48 & 44 & 4.5 \\
July, 1963 & 79 & 1 & 75 & 25 & 4.4 \\
Aug., 1963 & 15 & 13 & 56 & 43 & 3.8 \\
March, 1964 & 29 & 13 & 67 & 20 & 3.0 \\
April, 1964 & 25 & 4 & 58 & 29 & 3.5 \\
\hline
\end{tabular}

Year-To-Year Variation in Clutch Size.-The possibility of differences in average clutch size in different years was investigated, using only samples that were sufficiently large (Table 1). The mean clutch size calculated from samples made in 1963 is higher than that for comparable months in 1962 or 1964. Although various reasons for this difference might be postulated, there 
is an obvious correlation of the differences with the average size of the females comprising the samples. The proportion of females in the largest size group (50-54 mm) is higher in the 1963 samples than in the other two years. This size class has been shown previously to have a higher mean clutch size than smaller ones and therefore samples containing a high proportion of these large females will give a higher estimate of clutch size.

It is obvious from these data that studies of clutch size in lizards must take into account the size distributions in the population sampled as well as seasonal differences that are independent of size of the lizards.

Numblr of Cilutches and Length of Reproductive Season.-The reproductive potential cannot be estimated from clutch size alone because utas lay several clutches per season. Hence, the length of the reproductive season is important in determining the number of possible clutches.

Tinkle (1961) defined the reproductive season as beginning at the time the majority of lemales showed signs of vitellogenesis and extending to the time when the majority are postreproductive, i.e., when the ovaries no longer contain enlarging follicles that are undergoing yolk deposition. In 1959 the season so defined extended to 141 days, in 1960 to 121. The time required for the development and ovulation of a clutch was estimated as 37-38 days. Dividing this latter figure into the length of the season and allowing due time for oviducal retention of the eggs prior to laying indicated sufficient time for 3 clutches.

That individual females did indeed lay more than a single clutch was predicted on two lines of evidence: (1) some females contained corpora lutea indicating recent ovulation and also contained enlarging, yolked follicles; (2) the majority of females in every sample of lizards taken during the breeding season were in some stage of reproduction, a finding that would hardly be possible unless the females were producing more than one clutch of eggs.

Proof for multiple clutches came from palpating females in the field each time they were recaptured. We found it possible to differentiate between oviducal eggs and large ovarian follicles and even to judge accurately the size of the follicles by palpation. By opening females in samples collected away from the study area after they had first been palpated, we were able to convince ourselves of the accuracy of this technique. Not only did this method supply information on the number of clutches laid by single females, but also with a measure of the time required to pass through various stages of follicle enlargement. It was, of course, unusual to catch a female exactly prior to ovulation twice in succession, but by pooling data from several females it was possible to reconstruct the cycle. The estimated 
times required for development of the eggs in the ovary, for ovulation, and oviducal retention are shown below:

Mean time estimate, days
39
43
46
49
51
52
54

Number of records
3
6
13
4
2
5
11

The average of all of these records is 48 days. Eleven estimates of the time during which eggs remained in the oviducts averaged 13 days. If this figure is added to my previous estimates of 37-38 days required for egg development to ovulation, a total of 50-51 days is obtained for the total time involved in one egg production-laying cycle, a figure not greatly different from the 48 days estimated by palpation.

Apparently a shorter period than the above is required later in the season. For the period from March through April an estimate of 50 days was obtained, but for May to August only 41. These additional figures inclicate that at least three clutches are possible in any season that extends over a period of about 4 months. Actual figures for the length of the reproductive season in different years are: 1959, 141 days; 1960, 121; 1963, 166; $1964,159$.

A few females were captured at intervals that were especially propitious in indicating the number of clutches laid. Detailed clata on these are presented below:

1. April 20, $3 \mathrm{~mm}$ follicles; June 4, oviducal eggs; June 13, eggs just laid; July 26, eggs just laid.

2. April 10, oviducal eggs; May 27, oviducal eggs; July 26, oviducal eggs.

3. March 29, large follicles; June 24, large follicles; August 2, just laid.

4. March 30, large follicles; June 16, large follicles; July 18, large follicles or oviducal eggs.

5. March 29, large follicles; June 30, large follicles; August 11, oviducal eggs.

6. March 30, large follicles; June 9, oviducal eggs: July 20, oviducal eggs.

7. April 9, just laid; Junc 2, oviducal eggs; July 12, oviducal eggs.

8. April 9, just laid; May 18, large follicles; June 4, 4-mm follicles; June 20, oviducal eggs.

9. April 9, large follicles; June 2, 3, oviducal eggs; July 28 , oviducal eggs.

In each of these 9 instances there is evidence for at least 3 clutches. I have calculated the theoretical time that should have been required for each of these females to pass through all of the reproductive stages at which they were observed and have compared these times with the actual period involved as shown below: 


Lizard Number
1
2
3
4
5
6
7
8
9

Actual Days
97
107
126
110
135
112
91
72
109

Theoretical Days

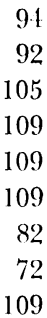

91

92

105

109

109

109

82

72

109

Numbers 3 and 5 show the greatest difference between observed and theoretical determinations. Number 3 was recorded as recently laid when captured on August 2. However, assuming that this female was now postreproductive, the eggs could have been laid much before August 2. Number 5 may have laid more than 3 clutches; this would explain the long actual time compared with the theoretical time, for we may simply have failed to capture the female during one of her reproductive sequences.

The only way to cletermine accurately the number of clutches laid is to capture all females at regular intervals and weigh them at each capture. The females lose about 25 per cent of their body weight after egg deposition so that the time of layings can be determined in this way. This should be done in my study areas, for it is still possible that I am underestimating the number of clutches. For example, female no. 2 on the previous pages was recorded with oviducal eggs on April 10, May 27, and July 26. This is definite proof that she laid three clutches, but there is also the possibility that one was laid between the May and July captures and another sometime in August.

The eviclence for at least 3 clutches averaging about 4 eggs each is overwhelming. Inasmuch as almost every female in the population is sexually mature at the onset of the breeding season, it follows that each will lay 12 eggs per season. I think for reasons given above that this is a minimum figure and it is less than the average number of hatchlings per female marked in the study areas each year. Hence, I hesitate to use the figures above to estimate the theoretical natality. I am hesitant, also, because of clata collected from females isolated in the laboratory.

One of my students, Cuellar (1966a) collected female utas containing oviducal eggs, allowed them to lay and then isolated them until they laid again. Eleven of 13 females laid 2 clutches of eggs each and 7 of these 11 laid 3. A total of 47 clays elapsed between the time the first females laid the first clutch and the time they deposited a second, but between the second and third an average of only 25 days was recorded. The time for development 
of the initial clutch was near our theoretical estimate from the field, but the time required for development of the third clutch was remarkably short. If such a short interval existed in the field, and such has been reported to me for utas in Nevada by Hoddenbach (pers. comm.), then my estimates of the number of clutches laid are conservative.

Preriod of Postifipositional, Egg Development.-We have observed actual egg deposition in Uta stansburiana only once. We have spent hours in the field digging and sifting through sand from sites that we felt were suitable for egg deposition because of the large number of hatchlings found around them, but were not successful at finding eggs.

We have observed egg deposition in the laboratory many times. Utas will unhesitatingly lay their eggs in banks of moistened sand provided in each terrarium.

By knowing from field collections of utas when females first began to deposit eggs, and by knowing the date on which hatchlings first appeared in the field, I have been able to estimate the time required for development in the two years when the above information was available. The two estimates are 65 and 77 days. It seems likely that hatching time of the later clutches is faster than that of the first because of higher substrate temperatures in summer. In the laboratory at about $30^{\circ} \mathrm{C}$, hatching time has varied from 59 to 79 (lays.

Size or Egas.-A few clutches have been removed from females to determine the weights of eggs prior to deposition. These data are shown below (weight in grams):

Number of eggs
in clutch
2
3
1
5
6

Number of
clutches
1
28
9
9
2

Nean
clutch weight
0.5
0.6
0.8
0.9
1.0

Mean weight
per egg
.27
.21
.21
.19
.17

The weight of each egg is only slightly less than the mean weight of the utas at hatching $(0.3 \mathrm{gm})$, the difference attributable to moisture uptake by the egg during incubation. There is relatively little difference between mean egg size in clutches containing differing numbers of eggs.

Sperm Storage in Utas.-Only recently has sperm storage in lizards been reported, though the phenomenon in snakes has been recognized for many years. One of my students (Cuellar, 1966a, 1966b) has made a thorough study of sperm storage in utas, the results of which are especially pertinent 
at this point. Hahn (1964) had shown that regression of the testes in utas is complete by late August. The time of latest hatching gives no indication that eggs are being fertilized beyond the period when males are normally sexually potent. Yet, Ciuellar (1966b) clemonstrated that female Uta stansburiana store sperm in specialized receptacles in the oviduct. He has further proved that these stored sperm are capable of fertilizing eggs in females isolated from males for at least 81 days, about the time required for the development of two clutches of eggs.

Why sperm storage should be a well-developed trait of a species in which the sex ratio is equal and in which there exists a facultative monogamy is not clear. Certainly, such storage insures fertilization in the absence of copulation, and maybe this is sufficiently valuable to promote the evolution of sperm storage receptacles. On the other hand, my experience with the species inclicates that a lemale seldom fails to attract the attention of the male cluring the breeding season. On the con trary, courtship attempts by males always far exceed the number of instances in which the courtship advances of the male are accepted by the female and lead to copulation. If occasional tail losses by females interfere with copulation then a powerful selective force exists for the elaboration of sperm storage. This possibility will be discussed again in the section on behavior.

A Summary or: Litrirature on Lizard Rrproduction.-It is my intention throughout this account to offer summaries and, in some instances, critiques on the literature relevant to each section. Such literature is scattered and has not been assembled or adequately discussed.

A general review of reproductive cycles in reptiles has not been written, although a fairly good summary was provided by Miller (1959) who remarked that reproduction had been studied in less than one per cent of the 6000 species of reptiles. I cloubt that this percentage has been increased appreciably since that time, but more cletailed information is available for some species and some generalizations can now be made.

I have made no attempt to include all literature records of clutch size. In the first place, most of them seem meaningless. There is so much variation in clutch size in many species that reports of the number of eggs laid by single females or by a few inclividuals are generally without value. Nevertheless there are about 50 studies of clutch size or litter size that are based on many individuals (Table 2).

The Gekkonidae and Teiidae have small clutches and the same may be true of the larger agamids. Within the Iguanidae, in which more species have been studied, the clutch size varies from one to 24 per female. Larger species generally lay more eggs than smaller ones, but exceptions in both 
directions (Phrynosoma and Uma) occur. Viviparous species have smaller broods than oviparous species of comparable size. Finally, almost without exception, older and larger lizards produce larger clutches than smaller, younger ones within the same species.

I think the extremes in clutch size are probably now known for lizards and attention should be turned to predictions that may be made from the available information. The first is that small clutch size may indicate that a species has increased its reproductive potential by reproducing more often rather than by increasing the number of eggs per clutch, or that it is a species in which mortality takes place relatively late in life rather than very early. The mean clutch size of Sceloporus graciosus is low for a Sceloporus (Table 2) and is among the lowest reported for any iguanid; there is also no evidence of multiple clutches. However, it is one of the longest-lived of all lizards thus far studied; young never outnumber adults so the replacement in the population is eviclently quite low. On the other hand, a species such as $U t a$ with a clutch size almost as small as that of $S$. graciosus lays several clutches and experiences nearly an annual population turnover. Obviously, a simple comparison of relative clutch sizes in these two species is meaningless, but a comparison of their total demography is most in. structive and makes the information on reproductive rates understandable.

There is little doubt that reproductive potential varies in response to selective forces at work in various species populations, but clutch size alone will not allow meaningful comparisons of these species. The number of clutches laid and the age at maturity should be determined whenever possible in studies of reptile reproduction.

It has been only a short time since Fitch (1956b) remarked that "Except for the anoles, which produce only one egg at a time, iguanids have not been known to produce more than one clutch per season." Now it is clear that multiple clutches are characteristic of iguanids and have been reported as well in scincids, teiids, agamids, and gekkonids.

To my knowledge multiple clutches have never been reported in any viviparous species; the long gestation periods may preclude them. It would be interesting to know if viviparity is limited to those species with delayed maturity and a long life expectancy. The postulate has been advanced that viviparity in reptiles is an adaptation to cold and dry conditions. I might suggest that viviparous species are the ones that can take advantage of such situations, but the evolution of viviparity may, in reality, be unrelated to them. A viviparous species must sacrifice fecundity for the advantages of viviparity, a sacrifice that may not be possible in highly competitive situations. 
It is unfortunate that one facet of information so of ten missing from life history studies is the exact age at maturity. The limited data available do suggest that multiple clutches are characteristic of early maturing species with a fairly high annual turnover and that viviparity is limited to species with clelayed maturity and presumably long life expectancy. However, I don't mean to imply, nor clo I think, that these are necessarily cause and effect relationships.

The data in Table 2 also indicate that predictions about mortality could be made if more information were available on number of clutches and average clutch size. The extremely high fecundity of Sceloporus olivaceus has been shown by Blair (1960) to be correlated with very high nest failure and high juvenile mortality.

The number of clutches of eggs produced by tropical compared with temperate species is unknown. Some tropical species seem to breed throughout the year (Baker, 1947; Daniel, 1960; Wilhoft, 1963; Church, 1962; Kopstein, 1938), but others are cyclical (Marshall and Hook, 1960); Harris, 1964; Wilhoft and Reiter, 1965). Even in those that do breed the year around, there are peaks of reproductive activity and in no case has it been demonstrated that the same females are producing successive clutches. Population turnover may be rapicl in some tropical lizards. Cagle (1948) has indicated that Hemidactylus garnoti [sic] may mature within 6 weeks after hatching. In such cases several generations may be represented during one breeding season. Information on the population dynamics of tropical lizards is critically needed.*

Information is also lacking on the factors that govern reproductive cycles in lizards, either tropical or temperate. Light has been implicated in studies in the temperate zone (Bartholomew, 1960; Fox and Dessauer, 1958; Mayhew, 1961), and even the quality of light has been suggested to have an effect (Mayhew, 1964). Temperature has also been shown to be an important factor (Bartholomew, 1953). Tinkle and Irwin (1965) showed that in Uta stansburiana temperature seemed to be of greater importance than photoperiod in initiating the reproductive cycles; they discussed reasons for cloubting that proper controls had been used in some previous experiments.

In the tropics, unfortunately, no experimental work has been done. Even on the equator, some lizards are cyclic in their reproduction (Marshall and Hook, 1960). The quality of food has been suggested by these authors as the factor responsible for the cycles (or at least for the low points in continu-

* The excellent paper by Inger and Greenberg (1966) did not appear until this manu. script had gone to press. I wish to call attention to their paper because it contains a wealth of data on reproduction of tropical lizards. 
TABLE 2

A Comparison of Clutch Size, Clutch Number, and Acie at Maturity in Viviparous and Oviparous Lizards

Figures are means unless otherwise noted; $v=$ viviparous species

\begin{tabular}{|c|c|c|c|c|}
\hline Species & $\begin{array}{l}\text { Age at } \\
\text { Mat. }\end{array}$ & $\begin{array}{l}\text { Clutch } \\
\text { size }\end{array}$ & $\begin{array}{l}\text { No. of } \\
\text { clutches }\end{array}$ & Authority \\
\hline \multicolumn{5}{|l|}{ Iguanidae } \\
\hline Sceloporus olivaceus & $<1 \mathrm{yr}$ & $\begin{array}{l}\text { Yearling } 11.3 ; \\
\text { 2nd year } 18.4 ; \\
\text { 3rd year } 24.5\end{array}$ & $\max .4$ & Blair (1960) \\
\hline Sceloporus merriami & & 3.7 & $2+$ & $\begin{array}{l}\text { Chaney and } \\
\text { Gordon (1954) }\end{array}$ \\
\hline Sceloporus jarrovi (v.) & & 10 & & Carpenter $(1960 a)$ \\
\hline Sceloporus undulatus & $<1 \mathrm{yr}$ & 7.6 & Prob. 2 & Crenshaw (1955) \\
\hline Sceloporus occidentalis & $2 \mathrm{yr}$. & 13.7 & & Fitch $(1940)$ \\
\hline Sceloporus cyanogenys (v.) & & $6-18$ & & Hunsaker (1959) \\
\hline Sceloporus orcutti & & 9.2 & 1 & Mayhew $(1963 a)$ \\
\hline Sceloporus graciosus & & 3.3 & & $\begin{array}{l}\text { Stebbins and } \\
\text { Robinson (1946) }\end{array}$ \\
\hline Sceloporus grammicus & & & $\begin{array}{l}1 \text { clutch } \\
\text { per } 2 \text { yrs. }\end{array}$ & Mulaik (1946) \\
\hline Holbrookia texana & $1 \mathrm{yr}$. & $\begin{array}{l}6.5 \text { June; } \\
\text { 3.6 Aug. }\end{array}$ & & Cagle (1950) \\
\hline Holbrookia texana & & 5 & 5 & C. Johnson (1960) \\
\hline Phrynosoma cornutum & & ca. 30 & & Givler (1922) \\
\hline Anolis carolinensis & & 1 & $6-9$ & Hamlett (1952) \\
\hline Anolis carolinensis & $1 \mathrm{yr}$. & 1 or 2 & & Cagle(1948) \\
\hline Crotaphytus collaris & $1 \mathrm{yr}$. & $\begin{array}{l}83-93 \mathrm{~mm}, 5.0 \\
97-102 \mathrm{~mm}, 7.5\end{array}$ & 2 & Fitch $(1956 b)$ \\
\hline Liolaemus multiformis (v.) & $1.5 \mathrm{yr}$ & 5.8 & & Pearson (1954) \\
\hline Uma notata & $2 \mathrm{yr}$. & 2.1 & & Mayhew (1966a) \\
\hline Uma scoparia & $2 \mathrm{yr}$. & 2.6 & & Mayhew $(1966 b)$ \\
\hline Uma inornata & $2 \mathrm{yr}$. & 2.8 & & Mayhew $(1965 b)$ \\
\hline Basiliscus vittatus & $<1 \mathrm{yr}$ & 4.2 & & Hirth (1963) \\
\hline \multicolumn{5}{|l|}{ Agamidae } \\
\hline Amphibolurus muricatus & & & 2 & Weekes (1934) \\
\hline Agama agama & $1 \mathrm{yr} .+$ & 5.6 & $2-3$ & Harris (1964) \\
\hline Agama agama & & $3-9$ & & Daniel (1960) \\
\hline \multirow[t]{2}{*}{ Agama agama } & & $\begin{array}{c}90-99 \mathrm{~mm}, 5.2 ; \\
100-109 \mathrm{~mm}, 6.4\end{array}$ & & $\begin{array}{l}\text { Chapman and } \\
\text { Chapman (1964) }\end{array}$ \\
\hline & & & min. 2 & $\begin{array}{l}\text { Marshall and } \\
\text { Hook }(1960)\end{array}$ \\
\hline \multicolumn{5}{|l|}{ Chamaelcontidae } \\
\hline Chamaeleo hohneli (v.) & & 10 & & Bustard (1965) \\
\hline Chamaeleo bitaeniatus (v.) & & 17.3 & & Bustard (1966) \\
\hline
\end{tabular}


TABLE 2 (cont.)

\begin{tabular}{|c|c|c|c|c|}
\hline Species & $\begin{array}{l}\text { Age at } \\
\text { Mat. }\end{array}$ & $\begin{array}{l}\text { Clutch } \\
\text { size }\end{array}$ & $\begin{array}{l}\text { No. of } \\
\text { clutches }\end{array}$ & Authority \\
\hline \multicolumn{5}{|l|}{ Teiidae } \\
\hline Cinemidophorus sexlineatus & & 2.9 & & Brown (1965) \\
\hline Cnemidophorus sexlineatus & & 2.5 & & Carpenter $(1960 b)$ \\
\hline \multirow[t]{2}{*}{ Cnemidophorus sexlineatus } & $<1 \mathrm{yr}$ & $2.0,1 \mathrm{st} y \mathrm{yr}$ & & \\
\hline & & 4.4 , older adults & 2 & ritch (1958) \\
\hline Cnemidophorus sexlineatus & & 3.1 & & Hoddenbach (1966) \\
\hline Cnemidophorus hyperythrus & $1 \mathrm{yr}$. & 2 & & Bostic (1966) \\
\hline Cnemidophorus tigris & & 2 & & $\begin{array}{r}\text { Goldberg and } \\
\text { Lowe (1966) }\end{array}$ \\
\hline Cnemidophorus tigris & & $\begin{array}{l}\text { 2, Texas; } \\
\text { 4, Colorado }\end{array}$ & $\begin{array}{l}\text { 2, Texas; } \\
\text { 1, Colo. }\end{array}$ & $\begin{array}{l}\text { McCoy and } \\
\text { Hoddenbach } \\
(1966)\end{array}$ \\
\hline Ameiva quadrilineata & $<1$ yr. & & & Ilirth (1963) \\
\hline \multicolumn{5}{|l|}{ Lacertidae } \\
\hline Lacerta muralis & & & 3 & Cooper $(1965)$ \\
\hline Lacerta viridis & $2 y \mathrm{r}$. & $6-21$ & 2 & Rollinat (1934) \\
\hline Lacerta agilis & 2 yrs. & $9-13$ & 2 & Rollinat (1934) \\
\hline Lacerta vivipara (v.) & 3 yrs. & $\begin{array}{l}3-5, \text { young } q \text {; } \\
8-12, \text { older } q q\end{array}$ & & Rollinat (1934) \\
\hline Lacerta vivipara (v.) & & $6-8$ & & M. Smith (1951) \\
\hline Lacerta sicula & & $3-4$ & $2-4$ & Kramer (1946) \\
\hline Tachydromus takydromoides & $1 \mathrm{yr}$. & $\begin{array}{c}40-50 \mathrm{~mm}, 3 \\
55-70 \mathrm{~mm}, 3-6\end{array}$ & & Fukada (1965) \\
\hline \multicolumn{5}{|l|}{ Scincidae } \\
\hline Eumeces fasciatus & $2 \mathrm{yr}$. & $\begin{array}{l}<69 \mathrm{~mm}, 8 \\
>70 \mathrm{~mm}, 10\end{array}$ & & Fitch (1954) \\
\hline Eumeces egregius & $1 \mathrm{yr}$. & 4.8 & & Mount (1963) \\
\hline Eumeces skiltonianus & $1-2 \mathrm{yr}$. & 4 & & 'Tanner (1957) \\
\hline Eumeces obsoletus & 3 yr. & 11.4 & & Fitch (1955) \\
\hline Eumeces septentrionalis & $2 \mathrm{yr}$. & 8.8 & & Breckenridge (1943) \\
\hline Leiolopisma zelandica (v.) & $2 \mathrm{yr}$. & 5.2 & 1 & Barwick (1959) \\
\hline Leiolopisma rhomboidalis & & 2 & & Wilhoft (1963) \\
\hline Leiolopisma fuscum & & 2 & & $\begin{array}{l}\text { Wilhoft and } \\
\text { Reiter }(1965)\end{array}$ \\
\hline Iygosoma laterale & & 3.3 & & $\begin{array}{l}\text { R. M. Johnson } \\
\quad(1953)\end{array}$ \\
\hline Lygosoma laterale & & $\begin{array}{l}4 \text {, north part } \\
\text { of range }\end{array}$ & $2-4$ & $\begin{array}{l}\text { Fitch and Greenc } \\
\qquad(1.965)\end{array}$ \\
\hline \multicolumn{5}{|l|}{ Anguidae } \\
\hline Gerrhonotus multicarinatus & & $\begin{array}{l}110-125 \mathrm{~mm}, 6-14 \\
125-145 \mathrm{~mm}, 9-17\end{array}$ & & Fitch (1935) \\
\hline Gerrhonotus coeruleus (v.) & & $2-10$ & & Fitch (1935) \\
\hline Anguis fragilis (v.) & & $7-8$ & & M. Smith (1951) \\
\hline Anguis fragilis (v.) & & 12 & 1 & Rollinat (1934) \\
\hline \multicolumn{5}{|l|}{ Xantusiidac } \\
\hline Xantusia vigilis (v.) & 3 yrs?? & 2 & & Miller (1951) \\
\hline Gekkonidae* & & & & \\
\hline
\end{tabular}

* In this family there are many reports, most of them indicating that 2 eggs per female is the usual clutch size in this family. Some species invariably produce only 2 eggs per clutch (Dutta, 1944; Church, 1962; Boyd, 1940; Inger and Greenberg, 1966). 
ously breeding species), but cycles near the equator have been more commonly correlated with rainfall (Wilhoft, 1963; Chapman and Chapman, 1964). In some species (Wilhoft and Reiter, 1965) there is no obvious factor with which the existence of cycles can be correlated.

Mayhew $(1965 b, 1966 a, 1966 b)$ has made a point of correlating the reproductive success of species of the genus $U m a$ with the quantity of winter rain. He assumes that the rainfall indirectly influences reproductive success through its effect on plant growth and consequent abundance of insects, the food supply of Uma. Sometimes the correlation between rainfall and reproductive success was exhibited by only one sex. In some months the sample sizes were so small (as low as 3) that I doubt if they were representative of the reproductive success of the population as a whole. Finally, in a species with overlapping age classes as in Uma, different frequencies of animals of different age classes might be partly responsible for his results.

The significance of fat storage to reproduction in reptiles needs further study as does the function of the corpus luteum. As long ago as 1934, Rollinat stated that the lizard Lacerta agilis possessed large fat bodies, particularly the females, that were depleted during the first two ovulations each season. He suggested that the lipid in them might be utilized for egg production. Other authors have noted the inverse relationship between fat storage and vitellogenesis (Darevsky, 1957; Chapman and Chapman, 1964; Hoddenbach, 1966). On the other hand fat-body build-up has been reported to be concurrent with reproduction (Marshall and Hook, 1960) or to be seemingly unrelated to the reproductive cycle (Barwick and Bryant, 1966).

Corpora lutea have been recognized in every species of lizard examined, and some detailed studies of the structure and histological origins have been made (Weekes, 1934; Boyd, 1940; Miller, 1951). There is at least one experimental study of corpus luteum function (Panigel, 1956). In viviparous lizards the corpus luteum retains an apparently functional state until near or after parturition. In oviparous species, the corpus luteum disappears soon after oviposition, so that the number of corpora lutea macroscopically visible in the ovary will give no indication of the total number of clutches previously laid. C. Johnson (1960) reported that lutea from four previous clutches were macroscopically visible in the ovaries of females (Holbrookia texana) late in the reproductive season. This report needs verification inasmuch as corpora atretica are easily confused with degenerating corpora lutea.

Finally, there are two curious reports in the literature that deserve brief discussion. Bustard (1966) indicated that the oviducts of some viviparous chamelons contained embryos of two very different sizes, suggesting the 
possibility of a second ovulation and fertilization during the course of pregnancy. The second paper is the oft-quoted one of Woodbury and Woodbury (1945) which purports to show that in Sceloporus graciosus vitellogenesis of ovarian follicles occurs in the fall and that these partially yolked follicles remain in a pre-ovulatory state until the following spring. This is the only report known to me of retention of yolked follicles by lizards during the nonreproductive season, although this phenomenon certainly occurs in snakes. The exact words of Woodbury and Woodbury are as follows: "During the summer and fall of one year, deposition of yolk on eggs to be laid the following season becomes apparent. ..." Inasmuch as their observations were microscopic, evidence of yolking might have been seen that is not macroscopically visible. Because they do not state what follicle size is attained in the fall, I cannot judge this possibility. It is possible that the enlarged follicles they saw in late summer were those of a second clutch to be laid that season. They had no lizards available trom the winter, few from early spring, and collection dates of the latter are not given. Therefore, the yolked follicles seen in the spring could have been yolked that spring rather than the previous fall. Yolked follicles are present in female Uta stansburiana in western Colorado, not far from the Woodbury's localities, in late March and early April, and these are known to have undergone vitellogenesis that spring. Until confirmation of this report is obtained I think it should not be cited as an exceptional reproductive type (see Miller, 1959).

I have said little about the reproductive cycle in male lizards, in part because I have done little work in this area and partly because it is of less interest from the standpoint of population dynamics. As a generalization, male lizards in the temperate zone undergo spermatogenesis in the fall, spermiogenesis in the spring (Dutta, 1944; Miller, 1959; Kehl and Combescot, 1955; Hahn, 1964; Goldberg and Lowe, 1966). On the other hand, two species may have different cycles in the same area. Uta stansburiana adhere to the generalization above, but Urosaurus ornatus in the same area emerge from hibernation with small testes which rapidly increase in size during the spring (Asplund and Lowe, 1964). In the tropics, males may be in reproductive condition all year even when the females of the same species are distinctly cyclic.

Literature Rfacorids of Incubation Time and Gestation in Lizards.Incubation time in lizards has been estimated in a variety of ways, hence estimates are not often directly comparable. Most reports are based upon hatching times in the laboratory. In field studies, incubation time has been determined by direct observation of the interval between nesting and hatching or has been indirectly estimated as the time between the first 
TABLE 3

Incuibation and Gestation Times Reported for Several Species of Lizards All figures are days unless otherwise indicated

\begin{tabular}{|c|c|c|}
\hline Species & $\begin{array}{l}\text { Incubation or } \\
\text { gestation time }\end{array}$ & Authority \\
\hline \multicolumn{3}{|l|}{ Iguanidac } \\
\hline Sceloporus olivaceus & $\begin{array}{c}\text { April-May, } \overline{\mathrm{x}}=70 \\
\text { May-Aug., } \overline{\mathrm{x}}=57\end{array}$ & Blair (1960) \\
\hline Sceloporus undulatus & $\bar{x}=43$ & Carpenter $(1960 l)$ \\
\hline Sceloporus undulatus & $48-58$ & Crenshaw (1955) \\
\hline Sceloporus graciosus & $50-55$ & $\begin{array}{l}\text { Woodbury and } \\
\text { Woodbury (1945) }\end{array}$ \\
\hline Sceloporus cyanogenys (v) & c. 52 & Hunsaker (1959) \\
\hline Crotaphytus collaris & $51-94$ & Fitch $(1956 b)$ \\
\hline Liolaemus multiformis (v) & ca. 150 & Pearson (1954) \\
\hline Pholidobolus montium & 216 & Bustard (1964) \\
\hline Anolis limifrons & ca. $1 \mathrm{mo}$. & Sexton et al. (1963) \\
\hline Holbrookia texana & 50 & Cagle (1950) \\
\hline \multicolumn{3}{|l|}{ Agamidae } \\
\hline Agama agama & ca. 60 & Harris (1964) \\
\hline \multicolumn{3}{|l|}{ Teiidae } \\
\hline Cinemidophorus sexlineatus & $\min .61$ & Brown (1956) \\
\hline Cnemidophorus sexlineatus & $\overline{\mathrm{x}}=53$ & Carpenter $(1960 b)$ \\
\hline Cnemidophorus sexlineatus & ca. 60 & Fitch (1958) \\
\hline Cnemidophorus hyperythrus & $50-55$ & Bostic (1966) \\
\hline \multicolumn{3}{|l|}{ Lacertidae } \\
\hline Tachydromus takydromoides & $\bar{x}=36$ & Fukada (1965) \\
\hline Lacerta agilis & $\begin{array}{c}41-90 \text {, } \\
\text { dep. on temp. }\end{array}$ & Rollinat (1934) \\
\hline \multicolumn{3}{|l|}{ Scincidae } \\
\hline Eumeces fascialus & ca. 6 weeks & Fitch (1954) \\
\hline Eumeces septentrionalis & $x=46$ & Breckenridge (1943) \\
\hline Eumeces obsoletus & 51 & Fitch $(1955)$ \\
\hline Eumeces egregius & $31-51$ & Mount (1963) \\
\hline Leiolopisma zelandica (v) & 12 weeks & Barwick (1959) \\
\hline Iygosoma laterale & min. 4 weeks & R. M. Johnson (1953) \\
\hline Lygosoma laterale & $4-5$ weeks & Lewis (1951) \\
\hline Egernia cunninghami (v) & $60-80$ & $\begin{array}{l}\text { Barwick and } \\
\text { Bryant (1966) }\end{array}$ \\
\hline \multicolumn{3}{|l|}{ Anguidac } \\
\hline Anguis fragilis (v) & $7-12$ weeks & M. Smith (1951) \\
\hline \multicolumn{3}{|l|}{ Xantusiidac } \\
\hline Xantusia vigilis $(\mathrm{v})$ & 90 & Miller (1951) \\
\hline \multicolumn{3}{|l|}{ Gekkonidae } \\
\hline Hemidactylus garnoti (sic) & $\min .45$ & Cagle (1946a) \\
\hline Hemidactylus flaviviridis & $33-34$ & Mahendra (1936) \\
\hline Hemidactylus flaviviridis & 21 & Dutta (1944) \\
\hline Gekko japonicus & $x=54$ & Fukada (1965) \\
\hline Several species & $\begin{array}{l}\text { 40-100, } \\
\text { gen. } 3 \text { mos. }\end{array}$ & Kopstein (1938) \\
\hline
\end{tabular}


seasonal collection of females containing oviducal eggs and the time of appearance of hatchlings in the field. Some of the available estimates are shown in Table 3.

For iguanids and teiids, 60 days seem to be the average incubation time and is seemingly independent of the size of the species or of its eggs. The short incubation time of some skinks seems surprising in view of the habitat occupied by many of them, but skinks may retain the eggs in the oviduct for a considerable time between ovulation and oviposition. This phenomenon has been demonstrated in Lacerta muralis (Cooper, 1965), which evidently retains its eggs in the oviduct for about a month following fertilization. The record incubation time of 216 days for Pholidobolus (Bustard, 1964) was determined in the laboratory at $80-90^{\circ} \mathrm{F}$ during the day, $60^{\circ} \mathrm{F}$ at night. This species is a high-altitude teiid from Ecuador and may have a long incubation time under natural conditions.

Viviparous species generally require 2 to 3 months for gestation; the longest record is 5 months in the montane Liolaemus (Pearson, 1954) in Peru. As noted previously, the minimum gestation time for viviparous species is about the same as the time required for some oviparous species to produce 2 to 3 clutches, so multiple clutches in these viviparous species, most of which occupy habitats with strong seasonality, seem out of the question.

\section{Hatchilings}

Time of Apprarancr.- The exact time at which hatchling utas first appeared in the field was carefully noted each year and these dates are shown below:

$\begin{array}{lccc}\text { Year } & \text { Area I } & \text { Area II } & \text { Off Areas } \\ 1960 & \text { June 17 } & & \\ 1961 & \text { June 18 } & \text { June 20 } & - \\ 1962 & \text { June 20 } & \text { June 14 } & \text { June 10 } \\ 1963 & \text { June 19 } & & \\ 1964 & \text { June 23 } & \text { June 27 } & \\ 1965 & & & \end{array}$

Only a difference of about two weeks exists in the earliest appearance over these 6 years.

One of the advantages of fat storage was postulated to be its assurance of early reproduction for the lizard and subsequent early hatching of its young. Lizards that hatch early will all mature in time to breed maximally the following season, i.e., they will have become mature long before the onset of the reproductive season. For this reason, I thought there might be 
an advantage accruing to early hatching lizards, and I have compiled data on the proportion of the adult population each year that was comprised by lizards hatching early and late the previous year. These data for the years 1961-1964 are shown for those lizards that were $23 \mathrm{~mm}$ or less snout-vent at the time they were originally marked (Table 4).

The lizards appear to be represented in the breeding population in about the same frequency in which they are hatched. There is a slight bias favoring those hatching in late July; however, these data do not suggest an

TABLE 4

The Time of Hatching and the Proportion Hatching at Several Intervals of the Reproductive Season Are Shown Together With Figures Indicating the Proportion of the Breeding Adults Comprised by Lizards Hatching; During; Each Interval Shown

\begin{tabular}{lccc}
\hline Time of hatching & $\begin{array}{c}\text { Number } \\
\text { hatching }\end{array}$ & Percent & $\begin{array}{c}\text { Percent among reproductive } \\
\text { adults in next generation }\end{array}$ \\
\hline June 1-15 & 1 & 0.1 & 0.0 \\
June 16-30 & 247 & 24.3 & 25.5 \\
July 1-15 & 537 & 52.9 & 45.5 \\
July 16-31 & 141 & 13.8 & 24.5 \\
Aug. 1-15 & 53 & 5.2 & 2.7 \\
Aug. 16-31 & 11 & 1.1 & 0.0 \\
Sept. 1-15 & 15 & 1.5 & 0.9 \\
Sept. 16-30 & 9 & 0.9 & 0.9 \\
Oct. 1-15 & 2 & 0.2 & 0.0 \\
Total & 1016 & & \\
\hline
\end{tabular}

advantage to early hatching, provided the lizards hatch prior to mid-August. Until this date there is still a sufficiently long growing season to insure that most of the young will mature in time to reproduce early the following spring. For those hatching in late August, maturity will be delayed until sometime the following spring or summer, so they will be at a reproductive (as well as a social) disadvantage compared with lizards hatching earlier.

The data on time of appearance of hatchlings for the years 1961-63 are shown in Figure 3. These three years were chosen because in them we concentrated upon getting all lizards marked as near their time of hatching as possible. As this figure shows, it would be impossible to determine the number of clutches represented. There are no distinct peaks because all of the females do not lay eggs at the same time, the developmental rate of the eggs is presumably variable, and some late-maturing females are laying a first clutch concommitant with the second clutch of other females. 


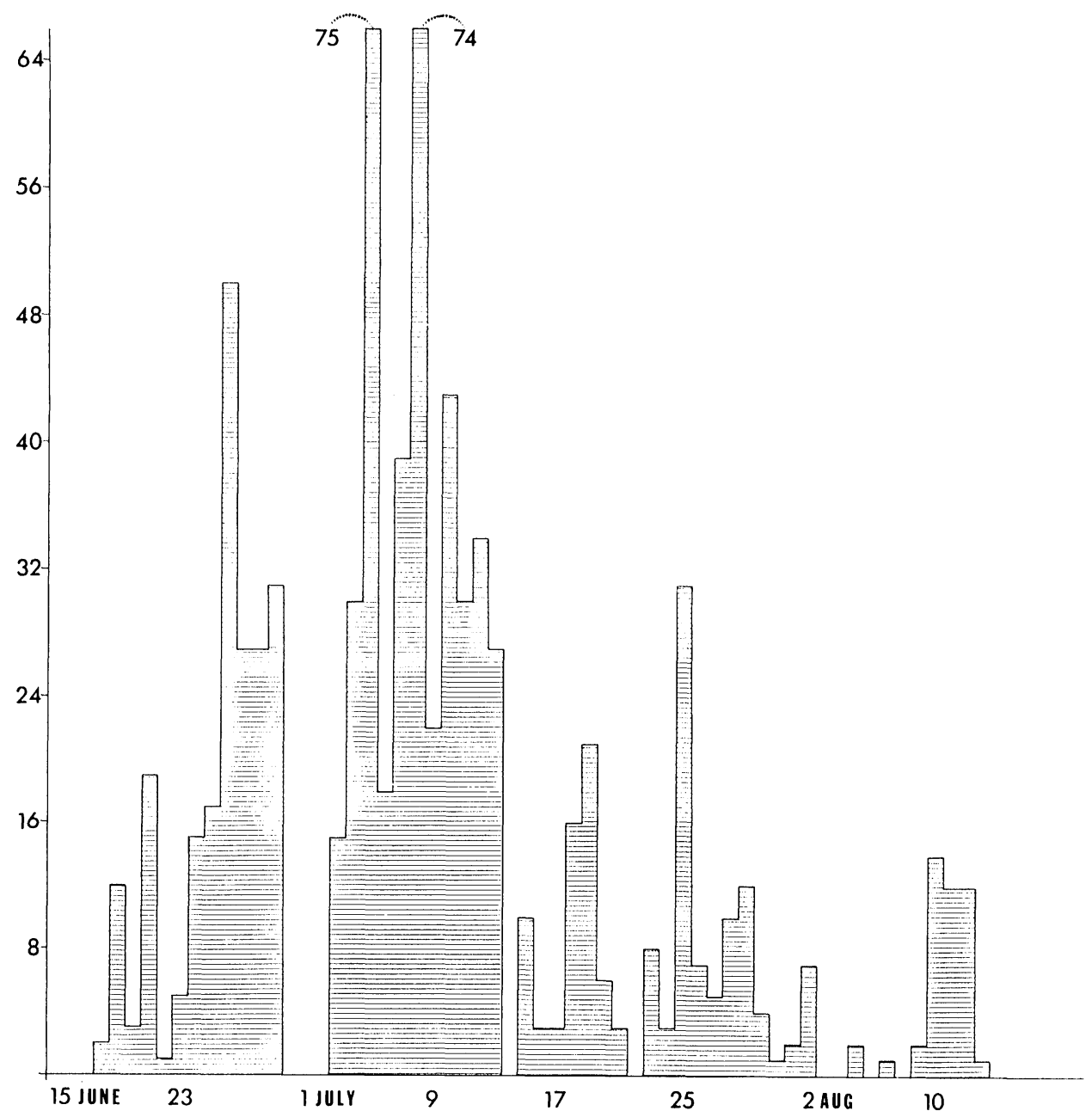

Fic. 3. Time of appearance of hatchling utas on 2 Texas study areas, 1961-63. Although hatchlings appeared as late as early October, the proportion hatching after midAugust was negligible and was omitted from the figure. The ordinate shows the total number recorded on each date.

Size and Appearance of Hatchling Utas.-Utas at hatching have an open yolk sac scar and a semi-transparent abdominal wall. The scar closes rapidly and the body wall quickly becomes opaque, for it is unusual to capture a lizard with an open scar or transparent abdomen. Only 17 young were captured while the yolk sac scar was still open; the smallest of these was $18 \mathrm{~mm}$ and the largest $23 \mathrm{~mm}$. The mean size at hatching is $22 \mathrm{~mm}$ 
(0.3 gm), but throughout this study I have considered any lizard of $23 \mathrm{~mm}$ or less a recent hatchling, and have designated the time of first capture of lizards this size as the date of hatching.

The sexes are similar at hatching. Both are distinctly striped, and the spotting characteristic of older males is not fully developed (Pl. II). By the time the lizards have grown to a snout-vent length of $33 \mathrm{~mm}$, the sexes are

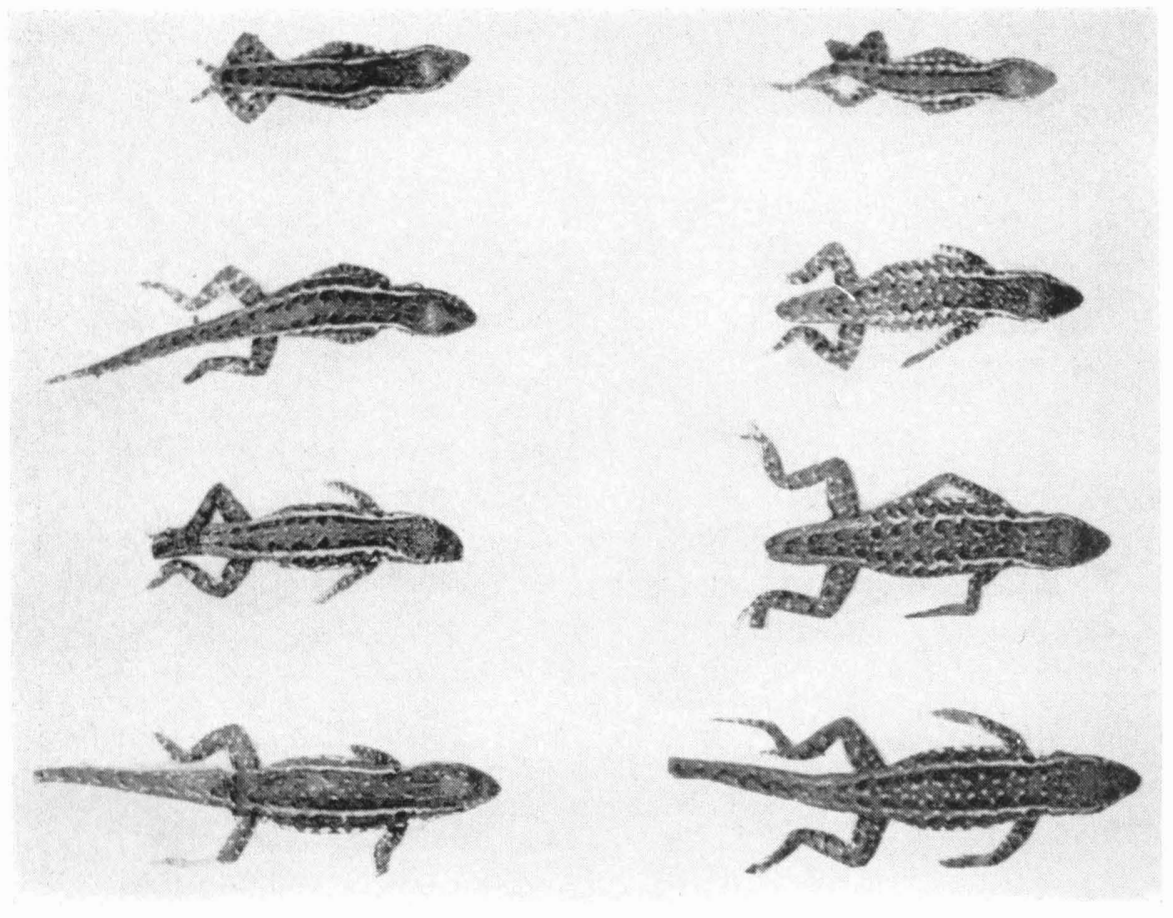

PLATE II

Photographs of female (left) and male utas. The smaller animals are a week or so old, the larger ones several weeks of age. The spotting characteristic of the adult male can be seen in some of the juveniles shown. Photo by Charles McKinney.

clearly distinguishable on the basis of pattern. The female retains the striped juvenal pattern, but this is altered in the male by the appearance of blue spots on the back and tail. Until this time, males can always be distinguished by a pair of enlarged scales just posterior to the cloaca at the tail base.

By the age of 8 to 10 weeks at a size of $35-40 \mathrm{~mm}$, some males develop active femoral pores, and most males develop them prior to their first winter and well before the onset of the breeding season. These structures may be 
indicative of approaching maturity, but their appearance is not indicative of breeding condition.

By fall or early winter most males hatched in the early summer have developed the blue and orange pigments to the point where the striped juvenal pattern is obscured; at this time they are difficult to distinguish on the basis of color, pattern, or size from the adults in the population (Pl. III).

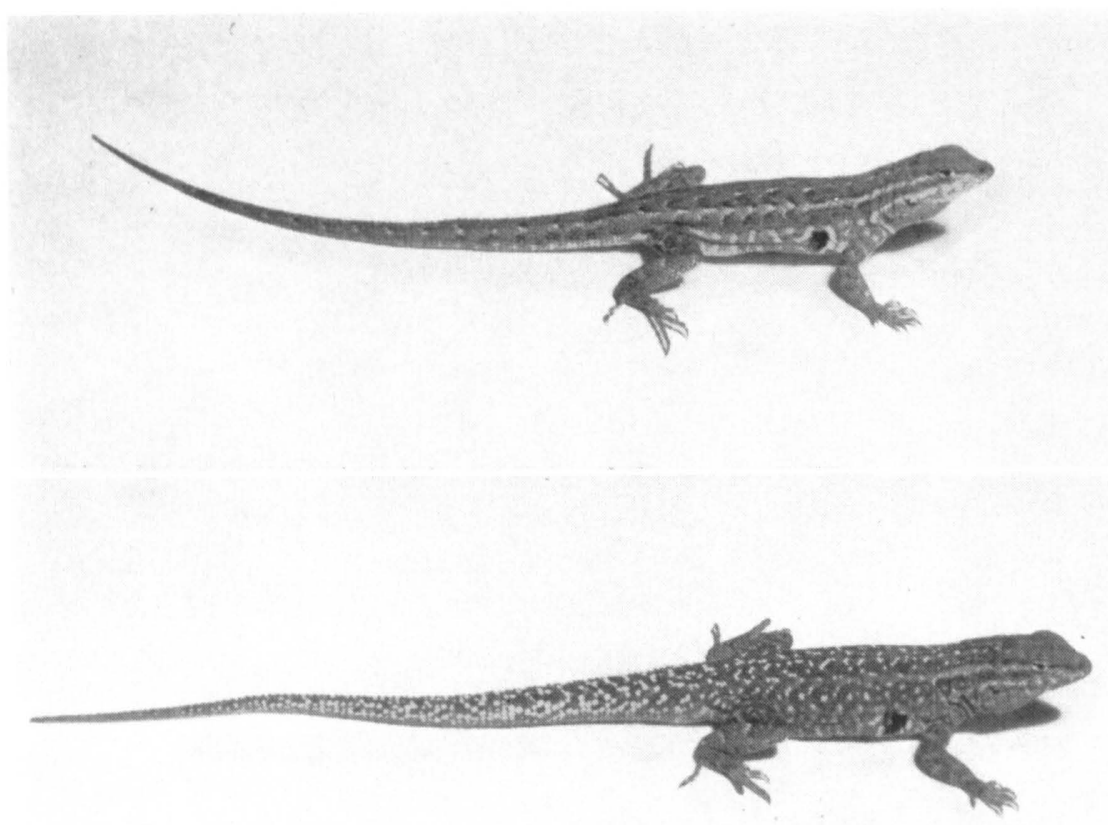

PLATE III

Adult female (top) and adult male. Note that the striped pattern characteristic of the juvenal male has all but disappeared. Photo by Isabelle Hunt Conant.

\section{The Growth of Utas}

Periodic recapture of marked animals has provided enormous quantities of data on growth. However, complete records of growth from hatching to maturity are available for only about 100 lizards. Rather than detail the growth of the individuals, I have chosen to treat the average growth of lizards of different sizes at various seasons to gain an understanding of variation in growth in the population. This procedure necessitated discarding well over one-half of the available information because on succeeding 
recaptures the same individual might be a member of two different size classes, or the captures might fall in two different seasons. In either event use of such clata would preclude accurate determination of variations in growth at different sizes and seasons.

I first analyzed separately the data for different years and different study areas, but I have shown only the significant differences in the compilation. Only data for the years 1961-1963, when intensive efforts were made to recapture juveniles frequently, were used in this section.

Growth of Hatchlings.-The growth of hatchlings is at first quite slow. Much of their maintenance energy during the first few days of their life may be derived from yolk remaining after hatching. The growth rate of hatchlings between 20 and $29 \mathrm{~mm}$ snout-vent is significantly slower than those 24-34 mm, especially in the females (Table 5).

There is practically no difference in the daily rate of growth from June to September, during which period 418 males increased in length at a rate of $.22 \mathrm{~mm}$ per day and 496 females at $.19 \mathrm{~mm}$ per clay. Assuming a steady growth at this mean increment, approximately 100 days would be required for a male to reach maturity and 105 days for a female. Thus, both sexes should mature within 4 months after hatching.

Only a few growth records are available for the fall months, October and November. Thirty-four males grew at a rate of $.15 \mathrm{~mm}$ per day cluring this period and 72 females at a rate of $.11 \mathrm{~mm}$. Therefore, even during the late fall the rate of growth is slowed by less than one-half the summer rate.

Growth of Subadult and Anult Utas.-Table 6 shows that the mean daily increment for males in the 40-49-mm size group from June to September was $.24 \mathrm{~mm}$ in 17 animals; for females the increment was .27 in 21 animals. Obviously the growth rate characteristic of young lizards continues right up to the attainment of mature size at which time growth becomes very slow. Utas that reach maturity in the fall of the year in which they hatch often grow very little during the subsequent breeding season, but a slow growth is resumed after the breeding season.

VARIATION IN GROWTH RATE.-There were significant clifferences in growth rate in different years. Only during the summers and among the smaller animals were sample sizes sufficiently large to study such differences (Table 7). A marked increase in growth rate occurred on both study areas in 1963 compared with the two previous years. This increase was noted in both size classes considered, but was most apparent in the hatchlings.

Such data as these suggest an increase in the available food supply or in the time during which the lizards could utilize the food. An interesting 


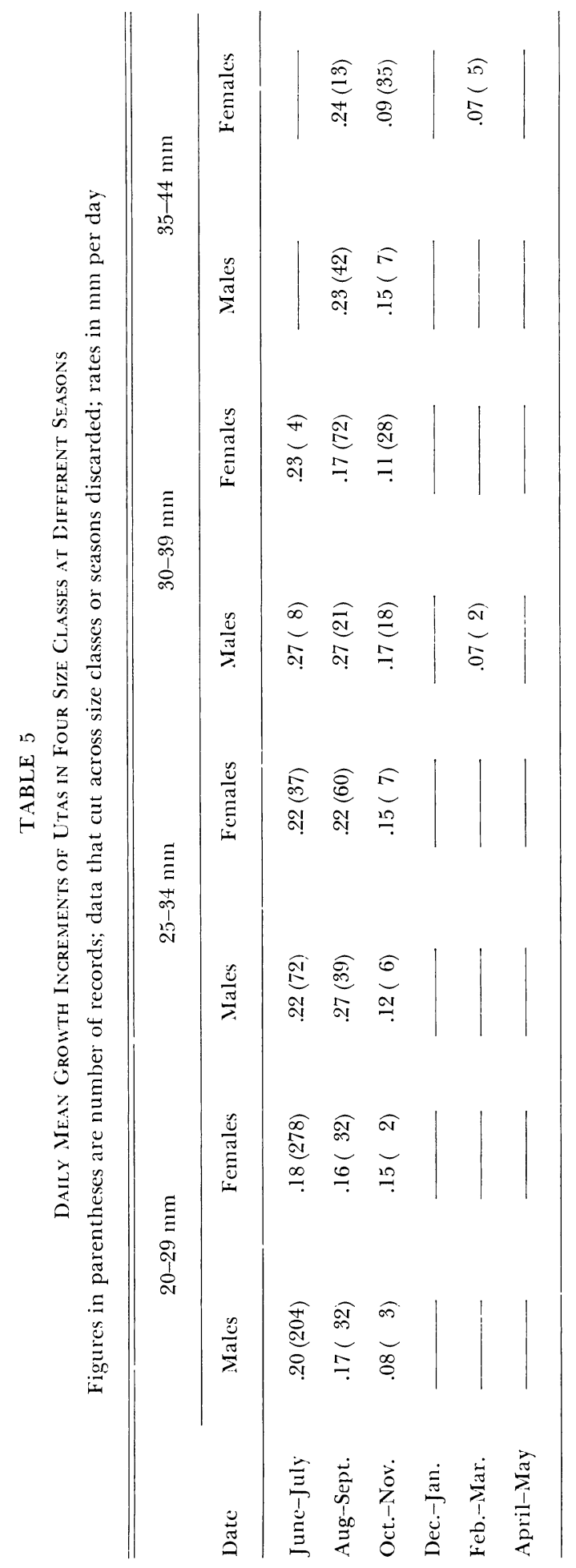


TABLE 6

Daily Mean Growth Increments of Subadult and Adult Utas

of Three Size Classes in Different Seasons

Figures in parentheses are the numbers of records

\begin{tabular}{|c|c|c|c|c|c|c|}
\hline \multirow[b]{2}{*}{ Date } & \multicolumn{2}{|c|}{$40-49 \mathrm{~mm}$} & \multicolumn{2}{|c|}{$45-54 \mathrm{~mm}$} & \multicolumn{2}{|c|}{$50-59 \mathrm{~mm}$} \\
\hline & Males & Females & Males & Females & Males & Females \\
\hline Junc-July & $.21(2)$ & $.27(21)$ & $.10(5)$ & $.32(3)$ & $.13(9)$ & \\
\hline Aug.-Sept. & $.24(15)$ & - & $.17(3)$ & 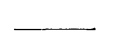 & $\ldots$ & \\
\hline Oct.--Nov. & $.11(19)$ & $.06(16)$ & $.08(21)$ & $\longrightarrow$ & — & - \\
\hline Dec--Jan. & $.02(4)$ & $.02(6)$ & $.05(2)$ & - & $.04(3)$ & \\
\hline Feb.-Mar. & $.07(4)$ & $.05(11)$ & $.03(12)$ & $.03(3)$ & - & \\
\hline April-May & $.06(3)$ & $.06(21)$ & —— & $.04(7)$ & $.04(13)$ & \\
\hline
\end{tabular}

TABLE 7

Differences in Mean Daily Growth Rates Between Differfent Years on the SAME Study Areas

Figures in parentheses are numbers of records.

Data are all from the months of June and July

\begin{tabular}{ccccc}
\hline $\begin{array}{c}\text { Area and } \\
\text { Year }\end{array}$ & \multicolumn{2}{c}{$20-29 \mathrm{~mm}$} & \multicolumn{2}{c}{$25-34 \mathrm{~mm}$} \\
\cline { 2 - 5 } $\begin{array}{c}\text { Males } \\
\text { Area I }\end{array}$ & Females & Males & Females \\
1961 & & $.17(59)$ & $.28(10)$ & $.21(3)$ \\
1962 & & $.20(31)$ & $.24(14)$ & $.18(10)$ \\
1963 & & $.27(13)$ & $.32(13)$ & $.26(5)$ \\
Area II & & & & $.15(1)$ \\
1961 & $.21(54)$ & $.18(79)$ & $.24(5)$ & $.19(7)$ \\
1962 & $.17(56)$ & $.14(67)$ & $.19(14)$ & $.27(11)$ \\
1963 & $.29(17)$ & $.23(29)$ & $.35(16)$ & \\
\hline
\end{tabular}

correlation is with the total numbers of juveniles registered on the study areas during the three years:

$\begin{array}{ccc}\text { Year } & \text { Area I } & \text { Area II } \\ 1961 & 455 & 489 \\ 1962 & 238 & 383 \\ 1963 & 318 & 498\end{array}$

The increased growth rate in 1963 came at a time when natality on both areas was higher than during the preceding year. Further, the number of young registered on area II was higher than in any previous year. 
Actual data on clensity of juveniles are available for June-July of these three years. These data are probably better than the previous ones in that they cover a shorter period of time during which most juveniles appear in the population; also, they show the actual number of young known to be on the area at that particular time:

$\begin{array}{ccc}\text { Year } & \text { Area } ~ & \text { Area II } \\ 1961 & 85 \text { per acre } & 81 \text { per acre } \\ 1962 & 36 \text { per acre } & 70 \text { per acre } \\ 1963 & 71 \text { per acre } & 109 \text { per acre }\end{array}$

These data are consistent in indicating higher densities during the period of increased growth rate. Therefore, it seems reasonable to conclude that the higher density coupled with faster growth indicates an increased food supply and further suggests that the population size is at least partially resource limited.

There is obviously much indiviclual variation in growth rate that I have not discussed in detail. Some animals show practically no growth and others grow at more than twice the mean rate. Those whose growth is retarcled may remain immature throughout the next breeding season; on the other hand, some of these retarded individuals suddenly assume an accelerated rate and may reach maturity midway through the reproductive season. However, it is much more common for lizards of retarded growth to be eliminated from the population prior to maturity, so that by the time of the breeding season almost all utas are in reproductive condition.

Growth of Young Utas in the Laboratory.-On September 16 of one year, 65 juvenal utas averaging $31 \mathrm{~mm}$ snout-vent were brought into the laboratory and on September 21 an additional 15 were added to the group. The lizards were fed on field-collected termites, Drosophila, and mealworms, and maintained under the conditions discussed in the introduction. Some clata pertinent to this growth experiment are shown below:

$\begin{array}{lccc} & \begin{array}{c}\text { Mean length } \\ \text { at start }\end{array} & \begin{array}{c}\text { Mean length } \\ \text { Oct. } 30\end{array} & \begin{array}{c}\text { Mean Iength } \\ \text { Dec. } 18\end{array} \\ \text { Males } & 31 \mathrm{~mm}(23) & 39 \mathrm{~mm} \mathrm{(19)} & - \\ \text { Females } & 31 \mathrm{~mm}(48) & 37 \mathrm{~mm}(4 \mathrm{I}) & 43 \mathrm{~mm}(25)\end{array}$

The males were utilized for another purpose after October 30, but during the approximately 40-day interval of observation they grew at an average rate of $.20 \mathrm{~mm}$ per day. During the same period females averaged 18 . These are about the rates observed in animals in the field, inclicating that the lizards under natural conditions are probably approaching their maximum growth potential. 
From October to December the females averaged $.12 \mathrm{~mm}$ per day, and the majority of them reached the size of sexual maturity prior to the end of the experiment.

The laboratory growth rates in females varied between .02 and $.27 \mathrm{~mm}$ per day, so they were no less variable under the uniform laboratory conditions and continuous food supply than they were in the field. There is no indication that the growth rates in the laboratory were faster than those in the field.

A Summary of Iitrrature on Lizard Growth.-There are few thorough studies of growth in lizards, and from almost none of these is it possible to define changes in growth rate with age. Although the most nearly accurate data have been obtained through marking and recapture, some studies have predicted growth rate from size composition of samples from natural populations. This is possible only if successive samples are taken at consistent intervals (usually monthly) beginning with the time of hatching when there are two very distinct size groups in the populations-the young of the year and all older animals. The hatchlings can then be followed in successive samples until they begin to overlap in size with the older lizards. In this way a fairly accurate indication of the mean growth rate is obtained by the increase in the average size of the hatchlings between samplings divided by the elapsed time. This technique will generally underestimate the growth rate because the successive hatching of second and third clutch individuals will reduce the mean size differences between successive samples.

Some authors have plotted size distributions of lizards that were collected at random. These data are quite misleading when used to estimate growth rates. In Table 8 , I have summarized the available data from the literature, usually restricting the citations to those that appear to have been determined by a reasonable procedure.

Rates of $0.2-0.3 \mathrm{~mm}$ per day have been so generally reported that this range could almost be taken as the average growth rate for lizards. The growth of Crotaphytus collaris reported by Fitch (1956b) from an area somewhat north of the natural range of the species is the fastest reported for any lizard, and the rate of $.10 \mathrm{~mm}$ per clay in Leiolopisma zelandica (Barwick, 1959) is the slowest reported from any field study. The fantastically slow rate of growth for Xantusia vigilis reported by Miller (1951) was not based upon any growth clata, but upon his assumption that the species required three years to reach maturity. The report by Bellis (1964) on the growth of Cnemidophorus sexlineatus was almost certainly based upon misconception about the age at maturity.

There is no apparent correlation between growth rate and the time 
TABLE 8

Comparative Growth Rates of Lizards in ma pfr Day Reported in the. Literaturf. All rates refer to juvenal animals unless otherwise noted

\begin{tabular}{|c|c|c|}
\hline Species & Growth rate & Authority \\
\hline \multicolumn{3}{|l|}{ Iguanidae } \\
\hline Sceloporus olivaceus & $\begin{array}{l}\text { Ist summer. } .30 q ; .37 \delta \\
\text { winter, } .05 \text { f and } q \\
\text { 2nd summer, } .28 q ; .21 \delta\end{array}$ & Blair $(1960)$ \\
\hline Sceloporus occidentalis & $.17,2$ nd growing season & Fitch $(1940)$ \\
\hline Sceloporus undulatus & $.29-.33 ; .06-.13$, 2nd scason & Crenshaw (1955) \\
\hline Crotaphytus collaris & $\begin{array}{l}\text { 1.00, just after hatching; } \\
42-52 \mathrm{~mm}, .71 ; 60-70 \mathrm{~mm}, .52 \\
74-80 \mathrm{~mm}, .30 ; 82-85 \mathrm{~mm}, .20\end{array}$ & Fitch $(1956 b)$ \\
\hline Basiliscus vittatus & 0.5 to 0.2 until mature & Hirth (1963) \\
\hline \multicolumn{3}{|l|}{ Agamidac } \\
\hline Agama agama & 0.2 , lst 6 months & Harris (1964) \\
\hline \multicolumn{3}{|l|}{ Teiidae } \\
\hline Cinemidophorus sexlineatus & $.05-.06 ?$ & Bellis (1964) \\
\hline Cnemidophorus sexlineatus & $.15 \delta ; .20 q$ & Carpenter $(1959 b)$ \\
\hline Cinemidophorus sexlineatus & $\begin{array}{l}0.5 \text {, in fast growing hatchlings; } \\
\text { one-half this rate } 2 \text { nd season }\end{array}$ & Fitch (1958) \\
\hline Ameiva quadrilineata & 0.4 to 0.2 , until mature & Hirth (1963) \\
\hline \multicolumn{3}{|l|}{ Iacertidae } \\
\hline Lacerta agilis; L. vivipara & .05, for first year & M. Smith (1951) \\
\hline \multicolumn{3}{|l|}{ Scincidae } \\
\hline Eumeces fasciatus & .35. summer & Fitch (1954) \\
\hline Eumeces septentrionalis & $.31-.37$ & Breckenrialge (1943) \\
\hline Eumeces obsoletus & $.30,1$ st 2 seasons & Fitch $(1955)$ \\
\hline Eumeces egregius & .16 (laboratory) & Mount (1963) \\
\hline Leiolopisma zelandica & .10 & Barwick (1959) \\
\hline \multicolumn{3}{|l|}{ Anguidae } \\
\hline Anguis fragilis & .25 & M. Smith (1951) \\
\hline \multicolumn{3}{|l|}{ Xantusiidae } \\
\hline Xantusia vigilis & $.02 ?$ & Miller (1951) \\
\hline \multicolumn{3}{|l|}{ Gekkonidae } \\
\hline Hemidactylus garnoti (sic) & $\begin{array}{l}\text { max. } 0.61 \text {; at least } 0.2 \\
\text { until mature }\end{array}$ & Caggle (1946a) \\
\hline
\end{tabular}

required to reach maturity. This presumably means that species which do not mature in one year simply have shorter growing seasons. However, in certain areas that are ecologically marginal for lizards (high mountains, New Zealand, British Isles) there are indications that slow growth rates prevail and result in delayed maturity. Almost all authors have reported 
some growth in lizards after sexual maturity, but at a rate of about .01 to $.05 \mathrm{~mm}$ per day.

There are no very significant differences reported in the literature between growth rates of males and females, nor differences between rates of immature lizards in their first or second growing seasons. However, seasonal differences in growth exist as demonstrated by my data on utas.

To what extent seasonal differences in growth reflect differences in temperature, photoperiod, or availability of food is not known. Laboratory studies have shown (Fox and Dessauer, 1957; Mayhew, 1965a) that the appetites and food intake of lizards are increased by long photoperiods, a fact indicated by my own experiments of photoperiodic effects in Uta. Mayhew (1965a) stated that Dipsosaurus dorsalis brought into the laboratory in the fall grew faster under the same laboratory conditions than individuals brought in during the following summer. There was also an indication that incandescent light was more stimulating to growth than infra-red. From his studies there is certainly reason to believe that there was a real difference between the rates of growth in his two experiments, but it is unfortunate that the experiments were not started with animals of the same size. The average length of his fall-collected lizards was about $65 \mathrm{~mm}$ compared with $80 \mathrm{~mm}$ in the summer group. Thus, some of the difference in growth rate that he observed might have been accountable to differences in the age of the lizards.

\section{SHEDDING}

Frequency of Shedding in Juvenal. Utas.-A phenomenon very likely related to growth rate is the frequency of ecdysis which, in utas, as in many lizards, occurs by stages; the entire skin is not cast as a unit. The fraying skin may cling to a lizard for a considerable time, imparting a grotesque appearance to the animal.

It has been difficult in all studies to obtain accurate data on shedding frequency because an individual is seldom recaptured at precisely the time it is shedding; also, it is most unlikely to be caught at this time several times in succession. In 1962 and 1963 we marked all young lizards with a dot of paint, the color of which was changed at regular intervals with note being made of whether the original paint was still present. When initially painted a young lizard may have just shed or be about to shed. The chances of getting an individual at either of these times should be equal, so with large numbers of records the average time between painting and repainting should approximate the average time between shedding. For example, if a lizard shed on July 10, but is not caught and repainted until July 12, and 
then sheds again on July 27, but is not caught and repainted until August 1, 17 days have actually elapsed between sheddings whereas I would have estimated 20. On the other hand, if the animal was repainted on July 15 and again on August 1, the interval between sheddings would have been underestimated. These under- and overestimates will presumably balance if a sufficient number of records are available.

The major weaknesses in my clata are in the fall, winter, and spring when daily reconnaissance of the study areas was not possible. During these periods a lizard may shed its skin and go unrecovered for a long period of time. For these periods all that can be determined is the frequency with which an individual was repainted over a given period of time. Hopefully, an approximation of shedding frequency was obtained by this technique.

TABI.E 9

Sheding; Friquincy OF JUVENAL I.JARIDS

All figures are mean days between molts except those in parentheses, which show the number of records available

\begin{tabular}{|c|c|c|c|c|c|c|}
\hline \multirow{2}{*}{ Date } & \multicolumn{2}{|c|}{$20-29 \mathrm{~mm}$} & \multicolumn{2}{|c|}{$30-39 \mathrm{~mm}$} & \multicolumn{2}{|c|}{ Overlapping Sizes } \\
\hline & Males & Females & Males & Females & Males & Females \\
\hline Junc-Aug. & $21.8(132)$ & $22.4(149)$ & $19.4(107)$ & $23.9(120)$ & $27.1(67)$ & $29.6(38)$ \\
\hline Sept.-Nov. & $\longrightarrow$ & - - & $1 / 33(8)$ & $1 / 33(15)$ & $1 / 56(5)$ & $1 / 39(9)$ \\
\hline Dec.-Feb. & 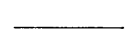 & - & $0 / 46(7)$ & - & - & — \\
\hline
\end{tabular}

The data for juvenal utas are shown in Table 9 in which the years and areas have been combined in the absence of any differences between them. Data were not used if the records between repainting overlapped seasons; if size groups were overlapped, such observations were placed in overlapping size classes whenever possible to maximize the proportion of the data that could be used.

Both male and female utas shed at about 3-week intervals during the summer. The 5 records of the exact number of days between sheddings vary from 7 to 21 (average 15). The increase in length of time between sheddings in the overlapping size classes (Table 9) results from the overlap into the adult class, which sheds less frequently. There are no apparent differences between the sexes in shedding frequency, but because there is a small difference in the growth rate of the sexes it would be surprising if a difference did not exist. My technique for measuring the frequency is probably too crude to detect a small difference between sexes.

The data for both sexes in the $20-29-\mathrm{mm}$ size group were combined to 
furnish additional details about shedding frequency in this group for which my data are strongest (Table 10). The mean interval between sheddings is 22.1 days with a range of $2-48$. The overall variation seems relatively slight; the variance is only 7.9 days and the standard error of the mean only 0.5 day.

TABLE 10

Detallfo Data on the Interval Between Shemdings in Male and Frmale Utas (Lumped) in the 20-29-m Size Class During; the Proriod June to August

\begin{tabular}{cc}
\hline $\begin{array}{c}\text { Number of days } \\
\text { between paintings }\end{array}$ & $\begin{array}{c}\text { No. of } \\
\text { Individuals }\end{array}$ \\
\hline $0-2$ & 2 \\
$3-5$ & 1 \\
$6-8$ & 9 \\
$9-11$ & 17 \\
$12-14$ & 27 \\
$15-17$ & 25 \\
$18-20$ & 35 \\
$21-23$ & 53 \\
$24-26$ & 36 \\
$27-29$ & 25 \\
$30-32$ & 14 \\
$33-35$ & 16 \\
$36-38$ & 13 \\
$39-41$ & 5 \\
$42-44$ & 2 \\
$45-47$ & 0 \\
$18-50$ & 1 \\
\hline
\end{tabular}

Ecipsis in Subadult and Adult Utas.-The data on these are shown in Table 11. No significant differences exist between males and females at any season. The size group $40-49 \mathrm{~mm}$ contains some animals that are not yet sexually mature, so it is not surprising that the shedding frequency in this group did not differ greatly from that of the juveniles. The same was also true of growth rates.

During the fall, the shedding frequency declines to about once every 5-6 weeks and generally ceases altogether during the winter. Finding lizards in the early spring that retain paint placed on them the previous fall is not uncommon. During the spring, shedding becomes more frequent again at intervals of about 2 months. As the adults go into the breeding season, the frequency is again increased to about once a month.

Shedding frequency is doubtlessly a correlate of growth rate, for the 
fastest shedding rates are found in the fastest growing young, and in juvenal lizards compared with adults. Even among adults ecdysis is frequent, indicating that renewal of the stratum corneum is essential even in the absence of significant growth. No data are available on shedding frequency in the laboratory.

Little information is available in the literature on shedding frequency in lizards, in part because it is difficult to obtain, but also because its importance is not immediately obvious. Blair (1960) obtained data for only the first 2 molts of sceloporus olitace'us, which came at about 4-week intervals. Little

TABLE 11

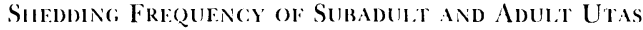
All figures are mean intervals between shedding in days. Figures in parentheses are numbers of records available

\begin{tabular}{|c|c|c|c|}
\hline \multirow{2}{*}{ Date } & \multicolumn{2}{|c|}{$40-49 \mathrm{~mm}$} & \multirow{2}{*}{$\frac{50-59 \mathrm{~mm}}{\text { Males }}$} \\
\hline & Males & Females & \\
\hline June-Aug. & $23.5(25)$ & $1 / 30(70)$ & $1 / 34(66)$ \\
\hline Sept.-Nov. & $1 / 38(19)$ & $1 / 40(10)$ & \\
\hline 1)ec.-Fel). & $0 / 67(5)$ & $0 / 68(5)$ & $0 / 70(8)$ \\
\hline March-May & $1 / 61(11)$ & $1 / 52(62)$ & $1 / 56(34)$ \\
\hline
\end{tabular}

or no shedding occurred in the winter and, surprisingly, adult lizards sometimes did not molt for as long as a year. Fitch (1956b) reported that molting in Crotaphytus collaris occurred at 2-3 week intervals between hatching and the first hibernation, and at about 3-week intervals in the second growing season. Mature adults shed their skin at about 25-day intervals. Fitch (1958) reported that no Cnemidophorus sexlineatus retained paint after 28 days, suggesting that this is the maximum time between sheddings. These estimates are in general agreement with those presented on utas.

\section{AgF at Maturity in Utas}

Having already predicted the time required to reach a mature size, I must now turn attention to actual data on the age at maturity. Females reach sexual maturity at a minimum size of $42 \mathrm{~mm}$, males at about $46 \mathrm{~mm}$. Obviously, lizards in the natural population will reach these sizes only a few months after hatching, but will not reproduce until the following spring when they average about 9 months of age. However, I am justified in consid- 
ering the age at maturity as the time when utas reach a mature size because we have shown that these will reproduce in the laboratory prior to the normal breeding season.

In this section of the study, I have used only animals whose life history was fairly completely known. I have used animals that were less than $24 \mathrm{~mm}$ when first marked and hence probably in their first week of life. I have taken their age at maturity to be the time between hatching and the recapture date on which they had first attained mature size. Unfortunately, this technique will almost always overestimate the time required to mature. For example, a female captured on September 29 was $39 \mathrm{~mm}$ and on October 27 was 42 $\mathrm{mm}$. October 27 is taken as her clate of maturity, but she may have reached $42 \mathrm{~mm}$ several days previously. If there was a very long period between the last two captures the data were not used.

TABLE 12

Tue Number of Days Required for Utas to Reach a Minimum Size at Maturity The figures shown are means with the range of variation in parentheses.

Only animals marked at a size of $24 \mathrm{~mm}$ or less, and presumably in their first week of hatching, are shown.See text for additional details

\begin{tabular}{crrrr}
\hline Size $(\mathrm{mm})$ & $\mathrm{N}$ & Males & $\mathrm{N}$ & Females \\
\hline 21 & 2 & $113(95-130)$ & 5 & $151(125-247)$ \\
22 & 13 & $168(94-329)$ & 10 & $135(101-245)$ \\
23 & 7 & $117(70-143)$ & 7 & $132(102-151)$ \\
24 & 11 & $82(61-125)$ & 7 & $82(61-106)$ \\
Totals & 33 & $125(61-329)$ & 29 & $124(61-247)$ \\
\hline
\end{tabular}

There are 33 males and 29 females (Table 12) for which fairly complete records indicate that about 4 months are required to reach maturity. The period to maturity in lizards with retarded growth ranged to almost a year in males and to eight months in females. At least it is clear that almost all utas hatching in the summer can reach sexual maturity in the fall or early winter, well ahead of the breeding season. As noted previously this is probably of great importance in allowing spermatogenesis to proceed in these young males to the spermatid stage prior to the beginning of the reproductive season. In females, attainment of maturity in the fall is important to allow fat storage.

A I Iscussion of the Literature on Age at Maturity in Lizards.It is most unfortunate for studies of natality and population dynamics that 
so little is known of age at maturity in lizards, for this lack of knowledge precludes estimates of natality and predictions about the form of the survivorship curve for the species. The data available have already been shown in Table 2. Of all lizards studied there are fewer than 10 species in which the exact age at maturity is known.

The age at maturity has been cletermined more often from the distribution of size groups in a frequency histogram than by following marked animals to maturity and this has certainly led to erroneous judgments of the age at maturity. To take my own work as an example, I (Tinkle, 1959) estimated the minimum age at maturity in the lizards Cnemidophorus tigris and C tessellatus as 2 years. This was done on the distribution of size groups in samples collected at different seasons, samples in which the size distribution was almost certainly biased by small samples and by collecting technique. I feel certain on the basis of much better information now available that at least tigris matures in one year. Similarly, the report of Bellis (1964) that females of Cnemidophorus sexlineatus required three years to mature was based on an attempt to assign ages to size classes and was certainly in error. The report by Miller (1951) that the small lizard Xantusia vigilis required three years to mature may be true, but it would be an exceptionally long period for any small lizard. However, his estimate was based upon the time that he thought was required (i.e., 3 years) for various cytological events to occur in the maturation of ova.*

Misinformation about the age at maturity may lead to mistaken ideas about the reproductive biology of a species. C. Johnson (1960) stated that a female Holbrookia texana taken in August contained small yolked follicles. Because this female was about the same size as juvenal females that had hatched earlier the same summer, he concluded that this female, too, was reproducing in the same summer in which it was hatched. This might occur, but it is more likely that the rapid growth of the hatchlings had brought them to a size that was overlapping with young (now adults) of the previous year. Reproduction during the same season in which a lizard has hatched may occur in the tropics, further increasing the difficulty of determining the reproductive potential of individual animals (see section on reproductive potential for (iscussion).

More students of reptile life history should mark hatchling animals to determine the actual time required for them to reach maturity. Such information would make life history information of much greater value to ecologists.

* In a paper that appeared after this went to press, Zweifel and Lowe, 1966 (Amer. Mus. Novitates, No. 2247) presented data tending to confirm Miller's estimates. 


\section{Growth in Weight by Utas}

In the period 1961-63 lizards were generally weighed at each capture, not only to obtain data on weight gain during ontogeny, but also to chart the change in weight of adults at different seasons and to compile data useful for estimating biomass. The data for each year and area were separately analyzed, but there were no significant differences so the data were pooled for discussion.

The weights of juvenal lizards at each $1 \mathrm{~mm}$ snout-vent length are shown in Table 13. Evidently little weight is gained during the first few

TABLE 13

Weights of Juvlenal. Male and Female Utas at Four Different Seasons and at Each l-mm InCREMTNT in SNOUT-Vent Length from Hatching up to the Minimum Size at Maturity

Figures in parentheses are numbers of records; weights in grams

\begin{tabular}{|c|c|c|c|c|c|c|c|c|}
\hline \multirow{2}{*}{$\begin{array}{l}\text { Snout- } \\
\text { vent, } \\
\text { mm }\end{array}$} & \multicolumn{4}{|c|}{ Males } & \multicolumn{4}{|c|}{ Females } \\
\hline & June-Aug & Sept.-Nov & Dec.-Feb. & Mar.-May & June-Aug. & Sept.-Nov & Dec.-Feb. & Mar.-May \\
\hline 20 & $.33(5)$ & & & & $.30(9)$ & & & \\
\hline 21 & $.29(19)$ & & & & $.30(67)$ & & & \\
\hline 22 & $.33(95)$ & & & & $.34(105)$ & $.41(1)$ & & \\
\hline 23 & $.37(92)$ & $.42(5)$ & & & $.39(113)$ & $.38(1)$ & & \\
\hline 24 & $.44(65)$ & .49 ( 2) & & & $.44(62)$ & - & & \\
\hline 25 & $.50(64)$ & $.51(1)$ & & & $.51(88)$ & $.55(6)$ & & \\
\hline 26 & $.57(88)$ & $.59(5)$ & & & $.59(86)$ & $.55(4)$ & & \\
\hline 27 & $.65(56)$ & $.77(6)$ & & & $.67(74)$ & $.80(5)$ & $.82(1)$ & \\
\hline 28 & $.75(58)$ & $.72(5)$ & & & $.72(66)$ & $.80(11)$ & & $1.81(1)$ \\
\hline 29 & $.79(67)$ & $.87(9)$ & & & $.79(68)$ & $.91(5)$ & & L- \\
\hline 30 & $.90(66)$ & $1.09(4)$ & & & $.88(64)$ & $1.01(9)$ & & \\
\hline 31 & $1.01(46)$ & $1.19(9)$ & $1.08(2)$ & - & $1.00(39)$ & $1.07(18)$ & $.88(2)$ & - \\
\hline 32 & $1.11(28)$ & $1.15(9)$ & - & $1.54(1)$ & $1.10(40)$ & $1.32(\mathrm{ll})$ & $1.14(4)$ & $2.13(1)$ \\
\hline 33 & $1.25(44)$ & $1.29(8)$ & & $1.38(4)$ & $1.14(20)$ & $1.25(17)$ & $1.47(1)$ & $1.35(2)$ \\
\hline 34 & $1.30(25)$ & $1.40(16)$ & & - & $1.25(11)$ & $1.39(24)$ & - & $1.48(2)$ \\
\hline 35 & $1.44(24)$ & $1.54(5)$ & & $1.73(1)$ & $1.37(6)$ & $1.53(28)$ & 1.21 ( 2) & $1.28(1)$ \\
\hline 36 & $1.56(14)$ & $1.69(12)$ & - & $1.69(1)$ & $1.53(4)$ & $1.63(26)$ & $1.80(1)$ & $1.55(3)$ \\
\hline 37 & $1.62(16)$ & $1.73(9)$ & $2.22(1)$ & $1.67(2)$ & $1.67(3)$ & $1.81(29)$ & $2.01(2)$ & $2.02(3)$ \\
\hline 38 & $1.88(8)$ & $1.95(11)$ & -- & - & $1.88(3)$ & $1.91(41)$ & $2.28(2)$ & $1.96(5)$ \\
\hline 39 & $1.94(5)$ & $2.12(17)$ & - & $2.25(1)$ & $1.98(1)$ & $2.13(30)$ & $1.98(3)$ & $2.03(3)$ \\
\hline 40 & $1.96(4)$ & $2.29(21)$ & $2.21(1)$ & $2.35(3)$ & $2.50(1)$ & $2.33(39)$ & $2.24(3)$ & $2.08(4)$ \\
\hline 41 & $2.28(3)$ & $2.50(20)$ & $-\cdots$ & $2.54(1)$ & $\longrightarrow$ & $2.47(26)$ & $2.57(6)$ & $2.42(5)$ \\
\hline 42 & $\longrightarrow$ & $2.48(15)$ & $2.88(2)$ & $2.50(2)$ & & & & \\
\hline 43 & $\longrightarrow$ & $2.91(22)$ & $2.93(1)$ & $2.76(2)$ & & & & \\
\hline 44 & - & $3.00(13)$ & $3.40(4)$ & $3.34(4)$ & & & & \\
\hline 45 & $3.21(3)$ & $3.20(17)$ & $3.28(4)$ & $3.96(4)$ & & & & \\
\hline
\end{tabular}


days of life; the data on growth indicated little or no elongation of the animal cluring the same period. After the first few days of life weight increases rapidly, doubling approximately every month during the summer and early fall. Although samples are small for a lew size groups they indicate that both sexes are somewhat heavier in the fall than in the spring or summer. It is cluring the fall that the maturing utas begin to store fat, and I assume this is the source of the increased weight. The information on juveniles in the winter and spring is meager, partly because I have little clata available from these seasons and partly because almost all utas have reached adult size by this time. However, even these limited data show clearly that there is no significant weight change cluring the winter or early spring. This would not be possible if the lizards were depending upon stored energy reserves during the winter and early spring. They are active during these seasons whenever it is sufficiently warm and food is available, as indicated by the full stomachs of lizards collected at these times. Because of the low temperatures prevailing, activity can probably be purchased at relatively little cost in energy which can, in turn, be obtained by feeding through the cool months. By this continued activity the utas are able to take advantage of an otherwise unfavorable season to continue growth, although at a slow rate. It is of more than passing interest, I think, that utas are the only lizards in the area that are ever seen cluring the winter months.

If the mean weight is plotted against snout-vent length, a remarkably uniform regression is obtained (Fig. 4), but the curve has less slope with advancing size than it does initially. If these same weight data are plotted against the average age of lizards at the different snout-vent lengths, a true rate curve may be obtained (Fig. 5). An obvious decrease in the rate of growth occurs as the lizards approach mature size. Females appear to require slightly more time to reach the same weight as the males, but there is practically no difference in the mean weight between males and females of the same length. Like all previous data there is wide variation among individuals in rate of weight gain. That the lizards change shape with age is clearly indicated. Subadults have a more elongate appearance than older animals of the same length.

The weights of adult utas are shown in Table 14. These data make clear that juvenal lizards hatched in one summer reach an average weight by fall that overlaps that of the parental class (compare Tables 13 and 14). Therelore, weight, like size, is a poor criterion for separating age classes. The weights of adult males and females are about the same if lizards of the same length are compared. However, males reach a greater length than females, so the average weight for all adult males is about one gram greater than that for adult females. 


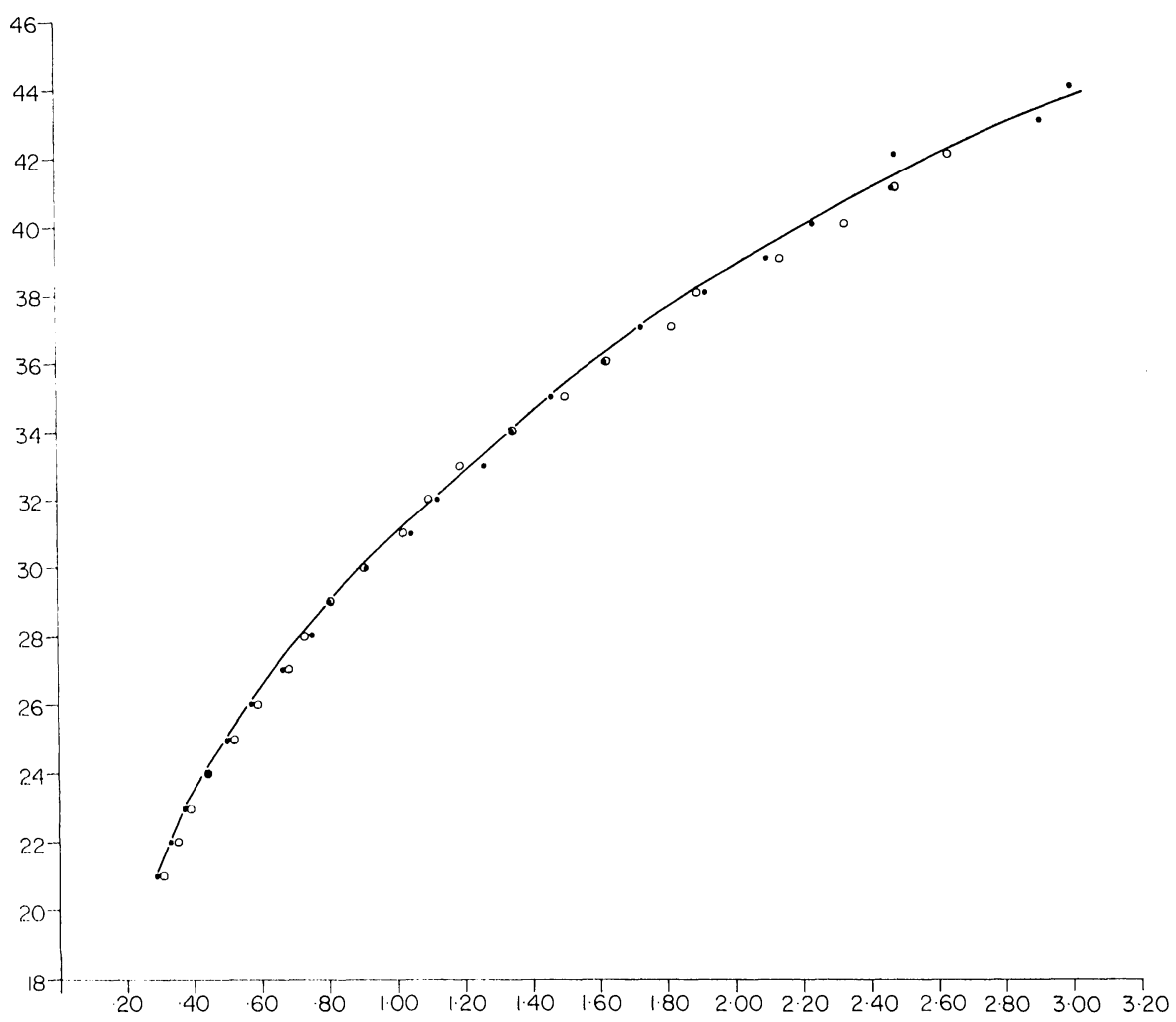

FIG. 4. Correlation of weight in grams (abscissa) with snout-vent length in millimeters (ordinate). Solid circles, males; open circles, females. Each point on the curve is the mean for a large number of records.

The weight data for each adult size class in the summer and fall indicate that the lizards are slightly heavier in the fall, but the overall means for all adults of all sizes for these two seasons are not significantly different. Hahn and Tinkle (1965) showed that utas utilize their stored fat reserves in the spring during the initial estrous cycle. These adults and maturing young of the same year do not replenish the depleted fat reserves until fall, at the end of the reproductive season. These authors also showed that fat storage in females was greater than in males. The data presented here do not show a greater weight gain by females than males during the fall, but because the difference in fat storage between the two sexes amounts to only 2 per cent of the body weight it would be difficult to demonstrate a difference in weight between the two sexes without extremely large samples.

In adults of both sexes the greatest average weights are attained in the 
spring. The reasons for this are clear in the case of females in which the beginning of reproduction and attendant enlargement of ovarian eggs produces weight increase. In both sexes, too, animals that did not reach mature size the previous fall again begin to grow rapidly in length and weight; males, in particular, double their weight after minimum size at maturity is attained.

Table 14 also shows that the mean weights of animals of the same length at different seasons are not greatly different. The smallest mean

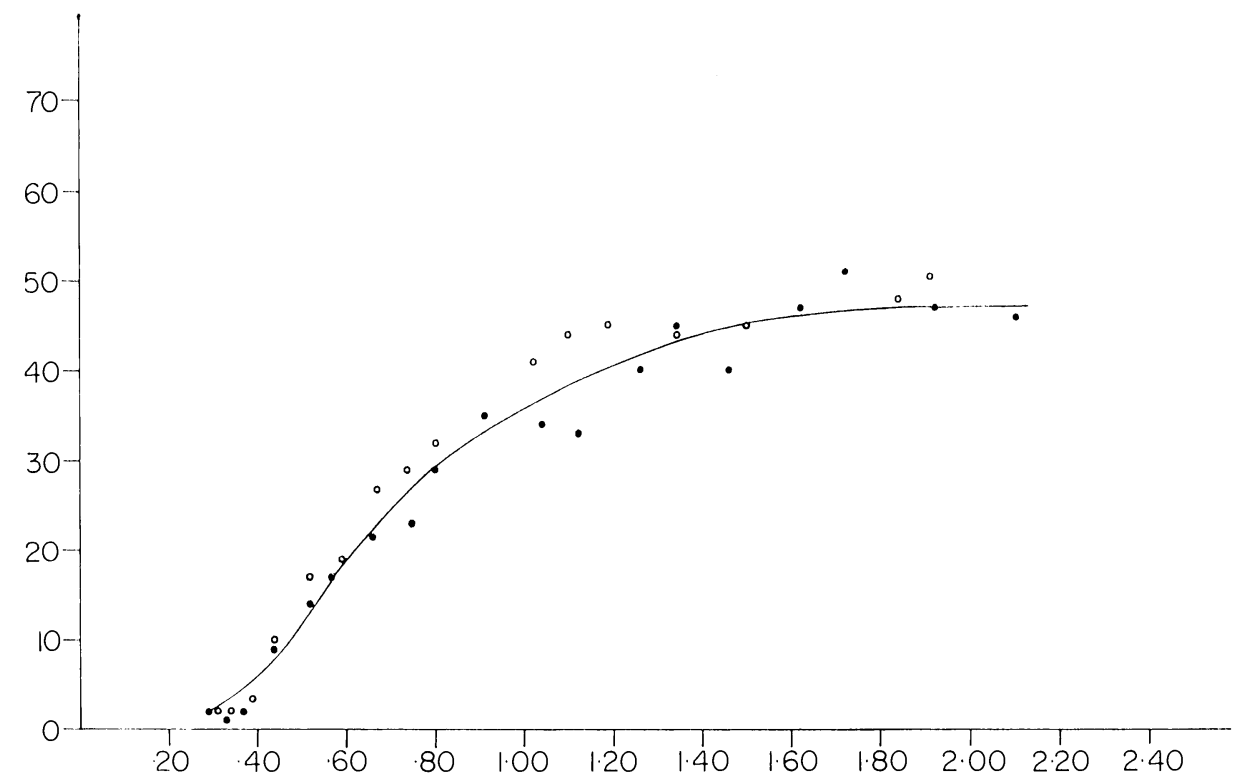

Fic. 5. Correlation of weight with age for first 8 weeks of life for those lizards that were marked at hatching. Solid circles, males; open circles, females. Each point on the curve is the mean of a large number of records. Abscissa, weight in grams; ordinate, days since hatching.

weight for males (Sept-Nov.) differs from the greatest (March-May) by only .83 gram or about 20 per cent of the mean body weight. In females the corresponding difference is only .37 gram. Despite these similarities, I think it is not difficult to discern that spring weights in males and females are always greater than summer weights for each size group examined. The difference is attributable to the increased activity in summer and the increasing temperatures that result in higher energy expenditures and a consequent loss of weight by many of the lizards. Therefore, to the conclusions of Hahn and Tinkle (1965) that fat is important to early reproduction 
TABLE 14

Weights of Adult Male and female Utas at Four Different Seasons from Minimum Size at Maturity to Maximum Size Recorded

Decimal figures are mean weights in grams; figures in parentheses are numbers of records

\begin{tabular}{|c|c|c|c|c|c|c|c|c|}
\hline \multirow{2}{*}{$\begin{array}{c}\text { Snout- } \\
\text { vent } \\
\mathrm{mm}\end{array}$} & \multicolumn{4}{|c|}{ Males } & \multicolumn{4}{|c|}{ Females } \\
\hline & June-Aug & Sept.-Nov. & Mar.-May & Dec.-Feb. & June-Aug. & S pt.-Nov & Dec.-Feb & Mar.-May \\
\hline 42 & & & & & - & $2.63(22)$ & $2.64(13)$ & $2.76(11)$ \\
\hline 43 & & & & & $2.44(2)$ & $2.87(15)$ & $2.88(8)$ & $3.25(29)$ \\
\hline 44 & & & & & $3.10(9)$ & $3.17(12)$ & $3.30(3)$ & $3.27(24)$ \\
\hline 45 & & & & & $2.93(23)$ & $3.22(11)$ & $2.92(1)$ & $3.65(21)$ \\
\hline 46 & $3.41(4)$ & $3.30(27)$ & $3.65(2)$ & $3.72(5)$ & $3.41(28)$ & $3.51(9)$ & $3.57(4)$ & $3.65(26)$ \\
\hline 47 & $3.68(2)$ & $3.86(20)$ & $3.96(5)$ & $4.14(12)$ & $3.56(19)$ & $3.45(5)$ & $4.07(4)$ & $3.98(19)$ \\
\hline 48 & $3.45(6)$ & $4.18(18)$ & $4.24(6)$ & $4.20(8)$ & $3.52(11)$ & $4.01(3)$ & $3.95(2)$ & $4.05(15)$ \\
\hline 49 & $4.08(9)$ & $4.39(16)$ & $4.78(9)$ & $4.57(11)$ & $4.24(4)$ & $4.17(2)$ & $\longrightarrow$ & $3.90(8)$ \\
\hline 50 & $4.34(17)$ & $4.88(14)$ & $4.54(7)$ & $4.91(24)$ & $4.40(4)$ & $4.80(1)$ & $4.11(1)$ & $4.30(7)$ \\
\hline 51 & $4.63(14)$ & $4.88(6)$ & $4.65(4)$ & $5.02(21)$ & $4.41(1)$ & & & $4.69(2)$ \\
\hline 52 & $4.80(13)$ & $5.11(8)$ & $5.46(8)$ & $5.27(16)$ & $\longrightarrow$ & & & $4.17(1)$ \\
\hline 53 & $5.02(8)$ & $5.54(3)$ & $5.75(8)$ & $5.48(17)$ & & - - & & $5.27(2)$ \\
\hline 54 & $5.19(2)$ & $5.48(6)$ & $5.44(2)$ & $5.24(9)$ & & & & \\
\hline 55 & $5.63(2)$ & $5.83(3)$ & $6.03(4)$ & $6.12(7)$ & & & & \\
\hline 56 & $6.07(1)$ & $\longrightarrow$ & - & $5.86(4)$ & & & & \\
\hline 57 & - & $\longrightarrow$ & - & $6.70(2)$ & & & & \\
\hline$x$ s & $4.41(81)$ & $4.14(138)$ & $4.38(59)$ & $4.97(140)$ & $3.37(102)$ & $3.28(58)$ & $3.41(23)$ & $3.65(173)$ \\
\hline
\end{tabular}

must be added the contention that the fat reserve is also partly used in the increased metabolic activity in the spring.

For all practical purposes there are no data of value in the literature on the weight gains of lizards under natural conditions. For obvious reasons such data are or will be valuable for estimating biomass, productivity, and energy flow, and more attention should be devoted to obtaining such data in future studies of the natural history of lizards.

\section{Growth of the Tail, in Utas}

The tail is an organ of very great importance in lizards in such diverse activities as fat storage, predator escape, mating, and territoriality. For these reasons we have spent considerable effort studying the growth and regeneration of this organ.

The study of tail growth presented the same problems as those encountered by the study of body growth, viz., the difficulty of recapturing the lizard more than once while it was in the same size class and season. Many data were discarded that cut across more than one size class or season, but sufficient data remain for some definite conclusions. 
The ratio of tail length to snout-vent length varies from about 1.5 to 1.7 in females, from 1.5 to 1.8 in males. If the mean tail length at each snout-vent length is graphed, a nearly straight line is formed in males. In females a change in the slope occurs at about the time of sexual maturity (Fig. 6). The tail obviously grows at a faster rate than the body for the ratio of tail length to body length changes from about 1.5 at hatching to 1.7 or higher at maturity.

The actual rate of growth of the tail has been studied by choosing data from those among our lizards that never sustained a broken tail during their life. Only those records in which tail measurements were made at least 10 days apart were used. Data from the two study areas were analyzed

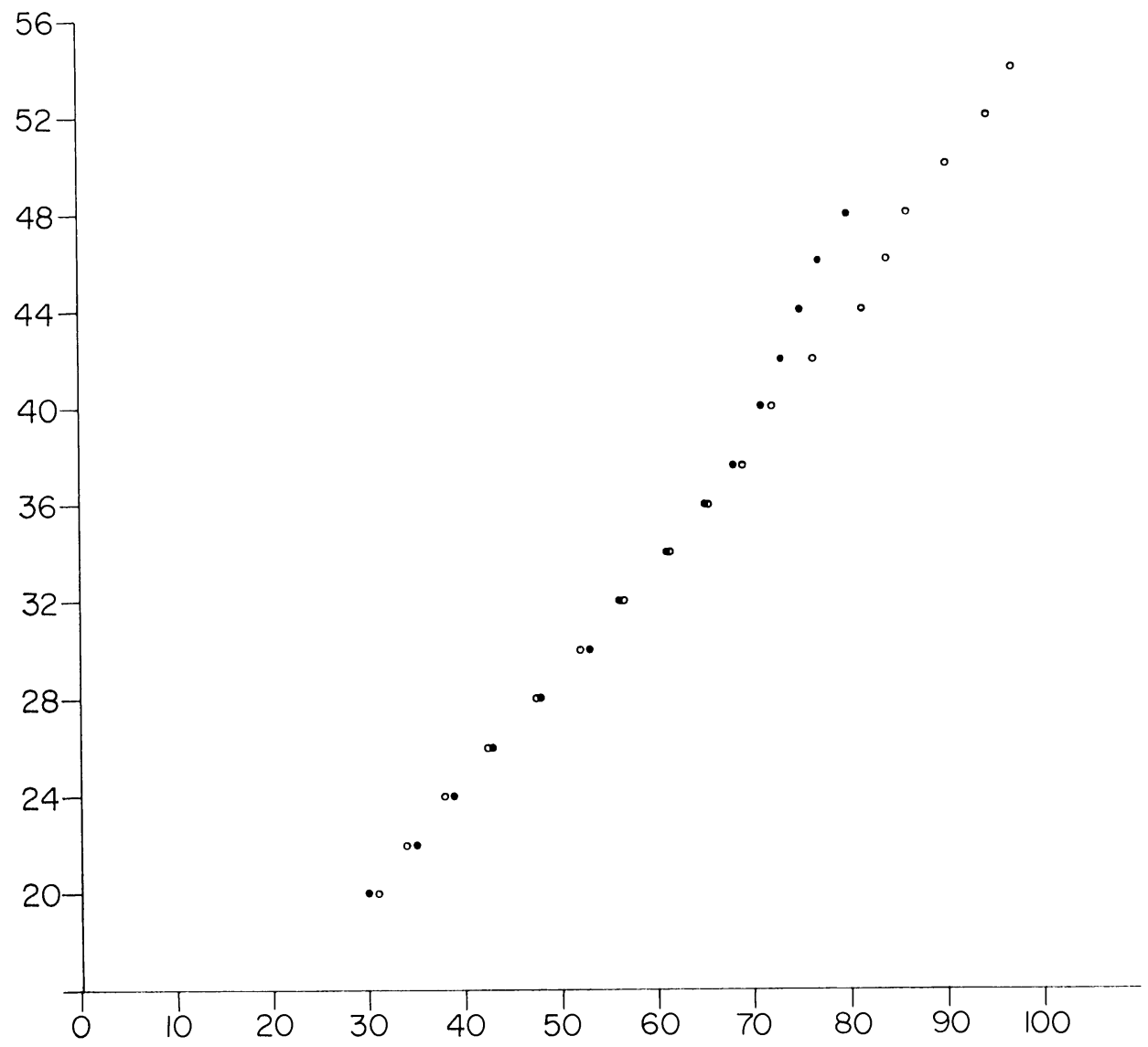

FIG. 6. Length of tail (abscissa) plotted against snout-vent length (ordinate). Solid circles, females; open circles, males. All figures in millimeters. 
separately, but there were no significant differences; data for different years were not analyzed separately. Almost all of the available data are from the summer months because our recapture efforts were concentrated at that season (Table 15).

There is a statistically significant difference in the growth rate of the tail between males and females. Over an entire summer this produces a tail about $10 \mathrm{~mm}$ longer in the male than in the female. Between the two size groups considered there was no significant difference in rate of tail growth for either sex. In effect the tail grows at a constant daily increment until about the time of sexual maturity, and this is reflected in Figure 6, which shows the relative constancy of the tail length to body length ratio in juvenal utas.

TABLE 15

Growth Rate. of the Tail, in ma plir Day in two Size Classes of JUVENAL LIZARDS AT DIFFERENT SFASONS

Only animals that never sustained a broken tail were used.

Decimal figures are means; figures in parentheses are numbers of records available

\begin{tabular}{lcccc} 
& \multicolumn{2}{c}{ Males } & \multicolumn{2}{c}{ Females } \\
\hline Date & $22-32 \mathrm{~mm}$ & $33-45 \mathrm{~mm}$ & $20-30 \mathrm{~mm}$ & $31-41 \mathrm{~mm}$ \\
\hline Junc-Aug. & $.54(173)$ & $.53(55)$ & $.45(189)$ & $.39(59)$ \\
Sept.-Nov. & $.36(3)$ & $.33(20)$ & $.20(3)$ & $.18(43)$ \\
Dec.-Feb. & - & $.08(7)$ & - & $-10(3)$ \\
March-May & & $.26(7)$ & - & \\
\hline
\end{tabular}

During the fall the rate of tail growth slows to about one-half that of the summer even when lizards of the same length in the two seasons are compared. Growth of the tail practically ceases during the winter, for which I have very few records, but increases again in the early spring at a rate not greatly different from that in the previous fall.

Adult lizards have been divided into two size classes to determine the rate of tail growth after sexual maturity (Table 16). As with growth of the body, growth of the tail is slow after sexual maturity; the rate seldom exceeds $.05 \mathrm{~mm}$ per clay. At first glance the data for adults may seem odd because males $46-50 \mathrm{~mm}$ long have a significantly faster rate of growth in the fall than in the summer. This is readily understandable if one remembers that a lizard of this size in June, July, or August is about a year old, while in September, October, or November most of the records are for animals hatched in the summer of that year, and therefore only a few months old. The difference in rates is attributable to the differences in the 
ages of the animals comprising the samples from the two seasons. This is true because of the faster absolute growth rate of young lizards compared with that of adults.

Rate of Growth in Broken and Unbroken Talis.-From the data presented thus far it appears that the growth rate of unbroken tails is about $0.5 \mathrm{~mm}$ per day. Data to be presented later on tail regeneration show that the rate of growth in the base of a regenerating tail is significantly slower than the rate in the intact tail. This indicates that if the lizard clepended enirely on the regrowth of the broken base to replace a tail, the process would be slow incleed. The rate of regeneration of a broken tail is

TABLE 16

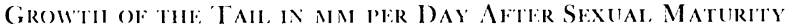

I wo different size groups of adults are considered at different seasons.

Only animals that never sustained a broken tail were considered

Decimal figures are means; numbers in parentheses are numbers of captures

\begin{tabular}{lcccc}
\hline \multicolumn{1}{c}{ Date } & \multicolumn{2}{c}{ Males } & \multicolumn{2}{c}{ Females } \\
\hline Junc-Aug. & $.16-50$ & $51-5.5$ & $42-16$ & $47-51$ \\
Sept.-Nov. & $.02(6)$ & $.02(8)$ & $.01(11)$ & $.02(9)$ \\
Dec.-Fel). & $.13(9)$ & & $.05(3)$ & - \\
March-May & $.04(16)$ & $.07(1.1)$ & $.03(9)$ & - \\
& $.03(40)$ & $.03(10)$
\end{tabular}

essentially the same as the growth rate of an unbroken tail. However, when the basal growth plus the regenerative growth is considered, the rate of tail growth is more rapid than is the rate in lizards with unbroken tails. Therefore, the value of regeneration lies not only in the replacement of the tail but replacement at a rate faster than would be possible without the regenerative process.

\section{RFGHNERATION}

Rrgeneration OF BROKFN TAILS.-The importance of tail regeneration to lizards in which the tail is easily broken cannot be exaggerated. The evolution of easy tail breakage is almost certainly involved in escape from predators. The tail is also important in balance; so rapid regeneration is undoubtedly of great significance to this species.

It was impossible to judge the frequency of tail breakage in or around the study areas because many of the observed breaks resulted from our 
efforts at capturing the lizards. For example, on July 17, 1961, a large series of juvenal lizards collected north of study area I showed 7 per cent with regenerated tails whereas 45 per cent of those in area I had regenerated tails. In other samples of juvenal lizards taken well away from the study areas, the frequency of breaks was 10 per cent or less. In contrast, 289 adults collected from the same areas showed 29 per cent of the females and 34 per cent of the males with broken tails, providing evidence of the importance of the breakage-regeneration mechanism during the ontogeny of the lizards.

Nearly a week is required for the formation of a callous over a fresh break. No regeneration occurs prior to this, and it is negligible until about 10 days after the break when the rate becomes rapicl. After the tail approaches its maximum length, the basal portion of the regenerated part begins to develop scalation that is very little different from the original. This process proceeds distally toward the tip. For a time, in some individuals, it is possible to discern three zones along the tail: the original base, the basal area of the regenerated segment with normal scalation developing along with its pigmentation, and the distal portion without scalation. At first glance, such a tail gives the appearance of having been doubly regenerated, i.e., a tail that was broken through the regenerated section and secondarily regenerated. Some authors have described such breaks, but it is not usually clear whether they actually saw the tail broken through the regenerated portion or whether this was inferred from the appearance of the tail. In all of the hundreds of tail breaks that I have observed, I have never seen one occur through the regenerated portion. Second breaks, which are rather frequent, always occur proximal to the old one.

Study of tail regeneration would be simpler if it were not for the fact that growth of the tail base occurs after the break. Because of this it is impossible in a young lizard with a regenerated tail to determine in which section an earlier break occurred.

One of the goals of this study was to quantify the rate of growth of the unbroken tail base. Also, I wished to determine the rate of regeneration. I was interested further in whether there were differences in these rates between juveniles and adults, between the sexes, between different size classes, and at different seasons. Despite the availability of thousands of records on regenerated tails, most of the clata had to be discarded for one or more of the following reasons:

1. Available recaptures overlapped different seasons. For example, a lizard whose tail was broken in August might not be recovered until October.

2. Recaptures on the same lizard overlapped different size classes. Many 
lizards captured, for example, at $27 \mathrm{~mm}$, were not recaptured until they were $40 \mathrm{~mm}$. Others were not recaptured until they had reached minimum size at maturity in which case they could no longer be considered juveniles.

3. Too long a period elapsed between recaptures. If a lizard whose tail was broken in October were not recaptured until February, at which time regeneration was complete, the time required for regeneration, and hence the rate, could not be determined.

4. Most tails were broken between captures. In these cases the date of the break was not known, so the data on this animal were without value.

5. Finally, because of error, the investigator sometimes failed to measure the tail base and regenerated part.

When all of the clata are culled for the above reasons, little is left, in some cases too little to accomplish the stated purposes. Nevertheless, the clata are strong for certain sizes and seasons and the trends are generally evident (Table 17). The tabular data indicate the following:

1. Rates of regeneration are generally faster in males than in females.

2. Rates of regeneration are about the same in spring and summer, but are considerably slower in fall and winter.

3. The rate of regeneration depends upon the site of the break. Tails broken near the base through the first third of the tail regenerate much faster than those broken in the midclle or in the distal third of the tail.

4. The rate of growth of the base that remains after a break is directly proportional to its length. In other words, the base grows faster if the break is distal rather than proximal.

5. There is little difference in rates of regeneration between juveniles and adults, but a much longer period of time would be required for complete regeneration in the latter.

6. The tail base of adults grows little or not at all following a break. Therefore, in adults the proximal end of the regenerated segment may be taken as the point at which the tail was broken.

It is also possible within certain limits to predict the time required for growth of a broken tail to near its original length (actually the original length is never attained). By knowing the length of the tail of a lizard at a given snout-vent length (Fig. 6), I could predict in which one-third of the tail the break had occurred. The mean rate of basal growth plus the mean rate of regeneration for tails broken in this third (Table 18) would allow prediction of the average time required for tail replacement (Table 19).

A few records chosen at random from my data indicated close agreement between these predictions and the actual time. However, differences in 
TABLE 17

Mean Rates of Regenferation and of Growth of Tail Base (in millimeters per day) for Lizards of Differfent Sizes at Different Seasons Only data were used from those lizards whose date of tail breakage was known. The data for juveniles and adults at the bottom of the table are for those individuals in which recaptures cut across size groups or seasons; in these size and season have been ignored. Figures in parentheses are numbers of records and Roman numerals at left signify in which third of the tail a break occurred; rates in mm per day

\begin{tabular}{|c|c|c|c|c|c|c|c|c|c|c|c|c|}
\hline \multirow{3}{*}{ Season } & \multicolumn{6}{|c|}{ Males } & \multicolumn{6}{|c|}{ Females } \\
\hline & \multicolumn{2}{|c|}{$20-32 \mathrm{~mm}$} & \multicolumn{2}{|c|}{$33-45 \mathrm{~mm}$} & \multicolumn{2}{|c|}{ Adults } & \multicolumn{2}{|c|}{$20-30$} & \multicolumn{2}{|c|}{$31-41$} & \multicolumn{2}{|c|}{ Adults } \\
\hline & Base & Reg. & Base & Reg. & Base & Reg & Base & Reg. & Base & Reg. & Base & Reg. \\
\hline I June-Aug. & $.22(17)$ & .55 & $.15(4)$ & 1.00 & $.08(3)$ & .53 & $.16(34)$ & .56 & $.13(10)$ & .85 & $.02(5)$ & .70 \\
\hline Sept.-Nov. & $.17(2)$ & .47 & $.08(3)$ & .39 & $.03(2)$ & .36 & $\longrightarrow$ & 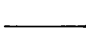 & $.04(7)$ & .50 & $.05(2)$ & .30 \\
\hline Dec.-Feb. & $\longrightarrow$ & $\ldots$ & - & $\ldots$ & $.03(2)$ & .32 & - & 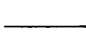 & $\longrightarrow$ & & - & \\
\hline Mar.-May & $\longrightarrow$ & 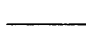 & - & 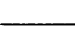 & $.03(5)$ & .67 & $\longrightarrow$ & 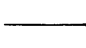 & $\longrightarrow$ & 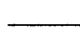 & $.01(6)$ & .48 \\
\hline II June-Aug. & $.29(33)$ & .45 & $.49(2)$ & .71 & $\longrightarrow$ & 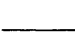 & $.23(25)$ & .36 & $.29(1)$ & .66 & 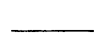 & \\
\hline Sept.-Nov. & $.18(3)$ & .31 & $.08(1)$ & .44 & $.00(1)$ & .36 & $.15(1)$ & .11 & $.15(3)$ & .49 & $\longrightarrow$ & 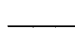 \\
\hline $\begin{array}{l}\text { Dec.-Feb. } \\
\text { Mar.-May }\end{array}$ & - & 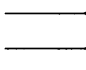 & $\overline{.18(1)}$ & .40 & $\overline{.05(3)}$ & .58 & $\square$ & 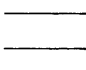 & - & 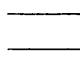 & $\overline{.03(4)}$ & .45 \\
\hline \multirow{5}{*}{$\begin{array}{l}\text { III June-Aug. } \\
\text { Sept.-Nov. } \\
\text { Dec.-Feb. } \\
\text { Mar.-May }\end{array}$} & $.37(17)$ & .17 & $.21(1)$ & .11 & - & 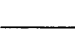 & $.31(15)$ & .12 & $\longrightarrow$ & 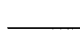 & $\longrightarrow$ & 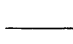 \\
\hline & $\longrightarrow$ & $\longrightarrow$ & $.36(1)$ & .00 & $\longrightarrow$ & 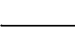 & $\longrightarrow$ & $\longrightarrow$ & $.15(1)$ & .04 & $\longrightarrow$ & 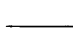 \\
\hline & $\longrightarrow$ & $\longrightarrow$ & $\longrightarrow$ & 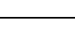 & 一 & ( & - & - & - & 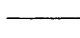 & $\longrightarrow$ & 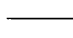 \\
\hline & \multicolumn{2}{|c|}{ Juveniles } & \multicolumn{2}{|c|}{ Adults } & & & \multicolumn{2}{|c|}{ Juveniles } & \multicolumn{2}{|c|}{ Adults } & & \\
\hline & $.18(30)$ & .55 & $.01(4)$ & .23 & & & $.13(37)$ & .36 & $.02(10)$ & .39 & & \\
\hline
\end{tabular}




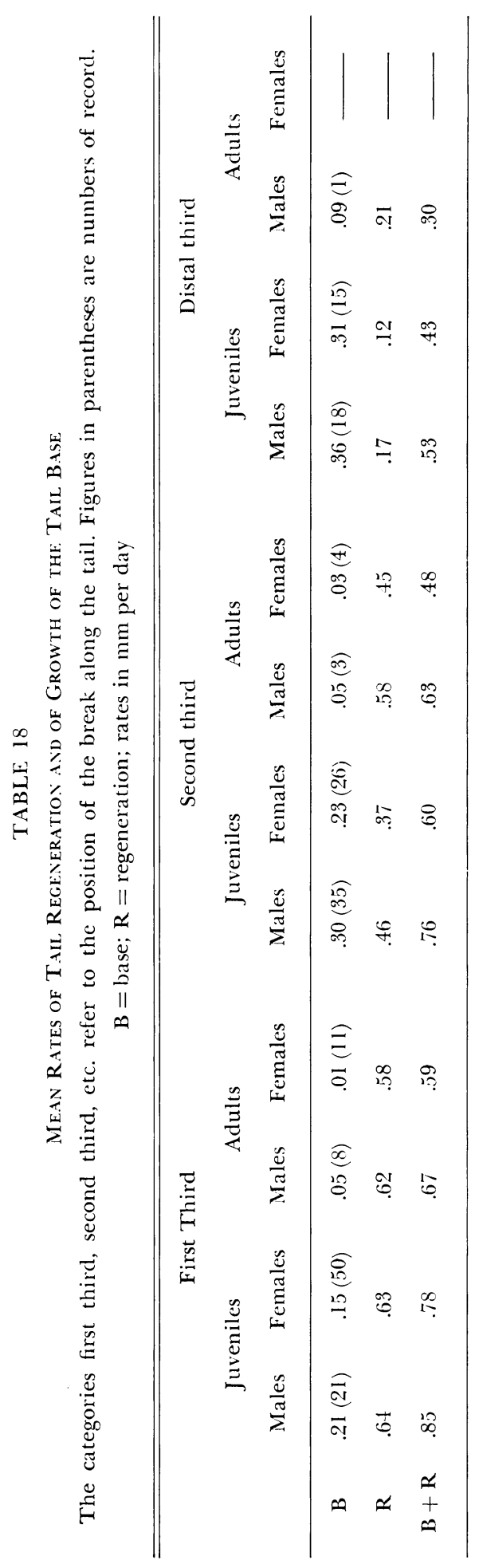


TABLE 19

Pridicted Time in Days Required for Regrowth of a Tail Broken in one of Three Positions in Animals of Different Sizes

Roman numerals refer to break position, whether in first third, etc. All lizards are juveniles

\begin{tabular}{|c|c|c|c|c|c|c|}
\hline \multirow{2}{*}{$\begin{array}{l}\text { Snout-vent } \\
\text { length, mm }\end{array}$} & \multicolumn{3}{|c|}{ Males } & \multicolumn{3}{|c|}{ Females } \\
\hline & I & II & III & I & II & III \\
\hline 21 & 32 & 21 & 9 & 35 & 27 & 12 \\
\hline 22 & 33 & 22 & 11 & 37 & 28 & 12 \\
\hline 23 & 37 & 25 & 13 & 39 & 30 & 14 \\
\hline 24 & 37 & 25 & 13 & 42 & 31 & 16 \\
\hline 25 & 40 & 26 & 13 & 44 & 36 & 18 \\
\hline 26 & 42 & 29 & 15 & 46 & 37 & 19 \\
\hline 27 & 44 & 30 & 15 & 47 & 40 & 19 \\
\hline 28 & 47 & 32 & 15 & 51 & 40 & 19 \\
\hline 29 & 49 & 33 & 15 & $5 \cdot 1$ & 43 & 19 \\
\hline 30 & 52 & 35 & 17 & $5 \cdot$ & 43 & 19 \\
\hline 31 & 54 & 36 & 17 & 56 & 44 & 21 \\
\hline 32 & 55 & 37 & 19 & 58 & 45 & 21 \\
\hline 33 & 56 & 38 & 19 & 61 & 48 & 21 \\
\hline 34 & 60 & 41 & 21 & 65 & 52 & 26 \\
\hline 35 & 61 & 42 & 21 & 67 & 52 & 26 \\
\hline 36 & 64 & 42 & 21 & 69 & 53 & 26 \\
\hline 37 & 66 & 43 & 21 & 72 & 55 & 26 \\
\hline 38 & 67 & 45 & 21 & 72 & 56 & 26 \\
\hline 39 & 68 & 46 & 21 & 74 & 57 & 26 \\
\hline 40 & 69 & 47 & 23 & 76 & 58 & 26 \\
\hline 41 & 69 & 47 & 23 & 76 & 58 & 26 \\
\hline 42 & 69 & 47 & 23 & & & \\
\hline 43 & 73 & 49 & 23 & & & \\
\hline 44 & 74 & 50 & 25 & & & \\
\hline 45 & 75 & 50 & 25 & & & \\
\hline
\end{tabular}

rates between individual lizards and between seasons make it difficult to use the table for individual animals. It is nevertheless useful for predicting the mean period required for regrowth of a broken tail in a series of lizards of a given size. Unfortunately, time since the break was incurred cannot be predicted because of elongation of the tail base. Some good information on tail regeneration is available in the papers of Blair, 1960; Fitch, 1954; Barwick, 1959; and Cagle, 1946b. All authors agree that regeneration is faster in tails that are broken proximally (the majority, incidentally) and the rate of basal growth is faster in tails broken distally. Maximum rates of more than $1 \mathrm{~mm}$ regeneration per clay have been reported by several authors (Blair, 1960; Breckenridge, 1943; Fitch, 1958; Barwick, 1959). A rate of 
$0.5 \mathrm{~mm}$ per day is about the average reported in the literature. Breaks through the regenerated part of a tail have been reported by Blair (1960) and Fitch (1940), but I have not observed this in utas. However, one of my students (Charles McKinney) has intentionally made such breaks in the laboratory and obtained normal regeneration.

Frequency of Tail Breaks.-I have selected those individuals marked as hatchlings that survived to maturity to discover the frequency of tail breaks during the lifetime of an individual. Among this group I have selected only those individuals recaptured a sufficient number of times to be certain of the number of breaks incurred (Table 20).

TABLE 20

Friqufncy of Breaks in Individual. Lizards whose Recapture Records Wre Sufficiently Detalled to Determine Number of Breaks Sustainfo (See Text for Additional Discussion)

\begin{tabular}{ccccccc}
\hline \hline \multirow{2}{*}{$\begin{array}{c}\text { Number of } \\
\text { Breaks }\end{array}$} & \multicolumn{3}{c}{ Males } & \multicolumn{3}{c}{ Females } \\
\cline { 2 - 7 } & Area I & Area II & Total & Area I & Area II & Total \\
\hline 0 & 26 & 27 & 0 & 39 & 41 & 0 \\
1 & 42 & 37 & 79 & 53 & 67 & 120 \\
2 & 20 & 16 & 72 & 26 & 17 & 86 \\
3 & 3 & 4 & 21 & 3 & 2 & 15 \\
4 & 0 & 2 & 8 & 1 & 0 & 4 \\
Totals & 91 & 86 & 180 & 122 & 127 & 225 \\
\hline
\end{tabular}

On area I there was 1.00 break per individual, on the average, among 91 males; on Area II, 1.03 breaks among 86. There was an average of 1.02 breaks per individual among 122 females on area I, .84 among 127 females from area II. In all 426 individuals there were 405 breaks or about .95 per individual. The frequency among males was only slightly higher than that of females.

About one-third of the lizards reached maturity without sustaining a tail break, and rarely was the tail broken more than twice. However, regeneration has been observed after four successive breaks, and there seems little doubt that the process could be indefinitely repeated were it not for the fact that the tail base in adults does not increase in length after a break. In juveniles the tail base may elongate many millimeters after a break so that a second break may be, relatively speaking, in the same position as the first.

The frequency of breaks reported here is probably not characteristic of 
the undisturbed population. The frequency of breaks observed in the study areas is about double that observed in large samples from outside the areas.

The data are included to demonstrate that multiple tail fractures are possible and, assuming equal pressures by the investigators on each sex, they are about as common among females as males. This finding may seem surprising, but was not unexpected in view of the highly aggressive nature of the females.

Blair (1960) reported that tail breaks occurred in 15 per cent of 1-yearold females, 24 per cent of males; in 22 per cent of 2-year-old females, 35 per cent of males; and in 35 per cent and 50 per cent of 3-year-old females and males, respectively, of Sceloporus olivaceus. In this species, aggressive encounters are evidently restricted to the males. Cagle (1946b) stated that about 30 per cent of the gecko Hemidactylus garnoti had regenerated tails as adults, about three times the proportion observed in young.

Apparently little is known about the frequency of multiple breaks in the same individual, but even so, the high proportion of breaks reported in the literature among adults compared with juveniles attests to the importance of the breakage and regeneration mechanism. It has sometimes been assumed that the frequency of breaks is directly proportional to predator pressure on a population. This may be true, but breaks also occur during aggressive encounters, particularly between males.

Bustard and Hughes (1966) have, rather curiously, attempted to derive average ages for lizards in a natural population from tail-loss data. However, the tail-loss data, because they must be obtained from recapture of marked animals, become superfluous and even poorer than the original recapture data. This is because estimates from the tail-loss data restrict consideration to those animals among those marked that sustained a broken tail.

\section{Feeding Habits of Utas}

Utas spend relatively little time foraging for food. Our consistent impression, gained from watching individuals for many hours, has been that these lizards are opportunistic feeders, i.e., they will readily eat almost any insect of suitable size that passes near them when they are basking or moving about in their home ranges.

Utas feed throughout the year when temperatures are conducive to activity. I have dug utas with full stomachs from winter retreats, indicating that they had fed recently. I have also found that food is abundant in winter, when the stomachs of utas usually contain larvae of moths and beetles that occur in abundance beneath surface cover and in the loose sand around 
packrat nests. Both of these sites are frequented by utas during the winter. Termites are also obtainable in the winter and are found frequently in the stomachs of utas. On February 18, 1963, six of 11 utas that were found frozen following a severe cold spell had full stomachs and all contained some food.

In laboratory experiments utas on long days consistently gained more weight than those on shorter ones. This is consistent with the experimental results of Fox and Dessauer (1957) on the salutary effect of long clay lengths on the appetites of lizards (Anolis). Utas in the laboratory will feed on almost any moving insects; the interest of the lizard seems directly proportional to the activity of the prey. The only small food items that utas usually avoid are red ants, although an occasional lizard will eat them and all of them eat numbers of small black ones.

In long periods of field observation we have actually observed utas cating the following prey: black ants, red ants (rarely), leafhoppers, carabid beetles, grasshoppers, and caterpillars. In three instances we counted the number of feedings. On June 3, 1962, an adult female resting beside a column of ants ate them at a rate of 25-30 per 10-minute observation period. On July 4, 1962, a female ate 60 times between 1530 and 2030, and was observed to eat 19 insects between 1800 and 1900. Finally, an adult male ate 50 ants between 1756 and 2030 on June 27, 1962. Most of these records were made during periods when the lizards were relatively inactive, periodically basking and feeding around a particular plant. At such times they will feed if the opportunity is presented, sometimes jumping several inches from the ground to catch a winged insect that has landed above their head.

Large samples of utas from most months of the year were collected early in this study. These were made available to William W. Milstead of the University of Missouri at Kansas City for use in his studies of comparative food habits of lizards. Dr. Milstead has generously provided his results to me for inclusion here.

The stomach contents of samples of lizards selected by Milstead to cover most of the activity period of the utas were analyzed volumetrically to determine the proportion of each food item in the total sample. The samples used were collected in 1959 and 1960, but from slightly different time periods in the two years. All samples came from the vicinity of the study areas.

An analysis of the stomach contents (Table 21) indicates that utas will feed upon any insect or arachnid of suitable size. This reinforces my impressions that they are opportunistic in their food choice. No conclusions con- 


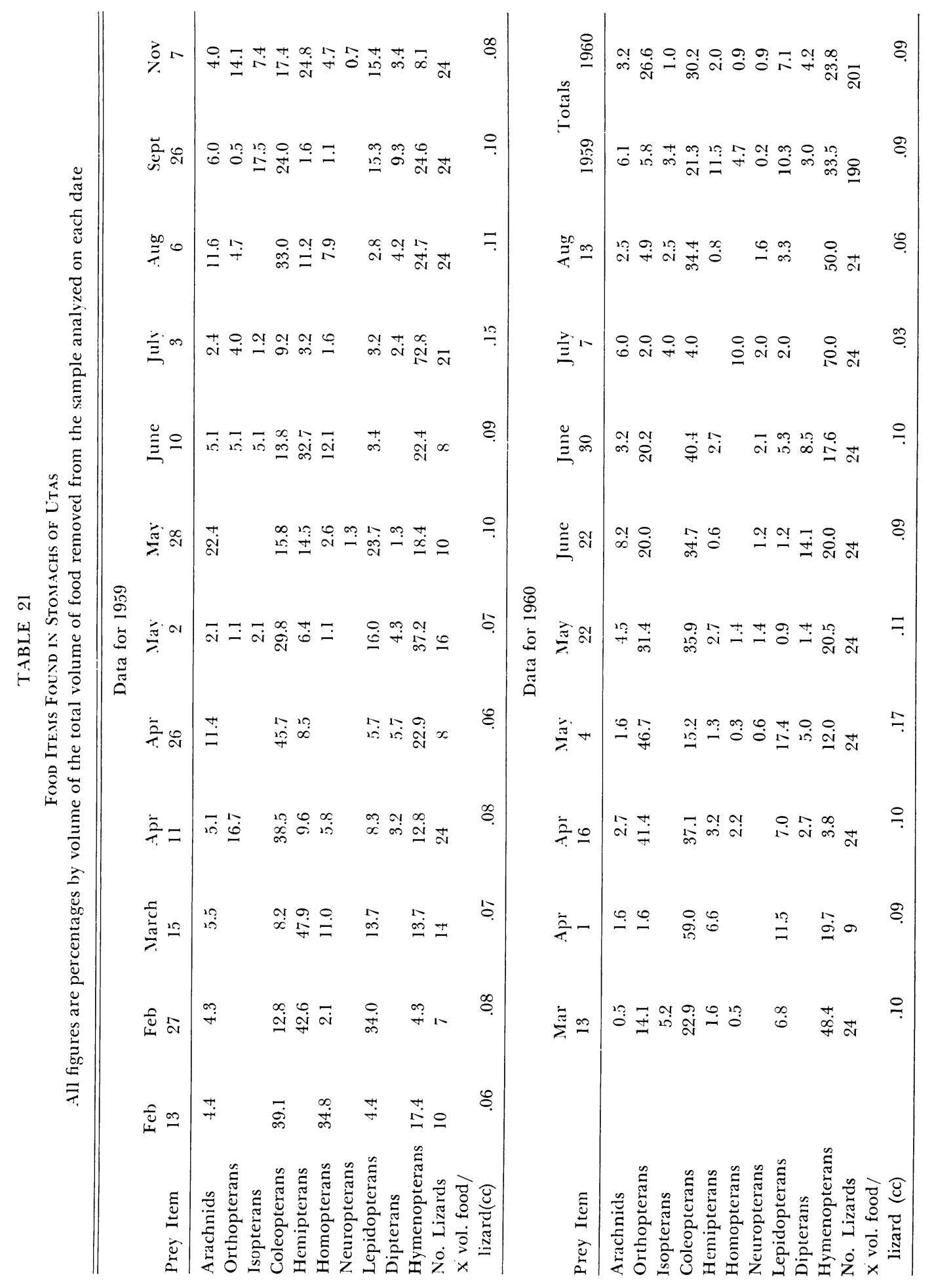


cerning food preference can be made because I have no data on the relative abundance of the prey items in nature. I frequently observed utas feeding upon ants and small beetles in the field, and these two items made up over 50 per cent of the food contents in the samples of both years. In addition, these items generally occurred in a high proportion of the stomachs of lizards in all of the samples.

The utas evidently feed upon those items that are most abundant. Prey species that, in most samples, make up a small portion of the diet occasionally make up a very large percentage. For example, arachnids in the May 28, 1959, sample and hemipterans in the February 27 and March 15 samples of the same year. Note also that orthopterans were uncommon in the diet in 1959, but relatively frequent in 1960 .

One sample, that of July 7,1960 , was composed entirely of juvenal lizards and that of August 13 was largely of young. In both, ants comprised over 50 per cent of the diet. This observation is certainly consistent with impressions gained from watching young animals while they fed.

Consistent seasonal changes in cliet are not clearly present. This is possibly the result of collecting individuals from different microhabitats cluring different sampling periods. For example, on cold, cloudy days the lizards would have been collected beneath surface debris; on cold, clear days they likely were collected around packrat nests.

I would like to go somewhat beyond the data in considering the volume of food eaten. The weight of the food removed by Milstead from the stomachs of adults was consistently around $0.1 \mathrm{gm}$ each. Inasmuch as a period of 2-3 hours sometimes elapsed between capture of the animal and its preservation, some digestion may have taken place. If a lizard were eating about 0.1 gram of food per day, then an average resident adult population of about 16 lizards per acre would require only about 1.5 grams of insects per day. Ignoring the juveniles, it seems likely that the utas cannot be considered a major link in the energy flow in their ecosystem. Data on this point are needed. I. R. Johnson (1966) estimated an energy assimilation by two species of iguanid lizards of 50-75 calories per gram per day. These figures agree well with my contention concerning energy flow as well as with calculated energy expenditure data (59 cal. per gram per day) for the lizard Sceloporus occidentalis (McNab, 1963).

Harris (1964) in a study of Agama agama in Africa reported a food intake of about $.015 \mathrm{gm}$ per gram of body weight per day. The adult male A gama averages about 80 grams, the female 30 , so the estimated intake of this large species is not greatly different per gram from that for $U t a$.

Thanks largely to the efforts of Knowlton (1934) Knowlton and Anthon (1935), and Knowlton and Thomas (1936) there is a considerable amount 
of information on the food habits of Uta stansburiana, mostly in Utah. Their studies were based on stomach analyses from several thousand utas, and agree with the data presented here in indicating a wide variety of prey items and differences in frequency of prey items in stomachs of utas from different plant associations. The studies of Hotton (1955) on lizard dentition suggested that the teeth of utas were adapted to a diet of prey of high or intermediate activity and with light- to medium-weight integuments. This would include the majority of small insect species.

Knowlton (1936) also studied the digestion time of utas by feeding them on freshly killed leafhoppers and measuring the time required for the insects to be digested beyond recognition. Over 98 per cent of the nymphs and 80 per cent of the adults were digested beyond recognition within 12 hours and a majority of the nymphs within 6 . On the basis of these data, I feel that my estimate of the quantity of food eaten per day is a minimal one. A figure twice my estimate seems reasonable, in view of the rapid digestion time.

\section{Causfs of Death}

Mortality is difficult to measure in natural populations. In thousands of hours of observation of utas very few instances of predation or cleath were observed; yet the rapid disappearance of young lizards from the population was obvious from our field data. Even when predation can be observed or discovered through examination of the stomachs of predators there is still no way of determining from such data the influence of predation on the population. Therefore, I will limit this discussion to a consideration of the known causes of individual mortality and, in a later section, will discuss mortality rates of the population.

Snakes and predaceous lizards were caught whenever they were seen in the study areas and the stomach contents removed by palpation. In this way I have collected most of the predation records below: June 3, 1963, fragments of Uta found in pellets of burrowing owl; July 12, 1963, Cnemidophorus tigris shot on this date had a hatchling Uta in its mouth; July 1, 1964, adult female Uta contained hatchling in stomach; September 14, 1964, a marked $U$ ta was removed from the stomach of a night snake (Hypsiglena torquata); March 14, 1965, a marked male Uta removed from the stomach of a prairie rattlesnake (Crotalus viridis); September 5, 1963, marked male Uta removed from stomach of an adult leopard lizard (Crotaphytus wislizeni); August 20, 1964, marked female $U$ ta removed from the stomach of a juvenal leopard lizard.

These 7 records, 4 of which involved marked utas, are all that we have available from the study areas or their immediate surroundings. However, 
during the early phases of this study, a large number of nocturnally active snakes were collected by driving roads in the area at night. Two of my students (McKinney and Ballinger, 1966) examined the stomachs of all of these snakes and obtained additional predation records:

Snake species

Glossy snake (Arizona elegans)

Diamond-back rattlesnake

(Crotalus atrox)

Coachwhip (Masticophis flagellum)

Longnosed snake

(Rhinocheilus lecontei)

Massasauga (Sistrurus catenatus)
No. of instances

of predation on Uta

7

1

3

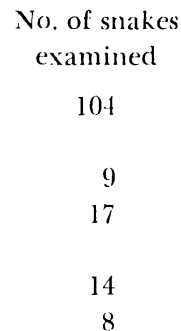

8

Other potential predators of utas such as Lampropeltis getulus, Pituophis catenifer, and Crotalus viridis did not contain remains of utas. All of these species with the exception of Sistrurus have been recorded in the study areas and, despite the absence of clear proof, undoubtedly take a heavy toll of lizards. The data above give a somewhat false picture of the toll because most stomachs of the snakes were empty. Of the 152 snakes above, 37 contained prey, so utas were present in about 35 per cent of the full stomachs.

Winter Kil.t.-One of the most serious sources of mortality to utas is winter kill. This was discovered quite by accident while I was digging into sites in an attempt to find where utas passed periods of unfavorable weather. In areas without surface litter in the form of board piles, sheet metal, and debris, utas dig into the loose sand that surrounds the margins of most packrat nests. Here they were often found buried in groups of 2 to 4 , usually on the west sides of the nests. By systematically digging into these nests and by lifting all surface debris in certain areas, we were able to find sufficient lizards on some occasions to estimate the number killed by severe weather (Table 22).

The results of the 10 observations in the table are somewhat difficult to interpret. It seems reasonable to attribute the deaths to winter kill, for many hundreds of lizards have been collected beneath surface debris in the early spring with no recorded dead. However, it is not clear that low temperatures were the cause of the winter kill.

On January 11, 1962, temperatures at the weather station near Wink, Texas, a few miles from our study areas, dropped to $-13^{\circ} \mathrm{F}$ with a snow cover. By January 13 when we dug lizards from the sand, most of the snow had melted and many lizards were found dead. The lowest temperatures recorded of sand from which lizards were removed was $0.5^{\circ} \mathrm{C}$. On January 
TABLE 22

Frequincy of Dead Among; lizards Collected from Late Fall to Early Spring; FOR THF PURPOSE OF DETERMINING; THE INCIDENGE OF DEATH DURING THIS PART OF THE Y'FAR

\begin{tabular}{|c|c|c|c|c|}
\hline Date & No. found & No. dead & Per cent dead & Situation \\
\hline 2.5 Oct. 57 & 17 & 2 & 12 & Surface litter \\
\hline 13 Feb. 59 & 40 & 0 & - & Surface litter \\
\hline 22 Dec. 61 & 25 & () & - & Buried in sand \\
\hline 13 Jan. 62 & 51 & 14 & 28 & Buried in sand \\
\hline 27 Jan. 62 & 52 & 8 & 15 & Buried in sand \\
\hline 3 Mar. 62 & 13 & 0 & - & Buried in sand \\
\hline 3 Jan. 63 & 20 & 0 & - & Buried in sand \\
\hline $17 \mathrm{Feb} .63$ & 110 & 27 & 25 & Surface litter \\
\hline 19 Feb. 63 & 15 & 2 & 13 & Buried in sand \\
\hline 13 Iec. 63 & 50 & 0 & - & Surface litter \\
\hline Totals & 393 & 53 & 14 & \\
\hline
\end{tabular}

3, 1962, we found no dead lizards despite low temperatures. Snow fell again prior to our next attempt to find buried lizards on February 17, at which time almost one-fourth of those found were dead. These dead were all beneath surface cover; 2 of 15 dug from the sand were dead. The air temperatures following the February snow were considerably higher than those that prevailed in January, indicating that the snow cover rather than low temperatures might be more important in the mortality of the lizards. The moisture from the melting snow percolates through the soil, displaces air trapped in the sand, and allows subsurface temperatures to fall.

In contrast to the observations above are those of December 10, 1963, when, following snow and subfreezing weather, none of 50 utas found was clead.

Subfreezing temperatures at night are characteristic of the winters in northwestern Texas. There is no inclication that these normal periods of cold weather are detrimental to the lizards. Periods when the temperatures during the day do not rise above freezing are uncommon, but do occur every winter. These, too, probably have little effect. It is the occasional occurrences of prolonged periods of very low temperatures near or below zero with some snow cover that are responsible, at least indirectly, for the winter kill. Assuming that lizards that we have dug from the sand or recovered beneath surface debris represent the population as a whole, it is apparent that unusual periods of severe weather may kill 25 per cent of the resident lizards. All 10 observations in Table 22 indicate a mortality of about 14 per cent even if observations are included in which no dead lizards were found. If these are excluded, a mortality in excess of 20 per cent is indicated. 
Adclitional data are available on such factors as depth of burial, sex, and size of the lizards in relation to total mortality. At a depth of 1-3 inches in the sand, only 17 per cent of the utas were dead; at 4-6 inches, 42 per cont; at 7-9 inches, 7 per cent; at 10-12 inches, 17 per cent. Mortality is highest at that depth at which soil temperature is lowest during the day. The data of February 17 and 19, 1963, from lizards removed from surface debris indicated that mortality in such exposed situations was double that observed among lizards buried in sand.

Males are more susceptible than females to winter kill. Of 309 live animals in which sex was determined during our observations on winter kill, 169 (55 per cent) were females and 45 per cent were males. This is approximately the sex ratio in large samples of adults from the population at most seasons of the year. However, among the dead lizards, the sex ratio was 51:49 in favor of the males. Nineteen per cent of dead lizards found were males and 15 per cent females. This higher mortality of males is one of the factors producing the biased sex ratio in the population that is discussed in a later section.

Data on mortality among lizards of different sizes during the winter are meager because measurements were taken of each lizard only during the observations of January 13 and January 27, 1962. The percentages of dead among the 31-35-mm, 36-40-mm, 41-45-mm, 46-5()-mm, and 51-54-mm size groups were $18,31,19,17$, and 34 , respectively.

One reason for the higher mortality in the largest size group is that all of the animals in the group were males. I do not know the reason for the high mortality among the $36-40-\mathrm{mm}$ animals, but would prefer to attribute this to sampling bias.

Mortal.tTy (Causfod by Handling.-Unfortunately, the investigators themselves were responsible for some deaths. Young utas are quite small and delicate and must be captured with very great care to avoid injury. The hatchlings were handled in large numbers beginning in 1961 when we inadvertently killed about 5 per cent of them. Fortunately, our record improved in succeeding years as the data below indicate:

$\begin{array}{ccc}\text { Year } & \text { Adults killed } & \text { Juveniles killed } \\ 1960 & 3 & 2 \\ 1961 & 4 & 52 \\ 1962 & 6 & 20 \\ 1963 & 3 & 7 \\ 1964 & 5 & 5 \\ \text { Totals } & 21 & 86\end{array}$

We killed 107 of 3492 lizards handled, a contribution of about 3 per cent to their total mortality. 
Deaths from Unknown Causes.-Eight records of death among utas on the study areas were from unknown causes. Seven of these were adults, of which 5 were simply found dead; one had been captured and released in good condition the day before its death. The other two adults were suspected victims of freezing. The single juvenal lizard was found dead with no evidence of predation or freezing.

Can these deaths be used as eviclence that the annual turnover in the populations is an inclication of a short physiological life expectancy? Perhaps not, but the fact that all but one were adults and that these lizards have proven difficult to maintain for long periods in the laboratory lend credence to the iclea.

The causes of mortality of individual lizards are poorly known. Many studies list potential predators, but it is rare (see Harris, 1964) that predation is actually observed, and never has its importance in controlling populations of lizards been ascertained. I think this will be true until field experiments manipulating predation pressure are performed. This type of experiment is particularly feasible now with utas because we are aware of their actual density and of the relative densities of predators. It would be a simple matter to manipulate either in enclosed areas.

Blair (1960) reported that the majority of nests (75-78 per cent of the clutches) of Sceloporus olivaceus were lost to predators, desiccation, or some other factor. A similar observation was made by Fitch (1956b) on Crotaphytus collaris, in which the number of young hatching from nests was about one-half the number of eggs laid.

\section{Injurils and Abnormalitifs}

A variety of injuries have been inflicted on lizards during their capture, but many natural injuries also occur, as do a few abnormalities. For the sake of completeness, this information is included below.

Tok Losses.-Loss of one or more toes is a common natural injury in utas. Some losses may result from improper toe clipping. If a toe is clipped too close to the base, the blood and nerve supply to an adjacent toe may be impaired with subsequent loss of that toe. I have eliminated this type of injury from the figures on frequency of toe loss shown in Table 23.

Two observations indicate one of the means by which toes are lost. On one occasion a juvenal uta was caught with a red ant securely clamped to the base of toes 18 and 19 , both of which were soon lost. In the second instance, the mandibles only of a red ant were found attached to the withered toe of a uta.

There is no difference between juvenal male and female utas in the 
frequency of toe loss, but adult males consistently show a greater frequency of toe losses than do females (Table 23). The frequency of lost toes in adult males is 5 times as high as in juvenal males. In females there is little difference in the frequency between juveniles and adults.

Losses of toes have never been a serious problem in interpreting our recapture data. Only about 100 of 3500 marked lizards lost toes. If such losses occurred before we marked the animal, we simply included the missing

TABLE 23

frequency of Toe losses anong; Junenal and Adult Utas During five Years Figures in parentheses are percentages of the total lizards marked

\begin{tabular}{|c|c|c|c|c|}
\hline \multirow{2}{*}{ lear } & \multicolumn{2}{|c|}{ Juveniles } & \multicolumn{2}{|c|}{ Adults } \\
\hline & Males & Females & Males & Females \\
\hline 1960 & $4(6.3)$ & $2(3.0)$ & $4(19.0)$ & $3(12.0)$ \\
\hline 1961 & $4(0.9)$ & $4(0.8)$ & $10(16.1)$ & $3(4.1)$ \\
\hline 1962 & $4(2.1)$ & $5(1.6)$ & $1(1.2)$ & $4(1.5)$ \\
\hline 1963 & $8(2.1)$ & $12(2.8)$ & $1(5.6)$ & () \\
\hline 196.4 & $1(1.4)$ & $9(3.0)$ & $7(7.2)$ & $3(2.5)$ \\
\hline Totals & $24(1.6)$ & $32(2.0)$ & $26(7.7)$ & $12(2.4)$ \\
\hline
\end{tabular}

toe as part of that lizard's permanent number. If lost after it was marked the lizard's permanent number was changed accordingly to avoid confusion in the recapture records. There was never any evidence of partial regeneration of a lost toe.

OTher Injuries.-Complete loss of a limb was occasionally observed. An adult female and an adult male, each missing a left front leg, were in obvious good health. The female was once watched for several days. She showed some postural compensation for her clefect, but was remarkably swift and agile in her movements. Another male of a known age of nine and one-half months was in apparent good health during its first breeding season despite loss of the entire right front foot. On June 28, 1962, we injured the arm of a $25-\mathrm{mm}$ juvenile at the time of capture. By July 4, the arm was gangrenous, and by mid-July it was lost. During the next month this lizard continued to grow and to gain weight at a normal rate, but disappeared from the population in August. On August 10, 1963, a 28-mm male was captured that was missing the left rear leg. This male was caught again on March 7, 1964, at an adult size. All of these cases of limb loss were among lizards that nevertheless had survived to adulthood, or nearly so, without a fourth limb. 
The recovery of utas from injuries to the limbs is only part of their remarkable ability to recover from a variety of accidents. On July 10, 1961, too much pressure applied to a $24-\mathrm{mm}$ male resulted in extrusion of one eyeball from its socket. Yet this male reached adult size by September 17, 1961, a rapid rate of growth and maturity for even an uninjured lizard. On May 5, 1962, an adult female was so forcefully captured that approximately one-hall inch of her lower intestine was extruded. The intestine was carefully forced back into the abdominal cavity, and she was recaptured several times, apparently in good health, over the next 60 days. On July 19, 1961, we captured a $25-\mathrm{mm}$ female that was missing a right eye. Yet, she survived nearly a year with this defect and reached sexual maturity despite it. A blind adult female was captured on October 8, 1961, but never recaptured.

Abnormal.rTifs.-Abnormalities among utas were rare. Only 6 types were observed among nearly 3500 lizards handled in the study areas. Two of these involved lizards with aberrant tails. In one, a 22-mm female, the tail was naturally crookel, apparently a defect in vertebral formation. This lizard is known to have survived for at least 4 months. The second was a 28-mm female with a deep basal constriction in the tail just posterior to the vent; the tail distal to this constriction was badly gnarled.

A 24-mm male had a clivided 18th toe with 2 claws; a 32-mm female was recorded with a similar abnormality of the 15 th toe.

A 23-mm male and a 24-mm male, had scale defects. One lacked scales in the left axillary and distal humeral areas. The second had no scales in one small area of the abdominal wall.

Finally, 4 instances of forked tails, all of them regenerated, were recorded. One of the tails was triply forked. All of these doubtless arose because of incomplete severance of a broken tail.

In summary, about 3 per cent of all utas handled show evidence of minor or major injury or abnormality. This is likely a minimal estimate inasmuch as those with more serious defects probably did not hatch or survived only a short while thereafter.

There are practically no data available from the literature on frequencies of injuries or abnormalities in lizards under natural conditions. However, Rand (1965) did provide some interesting information on toe losses in the iguanid lizard Tropidurus torquatus. His data were based entirely on samples from populations and not upon the frequencies in natural populations. He found that $30-40$ per cent of 164 lizards had lost a toe. The frequency was higher among males than females (though not significantly so) and higher among adults than juveniles. His data are important, as he points out, in indicating that lizards survive to maturity with 
more loss of toes or with more damage to them than would be inflicted by any marking experiments.

\section{The Behavior of Inidividal Utas}

Dispi.Ay BobBing;-The behavior pattern most persistently displayed by individual utas is a "push-up" or bobbing motion that is performed before and just after movement of the lizard. The movements of utas are usually short scampers of 5-10 feet after each of which, and usually prior to each, they perform push-ups. Such push-ups have been photographed and analyzed frame-by-frame by Carpenter and Grubitz (1961). The entire push-up is composed of 4 or 5 very rapid vertical motions lasting a fraction of a second. These push-ups are performed by juveniles and adults, seemingly regardless of the presence or absence of other lizards. The function of these species-specific bob patterns is largely conjectural. It may serve as advertisement to other lizards of the same species that the area contains a resident animal. Hunsaker (1962) gathered some experimental results from lizards of the genus Sceloporus indicating that bobbing is attractive to other lizards of the same species. Such behavior might aid in maintaining the integrity of a conspecific group in a mixed species population.

Courtship and Aggression.-The male reaction: The reaction of a male uta to the sight of another uta is one of instant alertness. The male will generally perform a push-up, or several of them, then move toward the intruder. While still at a distance of several feet from the other lizard, he will shift into either aggressive or courtship behavior depending upon the sex of the intruder. This sex recognition at a distance is probably facilitated by the very striking sexual dimorphism in Uta stansburiana stejnegeri. If the intruder is a female, the male arches his back and approaches her while performing the very rapid and shallow head-bobbing which has been termed a shudder-bob. When within a few inches of the female, the male typically begins to circle her with his body slightly inclined toward her, exposing to her a broader view of his clorsum. If the intruder is a male, the resident male will distend his throat ventrally, exposing the dark dewlap color, arch his back strongly and approach the other male on stiff legs with his dorsal surface inclined toward the other male. In these displays the resident male attempts to maintain a lateral posture with respect to the other male, maximizing the effect of the arched and compressed body and extended (lewlap.

One of my students (Ferguson, 1966a) showed in a series of experiments that aggressive reactions of resident male utas in the laboratory could be elicited by introducing live or dead male utas or even live males that were 
painted black; presentation of live or dead females always elicited courtship rather than aggression, indicating that body form and color of the introduced lizard were ordinarily sufficient for sex determination by the male. However, the strength of his reaction, as will be discussed later, may be altered by the behavior of the non-resident upon being initially challenged by the resident.

If the intruder into the area of a resident male is another male, the generalized reaction between the two may be seen in the following diagram:

\section{Resiclent}

Gives assertion push-up)

Begins aggressive approach

Attacks intruder

Pursues fleeing male

for short distance with

continued assertion behavior
Intruder

Flees or gives assertion push-up Flees or returns challenge

Flees or (rarely) fights

These encounters rarely result in retreat of the resident male; almost invariably it is the intrucler that flees, but sometimes only after a fight in which physical clamage may be inflicted. The resident male, during such a fight, usually attempts to bite the intruder in the tail or flank, but may also rush forward and ram the flank of the intruder with his head. We have observed loss of tails in such fights and have seen the skin broken by the biting. Scars, presumably from such encounters, are frequently found on the backs of adult males.

The Frmale Rfaction.-Aggressive behavior seldom has been observed among female lizards of any species. This is, I think, because females move about less than males and are less likely to encounter one another. Many hours of continuous observation frequently fail to disclose social interactions between them. However, by the simple expedient of introducing non-resident females into the visual field of residents on my study areas, I have been able to increase the number of interactions observed.

The reaction of a female to an intruding female involves an increase in the bobbing frequency of the resident and then the assumption of a stifflegged and arched posture similar to that of the aggressive male. Maintaining such posture, the resident female will approach the intruding female with lateral orientation to her and will generally proceed immediately to the attack unless the non-resiclent female retreats. The aggressive response of a female is just as vicious as that of the male, and she is more likely to attack before performing a long ritualistic display.

The reactions of a female to a courting male are varied and almost 
always involve rejection of the male. The first reaction to a male is usually a return of his assertion bob. When the male begins circling and shudderbobbing, the female may arch and give an aggressive display, may shudderbob, or may simply retreat a short distance. All three movements are rejection responses. Although a male may court a rejecting female several times before he is finally discouraged, his advances will never end in copulation until the female adopts a submissive posture. Clarke (1965) reported that in several species of lizards as long as the females contained oviducal eggs, and for several days after oviposition, they would reject courting males. In these rejection ceremonies the red and yellow color marks of the gravid female were advertised to the male in the rejection posture.

The submissive sign of the female is simply one of ceasing her retreat from the courting male and of lowering her body against the substrate. Such a reaction is soon followed by attempted copulation.

Copulation-Copulation is usually preceded by the male licking the flank and inguinal region of the female, perhaps as a means of pacifying her. Following this, the male usually grasps the shoulder skin of the female, but he may take hold of the flank initially and later shift to the shoulder. The female may move while the male is attached, but after a few seconds to several minutes the male curves his back strongly in a horizontal plane and pulls his tail beneath that of the female. Several attempts may be made before the male is able to attain a satisfactory copulatory position. The female, then, raises her tail, presumably to facilitate intromission. It is at this point where the absence of a tail might interfere with copulation. If so, then an animal which was capable of storing sperm from previous inseminations would have an advantage, as would an individual with rapid tail regeneration. Actual copulation lasts for only a few seconds and involves fewer than a half dozen pelvic thrusts by the male after which the two lizards separate. For a short time after separation, the male's hemipenis is exserted and tumescent, but it is soon withdrawn in to the tail base.

\section{I) rtalls of Behavior Patterns}

Aggrission.-Utas are evidently aggressive throughout their home ranges. They do not restrict their defense to a small territory within their home range, although the intensity of their aggression may be greater around selected areas. The aggression is not limited to a group of clominant animals in a social hierarchy as far as I have observed. In the laboratory, however, such dominance hierarchies generally become established.

Numerous natural, unstaged encounters were observed in our hours of 
field observation. I have selected a few that are representative for detailed presentation:

1. The red + male retreated from the arch and bob display of the red neck and red plus male. In this instance the dominant male was smaller than the non-resident and lacked a complete tail.

2. An adult male being pursued by an observer paused in its retreat when it caught sight of another male in its home range. It immediately made aggressive gestures toward the intruding male and drove it away, seemingly ignoring the presence of the observer.

3. The most vicious fight ever observed between marked male utas occurred on April 19, 1963. Both males were large and both had regenerated tails. One male would exhibit an aggressive posture toward the other, the other would respond in kind and would then be attacked. The attacked male then responcled by attacking the other. Six to ten separate fights, the total depending upon which sequences were considered separate fights, took place for 20 minutes before one of the males finally retreated.

These three observations indicate that dominance of a lizard is not always linked with size, that the aggressive response is extremely strong, and that partitioning of the habitat into fairly discrete home ranges may result from some vicious fighting between adjacent lizards over home-range boundaries. Once these boundaries are established, they appear to be respected. Most encounters observed do not result in fighting; ordinarily the aggressive display of a resident lizard is sufficient to cause retreat of the non-resident. Conditioning as a result of past experience doubtless plays a part in cletermining the reactions of one male to another.

Filid Explimiments on Aggression.-A pair of adult utas was chosen for a detailed study of their reactions to non-resident lizards. I)uring part of this study a fence was constructed of hardware cloth enclosing an area of about 15 by 30 feet, in which the pair spent much of their time. The fence was intended to impede the retreat of non-residents when challenged by the resident pair.

A non-resident female tied on a thread was introduced to the resident female at 7:15 P.M. This female was vigorously attacked by the resident, but the thread prevented retreat. After 3 minutes, the resident attacked again; two minutes later she attacked a third time. Despite the adoption of a submissive posture (body flat against the sand) by the non-resident, she repeatedly incurred attack by the resident.

That factors other than residency may be important in aggressive reactions was indicated when 2 non-resident females were placed within 
4 feet of the resident, at 11:30 A.M., and the latter showed no interest in them until one suddenly moved closer to it. The resident responded with an aggressive threat, but clid not attack. A minute or so later the resident moved toward one of the intruders while maintaining a threatening posture and soon straddled the non-resident. The non-resident became submissive and flattened herself closely against the sand. In this position she no longer evoked threats from the resident. She remained in this submissive position for 15 minutes and then retreated to cover. Three clays later at 5:30 and 5:50 P.M., the resiclent vigorously attacked both of these females upon their initial appearance and drove them into heavy cover. Whenever the nonresidents appeared they were again attacked-a total of 9 times over a period of 50 minutes. The following day the non-resident females were observed to retreat immediately at the appearance of the resiclent without provoking either threat or attack from her.

There is little cloubt that the degree of aggression varies even between the same individuals. The reasons for this are not clear, but the state of estrous of the female, the temperature, nearness of the resident to a favored site in the home range, and numerous other lactors must play a part. There is no cloubt that utas can learn to recognize a lizard ${ }^{\circ}$ with which they have had previous encounters, and it is this sort of conditioning that plays a large part in cletermining their future reactions to the same lizard.

The vigorous aggressiveness of males was also revealed by field experiments. A clead male tied to a thread was suspended near a resident male which immediately began assertive bobbing. After this initial reaction, he paid no further attention to the dead male for a lew moments. Suddenly, the resident attacked the dead male, seized its tail in his mouth and, with several quick rolling twists, severed the tail from its body. A few moments later the dead male was bobbed by the observer and was again vigorously attacked. On another occasion a male and female were tied to opposite ends of the same thread and placed near this same resident male. The resident's first reaction was to attack the male, which he did twice before courting the female.

In another experiment, a tied male was introduced to a resident female. The male did not attempt to court despite bobbing by the female, a behavior that usually stimulates courtship in the male. However, the resident male usually seen with this female sucldenly entered the scene and displayed aggressively toward the non-resident male. Perhaps because the thread prevented retreat of the non-resident male it was vigorously attacked. After this attack, the tied male was moved to a point 12 feet from the resident male. Here the tied male remained essentially motionless and yet was noticed by the resident which bobbed vigorously, assumed a 
threat posture, and attacked the tied male, inflicting a severe bite on its tail, causing bleeding.

Within the fenced enclosure, the resident male was victorious over two alien males in several encounters over a period of several days. These males were unrestrained within the enclosure; despite this fact, they were unable to find any site within the enclosure in which they were not consistently attacked by the resident. Once, late in the evening, I held one of the nonresident males in my hand and artificially bobbed him with a finger. He was attacked by the resident male who bit him in the leg, twisted quickly, released him, and then attacked again, biting the non-resident in the flank.

One interesting observation that indicates retention of territorial drive after absence from a familiar area was made on June 9, 1962, when a resident male was found outside and some distance from the enclosure. The enclosure was visited last on June 3, so I do not know when the resident escaped. In any event, he was captured and returned to the enclosure in which I had earlier placed two non-resident males. The re-introduced resident immediately threatened the white-stripe male which assumed a submissive posture. The resident then turned his attention to the white-cross male and drove him into a thicket. Between 4:15 and 5:20 P.M., the resident male attacked the intruders whenever they came into his range of vision, a total of 10 times. One of these attacks was made even after the nonresident male had been turned on his back by the observer.

Some Quantification of Observed Behavior.-Unless continuous observation is made of individual lizards, little social interaction will be seen in the field. For this reason, during some summers we followed individual lizards all day or for parts of it and recorded all of the interactions and the results of them. In addition, one of my students (Louis Irwin) elected to spend one-half of one summer making continuous observations on a selected group of resident utas. From all of these observations, some general statements can be made.

Sixty-nine courtships, of which 12 resulted in copulation, were observed. In 57 instances the female rejected the male. In only 2 of the 69 did the behavior of the female appear to initiate the courtship. In these two instances the female appeared to direct assertive bobbing toward a nearby male. On June 22, 1962, a male courted and was rejected by the same female 7 times before losing interest; on other occasions we have observed males that lost interest after a single rejection. In all instances in which copulation occurred, and the female could be caught and palpated, she contained developing ovarian follicles $3 \mathrm{~mm}$ or greater in diameter. The female always rejected the male when she was carrying oviducal eggs. 
Ferguson (1966b) has demonstrated that the injection of FSH will increase the frequency of courtships that result in copulation by increasing the submissivity of the females.

It is obvious to me that female utas show most of the characteristics that are associated with the state of estrous in mammals; it therefore seems rasonable to use the term estrous to describe their reproductive cycle. Indeed, for similar reasons, Harris (1964) has used the term to describe the state of reproductive readiness in lizards of the genus Agama.

Copulation in Uta s. stejnegeri is a short affair, lasting but a few seconds, although longer periods have been observed. The brief duration of copulation at first led me to believe that the observers were disturbing the lizards, resulting in a shortening of the normal mating time. However, cloacal smears of several females made just after copulation revealed masses of motile sperm, not present in females that had not been observed in copulation, and were selected at random from the population.

The results of aggressive encounters are shown below:

\begin{tabular}{|c|c|c|c|c|c|}
\hline & $\begin{array}{l}N \text { agoressive } \\
\text { encounters }\end{array}$ & $\begin{array}{l}\text { Submission } \\
\text { by intruder }\end{array}$ & $\begin{array}{l}\text { Threat by } \\
\text { resident; } \\
\text { retreat by } \\
\text { intruder }\end{array}$ & $\begin{array}{l}\text { Movement of } \\
\text { resident } \\
\text { toward intruder } \\
\text { after threat }\end{array}$ & $\begin{array}{l}\text { Fighting } \\
\text { or biting }\end{array}$ \\
\hline Males & 25 & 1 & 14 & 8 & 2 \\
\hline Fiemales & 6 & 0 & 1 & 4 & 3 \\
\hline
\end{tabular}

Although females seldom meet because of their more limited movements compared with those of males, they seem even more aggressive. Onehalf of the small number of female encounters ended in actual fighting or in chasing and biting the intruder by the resident. Fighting among males was much rarer. If we think back to the experiments in the pens, this difference is readily explainable. In both sexes, repeated encounters between the same lizards lead to a ritualization of the aggressive ceremony. If contact between females is less frequent than contact between males there is less opportunity for ritualization to replace fighting among females.

Discussion ol Courtship and Aggrission.-Tinkle et al. (1962) suggested that utas were primarily monogamous. Irwin (1965) agreed that although monogamy was the rule, promiscuous courtships did occur, but did not, in his observation, result in copulation. If monogamy exists in these lizards it is unquestionably a facultative type that is promoted by male-male and female-female aggression. As a result of these aggressive interactions, the opportunity for interactions outside the pairs is reduced. This is indicated by the observation that of 100 interactions observed in the field, 70 
involved courtship and only 30 aggressive encounters between members of different pairs.

There are no indications of social hierarchies in the field. Our experiments leave little cloubt that a lizard will not long tolerate the presence of another of the same sex. Submission of a non-resident is not sufficient to stop the aggression of a resident; retreat of the non-resident is usually required.

Males, as will be brought out in a later section, extensively "patrol" the margins of their home ranges. They will consistently court any female that is encountered and threaten any other male. The high frequency of rejections of males by the females may result in the maintenance of a low mating threshold in the male. Certainly, the rejection by fertile females prevents gametic wastage. However, this wastage may be of less importance than is the restriction of copulation for another reason-vulnerability to predation. Copulating utas are quite oblivious to disturbance and, as a result, may be quite easy prey at such times. Rejection of the male by the female at all times other than that essential for fertilization reduces the danger to both partners.

During the late fall and winter, aggressiveness wanes, and as many as 6 aclult lizards, 3 of one sex, have been found together in a single packrat nest. The explanation for this reduced aggression presumably lies in postreproductive hormonal changes in the lizards, but regardless of the explanation it is important to the individuals to be able to congregate around favored winter retreats. In addition to the protection afforded by such sites as packrat nests and piles of debris, food is also concentrated there cluring the winter.

Heterosfyual Aggression and Aggression Between Juvinills.-Heterosexual aggression has been observed in the field, but it evidently resulted from mistaken sex identification by the lizards. Irwin (1965) mentioned that the only 2 encounters between utas that involved vigorous fighting were heterosexual.

On June 9, 1962, a resident female moved suddenly into the visual field of a male which darted immediately to her and seized her by the flank. The female struggled, broke free, and fled. On March 7, 1963, a female suddenly bolted from beneath a yucca, crossing the line of sight of a male. The male pursued and caught her after a chase of a few feet, seized her in his mouth at midbody and shook her vigorously before releasing her. In both instances, it appeared that the sudden movement of the iemales stimulated the males to attack, rather than to court. It is also possible that these males had had recent encounters with other males so that the aggressive drive was still very high compared with that for courtship. 
Juveniles begin the species-specific bobbing behavior immediately after hatching. Such behavior has been observed by us in utas as small as $22 \mathrm{~mm}$ snout-vent. For a short time after hatching, juveniles may be found together in a single yucca; as many as 4 have been captured from beneath the base of a single plant. As the utas become aggressive they spread out. On July 28, 1963, two females less than $30 \mathrm{~mm}$ snout-vent were engaged in bobbing, arching, lateral display, biting, and wrestling. On the same day two others of undetermined sex were observed; bobbing and chasing by one resulted in retreat of the other. (On July 15, 1962, two juveniles of $30 \mathrm{~mm}$ were olsserved near the edge of a packrat nest. One suddenly arched and bolbbed in threat gesture; the other, which had been moving, stopped for a lew moments. When it moved again it was immediately attacked and chased about 3 feet in to the packrat nest.

At about $30 \mathrm{~mm}$ snout-vent the young also begin to attract aggressive gestures from the adults. On July 6, 1962, a juvenal uta bobbed at an adult male which bobbed back. The juvenile then assumed a submissive posture and was disregarded by the adult. On July 15, 1962, a juvenal female arched and bobbed at an adult who paid little attention at first. When the juvenile persisted in bobbing, the adult moved toward it in a menacing posture, forcing it to retreat. On July 28, 1963, an adult male was observed on several occasions to drive a half-grown lizard out of his area.

The interactions between juveniles and between them and resident adults begin when the young are $30-35 \mathrm{~mm}$ long. This size also corresponds with the size at which juvenal lizards begin extensive movements (as indicated by our recapture data).

Brhavior of Utas Toward Other Liznrds.-Only 2 other species of lizards are common on the study areas; one of these, the horned lizard, is seldom seen. It is only with the abundant and exceedingly active whiptail (Cnemidophorus tigris) that interactions are fairly frequent. Of the 13 observed encounters between individuals of this species and utas, flight by the utas occurred only twice. On 4 occasions the utas showed no apparent reaction other than an alert posture; on 9 occasions (including the two involving flight) the utas assumed an aggressive display posture with considerable bobbing, and once a whiptail was attacked and driven away by a female uta. No reaction was elicited from utas on the two occasions that they were approached by horned lizards. It is surprising that utas show little fear of large lizards such as the whiptail because the latter are occasionally their predators.

Behavior in THE: LABORATORY.-Many aspects of the behavior of $U t a$ stansburiana stejnegeri, but particularly of the behavior that releases 
courtship and aggression, have been studied by Ferguson (1966a) and duplicate to a large extent my own observations.

The most general statement that can be made about the laboratory behavior of these lizards is that their normal aggressive reactions quickly become subdued. When first introduced into a large terrarium lizards of both sexes behave aggressively toward others of the same sex, and fighting may be observed frequently. This behavior soon gives way to a sort of hierarchy in which one or two individuals dominate the others, but even in these instances they rarely display their dominance. Adult females adjust much better than males and do much better in captivity.

It is probably because of the suppression of normal behavior that homosexuality becomes a fairly frequent occurrence. This usually involved males courting other males and may result in vigorous attempts at copulation. We have also observed females courting other females as well as males, and actually attempting copulation with both. Thus, it is clear that the normal behavior patterns for copulation exist in females. No such homosexual behavior has ever been observed in the field; this, as dominance hierarchies, appears to be an artifact of laboratory confinement.

$\Lambda$ great many normal copulations have been observed in the laboratory, the success of which was sometimes checked by making cloacal smears of the females involved. The longest of those observed in the laboratory lasted 12 seconds, the shortest 5 . Thus, copulation in the laboratory appears to be the same as observed in the field. However, two cases of rape were observed in the laboratory, but never in the field, nor does it seem likely that it would occur in nature. Attempted copulation of a dead female by a male has also been observed in the laboratory.

The Daily Activity of Individual Lizards.-Irwin (1965), by continuous observation of individuals throughout the day, provided the first really thorough and quantitative study of the diel cycle of any lizard. By measuring the distance moved by each lizard during each one-half hour of the day, he was able to express activity in terms of feet moved per hour. His data show clearly that activity of males $(\overline{\mathrm{X}}=6.3$ feet per move) is always greater than that of females $(X=4.1)$, and that the peak of activity occurs between 5:30 and 7:30 P.M., but some activity takes place at all hours of the day. It simply cannot be said that utas become completely inactive at midday, though this may be true of some individuals.

Except for some more details on movement to be discussed later, little else of quantitative value can be added to Irwin's discussion. However, a general composite description of the normal cycle of activity for individual utas is not available from the literature, so this is provided here. 
Utas emerge shortly after sunrise in the summer and spend most of the early morning hours basking and moving about, generally for distances of only a few feet. During the middle of the day, utas remain in or near shade; on extremely hot days they crawl beneath the basal fronds of yuccas; almost never do they retreat underground. Individuals have been observed to remain in shaded spots for periods of 3 to 5 hours without significant movement. A substantial amount of feeding may occur during these periods of relative quiesence, particularly on small ants that are active around the yuccas. After 5:00 P.m. activity abruptly increases. Males begin what appears to be active patrolling of their home-range perimeters, moving from bush to bush. Neither sex spends much time in the open; they move quickly across areas between plants. During such moves, the tail is lifted from the sand surface and never dragged.

Movements of utas across open ground appear to be rapid; on one occasion, we conducted an experiment to test their running speeds. An area in their usual habitat was completely cleared of ground cover and a circle was inscribed in the sand. Utas were released at the center of the circle on a clear, warm day (air temperature $35^{\circ} \mathrm{C}$; sand temperature $50^{\circ} \mathrm{C}+$ ) and the time required to reach the boundary of the circle was measured with a stopwatch. The average speed of 12 lizards tested was 5.0 $\mathrm{mph}$, and varied from 3.5 to $7.3 \mathrm{mph}$. All of the slow records were recorded for lizards that delayed slightly before they began running or didn't move in a straight line to the circle boundary. If these are eliminated, the average running speed was $6 \mathrm{mph}$. Although a lizard can probably sustain such speed for only a very short time, this is generally all that is required to cross the short open spaces between sheltering plants.

Ordinarily, at each stop the animal pauses to bask in open shade or partial sunlight, the length of time depending upon the prevailing air temperature and the intensity of the solar radiation. During these basking stops the utas perform a curious ceremony which consists of moving the forearms forward and backward in unison several times in rapid succession. The motion suggests that used in digging, but the feet are not in contact with the substrate.

Feeding is concentrated cluring the afternoon and is, again, largely opportunistic. If prey of a suitable size chances by it is eaten, but does not appear to be actively sought by the lizard.

Obviously, because of the greater activity, social interactions increase in the late afternoon, particularly between the males patrolling their home ranges. By plotting the outermost points at which lizards had been seen, and connecting them to form a polygon, the area covered by an individual lizard was enclosed. Then the number of times that the lizard was seen 
moving near the periphery of this area was compared with the number of times it was centrally located. Only lizards with 25 or more locations were used for this purpose. Of 2133 observed locations, 1111 were peripheral and 1022 central, so roughly half of all of the movements are in the peripheral areas of the home ranges. It follows, then, that most of the encounters between individuals of the same sex should be in the peripheral part of the home range. Of 14 contacts observed between the individuals above, 11 were peripheral and all involved aggressive encounters. These data make it clear that the area defended and the home range are essentially the same and hence the lizards are territorial throughout the home range.

In late evening basking activity increases again and the distance moved falls to about the same level observed in the mornings. Usually, shortly after sundown, the utas become quite nervous and move about a lot, but only a foot or so at a time. This same type of apprehensiveness has been observed in utas in the winter or on cool clays at other seasons. Using the clistance moved by disturbed lizards as an indication of their wariness, Rand (1964) found that Anolis lineatopus was more wary at low than at high temperatures.

The period of late evening "nervousness" is soon followed by burial in the sand. The lizard selects a spot, generally near or in a mesquite clump, pushes his snout in to the sand, and, by pushing forward with stiffened hind legs, submerges the entire body. Several attempts may be made before the lizard ceases all activity. It may emerge from the sand, move a short distance, and bury itself a second time. Burial occurs at air temperatures of 25-30 $\mathrm{C}$, and at a time when measured sand temperatures are about the same as those of the air. The time of burial may be as much as one hour before sunset or one-half hour after, but the mean time in the summer is at sunset, or about 8:00 P.M.

On some occasions utas climb onto mesquite limbs in the late evening and pass the night there a foot or so off the ground. Rarely, utas have been seen abroad at night. On June 20, 1961, an adult male was found out on open sand at midnight, air temperature, $22^{\circ} \mathrm{C}$. On October 6, 1962, a uta was discovered, presumably sleeping, in a broomweed at 11:00 P.M. When disturbed, it immediately ran to refuge beneath the base of an adjacent yucca.

In brief, utas are quite sedentary. They do not actively forage like Cnemidophorus. Their energy budget must be minimal, for the only major expenditures of energy other than that required for maintenance occur during patrolling activities and in the infrequent social encounters.

Essentially, the same sort of activity patterns persist through the year. In the winter and early spring activity is shortened and a greater proportion 
of time is spent in basking. Nevertheless, they are active throughout the year whenever days are sunny; they may be seen basking at air temperatures only a few degrees above freezing. Activity in winter is suppressed on cloudy or windy days. On some occasions during each year inclement weather forces them to remain in a state of torpor for periods of a week. It is during such times, as demonstrated earlier, that winter kill may take a heavy toll. One interesting difference from summer behavior is the tendency for utas to seek shelter in mammal burrows when disturbed.

Some Comments on the Literature of Lizard Behavior.-The little available literature on lizard behavior was summarized recently from rather different points of view by Evans (1961) and by Clarke (1965). Territoriality, or at least aggression, is characteristic of most lizards studied. It is not always clear that the aggression is directed toward defense of a particular area, so it is perhaps better to speak of aggressive behavior rather than territoriality. There are some species such as Leiolopisma zelandica that have been reported as non-aggressive (Barwick, 1959). There are also some in which aggression is evidently not limited to encounters between lizards of the same sex. Bustard (1965) reported that females of Chameleo hohneli will attack other lizards of either sex if they get too close. I have observed a similar behavior in at least one species of $U t a$ in which the female rejection response involves making menacing advances and nipping at courting males.

Under natural conditions, female aggression has been reported by Evans (1938a) in Anolis sagrei, by Fitch (1956b) in Crotaphytus collaris, and Harris (1964) in Agama agama. As I have noted for utas there seems to be little hesitation on the part of a male confronted by another lizard in exhibiting either aggression or courtship depending upon the sex of the other. Sex recognition seems almost immediate. Noble and Bradley (1933) reported from their laboratory studies of Anolis carolinensis that males exhibited courtship behavior toward other lizards regardless of sex, and that aggression was then elicted by the subsequent behavior of the other lizard. Evans (1938b) compiled evidence to indicate that such was not the case, and that sex recognition occurred at a distance. One of the major results of aggressive behavior is spreading of the population fairly evenly in relation to its resources. The function may be associated with mating advantage. However, carried to an extreme, aggression would result in less efficient utilization of resources in years or areas when the resources were unusually abundant. Compression of territory size could result in a greater density and so might the establishment of social hierarchies. In most studies of lizard behavior it has been noted that some type of social hierarchy is quickly established under crowded laboratory conditions. For example, Carpenter 
(1960b) observed that 2 males soon became dominant in a group of 6 captive Urosaurus ornatus, and with a little more time one of the two became dominant over the other. When this major dominant was removed, the behavior of the subdominant animal changed and he became the dominant, retaining his social position even after the original dominant was returned to the enclosure. Removal of both dominants allowed a third lizard to assume the dominant position. In Carpenter's observation it appeared that the dominant lizard became darker. In utas, I have observed that a dominant male appears to get brighter, particularly the orange spots, during aggressive displays. Somewhat similar behavior of male lizards in a dominance system was observed by Carpenter (1961) in Sceloporus merri$a m i$, in which most of the social interactions in a group of captives became restricted to two dominants.

Clarke (1965) in his excellent studies of behavior in the lizards Holbrookia, Callisaurus, and Cophosaurus found formation of dominants-subdominants hierarchies in the laboratory. In his view the hierarchies were brought about by the increased frequency of contacts between individuals in confined quarters. In Uta stansburiana such hierarchies also become established and lead to a reduction in strife within the entire group.

The frequency with which hierarchies are formed in the laboratory by many species of lizards certainly suggests that, under conditions of high density, when contacts between individuals are increased in the field, hierarchies might form in nature. Such a phenomenon has been reported by Evans (1951) in the large iguanid lizard Ctenosaura pectinata and in the agamid lizard, Agama agama, by Harris (1964), and perhaps reaches the extreme in the marine iguana of the Galapagos. As will be cliscussed later, they may also occur in some populations of utas. If hierarchies do form in nature under high clensities, the importance of aggression for controlling population size might be questioned. However, if the breeding under a hierarchical arrangement is limited to a few individuals, population numbers may be controlled in this way. It remains to be demonstrated, however, that such a restriction occurs in nature.

The outstanding work of Harris (1964) on A gama deserves further consideration. He has recorded an instance of the means by which territorial boundaries become established. Two males with adjoining home ranges fought several times over a path between their boundaries. Gradually, fighting was reduced until the two males would bob back and forth at one another across the path, but would seldom physically violate the boundary. Male A would be beaten when he entered into B's territory and vice versa, providing an excellent example of the psychological advantage enjoyed by a resident lizard in its own territory. 
Harris' work is also unique for its analysis of territorial limits and of social hierarchies. By moving models of male lizards into and around the home range of resident males he was able to define with some precision the area in which a male lizard exhibited true territoriality, an area of 600-900 square feet. The social hierarchy in Agama particularly involved the females. Never was a clominant lemale observed to leave the dominant male lizard with which she was associated. Desertions by subordinate females were common.

As a final point I would like to stress the fact that the stereotyped push-up or bobbing behavior and the aggression and courtship ceremonies of lizards would lend themselves nicely to quantification and component analysis that has proven so useful in studies of fish and bird behavior. We still have no information of which aspects of these behavior patterns might be important as isolating mechanisms for lizards. For some behavior patterns, e.g., push-ups, there is yet no clear evidence of the function.

The Dali, Periodicity of Utas.-It has been stated frequently in the literature that lizards of this or that species are more active at one time of day than another, or are completely unavailable for capture at certain times, usually at midclay. In some areas utas, too, appear to be absent at certain times of the day, but this is not the case in western Texas. Some reports of lizard periodicity may also be based upon the periodicity of the investigators who choose not to be in the field at certain times. Irwin (1965) demonstrated that utas are carrying on some above-ground activity at every hour of the day, although they are relatively quiescent during extremely hot periods.

One of the problems in studying periodicity lies in obtaining a basis for comparison of the number of lizards seen at each hour of the clay because effort expended to capture or sight the lizards may be concentrated at certain hours. Each time we worked a study area we recorded the total time required to cover the area, the number of people involved, and the time at which each capture was made. Therefore, data were available to calculate the number of minutes that a lizard was subject to observation at any hour of the day. From such data I have determined the number of lizard captures per unit effort (man-hours) for every hour of the day. The data for both study areas from June, 1961, through May, 1965, have been lumped into two seasons which represent, roughly, the reproductive and non-reproductive seasons (Fig. 7).

The data for April to September certainly indicate a decrease in the number of captures during the midclle of the day as well as very early or very late. However, the number of hours devoted to capturing lizards at 

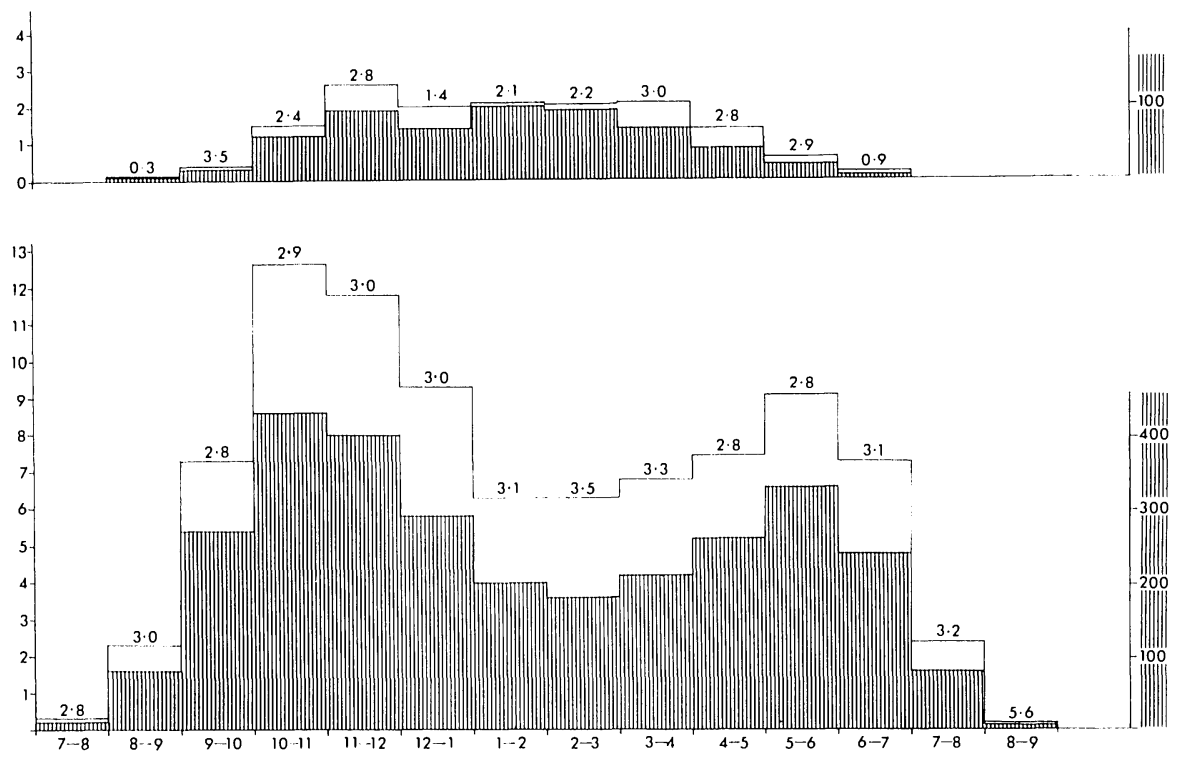

Fic. 7. Periodicity of utas. Abscissa shows time of day from 7:00 A.M. to 9:00 P.M. Left ordinate is number of captures (hundreds). Right ordinate is number of man hours. The bottom histogram is for the period April to September, the top October to March. Figures above each histogram are numbers of lizards captured per man hour of effort. Banded sections of histogram represent total man hours; clear section, number of lizards captured.

these times is correspondingly low. The efficiency with which utas were captured (the catch per unit effort) was higher at midday than at any other time except late evening when the conspicuously increased activity of the lizards made them easier to locate.

The data for October to March indicate that lizards are somewhat more difficult to capture at this season. This is because of their increased wariness at low ambient temperature; also, fewer are seen active at any particular time. Captures before 9:00 A.M. and after 6:00 P.M. were exceedingly rare.

These data show that if periodicity is defined simply as being exposed to observation or capture, there is little difference at different times of the day. What these data cannot show is what differences exist at different hours in the degree of activity. Such data are available from Irwin's (1965) paper based on 32 lizards that were watched a total of 200 hours over a period of 57 days in the summer of 1963. The distance that each lizard moved is shown in a somewhat different form from that used by Irwin (Table 24). The figures shown were extrapolated from Irwin's graph and are 
approximate. These data do indicate a reduction in movement at midday. Apparently, males increase their activity earlier in the late afternoon than do females.

\section{Home Range and Movement}

The area occupied by an animal and utilized in its search for food, for mates, and for shelter has been generally called the home range. The term has been redefined in various ways and even broken into components

TABLE 24

MOVENENTS by Utas AT DIFFERENT Hours of the Day

All figures are mean feet per hour for several animals observed at each hour.

Data are approximations from Irwin (1965)

\begin{tabular}{crc}
\hline & \multicolumn{2}{c}{ Mean feet per hour } \\
\hline Hour & Males & Females \\
\hline $8-9$ & 73 & 34 \\
$9-10$ & 60 & 47 \\
$10-11$ & 73 & 34 \\
$11-12$ & 75 & 24 \\
$12-1$ & 58 & 30 \\
$1-2$ & 21 & 15 \\
$2-3$ & 41 & 13 \\
$3-4$ & 56 & 15 \\
$4-5$ & 66 & 19 \\
$5-6$ & 141 & 34 \\
$6-7$ & 167 & 54 \\
$7-8$ & 75 & 73 \\
\hline
\end{tabular}

such as an activity range or home realm. Studies of home range are important in indicating the size of area necessary to sustain an individual; the degree of overlap of home ranges indicates something about the social structure of the population.

I would like to make it quite clear that the fact that utas defend their entire area of familiarity makes it possible to use the terms home range and territory interchangeably when speaking of utas. It apparently is true that some portions of the home range are more vigorously defended than others. It is probably the size of these vigorously defended areas that sets a limit on the extent of the possible compressibility of individual territories. Throughout the ensuing discussions I have used the term home range for the activity area of the utas even though this entire area is evidently defended. 
There is no doubt of the importance to utas of the home range or of the reality of such an area. The lizards seem to know rather precisely where mammal burrows, packrat nests, and other refuges are located. On several occasions we have purposely chased utas, attempting to drive them into unfamiliar areas. This is difficult to accomplish; the utas are more likely to double back toward the pursuer than to move into unfamiliar areas, particularly if such a move involves traversing an open area.

How the lizard becomes familiar with the boundaries of its home range seems apparent from the data on relative movements to be presented later. The distance that a lizard moves is directly proportional to its age. Hatchlings may be found for several weeks no more than a few yards from their hatching site. Their movements and the area with which they are thoroughly familiar increase as they mature. This gradual familiarity with the area must be important in avoiding enemies and in contending with other utas. The established resident, as we have already seen, is at a decided advantage.

Despite the apparent reality of the home range, it has proved difficult to measure it accurately; this has also been true with other vertebrates. Some of the clifficulties encountered with the utas are as follows:

1. The lizards tend to confine themselves to areas much smaller than the home range. Unless a very large number of recaptures are obtained, almost all captures will be made in the smaller area and an underestimate of home-range size will result.

2. The home range is sometimes shifted. This is obvious when a lizard has been captured several times in a certain area and is then captured several times in a second area without returning to the first. Shifts by adult animals occur, but most shifts take place between the time a lizard is young and the time it matures.

3. Males are much more active than females, so there is a greater probability of catching them at all points in their home range than is the case with females.

4. Some animals occur at the margins of the study area with some captures within the area and some outside. The home ranges of such animals are always underestimated if the bulk of their home range lies outside of the area no matter how many recaptures may be made of them.

5. Lizards are less active in the winter and early spring than at other seasons. This makes it difficult to compare the home-range size of a lizard with numerous captures during the winter with one whose captures have been made at another season.

Because the home range is of primary importance during the breeding season and because this season can be rather clearly defined, I have used 
only those captures made during the breeding season for computing homerange size and for making comparisons between different individuals. The breeding season covers the period from March to September and is the period when our recapture data are particularly strong. I have also considered only adults of breeding size and only residents of the study area (3 or more captures within the area) I have eliminated from consideration most marginal animals as well as all whose recaptures fall on or near a straight line. After all of these eliminations, I am still left with more than 300 lizards with a mean of 10 recaptures each on which to base my estimates.

TABLE 25

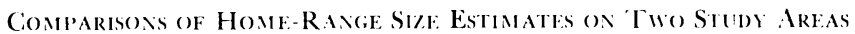
dor Siveral Yiars by thr. Manimum Polycon Ticinique:

Figures are in square feet. Numbers in parentheses are mean numbers of captures on which the estimates are based

\begin{tabular}{|c|c|c|c|c|c|c|c|c|}
\hline & \multirow[b]{2}{*}{$N$} & \multicolumn{3}{|c|}{ Area I } & \multicolumn{4}{|c|}{ Area II } \\
\hline & & Males & $N$ & Females & $x$ & Males & $\mathrm{N}$ & Females \\
\hline 1960 & 11 & $36.17(7)$ & 11 & $785(6)$ & 一 & - & - & $\longrightarrow$ \\
\hline 1961 & 14 & $4224(10)$ & 16 & $881(7)$ & 19 & $2889(7)$ & 21 & $1206(7)$ \\
\hline 1962 & 15 & $5418(13)$ & 13 & $1372(12)$ & 14 & $5029(13)$ & 20 & $1394(10)$ \\
\hline 1963 & 9 & $33.18(7)$ & 10 & $3460(14)$ & 7 & $8701(14)$ & 7 & $3101(16)$ \\
\hline 1964 & 18 & $4133(11)$ & 22 & $975(10)$ & 15 & $3295(10)$ & 26 & $8.55(8)$ \\
\hline 196.5 & 11 & $11391(12) *$ & 7 & $2689(9)$ & 10 & $5421(10)$ & 18 & $235.1(10)$ \\
\hline Totals & 78 & $5261(10)+$ & 79 & $1461(10)+$ & 6.5 & $4459(10)+$ & 92 & $1527(9)+$ \\
\hline
\end{tabular}

* High mean due to inclusion of 1 male with home range $=5.5,000) \mathrm{s}(\mathrm{f}$. $\mathrm{ft}$.

$+\overline{\mathrm{x}}$ home range size of all males $(143)=4896$ (10) $(.11$ acre $)$.

$\ddagger \overline{\mathrm{x}}$ home range size of females $(171)=1497$ (9) (.03 acre).

Estimation by Minimum Polygon.-By plotting all of the captures on a graph and connecting the outermost points one can form a polygon around the area in which all of the recaptures were made. Tinkle et al (1962), after only one summer of work on one of the study areas, estimated the size of the home range at .06 and .02 acre in adult males and females, respectively. These figures were based upon 15 males and 19 females captured an average of 5 times each. Now, on the basis of 143 males and 171 females with an average of 10 and 9 captures, respectively, I estimate the size of the home range as .11 acre for males, .03 for females.

The results vary widely for different years (Table 25) and bear further discussion. One of the factors that might affect home-range size in utas is density, for home-range size will be compressed when density is high, 
expanded when it is low. Obviously, the relationship cannot be perfect because of the considerable overlap of home ranges. Also, it might be asked how the lizards are aware of the change in density. This is a simple matter; the lizards are always moving about the margins of their home ranges. If unchallenged they will gradually incorporate more area.

In males (Table 25) the relation of density to home-range size is not at all clear. This may be because the greater movements of the males and the greater clegree of overlap of their home ranges compared with females leaves little area for expansion cluring times of low density. Females, on the other hand, clo indicate a clear inverse relation between home-range size and density. In both sexes the interpretation is clouded by differences in the average number of captures from year to year.

If the resources in each study area were randomly distributed and each lizard were equally aggressive and non-overlapping in its movements, a home-range size of .11 acre would allow about 19 resident males on our 2.06-acre study areas. This is higher than clensity estimates presented later, but inclicates that estimates of size of home ranges are reasonable if inexact. In any event, few conclusions can be drawn from the estimates nor do they have predictive value.

Estimates of Home-Range Size by Tracking Lizards.-In the summers of 1962 and 1963 a few marked lizards were followed periodically for periods ranging from one to several days. l)uring these periods each observer noted the coordinate location of the lizard each time it moved and a composite drawing of its home range was made from these data. Fortunately, many of the lizards chosen for tracking were those for which we also had available good recapture data so that the home-range size by the two methods could be readily compared. These comparisons are available for 8 females and 9 males (Table 26). Males evidently cover larger areas than is evident from recapture clata, but females cover somewhat smaller ones. This difference between the sexes was predictable because the probability of seeing a sedentary female cover most of its home range is less than is the case for males, particularly because males spend more time near the periphery of the home range than do females.

Of the 17 lizards shown in Table 26, three of 9 males and 6 of 8 females had larger home ranges based upon recapture data than upon tracking, so the latter technique cloes not consistently produce a larger estimate. One reason for this is the great variation in the activiy of an individual lizard on different days. If the lizard is watched one or more days when it is quite active a large estimate of its home-range size will be obtained, but the estimate may be quite low if the animal is watched on 
other days. The best technique, perhaps, would be to follow selected individuals for periods of about a week at different seasons. In this way an accurate impression of home-range size at different seasons should be gained. However, tracking lizards for only short periods is obviously not a more reliable method of estimating the size of its home range than are periodic recaptures and, in the case of females, may be definitely inferior to recapture data.

TABLE 26

Comparison of Hone-Range Size Estimates of Several Individuals made by both Minimum Polygon and Tracking Technique

Figures are in square feet; number of locations used for each estimate in parentheses

\begin{tabular}{rrrr}
\hline \multicolumn{2}{c}{ Males } & \multicolumn{2}{c}{ Females } \\
\hline Polygon & Tracking & Polygon & Tracking \\
\hline $8697(9)$ & $4680(42)$ & $1352(13)$ & $1392(31)$ \\
$11322(27)$ & $7584(33)$ & $1365(22)$ & $508(35)$ \\
$5760(27)$ & $5780(48)$ & $3221(30)$ & $2492(37)$ \\
$6308(26)$ & $16620(179)$ & $1497(13)$ & $1284(43)$ \\
$7253(21)$ & $13976(69)$ & $2352(19)$ & $1532(39)$ \\
$6207(19)$ & $6592(53)$ & $+128(19)$ & $3144(23)$ \\
$7336(15)$ & $13972(169)$ & $2656(16)$ & $6084(44)$ \\
$1788(7)$ & $5508(60)$ & $2 \times 08(20)$ & $1416(53)$ \\
$11640(14)$ & $8796(26)$ & & \\
$7701(18)$ & $9279(75)$ & $2422(19)$ & $2232(38)$ \\
\hline
\end{tabular}

Rriation Between Home-Range Size and Number of Captures.There should, in theory, be a direct relation between the number of captures and the computed size of the home range. This is because increasing the number of captures increases the probability of capturing a lizard in all parts of its home range. However, the disturbance to the animal involved in repeatedly capturing it may interfere with its normal movements. This was the reason that we decided to paint utas with different insignia so that their locations might be recorded at a glance.

Figures 8 and 9, which utilize the same data as Table 25, show the relation between home-range size in both sexes based upon differing numbers of captures. Without any sophisticated treatment of the data one can see that there is little correlation between number of captures and computed home-range size. On the other hand, in neither sex are there many individuals with fewer than 10 captures that have large home ranges. Increasing the number of captures beyond 11 does not result in any appreciable increase in the mean size of home range. 


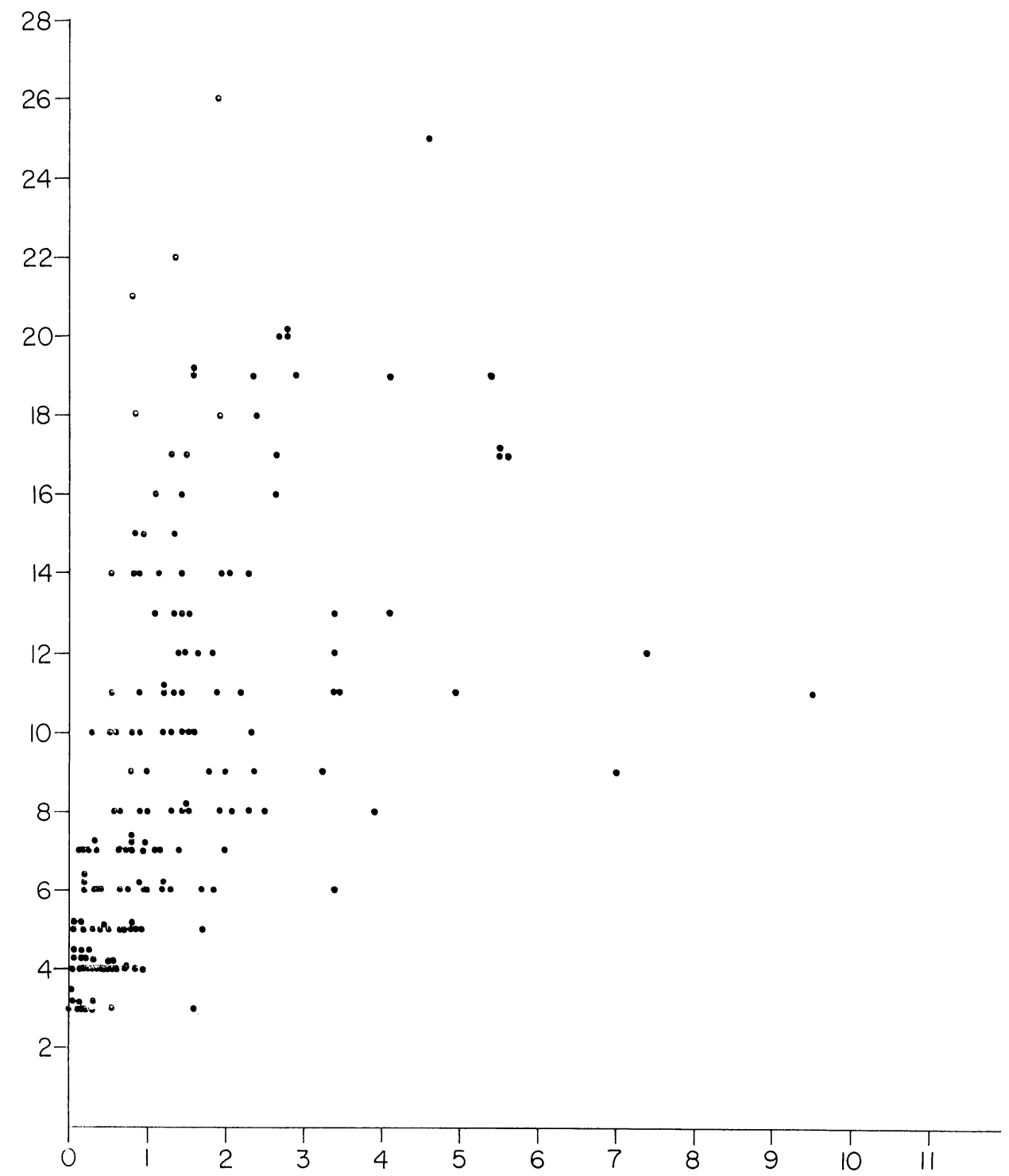

Fic. 8. Home-range size of females. Abscissa shows home-range size (minimum polygon) in thousands of square feet. The ordinate shows the number of captures on which each esti. mate of size is based. No individuals captured fewer than three times were used. 


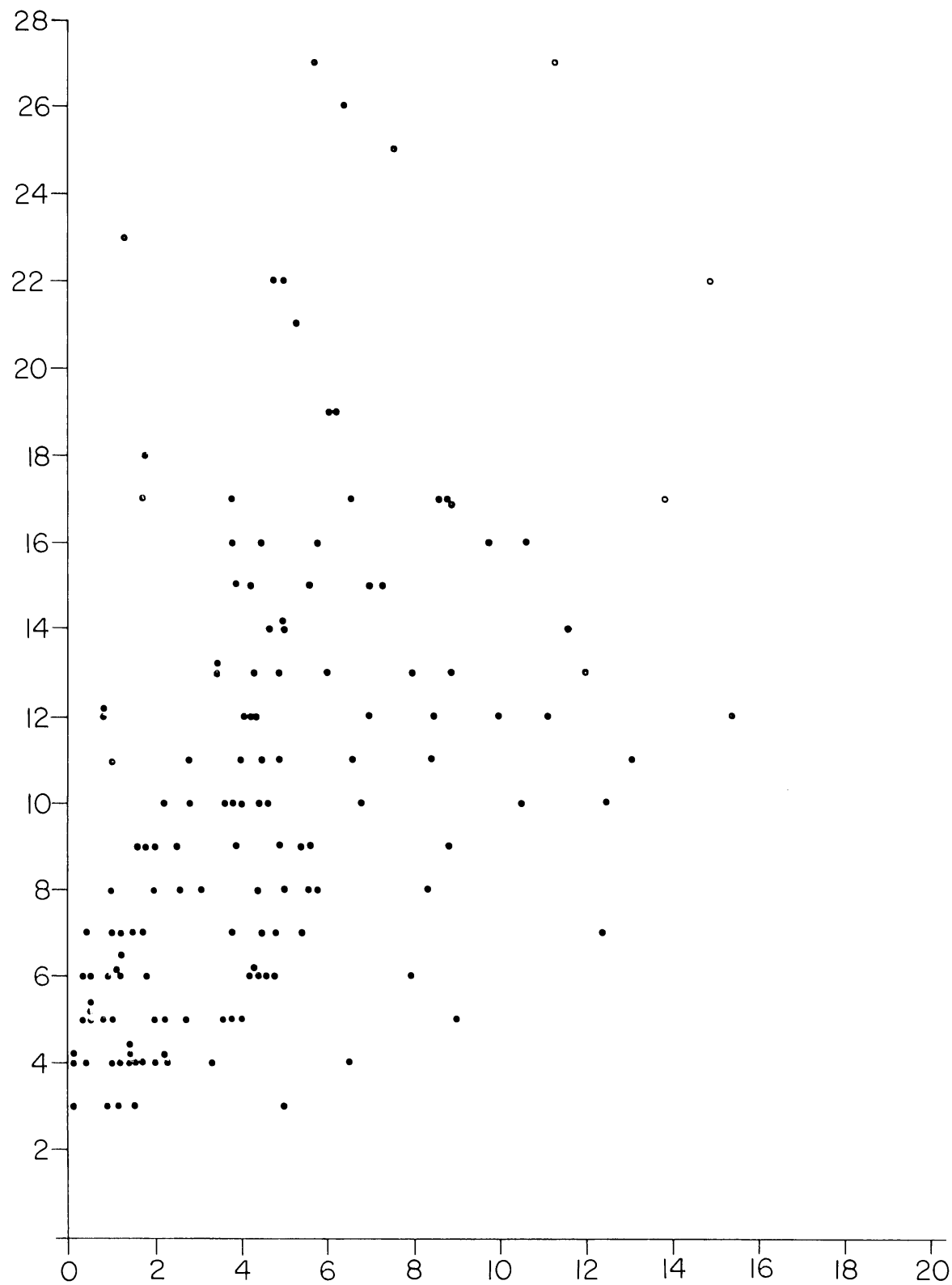

Fic. 9. Home-range size of males. Information same as for Figure 8. 
If only the 59 females and 57 males with 11 or more captures are considered, a mean home-range size of 2300 square feet $(.05$ acre) for females and 6340 square feet $(.15$ acre) for males is obtained. The difference of about $3: 1$ in the relative size of male:female home range is still evident.

The Home Range of Juvenilis.-It is difficult to capture young utas enough times while they are still small to obtain an accurate estimate of their home-range size. After they are about half-grown, antagonism between them and with the adults, as well as their own energy demands, force them to move about more and to expand their home ranges. During two years of this study an attempt was made to capture utas frequently between the time of hatching and the attainment of a size of $35 \mathrm{~mm}$. Inasmuch as only about 6 weeks are required for growth to this size, we were unable to obtain a large number of captures on them. However, we were able to obtain an average of 4 captures each on 151 males and 206 females which indicated home ranges so consistent in size that I do not hesitate to use such data. By minimum polygon technique home ranges of inclividuals of both sexes were estimated to be about 1300 square feet $(.003$ acre) in area.

The following conclusions can be drawn from the data presented on home-range size:

1. The home ranges are small compared with those of many other lizards that have been investigated.

2. The home ranges of males are unquestionably larger than those of females.

3. Aclults occupy home ranges that are many times larger than those of juveniles.

1. Size of home range is highly variable in different individuals making the mean home-range size almost useless for estimating movements.

5. In contrast to what was stated by Tinkle et al. (1962) there is considerable overlap of the home ranges of males, but not of those of females. Males frequently pass within a few feet of one another in heavy vegetation without seeing each other. Unless challenged, a male may wander extensively and overlap the home ranges of adjacent males in the process.

Estimates ol Home Range by Probability Density Function.-The theory of utilizing the probability clensity function in estimating relative movements of lizards has been cliscussed in detail by Tinkle (1967). Briefly the technique consists of finding the geometric center of all recaptures on an indiviclual and measuring from this center to all capture points to obtain a series of recapture radii. These radii collected from several individuals may be treated statistically to obtain a mean recapture radius. 
By using this mean plus 2 standard deviations of it as the radius, a circle may be drawn that will enclose 95 per cent + of all the capture locations of individual lizards. The area of this circle may be calculated to obtain a generalized estimate of size of home range. It is possible to draw any number of circles depending upon the number of standard deviations one uses. Almost all captures of utas fall within 2 standard deviations of the geometric recapture center. The technique assumes a circular home range. It is also clear that the same mean recapture radius can be obtained from recapture locations that would give very different home-range shapes by minimum polygon. This technique will almost certainly overestimate the home-range size. The home range of adult female utas, size estimated by probability density function, is about .15 acre, that of the male .49 , considerably larger than those indicated by recapture data or by tracking lizards.

The usefulness of recapture radii may be in comparing populations and not in computing home-range size. Our data show that the mean recapture radius is essentially constant for varying numbers of individuals, varying numbers of captures and varying lengths of time over which captures are made. The data illustrating these facts have been presented elsewhere, but some of them to which additional data have been added merit further discussion.

Table 27 shows the remarkable constancy of the mean recapture radius computed from varying numbers of individuals from the first few captured during this study to all lizards handled. Table 28 shows the mean recapture radius computed for the populations on two study areas over a period of several years. This table is modified from that presented by Tinkle (1967) to show the aterage density of resident adults through the breeding season.

The recapture radius is remarkably constant so long as density does not decrease markedly. When density is lowered, the females show striking and significant increases in home-range size. This relationship is not so clear in males, as was discussed earlier, because of the considerable overlap of their home ranges.

I will return to the utility of the recapture radius in the section of comparative demography. Suffice it to point out here that its remarkable constancy enables us to predict the relative movements of individuals in the population from relatively few data. This makes possible the comparison of movements in different populations in different habitats in several parts of the range of a species.

Homing.--Nineteen utas captured north of study area I were displaced 300 feet north of their capture location. 1)uring the next 3 days, none of 
TABLE 27

Mean Recapturf: Radius and the Home-Range Size Estimate Computed from it

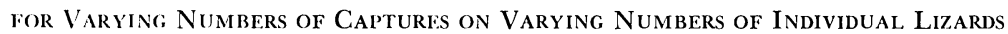
Figures for means are feet

\begin{tabular}{|c|c|c|c|c|c|c|}
\hline \multirow{2}{*}{ Category } & \multicolumn{6}{|c|}{ Females } \\
\hline & $\mathrm{N}$ & Mean & Acre & $\mathrm{N}$ & Mean & Acre \\
\hline $\begin{array}{c}\text { All captures on } \\
\text { all lizarcls }\end{array}$ & 1325 & $37.4 \pm 0.63$ & .49 & 1481 & $20.4 \pm 0.35$ & .15 \\
\hline $\begin{array}{l}\text { 1st capturce on } \\
\text { all }\end{array}$ & 131 & $38.6 \pm 1.94$ & .50 & 147 & $21.5 \pm 1.11$ & .16 \\
\hline $\begin{array}{l}\text { lst capture on } \\
\text { lst } 23\end{array}$ & & $36.3 \pm 4.29$ & .48 & & $17.9 \pm 2.07$ & .10 \\
\hline $\begin{array}{c}\text { 1st } 2 \text { captures } \\
\text { on all }\end{array}$ & & $36.0 \pm 1.34$ & .45 & & $21.4 \pm 0.79$ & .17 \\
\hline $\begin{array}{c}\text { 1st } 2 \text { captures } \\
\text { on } 1 \text { st } 22\end{array}$ & & $34.4 \pm 2.88$ & .44 & & $18.5 \pm 1.67$ & .12 \\
\hline $\begin{array}{c}\text { Ist } 3 \text { captures } \\
\text { on all }\end{array}$ & & $36.5 \pm 1.12$ & .47 & & $20.3 \pm 0.61$ & .15 \\
\hline $\begin{array}{c}\text { lst } 3 \text { captures } \\
\text { on lst } 11\end{array}$ & & $33.5 \pm 2.37$ & .43 & & $17.6 \pm 1.79$ & .10 \\
\hline $\begin{array}{l}\text { Ist } 4 \text { captures } \\
\text { on all }\end{array}$ & .520 & $36.8 \pm 0.99$ & .49 & 621 & $20.9 \pm 0.54$ & .15 \\
\hline $\begin{array}{l}\text { lst } 4 \text { captures } \\
\text { on 1st } 12\end{array}$ & & $36.1 \pm 3.30$ & .48 & & $28.8 \pm 0.69$ & .13 \\
\hline $\begin{array}{l}\text { 1st 5 captures } \\
\text { on lst } 10\end{array}$ & & $35.5 \pm 3.36$ & .49 & & $19.8 \pm 1.79$ & .14 \\
\hline
\end{tabular}

these lizards was relocated, but four of them were found on the fourth day. All of these were males, and two were still in essentially the same area in which released. One of the remaining two had returned to within 25 feet of its original location and another had moved 200 feet in the correct direction. By the 14th day, another of these four males had returned to within 100 feet of its original capture location. Only two of the females originally released were recovered and both were in essentially the same position as released. Although the results of the experiment might indicate some degree of homing ability, the time elapsed between release and return provided ample time for random search by the lizards for familiar landmarks. Too, the males are undoubtedly familiar with larger areas than the females and would more quickly find familiar landmarks. Finally, only about one-third of the lizards were relocated during the two weeks of the experiment, so I am reluctant to attribute any directed homing ability to the utas. 


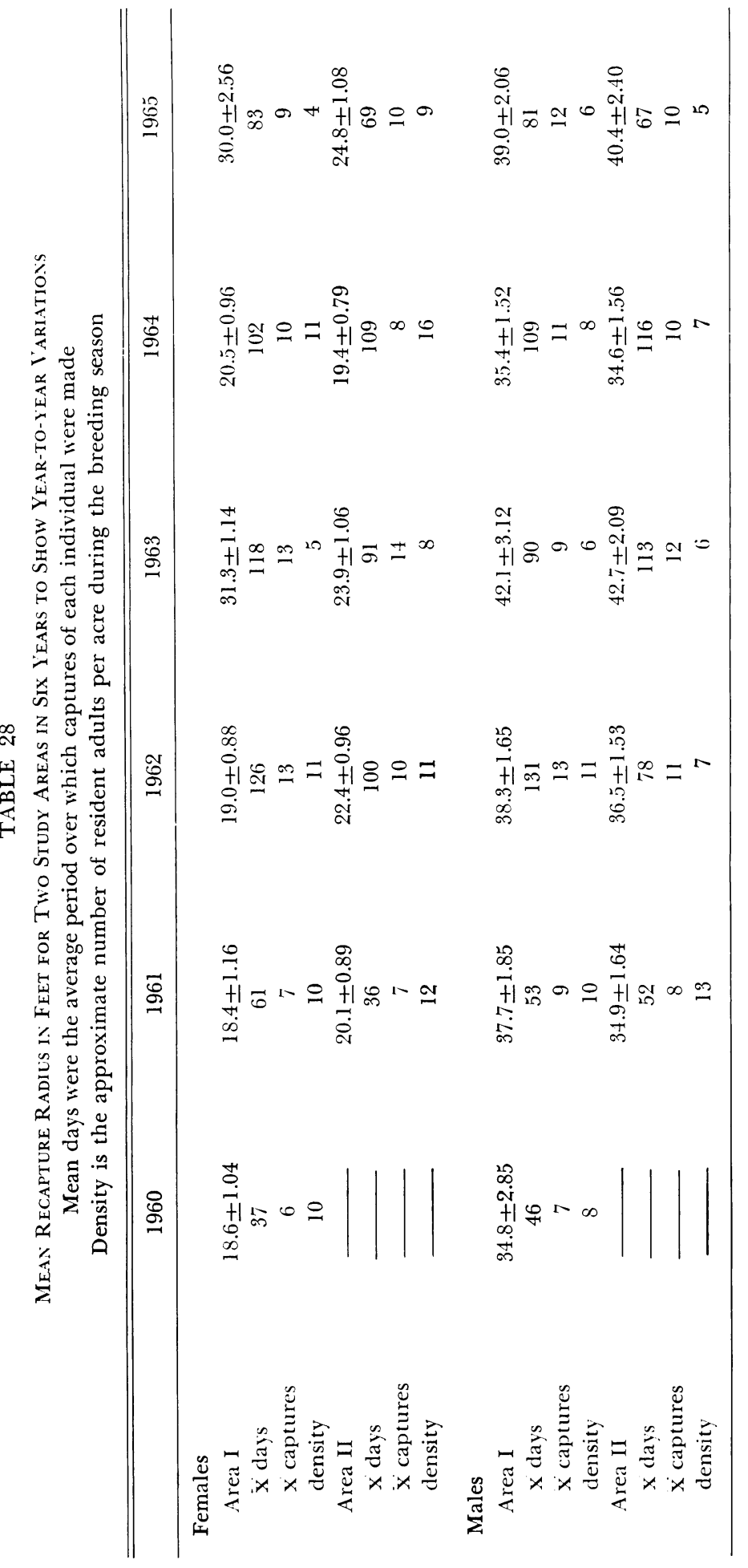


Movements of Utas: Distance Between Captures.-The distance between captures was calculated to determine how close the mean distance between captures was to the mean recapture radius and to determine whether, in the case of juveniles, it provided another useful means of comparing relative movements of lizards of different size.

The lizards were initially divided into 16 size classes, but in many instances data were insufficient to compare different years and areas. In addition, major differences were seldom observed, so the clata for all years have been lumped to compare different size groups and the data for all size groups have been lumped to compare different years.

The comparison of distance between captures for different size groups is shown in Table 29. There are only minor differences between the two

TABLE 29

Distance: Britwern Ciaptures for Utas of Different Size The figures are mean distances in feet. Number of records in parentheses

\begin{tabular}{|c|c|c|c|}
\hline & & Males & Females \\
\hline \multirow[t]{4}{*}{ Areal 1} & $2(0-29$ & $15.2(167)$ & $12.6(249)$ \\
\hline & 3()$-39$ & $23.8(103)$ & $26.2(86)$ \\
\hline & $40-49$ & $39.8(\quad 33)$ & $23.5(23)$ \\
\hline & Adults & $51.1(85.1)$ & $27.4(816)$ \\
\hline \multirow[t]{4}{*}{ Area Il } & $20-29$ & $12.9(314)$ & $11.2(390)$ \\
\hline & $30-39$ & $24.3(\quad 82)$ & $21.1(83)$ \\
\hline & $40-49$ & $32.4(25)$ & $19.2(\quad 19)$ \\
\hline & Aclults & $17.9(861)$ & $28.1(1118)$ \\
\hline \multirow[t]{4}{*}{ Totals } & $20-29$ & $13.7(481)$ & $11.7(639)$ \\
\hline & $30-39$ & $24.0(185)$ & $23.7(169)$ \\
\hline & $40-49$ & $36.6(58)$ & $21.6(42)$ \\
\hline & Aclults & $49.5(1715)$ & $27.8(1934)$ \\
\hline
\end{tabular}

study areas. The mean clistance between captures is about the same for males and females until sexual maturity is reached after which males move about twice as far as clo females. For both sexes, but particularly for males, the mean distance between captures is larger than the mean recapture radius, which was 20.4 and 37.4 feet for females and males, respectively. These data are consistent with those to be presented on movement away from the hatching site in indicating a gradual increase in movements as the lizard matures.

Table 30 compares the mean distance between captures in different years, when strong clata were available. Little information on relative movements of juveniles is available after 1963. There are some obvious differences 
TABLE 30

Mean Distance Between (aptures on two Study Areas Over a Threk-lear Plerion)

Figures are mean distances in feet followed by numbers of records in parentheses

\begin{tabular}{|c|c|c|c|c|}
\hline & \multicolumn{2}{|c|}{ Area I } & \multicolumn{2}{|c|}{ Area II } \\
\hline & Males & Females & Males & Females \\
\hline \multicolumn{5}{|l|}{1961} \\
\hline Juveniles & $15.9(159)$ & $15.0(177)$ & $12.3(201)$ & $13.0(269)$ \\
\hline Adults & $45.6(144)$ & $28.0(114)$ & $43.0(144)$ & $27.7(195)$ \\
\hline \multicolumn{5}{|l|}{1962} \\
\hline Juveniles & $21.5(130)$ & $18.7(181)$ & $17.4(190)$ & $14.9(183)$ \\
\hline Adults & $49.9(259)$ & $23.3(214)$ & $47.6(202)$ & $23.8(252)$ \\
\hline \multicolumn{5}{|l|}{1963} \\
\hline Juveniles & $24.5(75)$ & $19.2(90)$ & $20.8(114)$ & $14.8(116)$ \\
\hline Adults & $61.3(89)$ & $35.0(149)$ & $63.0(184)$ & $32.2(261)$ \\
\hline \multicolumn{5}{|l|}{196.1} \\
\hline Adults & $45.6(213)$ & $25.0(263)$ & $14.3(183)$ & $23.5(210)$ \\
\hline \multicolumn{5}{|l|}{1965} \\
\hline Adults & $60.1(149)$ & $31.7(76)$ & $38.9(148)$ & $33.8(191)$ \\
\hline
\end{tabular}

between years that require consideration. The data show an increase in the mean clistance between captures over the three-year period. For males, the increase was slightly greater from 1961-1962 than from 1962-1963. The figures in Table 31 show a steady decrease in very young males $(20-29 \mathrm{~mm}$ ) on both study areas. Inasmuch as this group has the smallest average movement one would expect a decrease in the mean clistance between captures when the majority of captures were on animals of this class. In females on area I the mean distance between captures was greater in 1962 than in 1961, but the means of 1962 and 1963 were not greatly different. The figures in Table 31 show, correspondingly, that in 196173 per cent of the captures were of 20-29 mm lizards as opposed to only 53 per cent in 1962. The proportion of this size class represented among the captures was about the same in 1962 and 1963. The data for females on area II cannot be accounted for so simply. The mean distance between captures for the three years was not greatly different nor were the proportions of 20-29-mm young for 1961-62. However, in 1963 a significantly smaller proportion of the captures were made on 20-29-mm animals; yet, this fact was not registered by a significant change in the mean distance between captures.

Another factor known to influence movements of lizards is population density. Both sexes showed an increase in mean distance between captures 
TABLE 31

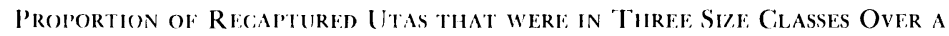

THREE-Y'iAR P'ERIOD ON TWO STUDY AREAS

All figures are percentages of total juveniles recorded each year

\begin{tabular}{|c|c|c|c|c|c|c|}
\hline & & Males & & & emales & \\
\hline & $20-29 \mathrm{~mm}$ & $30-39$ & $40-49$ & $20-29$ & $30-39$ & $40-49$ \\
\hline 1961 & & & & & & \\
\hline Area I & 71 & 20 & 6 & 73 & 23 & 4 \\
\hline Arca II & 84 & 12 & 4 & 75 & 19 & 6 \\
\hline 1962 & & & & & & \\
\hline Area I & 48 & 50 & 2 & 53 & 34 & 13 \\
\hline Area II & 71 & 24 & 2 & 78 & 19 & 3 \\
\hline 1963 & & & & & & \\
\hline Area $I$ & 29 & 67 & 4 & 56 & 42 & 2 \\
\hline Area II & 43 & 5.1 & 3 & 6.5 & 35 & 0 \\
\hline
\end{tabular}

from 1961 to 1962 , but on area I more certainly than on Area II. The clensity of juveniles on the two areas was about the same in 1961, but considerably greater on area II in 1962. The density on both areas in 1963 was higher than the previous year and yet the lizards show an increase in the mean distance between captures on both areas.

Density and size of individuals are probably not responsible for all of the differences observed, but these two factors will account for most of them. It is at least clear that the distance beween captures is useful for demonstrating the gradual increase in distances moved by utas as they mature.

The data for adults are also shown in Tables 29 and 30, and are not complicated by considerations of size because all of the data are from sexually mature animals, so all individuals are within a few millimeters of one another in length. The data for adults seem readily explicable in terms of density because the major increases in the mean distance between captures occurred in 1963 and 1965, when the density of adults declined significantly on both study areas. The differences, as anticipated, were more striking in males than in females, and the reasons for this have been discussed in cletail in previous sections.

Discussion of Litrerature: on Home Range and Movements.- It is a surprising fact that there is still almost no satisfactory data on home ranges of lizards. It is difficult to compare that which is available because of differences in the techniques used. The home-range size by minimum polygon technique has been determined for the species listed below: 
Sceloporus olivaceus (Blair, 1960): .017 and .027 acre in juvenal females and males, respectively; .07 and .17 in adult females and males.

Uta stansburiana (Jorgenson and Tamner, 1963): .10, .03, .04 acre in adult males, adult females, and juveniles, respectively.

Basiliscus vittatus (Hirth, 1963): .03 acre in adult males and females; .04 and .06 acre in juvenal females and males, respectively.

Ameiva quadrilineata (Hirth, 1963): .11 and .05 acre in adult males and females, respectively; .07 and .06 acre in juvenal males and females.

Cnemidophoîls tigris (Jorgenson and Tanner, 1963): .50, .24, and .09 acre in adult males, females, and juveniles, respectively.

To my knowledge these are the only studies in which home-range size has been determined from fairly large numbers of captures. Several other records, such as those for Holbrookia maculata, Sceloporus undulatus, Cnemidophorus gularis, and C. tigris, based upon one or a few individuals (Milstead, 1959, 1961), fall within the range of variation of home range size based on the five species listed above.

The data on Ameiza and Basiliscus, which indicate larger home ranges for juveniles than for adults, bear further discussion. This relationship between home-range size of adult and juvenile has also been reported by other authors. I think in all such cases that what is called the home range of juveniles is probably a composite of areas occupied by a young animal as it disperses, and is not comparable with the home range of an established adult.

The size of the home range is almost certainly associated with density, the presence or absence of territorial behavior, and the productivity of the habitat, as well as with the technique used to measure it. Ordinarily all of these variables are not investigated in a single study; so little can be gained by further consideration of the data available on home-range size in different species.

Calculation of home-range size has not been the most common means used to measure the movements of lizards in natural populations. The average distance between captures or the average maximum distance between captures has been employed more commonly. The data on lizard movements using these techniques are shown in Table 32. Again, in inspecting and comparing these data, we are faced with the problem of comparing measurements based upon vastly different numbers of individuals, major differences in average number of recaptures, and in time intervals between captures. Until it can be demonstrated that the mean distance between captures is not seriously affected by the variables above, in addition to 
TABLE 32

Distance Between Captures for Several, Species of Lizards Reported in the Literature

\begin{tabular}{|c|c|c|c|}
\hline Species & $\begin{array}{l}\text { Nean distance } \\
\text { between captures }\end{array}$ & $\begin{array}{l}\text { Mean maximum } \\
\text { distance be- } \\
\text { tween captures }\end{array}$ & Authority \\
\hline Sceloforus undulatus & & $\begin{array}{l}\text { \& \& } 126 \mathrm{fect} \\
\text { 웅 } 76 \mathrm{fect} \\
\text { juv. } 25 \mathrm{fect}\end{array}$ & Carpenter $(1959 a)$ \\
\hline Sceloporus occidentalis & & $\begin{array}{l}130 \text { feet ol } \\
\text { less; along } \\
\text { fence row }\end{array}$ & Fitch (1940) \\
\hline Sceloporus graciosus & & $\begin{array}{l}\text { 숭 ㅇ } 82 \mathrm{fect} \\
\text { 오 오 } 59 \mathrm{fect}\end{array}$ & Stebbins (1944) \\
\hline Phryosoma solare & 70 feet & & Lowe (1954) \\
\hline Eumeres fasciatus & $\begin{array}{l}\delta \& 47-91 \text { feet } \\
\text { of 우 16-28 feet } \\
\text { jux. 15-82 feet }\end{array}$ & $\begin{array}{l}\hat{\delta} \text { fs } 69 \mathrm{fect} \\
\text { 오 } 15 \mathrm{fect} \\
\text { juv. } 61 \text { fect }\end{array}$ & Fitch (1954) \\
\hline liumeces obsoletus & & $\begin{array}{l}\text { of } \delta 90 \mathrm{fect} \\
\text { 우 우 } 5.5 \mathrm{fect} \\
\text { juv. } 47 \mathrm{fect}\end{array}$ & Fitch $(1955)$ \\
\hline Iciolopisma zelandica & & $5-10$ fect & Barwick (1959) \\
\hline $\begin{array}{l}\text { Cmemidophorns sex- } \\
\text { limeatus }\end{array}$ & $\begin{array}{l}40-50 \text { feet, } \\
\text { both sexes }\end{array}$ & & Bcllis (1964) \\
\hline $\begin{array}{l}\text { Cincmidophorus sex- } \\
\text { line'alus }\end{array}$ & $\begin{array}{l}\delta \text { \& } 125 \text { feet } \\
\text { of } \text { o } 171 \text { feet }\end{array}$ & & Fitch (1958) \\
\hline
\end{tabular}

density, linearity of the habitat, and technique used, I must conclude that such information may be of little value.

Movement from the Hatching Site.-The point at which any lizard less than $23 \mathrm{~mm}$ was initially captured has been designated the hatching site. Gencrally this point of capture is beneath a yucca or other vegetation or in and around packrat nests and mesquite thickets.

The movement of young lizards away from the hatching site as they grow larger best expresses the increasing utilization and familiarity with larger areas, the progressive enlargement of home-range boundaries.

Initially the clata were analyzed separately for clifferent years and for the two study areas, but either there were no clifferences or the data were too weak in some instances for useful comparisons. These data for different seasons and size classes are shown in Table 33. Data that overlapped seasons or size classes were eliminated; even so, the data are fairly strong at least for the early ontogeny and for maturity. 


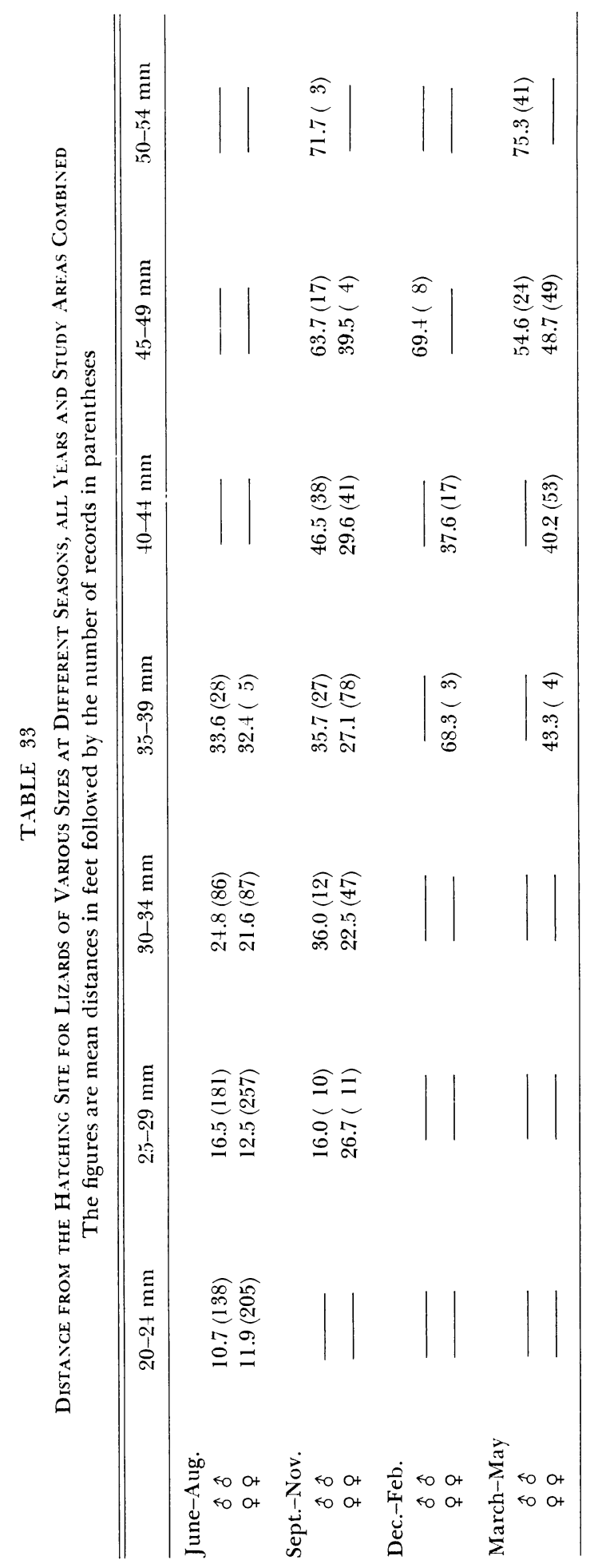


The movement by very young lizards $(20-29 \mathrm{~mm})$ is extremely low, averaging 10-12 feet in both sexes. On this basis, it seems very unlikely that appreciable immigration into the study areas occurs by animals of hatchling size, a fact that has considerable significance for the measurement of natality. By the time that they are about one-half grown, individuals of both sexes have dispersed to an average distance of 25 feet from their hatching site. At sexual maturity, lemales are located at an average distance of fifty feet from their hatching site, males at 60 to 70 feet. These figures represent just about two mean recapture radii or the approximate computed diameter of an average adult's home range.

These data inclicate that young lizards establish home ranges by continual probing into unfamiliar areas and gradual incorporation of such areas into their home ranges, a process that continues until their homerange boundaries are too large to defend successfully. Home-range establishment is not always so simple a process because some of the utas establish home ranges as adults that do not even include the area they occupied as juveniles.

Harris (1964) made the interesting observation that all hatchling males of Agama agama leave the areas they occupied as juveniles, but young females may remain and even eventually mate with the dominant resident male in the same area. The only other clata on movements from the hatching site by lizards are those of Blair (1960) who reported that females were an average of 160 leet, males 234 feet, away from their hatching site by the time of sexual maturity. That the degree of dispersal of young lizards may be strongly influenced by the age structure of populations will be discussed in the section on comparative demography.

Distance from the Hatching Site to the Adult Home Range.-There are records available for 50 utas $(22$ \& o ; 28 q $q)$ that were marked at hatching and later became residents of the study areas, and were recaptured a sufficient number of times to determine the geometric centers of their adult home ranges cluring the breeding season. This distance (hatching site to geometric center) varied from 8 to 252 feet in males (mean 84) and from 14 to 176 feet in females (mean 53).

The significance of these figures may not be readily apparent, but I think they might be used to estimate the mean distance of potential gene flow per generation. This idea is based upon the assumption that a lizard is hatched within the home range of its parents and that the geometric center of its adult home range represents the average point at which its mating activities have been concentrated as an adult. Other figures might be used for calculating the mean distance of gene flow per generation, such as 


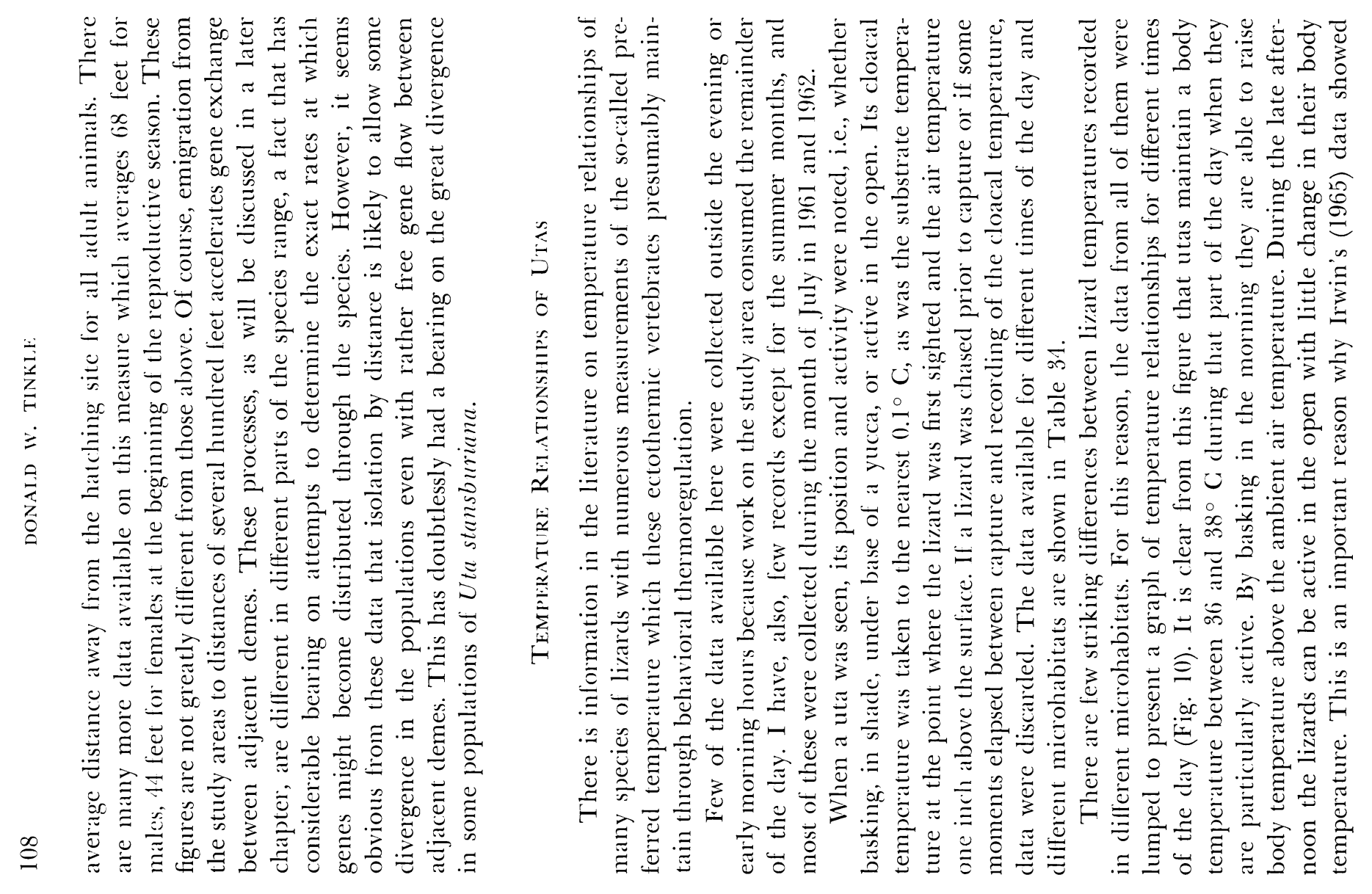




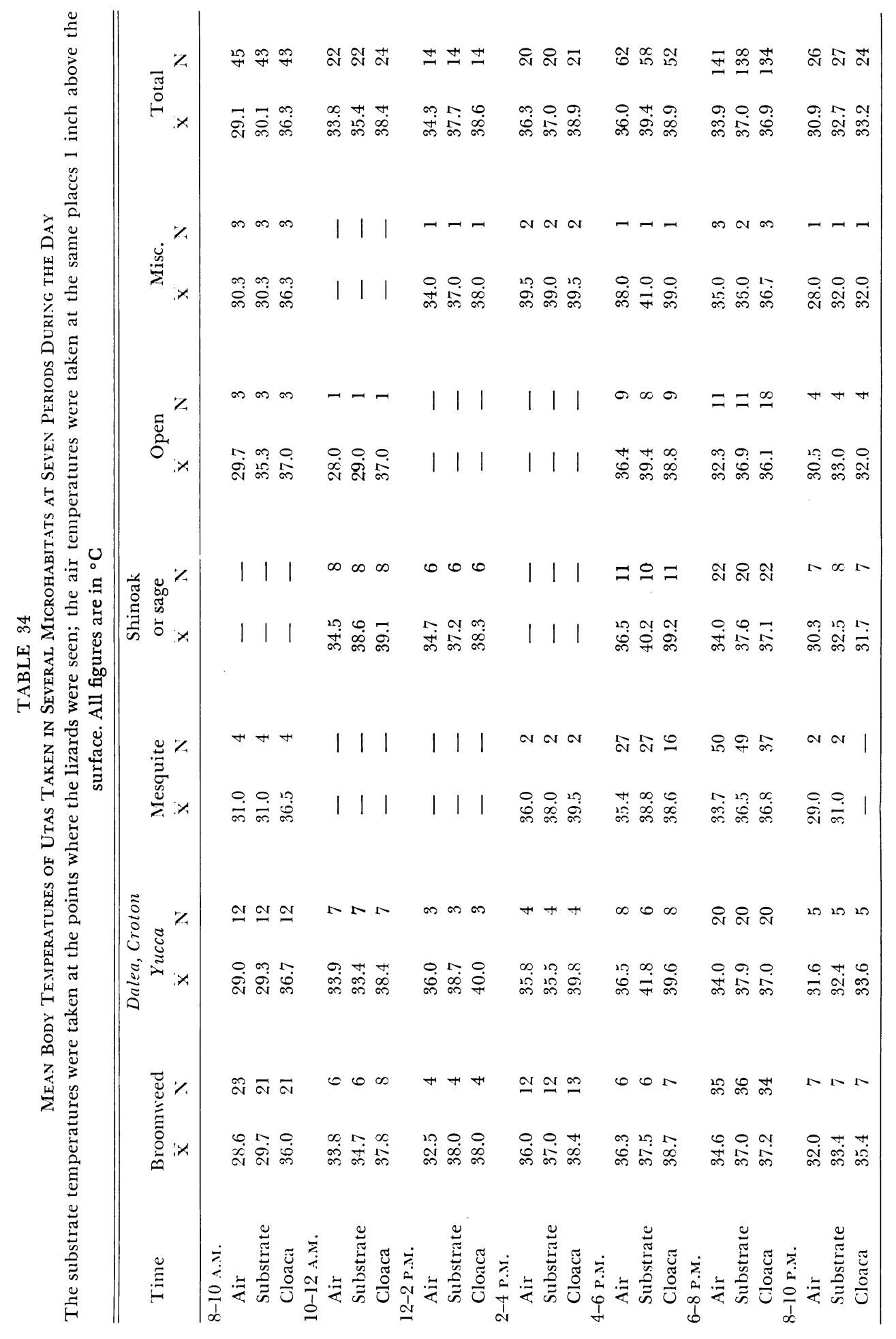


quantitatively that the peak activity period of utas was between 5:30 and 7:30 P.M., for this is the time of the day when the substrate temperature closely approximated the preferred body temperature of the lizard. The angle of incidence of the sun's rays is such that overheating through excessive insolation is not a serious problem in late afternoon.

In Figure 10 it appears that substrate temperatures from 1:00 to 3:00 P.M. are lower than at 5:00 P.M. This, of course, is not the case. All substrate temperatures were taken where the lizard was seen; at midday these would be primarily in the shade beneath yuccas or other plants where substrate temperatures are frequently $20^{\circ} \mathrm{C}$ below those of the open sand. The data of Figure 10 make it clear that utas in the afternoon are choosing sites with thermal gradients near their preferred temperature. My own data and the figure of Irwin (1965, p. 100) show that surface temperatures of the sand exceeded $50^{\circ} \mathrm{C}$ during most of the clay, so substrate temperatures recorded during the hotter periods of the day should be lower than those recorded later for the choice of the lizards dictated where our substrate temperatures were taken.

Lizards burrow into the sand in late evening and their body temperature will be essentially that of the substrate throughout the night.

Summer rains have a profound effect on lizard temperatures and their activity. After heavy rains on June 14-16, 1961, temperatures were taken of 14 active lizards between the hours of 2:00 and 4:00 P.M. The mean air temperature was $21.6^{\circ} \mathrm{C}$, substrate 22.7 , and body temperature 28.7 . All of these figures are 10 clegrees or more below the average at this season. On such days the lizards are active all day. Juveniles, particularly, may be seen foraging in the open near sheltering vegetation. Record numbers of total captures in a single day during the years of this study were established on the unseasonably cool days following thunderstorm activity.

I think it unfortunate that I failed to obtain clata on lizard temperatures during the winter, for this is presumably the period when the greatest differences occur between body and substrate or air temperatures. Lizards have been observed to be active in every month of the year and at air temperatures as low as $4^{\circ} \mathrm{C}$. However, there is generally little activity at air temperatures below $10^{\circ} \mathrm{C}$. At such times the lizards quickly become torpid if they are lifted from the substrate and shaded.

Utas are certainly active in winter at temperatures which are far below the activity temperatures recorded in the summer. This observation suggests possible acclimation in temperature preference, but such an interpretation might be erroneous. McGinnis (1966) found that more than one-half of cloacal temperatures taken of Sceloporus occidentalis during the winter were below the minimum recorded from these lizards in the summer. However, 


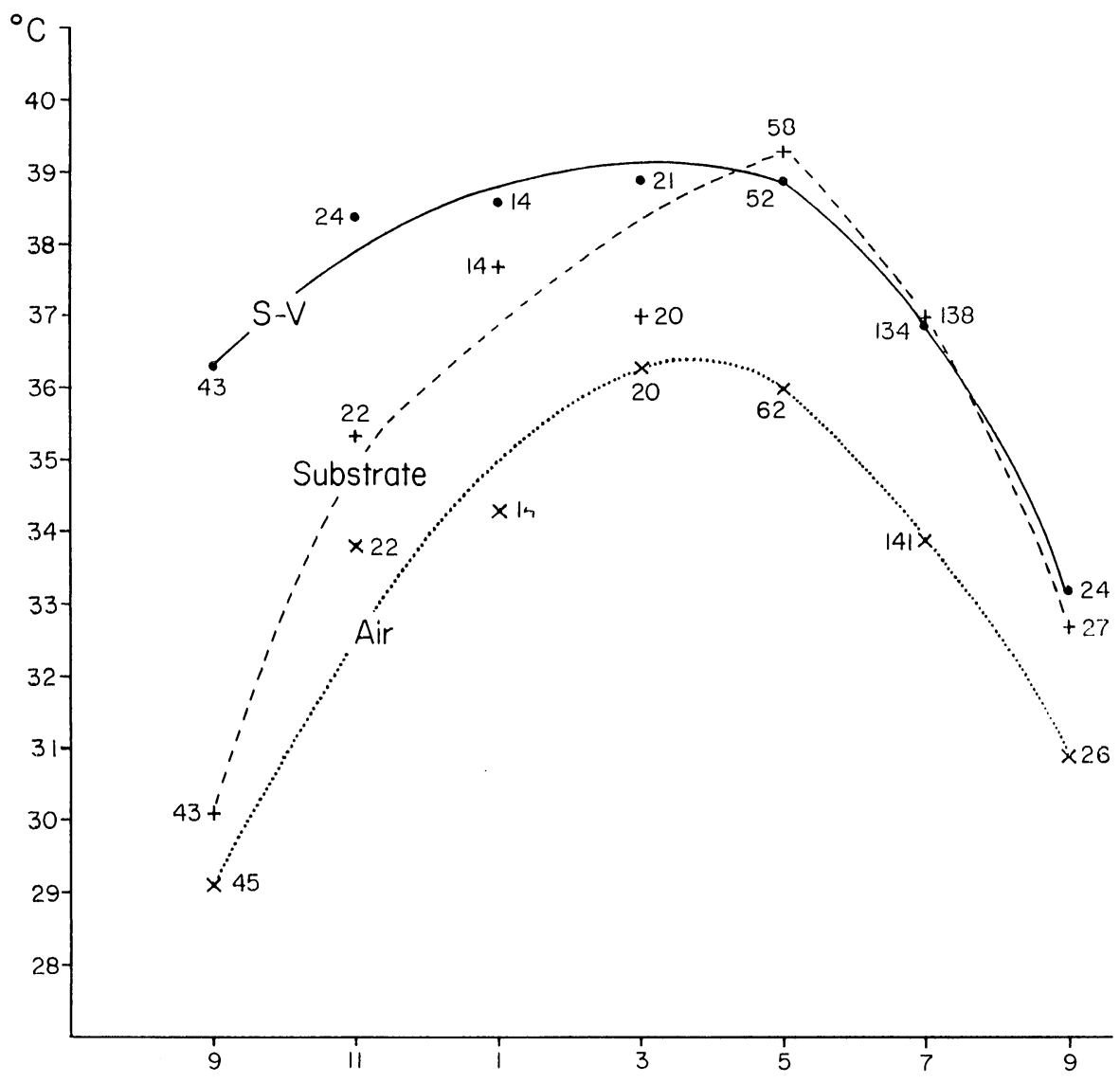

Fig. 10. Mean cloacal temperature (S-V), mean substrate temperature (broken curve), and mean air temperature (dotted curve). Abscissa, time of day from 9:00 A.M. to 9:00 P.M.; ordinate, temperature in ${ }^{\circ} \mathrm{C}$. The points on the curve are means and the numerals are the number of records on which the mean was based. See text for explanation and discussion.

when the lizards were brought to the laboratory in winter and placed in a temperature gradient they still showed a preference for the same temperature as during the summer. Thus, the low winter temperatures evidently indicate that an animal is simply unable to achieve its preferendum rather than a downward shift in the preferred temperature by acclimation.

The literature on behavioral thermoregulation in lizards has been vast since the pioneering studies of Cowles and Bogert (1944). The literature has been reviewed several times (see Schmidt-Nielsen and Dawson, 1964), and leaves little doubt that lizards do maintain a rather narrow range of 
body temperature while they are active. The interesting question remaining is why do these preferred temperatures exist and why are they different in different species. Answers to these questions are being provided through studies which show a correlation of temperature-induced sterility, optimum enzyme activity, and protein denaturation with the preferred body temperature of lizards (Licht, 1964a; 1964b; 1965).

The Critical Thrrmal. Maximum of Utas.-Some experiments were conducted in the field to determine how closely a lizard in nature was approaching the critical thermal maximum in its claily activities. The GTM was defined as the temperature at which coordinated locomotion became impossible so that remaining at this temperature would lead to death of the individual. Such experiments were suggested by observation of two adult utas which, when chased across open sand for about one minute, died of apparent heat prostration. Similar experiences, particularly with juveniles, have occurred several times since these experiments were carried out.

The lizards were tied, with a thread attached to one leg, to a stake driven in open sand. The lizard was released onto the sand after weight, length, cloacal temperature, air temperature and sand temperature were recorded. The lizard was allowed to remain on the sand until it became ataxic, at which time a stopwatch reading was taken of the elapsed time from initial release, and the cloacal temperature recorded as the CTM for that individual. The time at which the lizards began to pant was also recorded. Three experiments were conducted on June 25, 1962, on August 3, 1962, and on July 20, 1964. All were conducted at sand temperatures of $55^{\circ} \mathrm{C}$ or higher. The last experiment involved only juvenal lizards while the first two included only adults (Table 35).

There are no significant differences between the mean CTM's recorded for juveniles, adult males, or females. The time required to reach CTM is shorter in juveniles than in adults, but among adults body size is not correlated with the time required to reach the CTM.

The highest temperature recorded from unrestrained lizards in the field was $41^{\circ} \mathrm{C}$, but temperatures above $39^{\circ} \mathrm{C}$ were unusual. Thus, the highest temperature recorded for any adult lizard was below the minimum CTM recorded for any adult. On the average there is a margin of about $5^{\circ} \mathrm{C}$ between the mean activity temperature and the average CTM.

Less than one minute on the hot sand on a clear day was required to raise body temperature to a critical point; the near cessation of movements during those hours when solar radiation is most intense is understandable in view of these figures. However, there is no indication that heat death plays any significant role in the mortality of these lizards. On the other 
TABLE 35

Data Pertinent to the Critical Thermal Maximum (CTM) of Uta stansburiana from 3 Experiments Conducted in the Field See text for additional discussion of experimental procedure. All temperatures are ${ }^{\circ} \mathrm{C}$

\begin{tabular}{|c|c|c|c|c|c|c|}
\hline & $\begin{array}{l}\text { Air } \\
\text { temp. }\end{array}$ & $\begin{array}{c}\text { Cloacal } \\
\text { temp. at start }\end{array}$ & $\begin{array}{l}\text { Cloacal temp. } \\
\text { at end (CTM) }\end{array}$ & $\begin{array}{c}\text { Time to } \\
\text { CTM (secs.) }\end{array}$ & $\begin{array}{l}\text { Weight } \\
\text { (gms) }\end{array}$ & $\begin{array}{l}\text { Per cent surviving } \\
\text { experiment }\end{array}$ \\
\hline \multicolumn{7}{|l|}{ Expt. 1} \\
\hline 12 ô $\hat{\sigma}$ & $35.8-36.8$ & $35.6-39.4$ & $43.0-45.8$ & $50-84$ & 4.43 & 17 \\
\hline 18 우우 & all 36.8 & $36.8-38.2$ & $42.4-45.8$ & 53-93 & 3.24 & 60 \\
\hline \multicolumn{7}{|l|}{ Expt. 2} \\
\hline 18 ô & . $\quad 40-42$ & $37.0-39.6$ & $41.2-45.0$ & $29-58$ & 4.60 & 50 \\
\hline 14 우우 & $\quad 40-42$ & $36.0-40.2$ & $42.0-46.2$ & $36-80$ & 3.10 & 50 \\
\hline \multicolumn{7}{|l|}{ Expt. 3} \\
\hline 12 ㅇํㅇ & 31 & $33.0-34.2$ & $38.4-42.8$ & $15-72$ & $\begin{array}{c}22-28 \mathrm{~mm} \\
\text { (not weighed) }\end{array}$ & 58 \\
\hline 13 우 우 & 31 & $33.6-33.8$ & $38.0-43.6$ & $20-65$ & $22-28 \mathrm{~mm}$ & 62 \\
\hline \multicolumn{7}{|l|}{ Totals } \\
\hline 42 ồ & & 37.2 & 42.7 & 46.8 & $\begin{array}{c}4.53 \\
\text { (adults only) }\end{array}$ & 43 \\
\hline
\end{tabular}

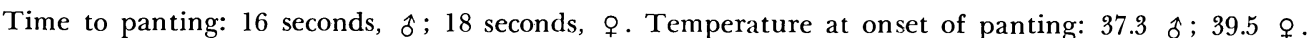


hand constant exposure to very high temperatures through the summer in this area may be somewhat debilitating and partially responsible for their short life expectancy.

Even at high air temperatures utas will be active all day if a cloud cover exists. Irwin (1965) noted that in 33 hours of observation on overcast days between 1:00 and 5:00 P.M., males moved an average of 127 feet per hour compared with only 48 under sunny skies at the same time of the day. A few of the utas used in the CTM experiments were staked on the sand when an occasional small cloud passed over the sun on an otherwise clear day. Despite no significant change in air or substrate temperature at such times, the reduction in radiation was sufficient to lengthen the time required to reach CTM to an average of almost 7 minutes. Obviously the margin of thermal safety is considerably extended in lizards even on partly overcast days.

The Thermal Environment of the Study Areas.-The discussion of thermal relationships of the lizards is incomplete and inadequate without some knowledge of the thermal environment in which they live. To indicate the temperature regimes available to the utas in various microhabitats at different seasons, continuous recordings were made of air or soil temperatures in various parts of the home ranges.

Air temperatures were recorded with 7-day Tempscribes throughout the summer at a height of about 1 meter above the sand surface in the open sun. These recordings show a regular fluctuation in the daily temperature from an average low of $70^{\circ} \mathrm{F}$ at night to a high of $100^{\circ}$ or above during the day. A sample of this record for the period July 6-13 is shown in Figure 11. This week was chosen because it appeared to be intermediate between the hottest and coldest weeks during the summer. As the graph indicates, air temperatures between noon and 5:00 P.M. are somewhat above the preferred temperatures of the utas. It is the extremely high sand temperature and direct insolation at these hours that suppresses lizard activity.

As noted previously, utas rarely retreat underground in summer during the heat of the day, but instead remain on the surface beneath the bases of yuccas or in heavy shade provided by mesquite. Simultaneous recordings of temperatures in the shade at the base of a yucca and 6 inches below the sand surface adjacent to the yucca provide an explanation for this behavior by the utas because the temperatures on the surface below the yucca are lower than those in the sand (Fig. 12). Air temperatures in the shade of a mesquite (off the ground surface) or in the shade of a sage plant (on the ground surface) are considerably lower than air temperatures in an unshaded area (Fig. 13). The high peaks in the graph for the sage represent afternoons when the prevailing winds allowed the recorder to be unshaded by the sage. 


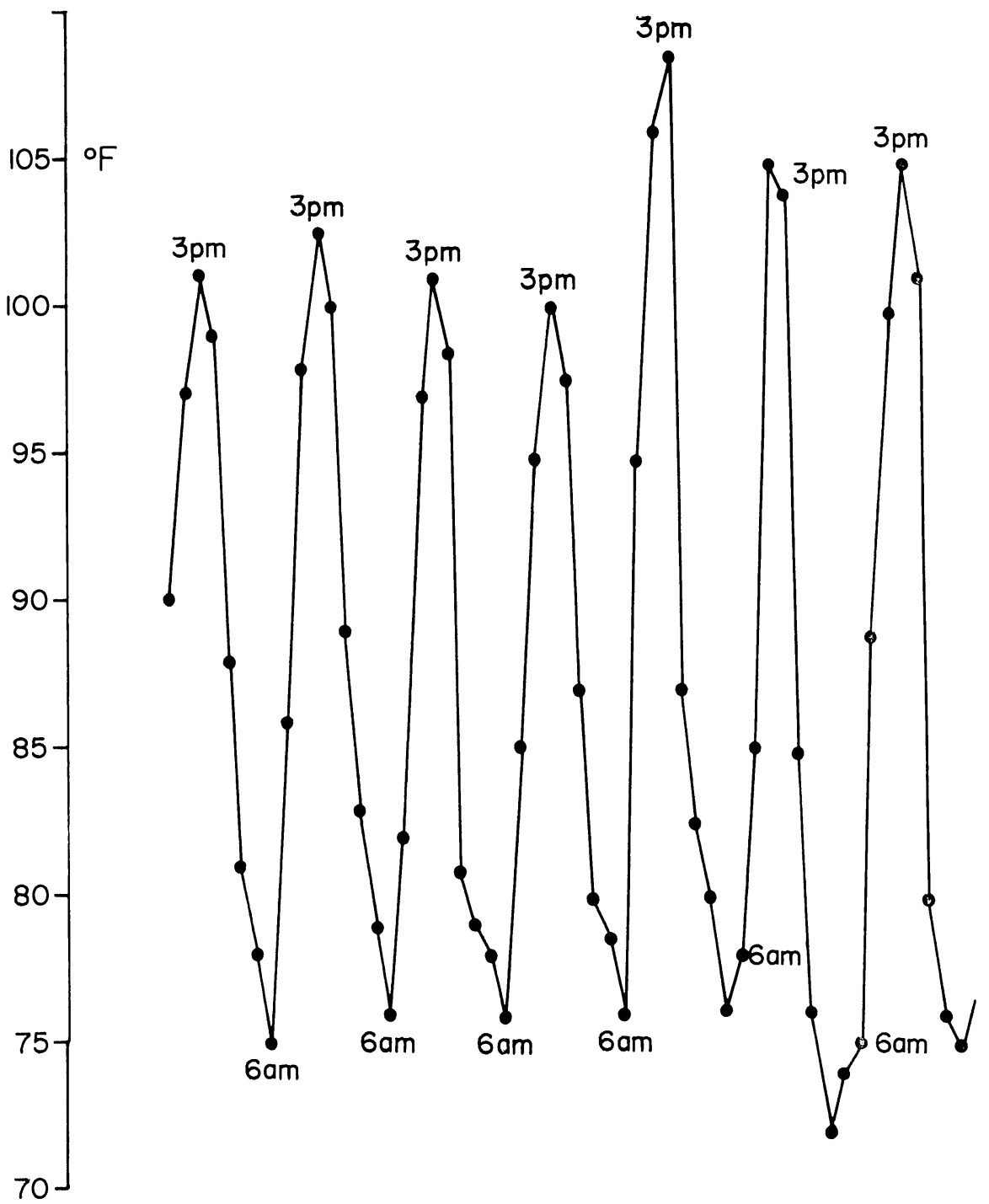

Fig. 11. Air temperatures (F) at 3-hour intervals recorded in an unshaded portion of the Texas study area at a height of 3 feet above the ground, July 6-13, 1962.

Three figures show pertinent data on microclimatic conditions during the winter. Figure 14 indicates that a lizard would receive little protection from cold at night if buried in the same shallow fashion that is characteristic during the summer. On the other hand, good protection is provided by burial to 4 inches. Figure 15 shows that subfreezing temperatures (air) were 


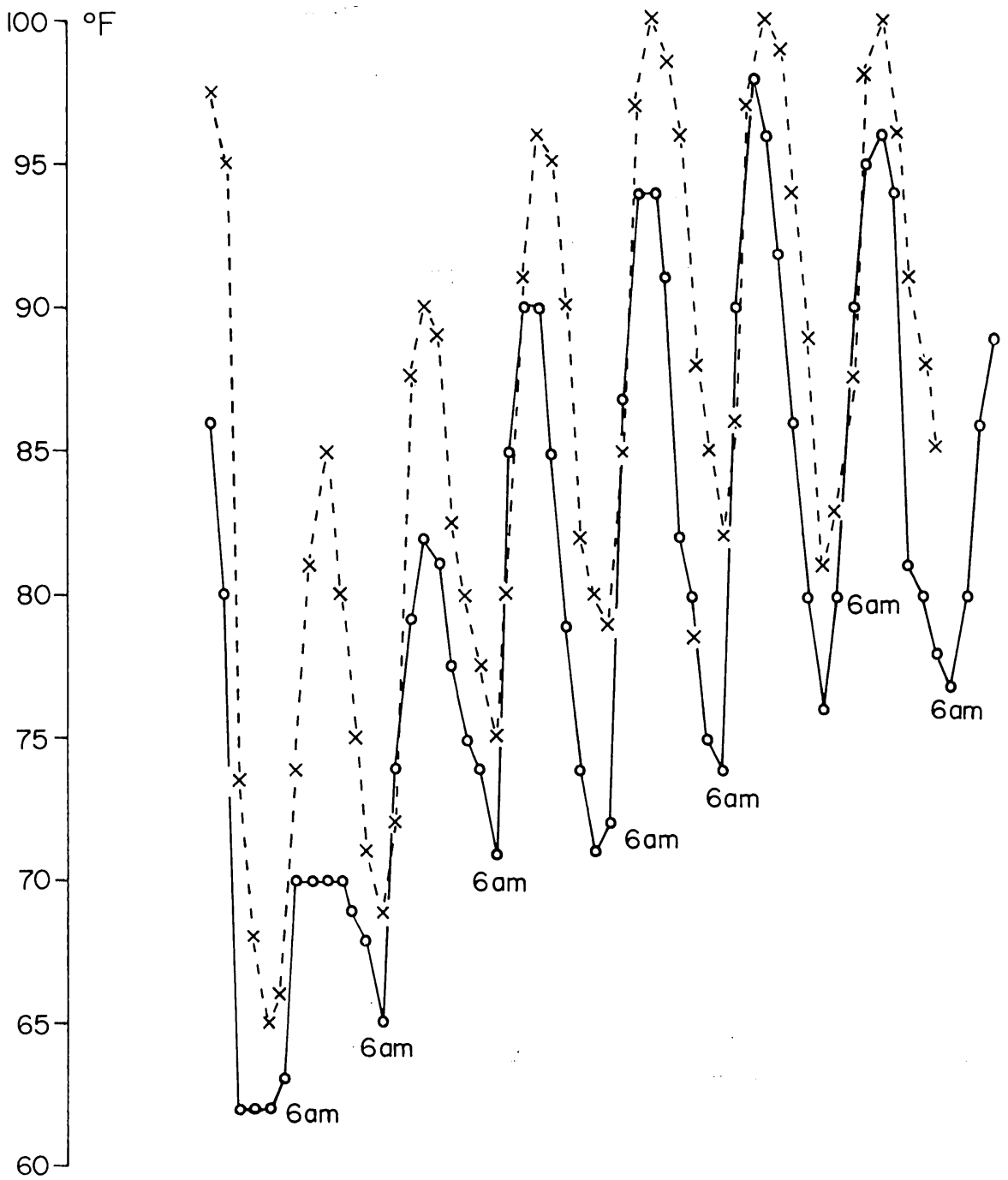

Fic. 12. Comparison of temperatures at surface in shade of yuccas (solid line) with those 6 inches beneath the surface of sand adjacent to the yucca (broken line), June 2-9, 1962. Early part of record made during a period of overcast skies. Dots on the record are placed at 3-hour intervals.

recorded every night, but the sand temperature never fell below $36^{\circ} \mathrm{F}$. This depth ( 4 inches) is about that from which most lizards have been collected during the winter from the sites of their periodic quiescence. Figure 16, finally, shows that despite the concentration of lizards around packrat nests 

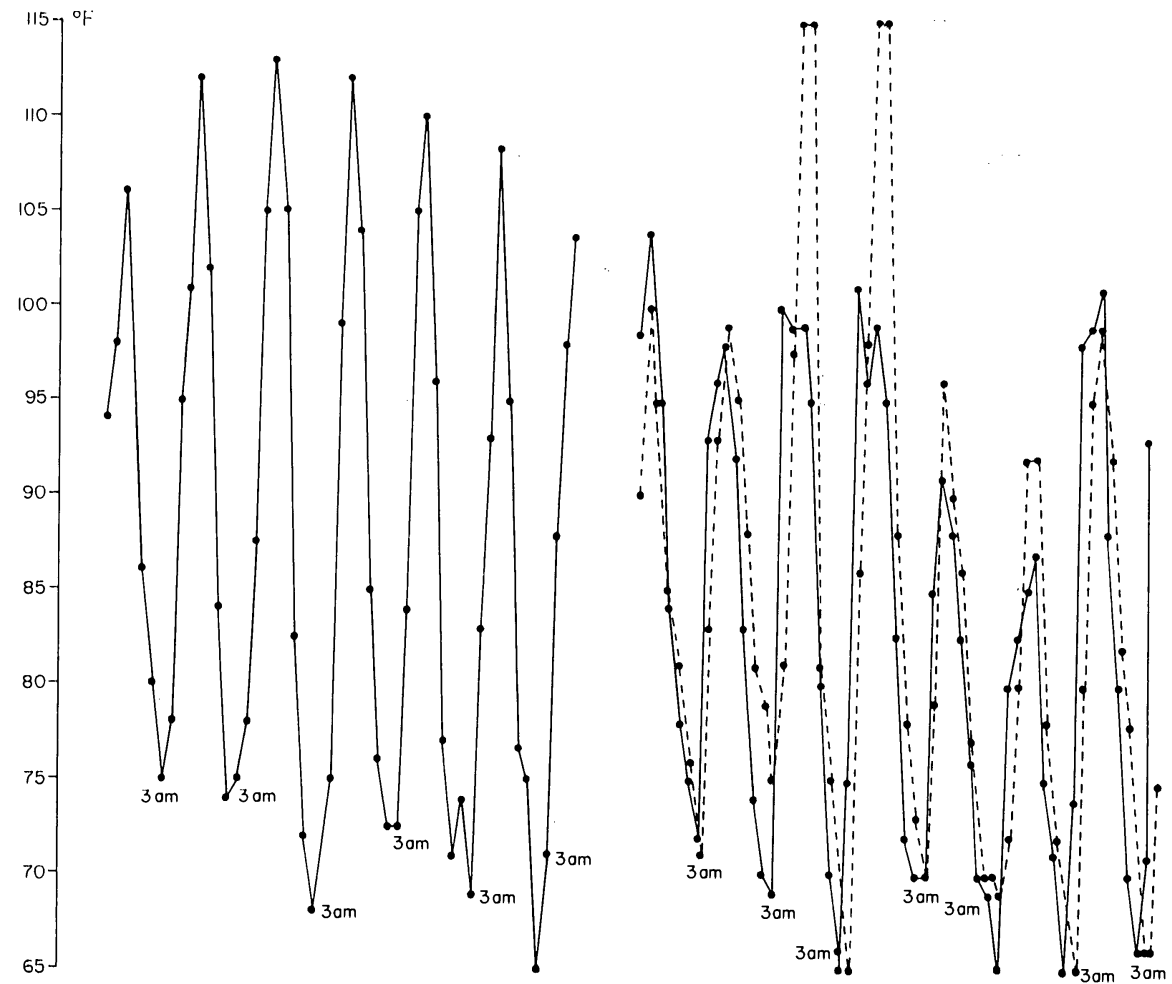

Fis. 13. Comparison of air temperature in sun (left, solid) with that at same height (3 feet) in shade of a mesquite thicket (solid, right) and on the surface beneath a large sage plant (right, broken), July 5-12, 1962. Dots on the record are at 3-hour intervals.

in the winter it is probably not the nest itself that provides shelter from the cold but rather the loose sand around the nest into which the utas burrow.

All of the figures show that favorable temperature regimes can be found in the habitat; this, of course, is obvious. The data also show why certain plants or certain sites or certain depths of burial are preferred by the utas.

The Demographic Properties of Uta Populations

NAtality.-The birth rate of utas was difficult to determine in unconfined areas. All young lizards marked during each reproductive season were counted as products of the adults of that generation to obtain a maximum estimate of natality. A more conservative figure was obtained by considering the juveniles marked during June to September as young of the year. Some 


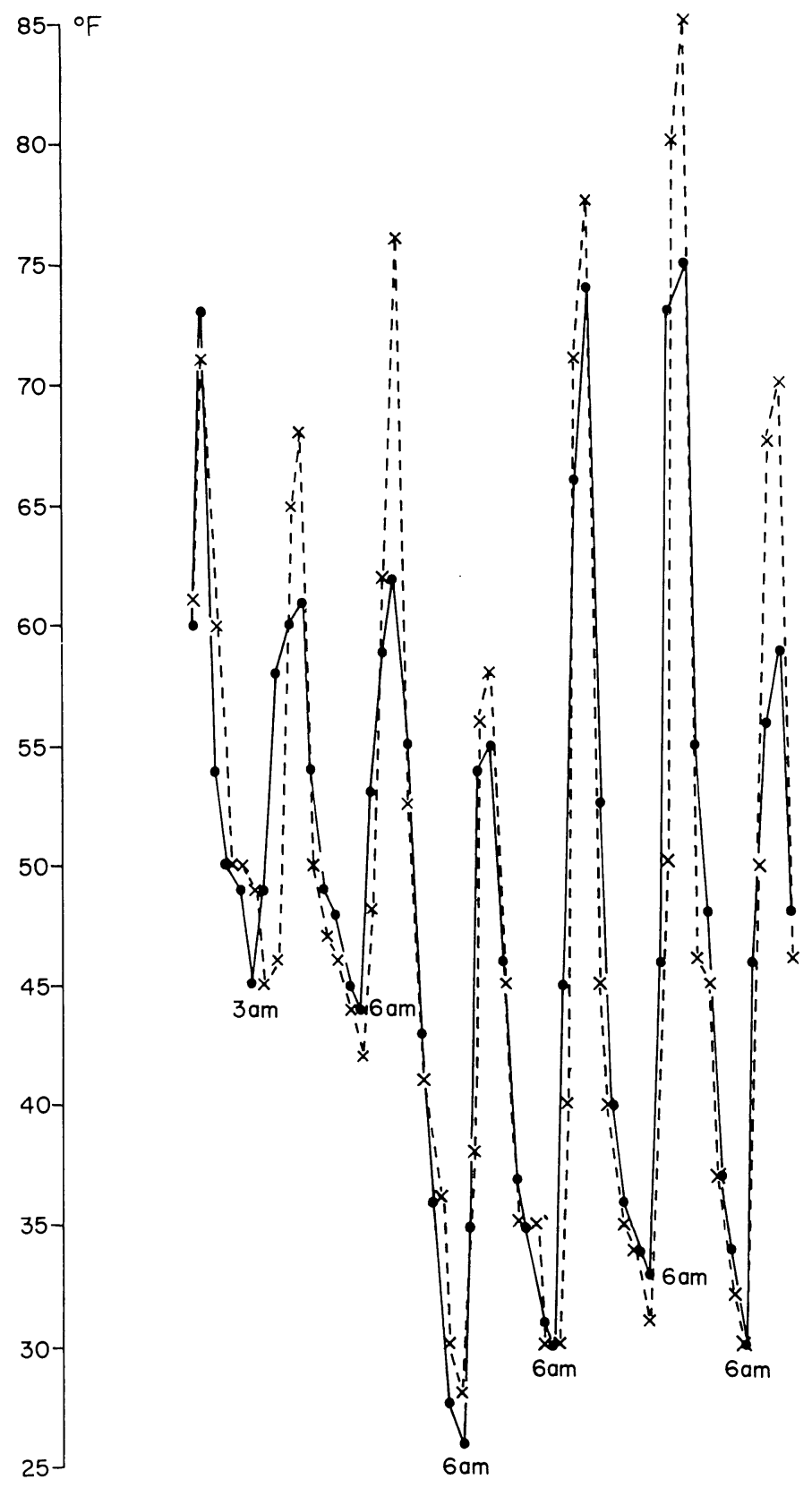

Fig. 14. Comparison of air temperature (solid line) with temperature 1 inch below the surface (broken line), December 16-22, 1961. Dots on the record are at 3-hour intervals. 


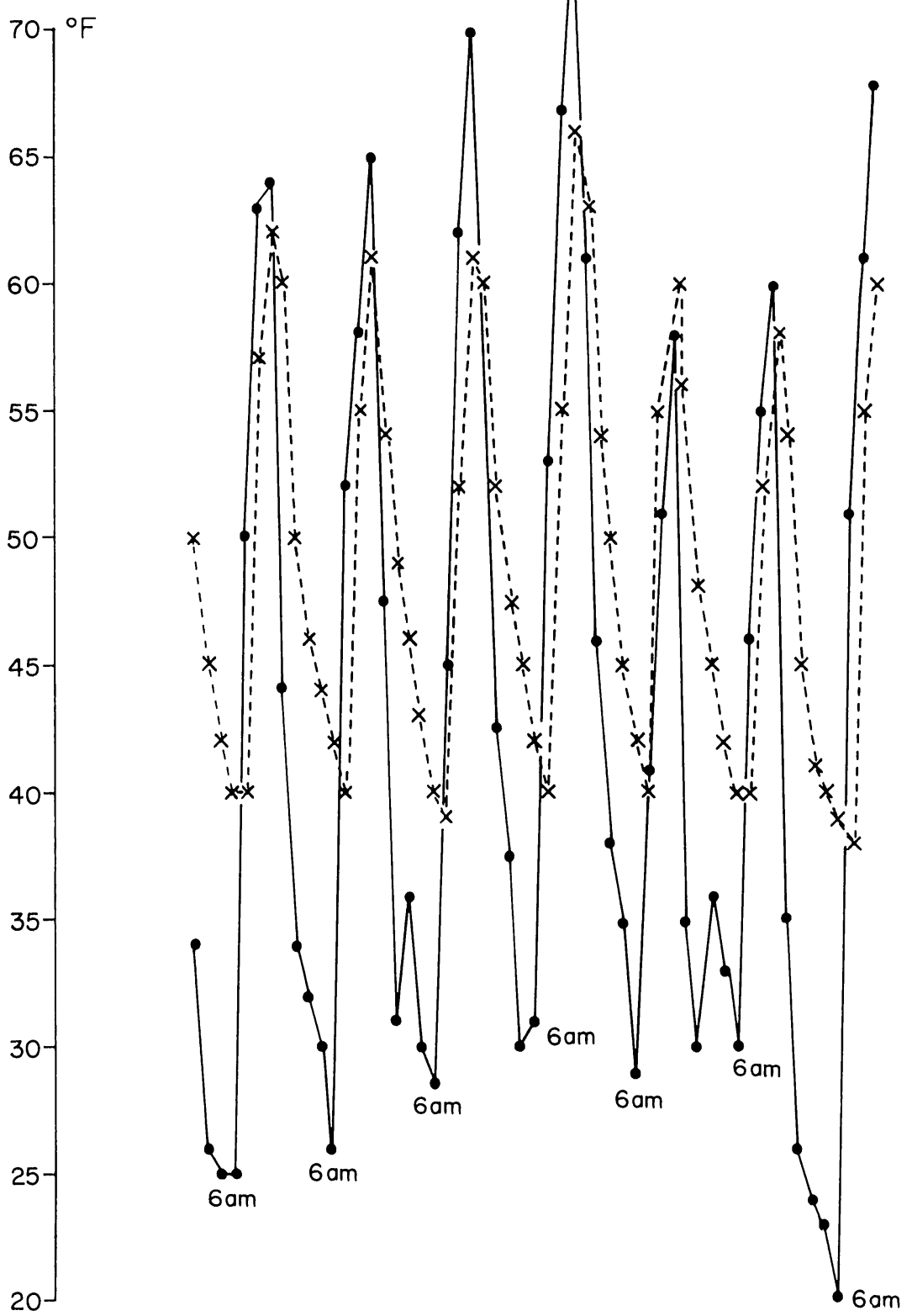

FIG. 15. Comparison of air temperature (solid line) above ground with that in an artificial burrow 4 inches below the sand surface (broken line), December 22-29, 1961. Dots on the record are at 3-hour intervals. 


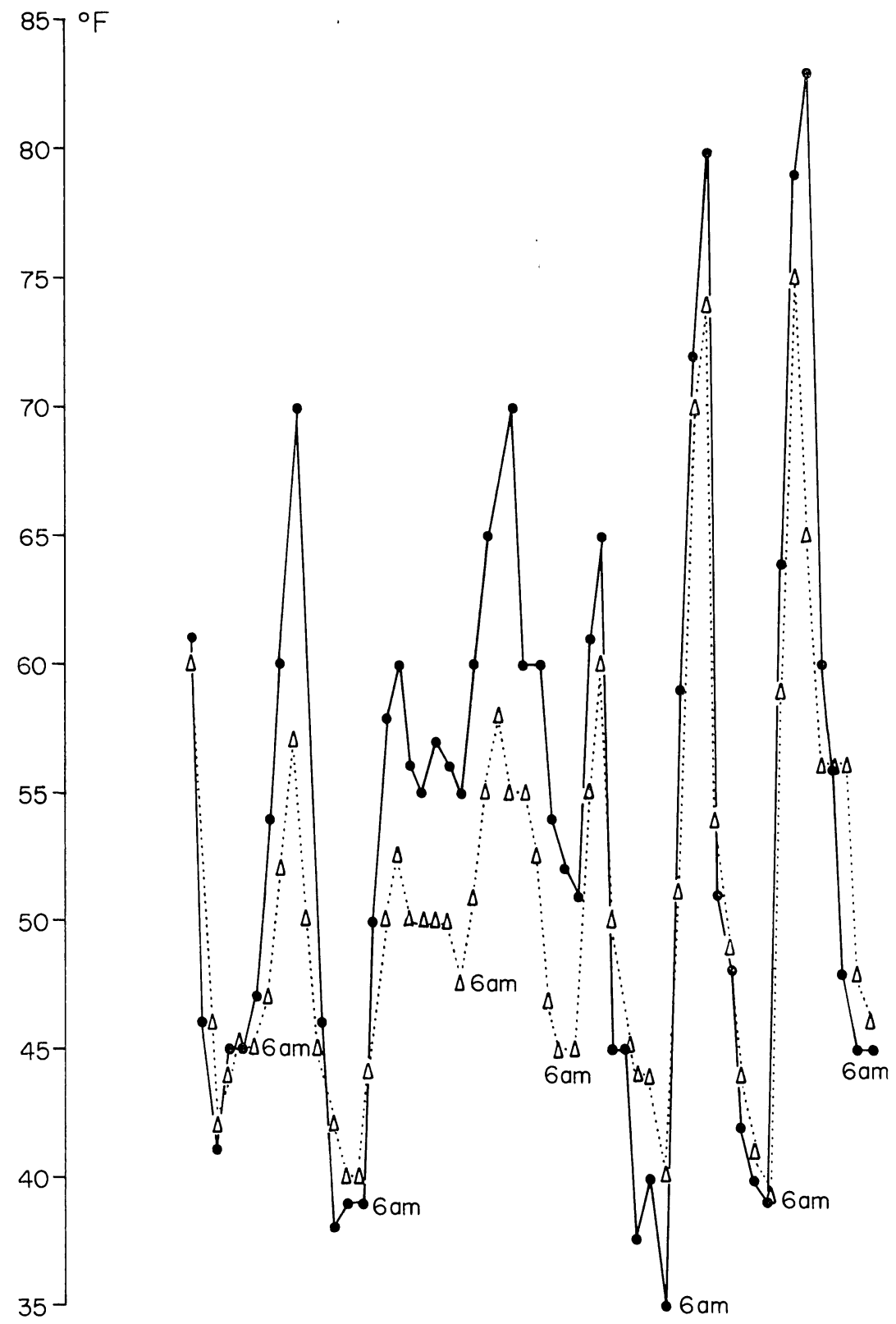

Fig. 16. Comparison of air temperature (solid line) above ground with temperature inside an adjacent packrat nest beneath the surface cover, but not in a burrow (broken line), November 18-25, 1961. Dots and triangles on the record are at 3-hour intervals. 
new utas were marked throughout the fall, winter, and following spring. It was not always clear that these animals were produced by the resident adults; many may have been immigrants. During June to September the areas were worked intensively and we generally were able to mark the young lizards soon after hatching, so I feel that the conservative figure for natality may be more nearly accurate.

It is best to recall that the reproductive potential per female, as estimated by the methods discussed in the section on reproduction, was about 12 young per female per generation provided she survived to produce three clutches. I pointed out that this figure of 12 young per female could be an underestimate. The data presented here on natality and later on survivor-

TABLE 36

Total Number of Young; Marked on the Two Study Areas in five Years

A Conservativi: Total is also Given

Sec text for a discussion of the two totals

\begin{tabular}{crcccc}
\hline Ycar & Area & Males & Females & Total & $\begin{array}{c}\text { Conservative } \\
\text { Total }\end{array}$ \\
\hline 1960 & I & $90^{*}$ & $94^{*}$ & $184^{*}$ & $175^{*}$ \\
& II & - & - & - & - \\
1961 & I & 239 & 216 & 455 & 378 \\
& II & 225 & 264 & 489 & 430 \\
1962 & I & 125 & 113 & 238 & 212 \\
1963 & II & 189 & 192 & 381 & 300 \\
& I & 147 & 171 & 318 & 307 \\
1964 & II & 243 & 255 & 498 & 459 \\
& I & 127 & 142 & 269 & 237 \\
& II & 155 & 155 & 310 & 277 \\
\hline
\end{tabular}

* Figures incomplete; all young not marked this year.

ship also provide evidence that the reproductive potential was underestimated. For this reason I have not chosen to use the data presented earlier on reproductive potential to determine the theoretical natality, but have relied instead on figures of the actual number of young lizards marked each year. The natality figures, based upon total numbers marked and on the conservative estimate discussed previously, are shown in Table 36 . The natality has varied by almost a factor of two over the several years of this study. Some of the changes, to be discussed later, are attributable to radiation effects, but others are not. One of the factors responsible has been a change in the number of resident adults from year to year. Data comparing the natality with the number of resident adults are shown in Table 37. 
TABLE 37

Correlation of Natality (Conservative Estimate) with Number of Resident Females Present Each Year; 1960 Omitted Because Data Incomplete

\begin{tabular}{ccccc} 
Year & Area & $\begin{array}{c}\text { Number } \\
\text { Resident }\end{array}$ & Natality & $\begin{array}{c}\text { No. young/ } \\
\text { resident }\end{array}$ \\
\hline 1961 & I & 19 & 378 & 20 \\
& II & 25 & 430 & 17 \\
1962 & I & 22 & 212 & 10 \\
& II & 23 & 300 & 13 \\
1963 & I & 10 & 307 & 31 \\
1964 & II & 17 & 459 & 27 \\
& I & 23 & 237 & 10 \\
$\mathrm{XSs}$ & II & 33 & 277 & 8 \\
& & 21 & 325 & 15 \\
\hline
\end{tabular}

Because there are several ways of estimating the number of resident adults, I have chosen the figures for the total number of adults that were residents of the study area at anytime from March to August, i.e., anytime during the reproductive season. These figures clearly indicate that each female is, on the average, producing more than 12 offspring per generation. Natality is generally lowest when adult density is highest, but the relationship is certainly not a straight line. For example, 19 females in 1961 produced an avcrage of 20 young each while 17 in 1963 produced an average of 27 . These figures are somewhat surprising in view of the fact that conservative figures for natality have been used; they suggest several possibilities:

1. Many females from outside sometimes lay eggs inside the study area.

2. Many, if not most, females lay more than 3 clutches.

3. Many hatchlings immigrate to the study areas shortly after hatching.

Non-resident females are occasionally captured inside the study areas during the breeding season. That these might be transients seeking nesting sites in the area cannot be ruled out, but it seems unlikely to me that females at the critical time of egg-laying would leave areas with which they were familiar in order to deposit eggs. Yet, such behavior has been reported by Blair (1960) in Sceloporus olivaceus. I think that some females simply lay more clutches of eggs. They are capable of doing so in the laboratory, and one of my former students, Gerard Hoddenbach, has informed me (in litt.) that he has solid evidence for the production of as many as six clutches in a single season by some Uta stansburiana in Nevada. Finally, there is some movement of young utas into the study areas, but my data indicate that this would not account for the discrepancies between calculated and 
theoretical natality. All three-nesting by non-resident females, underestimation of the reproductive potential, and immigration-play a part in making the natality estimates inexact.

Tinkle et al. (1962) stated their belief that there is little prehatching mortality in Uta. With the exception of the two years when lizards on the study areas were radiated (Area I, 1962; area II, 1964), the number of young per female has equaled or exceeded the number predicted from data on clutch size or clutch frequency. If the females on the study areas were producing more than three clutches, as the data now indicate, then my opinion on the matter of prehatching mortality might be altered.

Although I have attempted to measure natality by marking the juvenal lizards as soon after hatching as possible, I have probably failed to obtain an exact measure because the death rate immediately after hatching is so high that it is simply impossible to register all the hatchlings before some of them disappear from the population. Even so, it is clear that the average number of 35-40 residents of the study area could be maintained with only about 15 per cent survivorship of hatchlings to maturity, provided that there was little mortality of adults during the breeding season.

It is unfortunate that the data most needed to calculate natality are the very ones most frequently unavailable for natural populations of lizards. The necessary data are the knowledge of age at maturity, the age-specific fertility, and the density of females. These data are not available for any species with the possible exception of Sceloporus olivaceus. The work of Blair (1960) must be regarded as exceptional in this regard.

I think, as stated previously, that even with fairly good data I have underestimated the reproductive potential. This must be obtained in future studies by analysis of large samples to determine the clutch size and seasonal and age factors that affect it. The number of clutches must be determined by capturing the same selected females at about weekly intervals for palpation and weighing. The loss of weight at the time of oviposition is so striking that the number of layings could be accurately determined. This procedure could be done more simply in the laboratory, but I doubt, in the present state of our knowledge, that this would be meaningful.

The Estimate of Crude Survivorship.-The major assumptions that must be made in estimating survivorship are that all marked animals are eventually recaptured and, if not, that they are no longer alive. Both assumptions are obviously invalid, but our method of searching beyond the boundaries of the study area for emigrants and marking large numbers of lizards over several years helped reduce the error. Animals that were never recaptured after marking were not used in the survivorship estimates. 
Tinkle (1967) presented data on survivorship of utas which are shown again in Table 38. The data show great consistency in the proportion of adults of one generation that survive to the next breeding season. Because the adults average about 9 months of age at the onset of their first reproductive season, it follows from the data in Table 38 that the proportion reaching 21 months of age is rarely above 10 per cent. To put the matter differently, there is about 90 per cent turnover of adults each generation.

The figure on survivorship of juveniles (Table 38) is less satisfactory than that for adults for the following reasons. By the end of each fall we have registered 90 per cent or more of the young produced on the study

TABLE 38

Crude Survivorship of Adult and Juvenal Utas in five Years on Two Study Areas

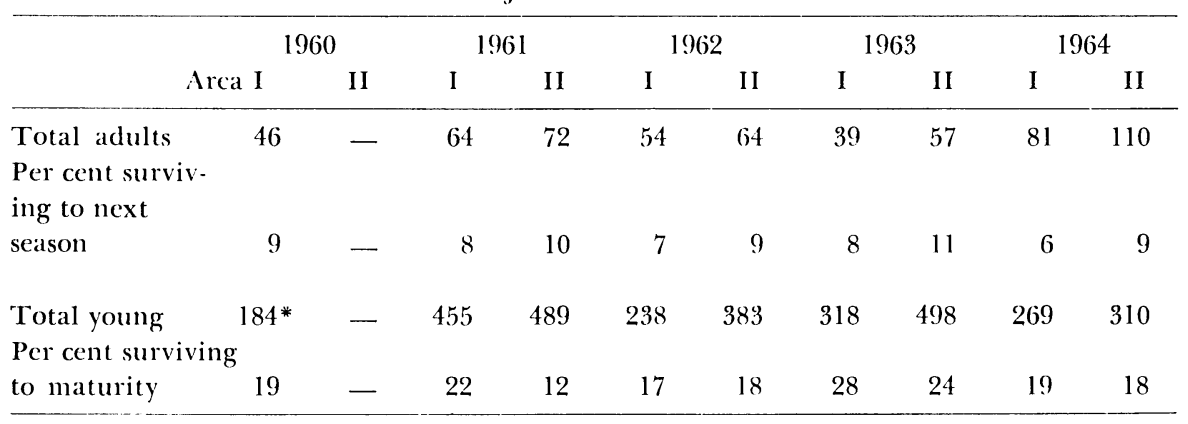

* Data incomplete.

areas, but there are always a few immigrants as well as a few juveniles that elude capture. Consequently, unmarked lizards are occasionally found during the winter and following spring, which may or may not be young of the previous summer. In Table 38 the crude survivorship data for juveniles included these questionable young of the year, but inclusion of them biases the survivorship data because (1) they may not be young of the year; indeed, they may not be young lizards at all; (2) the survivorship of these animals is generally assured because they are of nearly or actual adult size when marked.

To refine my estimates of crude survivorship of juveniles, I here redefine a young of the year as a lizard first marked at a size less than size at maturity between June and September, the months during which the study areas were worked intensively. The revised figures on juvenile survivorship are shown in Table 39. A juvenile was considered a survivor if it was recaptured at an adult size anytime after the onset of the reproductive 
season. These data indicate a slightly lower survivorship than did those in Table 38, but both sets of data show that survivorship higher than 20 per cent is rare. The highest survivorship occurred in the winter of 1963-64, which was an exceedingly mild one in the area (see section on winter kill), and led to very high numbers of adults on the two study areas during the 1964 breeding season (Table 38). The survivorship of females is greater than that of males. This is consistent with the data on winter kill presented earlier and with the information on age-specific mortality to be presented later.

TABLE 39

Revised Figures on Crude Survivorship of Juvenal Utas on Two Areas in Five Years See text for discussion. Figures in parentheses are percentages

\begin{tabular}{crcccc}
\hline & & \multicolumn{2}{c}{ Juveniles produced } & \multicolumn{2}{c}{ Surviving to maturity } \\
\cline { 3 - 6 } Year & Area & Males & Females & Males & Females \\
\hline \multirow{2}{*}{1960} & I & $86^{*}$ & $89^{*}$ & $16(18.6)$ & $12(13.5)$ \\
& II & - & - & - & $37(20.1)$ \\
1961 & I & 194 & 184 & $23(11.9)$ & $30(13.3)$ \\
& II & 205 & 225 & $18(8.8)$ & $17(16.7)$ \\
1962 & I & 110 & 102 & $14(12.7)$ & $19(12.4)$ \\
& II & 147 & 153 & $19(12.9)$ & $50(30.3)$ \\
1963 & I & 142 & 165 & $33(23.2)$ & $65(27.4)$ \\
& II & 222 & 237 & $36(16.2)$ & $23(17.8)$ \\
Totals & I & 108 & 129 & $18(16.7)$ & $25(17.6)$ \\
& II & 135 & 142 & $21(15.6)$ & $278(19.5)$ \\
\hline
\end{tabular}

* Figures incomplete.

The data on survivorship of juveniles hatched in 1964 are particularly important because in June and July of 1965, at the termination of the field study, utas were killed around both study areas out to a distance of several hundred feet in an intensive effort to find emigrants and obtain precise mortality estimates. The data for 1964 were consistent with those of other years and, I think, as accurate as could be obtained for a natural population.

Survivorship Time of Resident Adults.-The data on crude survivor. ship tell us nothing of the time when the adults are disappearing from the populations. This is obviously important to know because if it is during the breeding season it affects the estimates of theoretical natality.

It has always been our impression that adult utas become scarce in late summer and early fall as some of the young of the year approach adult 
size. At first I thought that the adults might be emigrating as a result of aggressive pressures from their maturing young, but search beyond the boundaries of the study area failed to confirm emigration. During the late summer it was common to find adult utas that did not appear to be as healthy as at the beginning of the reproductive season. Many had lost weight and appeared generally unthrifty.

During the first two years of this study, very little information about the resident adults was obtained outside June, July, August, and September. Beginning in early 1962, we attempted to work the study areas intensively a sufficient number of times in the early spring to register the number of resident adults at that season-the beginning of the reproductive period. By so doing we were able to obtain estimates of the total numbers of resident adults present throughout the breeding season rather than just during the later part of it. These data are shown in Table 40.

From Table 40 the reader may have difficulty understanding why, in some years, there were more resident adults later in the reproductive season than at the start. Immigrants into the area or underestimation by the investigator of the number present early in the season were responsible for this discrepancy. It is easy to underestimate because the study areas could not be worked nearly so intensively from March to May as was possible from June to August.

Two facts are clear from Table 40. There is a remarkably constant number of adults in the area from March to June, the period during which most reproduction is accomplished. There is a marked reduction in numbers in July and a further reduction in August with the number present in the last month being only one-third the number present in the early months of the breeding season. Mortality of adults evidently increases in late summer, but the reasons for this are not clear. However, the disappearance of the older adults coincides with the maturation of the young of the year, and I feel, intuitively, that competition between the established adults and their maturing young is minimal and partly responsible for the low degree of emigration of subadult animals.

Age-Specific Mortality.-The crude data presented for juvenile survivorship do not indicate the form of the survivorship curve. To obtain information on age-specific death rate $I$ have restricted consideration to those juveniles marked within a few days of hatching (482 ô $\hat{o} ; 585$ q $)$. I have made the simplifying assumption that the time of last capture was the date of death and have not considered hatchlings never recovered. The data for both populations for several years were combined to produce the life table shown in Table 41, in which the last three age classes represent 
TABLE 40

Numbers of Resident Adults Present on the Study Arfas in Six Years, During; Each Month of the Reproductive Season

\begin{tabular}{|c|c|c|c|c|c|c|}
\hline & March & April & May & June & July & August \\
\hline \multicolumn{7}{|l|}{1960} \\
\hline Females I & - & - & - & 12 & 11 & 4 \\
\hline Females II & - & - & - & - & - & - \\
\hline Males I & - & - & - & 10 & 10 & 7 \\
\hline Males II & - & - & - & - & - & - \\
\hline \multicolumn{7}{|l|}{1961} \\
\hline Females I & - & - & - & 17 & 8 & 5 \\
\hline Females II & - & - & - & 25 & 13 & 4 \\
\hline Males I & - & - & - & 15 & 8 & 4 \\
\hline Males II & - & - & - & 20 & 10 & 10 \\
\hline \multicolumn{7}{|l|}{1962} \\
\hline Females I & 20 & 20 & 12 & 11 & 6 & 3 \\
\hline Females II & 18 & 19 & 18 & 18 & 11 & 8 \\
\hline Males I & 17 & 18 & 15 & 17 & 12 & 8 \\
\hline Males II & 15 & 15 & 14 & 14 & 8 & 5 \\
\hline \multicolumn{7}{|l|}{1963} \\
\hline Females I & 8 & 10 & 10 & 9 & 8 & 4 \\
\hline Females II & 14 & 14 & 15 & 16 & 10 & 8 \\
\hline Males I & 10 & 10 & 8 & 10 & 7 & 3 \\
\hline Males II & 9 & 10 & 14 & 12 & 9 & 7 \\
\hline \multicolumn{7}{|l|}{1964} \\
\hline Females I & 20 & 20 & 20 & 22 & 14 & 9 \\
\hline Females II & 31 & 32 & 34 & 33 & 11 & 8 \\
\hline Males I & 15 & 15 & 15 & 15 & 12 & 7 \\
\hline Males II & 13 & 13 & 15 & 17 & 10 & 6 \\
\hline \multicolumn{7}{|l|}{$1965^{*}$} \\
\hline Females I & 6 & 5 & 8 & 6 & - & - \\
\hline Females II & 12 & 12 & 17 & 19 & - & - \\
\hline Males I & 11 & 11 & 12 & 12 & - & - \\
\hline Males II & 5 & 5 & 8 & 9 & - & - \\
\hline
\end{tabular}

* Adults killed at end of June.

very roughly the ages at the time of the deposition of 1st, 2nd, and 3rd clutches. The death rate for females is lower than that of males in almost all age classes. Mortality is high during the first few weeks of life, but fairly constant thereafter (Fig. 17). Perhaps 15 per cent of the females survive to sexual maturity, but less than 10 per cent of the lizards live past the age of one year. 
Table 41

Life Table for Uta stansburiana Combining Data on Animals Marked at or Near Hatching, Over a Five-yfar Period on Two Study Areas

The figures in the table are based on 482 males, 585 females; $1 \mathrm{x}=$ number alive at beginning of each age interval; $d x=$ number dying during the interval; $\mathrm{qx}=$ percentage dying of those alive at the beginning of the interval

\begin{tabular}{|c|c|c|c|c|c|c|}
\hline \multirow{2}{*}{$\begin{array}{c}\text { Age } \\
\text { interval } \\
\text { (weeks) }\end{array}$} & \multicolumn{3}{|c|}{ Females } & \multicolumn{3}{|c|}{ Males } \\
\hline & lx & $\mathrm{dx}$ & $q x$ & $1 x$ & $\mathrm{dx}$ & $q x$ \\
\hline $0-1$ & 1000 & 350 & .34 & 1000 & 380 & .38 \\
\hline $1-2$ & 650 & 52 & .08 & 620 & 56 & .09 \\
\hline $2-3$ & 598 & 90 & .15 & 564 & 73 & .13 \\
\hline $3-4$ & 508 & 76 & .15 & 491 & 83 & .17 \\
\hline $4-5$ & 432 & 43 & .10 & 408 & 57 & .14 \\
\hline $5-6$ & 389 & 66 & .17 & 351 & 70 & .20 \\
\hline $6-7$ & 327 & 20 & .06 & 281 & 45 & .16 \\
\hline $7-8$ & 307 & 25 & .08 & 236 & 21 & .09 \\
\hline $8-9$ & 282 & 11 & .04 & 215 & 19 & .09 \\
\hline $9-10$ & 271 & 19 & .07 & 196 & 18 & .09 \\
\hline $10-11$ & 252 & 20 & .08 & 178 & 16 & .09 \\
\hline $11-12$ & 232 & 5 & .02 & 162 & 2 & .01 \\
\hline $12-13$ & 227 & 9 & .04 & 160 & 0 & .00 \\
\hline $13-14$ & 218 & 7 & .03 & 160 & 6 & .04 \\
\hline $14-15$ & 211 & 13 & .06 & 154 & 5 & .03 \\
\hline $15-16$ & 198 & 2 & .01 & 149 & 0 & .00 \\
\hline $16-17$ & 196 & 8 & .04 & 149 & 1 & .01 \\
\hline $17-18$ & 188 & 8 & .04 & 148 & 11 & .01 \\
\hline $18-19$ & 180 & 13 & .07 & 147 & 3 & .02 \\
\hline $19-20$ & 167 & 2 & .01 & 144 & 4 & .03 \\
\hline $36-37$ & 131 & 12 & .09 & 103 & 4 & .04 \\
\hline $43-44$ & 86 & 3 & .04 & 72 & 6 & .09 \\
\hline $50-51$ & 56 & 7 & .12 & 43 & 9 & .20 \\
\hline
\end{tabular}

The maximum longevity observed among hatchlings during this study was 100 weeks for a single female and 97 weeks for one male. Fewer than 1 per cent of the males lived 57 weeks; of females, 60 weeks. The average life expectancy at hatching is about 18.5 weeks.

Although the data may not be exact, I do not hesitate to state that the suggestion of Tinkle et al. (1962) that the populations might show an essentially annual turnover has been verified.

To say that the population turnover is essentially complete every year is not to deny that some animals may live two or more years. If we had a population of infinite size, I am certain that an occasional animal 3 or more years of age would be found. As a matter of fact I have recorded one female 


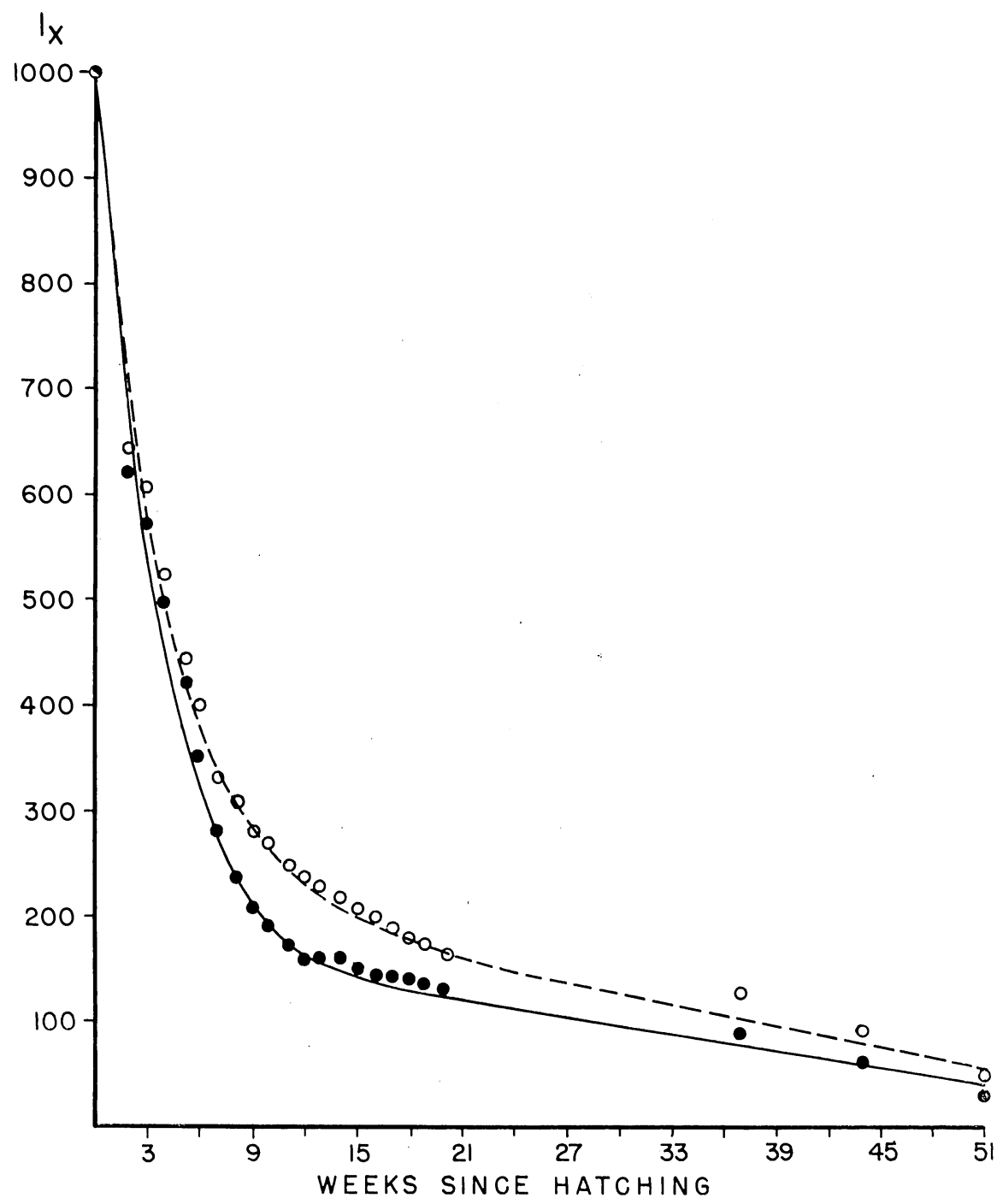

FIc. 17. Survivorship curve for Lta stansburiana males (solid line) and females (broken line) based on data in Table 41. See text for discussion.

first marked as a 50-mm adult in May, 1963, that was last recorded in March, 1965, at an age of at least three years. However interesting these may be as records of longevity they are of little importance in the dynamics of the population. The fact remains that the majority of young are produced by lizards that are themselves young of the previous year and that will be 
gone from the population, for the most part, by the time of the next breeding season.

The survivorship data do not show a consistent relationship with natality. In other words, survivorship is not always highest when natality is lowest. Other things than the number of competing individuals play a major part in survivorship.

Whether the survivorship data presented will balance with the estimated reproductive potential remains to be discussed. If each female laid 3 clutches averaging 4 eggs each, then 12 young per female would be produced, of which 6 would be females. Survival of 15 per cent of these to maturity would result in 0.9 adult females. This is all that is required to maintain a constant population level because there is only 90 per cent turnover of the adult females. However, Figure 17 and the data in Table 40 indicate that of the 15 per cent surviving to maturity, only two-thirds will live through the reproductive season. These considerations, again, give cause for doubt that my estimates of reproductive potential are correct. However, if the data of Table 37 on actual natality are used, each resident female produced 15 young. This number is sufficient to maintain a constant population size if every female surviving to maturity lives long enough to produce at least 13 or 11 offspring. To accomplish this some, if not most, of the females must produce more than three clutches.

I) ISCussion of Literature on Survivorship in Lizards.-Data on survivorship in lizard populations are rare. Blair (1960), basing his estimates on theoretical natality rather than on the small number of juveniles actually marked, estimated that $6-20$ per cent of the hatchlings survived to maturity and that about 20 per cent of the adults survived to a second breeding season. Fitch $(1956 b)$ reported much higher survivorship in Crotaphytus collaris, in which nearly 40 per cent of the young survive to sexual maturity, and about one-half of these live to a second season. Crenshaw (1955) reported, among a selected group of hatchlings, that 50 per cent loss occurred during the first 6 weeks of life and 68 per cent in the first 2 months, suggesting a mortality schedule similar to that which I have found in utas. Similarly, Hirth (1963) reported that less than 10 per cent of the lizards Basiliscus vittatus and Ameiza quadrilineata live for one year and only 2 per cent of Basilicus survive two years. Sexton et al. (1963) and Storr (1965) suggest essentially annual turnover in Anolis limifrons and Amphibolurus isolepis, respectively, but these reports are based primarily on a consideration of size groups present at different times of the year rather than on recapture of marked animals of known age. Finally, Fitch (1958) reported 50 per cent reduction each year in adult populations of Cnemidophorus sexlineatus. 
Although only a smattering of data are available, these indicate widely different demographies in different species populations.

IMMigration AND EMigration.---The fact that there is essentially annual turnover in the populations, as pointed out earlier, may be partly responsible for the low degree of movement out of the study areas inasmuch as competition between established adults and subadults is thereby minimized. ()f course interactions between maturing young cause emigration, also, but probably not as significantly as in those populations in which the competition among juveniles is compounded with that between juveniles and adults.

The exact amount of emigration is difficult to determine for any population, but I think that my data are fairly accurate because during three summers of this study we worked several hundred feet beyond the bounclaries of the study areas. On other occasions large numbers of utas were collected from areas several hundred yards beyond each of the study areas. Finally, at the termination of field studies in the summer of 1965, an attempt was made to kill all utas out to 500 feet beyond the area boundaries. This was clone to try to obtain maximum survivorship figures for one year as well as maximum emigration figures against which to compare estimates made in other years.

If a hatchling lizard were marked within the study area and recaptured for the last time outside the area, it was considered an emigrant. Similarly, lizards marked as juveniles within the study area, but which established home ranges, as adults, in the margins of the study areas were emigrants. Of 1077 juveniles marked in 1961-63 within the area, 132 were emigrants on one of the bases given above. This indicates emigration of about 12 per cent; actually the figures for the three years vary from 9 to 16 per cent. Only 7 per cent of these 132 emigrants had made major movements, the maximum being 800 feet from its original capture point. These data are discussed in much more detail elsewhere (Tinkle, 1967).

In the summer of 1963, two tape lines were laid off around the boundaries of one of the study areas. All lizards in the 3.7-acre inner zone were captured, marked, and released, and those in the 4.0-acre outer zone (average distance from study area boundary, 150 feet) were killed. Only 7 marked animals were killed in the outer zone. Of the 159 lizards captured in the inner zone or killed in the outer, only 6 per cent were emigrants from the study area.

The results of killing utas around the study areas in 1965 were surprising in that only 1 of 115 lizards killed 50 to 200 yards beyond the area boundary was marked and only 6 of 53 within 50 yards of the area were marked. Six of the 7 were males. Only about 4 per cent emigration is indicated by these data. 
The degree of immigration is somewhat more accurately estimated in that the study areas were worked much more frequently and intensively than were the margins. If a juvenal uta marked outside the area became a study area resident during its ontogeny it was considered an immigrant. Of 741 such lizards, 112 ( 15 per cent) were immigrants on this basis. Fortyeight of 230 adults (21 per cent) could be considered immigrants on the same basis.

These estimates for emigration and immigration, though somewhat crude, indicate an essential balance between the two processes.

From the point of view of someone interested in the evolutionary aspects of population dynamics, an accurate estimate of immigration and emigration is important as an indicator of the potential amount of gene

TABI.E 42

Maximum figures on the Proportion of ImMlgRants among, Residfent Adults on Two Study Arias in Four Y'fars

All figures are percentages except those for total residents. See text for discussion

\begin{tabular}{|c|c|c|c|c|c|c|c|}
\hline \multirow[b]{2}{*}{ Year } & & \multicolumn{3}{|c|}{ Area I } & \multicolumn{3}{|c|}{ Area II } \\
\hline & & Males & females & $\begin{array}{l}\text { Total } \\
\text { residents }\end{array}$ & Males & Females & $\begin{array}{l}\text { Total } \\
\text { residents }\end{array}$ \\
\hline 1962 & & 48 & 50 & 45 & 38 & 35 & 39 \\
\hline 1963 & & 50 & 50 & 22 & 54 & 71 & 30 \\
\hline 1964 & & 47 & 22 & 42 & 31 & 28 & 49 \\
\hline \multirow[t]{2}{*}{1965} & & 23 & 78 & 22 & 73 & 35 & 28 \\
\hline & X's & 43 & 44 & & 46 & 39 & \\
\hline
\end{tabular}

exchange between demes and within them. For this purpose, I tried to obtain a maximum estimate of movements into the population by the following process. In the years 1961-64, almost all young utas were marked cluring the summer and early fall. If it is assumed that young lizards marked after fall were immigrants and that adults marked outside the area and later becoming study area residents were also immigrants, then I can determine what proportion of the breeding population from 1962-65 was composed of immigrant lizards. The figures obtained are maximal because I am certain that many young lizards marked in fall and winter were produced on the area. No comparable figures can be given for emigration, but I assume the two processes are balanced (Table 42).

These data indicate a much higher degree of immigration than those previously considered. In some years, more than one-half of the breeding adults were immigrants. It is difficult to draw any conclusions concerning correlations between the proportion of immigrants among the adults and 
the density. For example, the percentage of immigrants among the residents on area $I$ in 1962 was about the same as in 1963 when the density was about half that of the previous year.

If immigration is, indeed, as high as an average of 40 per cent, then essential panmixia is indicated. Knopf (1963) compared the variation in lizards from the Kermit populations with that in populations 23 airline miles away in similar habitat and found few significant differences in 13 morphological characters, a possible inclication of free gene flow through the intervening populations.

Essentially no data are available in the literature on movements in and out of lizard populations. Blair (1960) did attempt to estimate immigration in Sceloporus olivaceus populations indirectly and obtained figures of 22 per cent of adult females and 34 per cent of adult males, or about 30 per cent immigrants in the adult population as a whole.

Unusually Long Movements.-Records have been kept of unusually long movements by lizards emigrant from the study areas. Such movements have been so rare that I am listing all of them below.

July 17, 1961: Adult of marked at $28 \mathrm{~mm}$ on July 14, 1960; captured 564 feet north of original location.

July 14, 1962. Adult of captured 80()-90() feet northeast of where it was marked as hatchling on July 19, 1961.

March 13, 1964. Adult o caught 300 feet south of location where she was marked as 31-mm juvenile on August 15, 1963.

June 14, 1964. Adult of captured 300 feet south of location where it had been seen last in September, 1963.

July 25, 1964. Adult $\&$ caught about 900 feet east of location where she was last seen in September, 1963.

March 20, 1965. Subadult of found 600 feet south of location where marked as a 25-mm juvenile on October 3, 1964.

Of some 3500 lizards marked, these are the only records of very long emigrations. There are too few records to be certain which sex is more often involved, at what time of the year emigrations occur, or in what direction. The whole list of such records was included because they do indicate that some lizards move several hundred feet out of the area. The odds of recovering individuals making such movements are low even when large samples are taken outside the area.

Finally, the margins of the study area were frequently investigated to distances of 300 feet beyond the area boundaries. Records were not always 
kept of the exact distance beyond the area or of the total number of unmarked lizards caught. For those occasions when such records were kept, 57 of 375 lizards captured out to 300 feet ( 15 per cent) were marked. Most of these came from within 100 leet of the areas and most had been originally marked outside the area. Of 451 lizards taken beyond 300 feet during investigations of the margins, only one was marked.

\section{Brffing Structurf: of thr: Population}

The breeding structure of natural populations is intrinsically interesting, but difficult to measure. Some data on the structure of the Kermit populations of utas have been presented previously (Tinkle, 1965b), but these warrant further cliscussion here.

TABLE 43

Srix Ratios of Utas Marked on Two Study Areas in Six Years

Figures in parentheses are percentages of males

\begin{tabular}{|c|c|c|c|c|c|}
\hline \multirow[b]{2}{*}{ Year } & \multirow[b]{2}{*}{ Area } & \multicolumn{2}{|c|}{ Juveniles } & \multicolumn{2}{|c|}{ Aclults } \\
\hline & & Males & Females & Males & Females \\
\hline \multirow[t]{2}{*}{1960} & I & $61(49)$ & 64 & $24(47)$ & 27 \\
\hline & II & - & - & - & - \\
\hline \multirow[t]{2}{*}{1961} & I & $231(51)$ & 219 & $34(43)$ & 46 \\
\hline & II & $129(44)$ & 167 & $34(43)$ & 46 \\
\hline \multirow[t]{2}{*}{1962} & I & $121(51)$ & 114 & $56(46)$ & 66 \\
\hline & II & $192(50)$ & 195 & $44(42)$ & 61 \\
\hline \multirow[t]{2}{*}{1963} & I & $145(47)$ & 164 & $29(46)$ & 34 \\
\hline & II & $234(49)$ & 244 & $49(48)$ & 54 \\
\hline \multirow[t]{2}{*}{1964} & I & $123(47)$ & 140 & $52(44)$ & 65 \\
\hline & II & $159(49)$ & 164 & $69(41)$ & 99 \\
\hline \multirow[t]{2}{*}{1965} & I & + & - & $41(54)$ & 35 \\
\hline & II & - & 一 & $43(49)$ & 45 \\
\hline Totals & & $1395(49)$ & 1471 & $475(45)$ & 478 \\
\hline
\end{tabular}

Over the years of this study I have developed the impression that the utas are primarily monogamous. The evidence for this resides in several observations. The sex ratio is approximately 50:50 among juveniles, but slightly altered in favor of females because of their lower mortality (Table 43). Utas are almost always found in pairs in the field. When home ranges were plotted on the study area grid, there was generally an indication that each female was associated with a particular male. Numerous courtships and copulations were observed by these presumably paired lizards; all copulations were between predicted mates. Finally, one of my students 
(Irwin, 1965) followed closely three pairs of utas for several weeks. Many courtships were observed, some outside the presumed pair bonds, but all of the copulations were between the predicted mates. As pointed out earlier the monogamy is presumably facultative and is produced by the aggressiveness of both sexes toward individuals of the same sex.

The question of interest is whether there is any advantage to monogamy, per se. Tinkle (1965b) suggested that monogamy might increase the degree of outcrossing in a relatively sedentary lizard. The assumption that must be made is that each male mates with but one female during his lifetime. This would provide greater outcrossing than if a single male mated with several females. However, if the single male came from another area, the amount of outcrossing might be greater than in the monogamous system if most of the monogamous pairs were sibs or close relatives. I clon't think my suggestion of the function of monogamy should be taken too seriously.

If those lizards that are monogamous produce more surviving offspring than those that are polygamous, and if the bonds that result in monogamous pairing are genetically based, then a selective advantage would accrue to 'monogamous lizards. In the absence of such evidence I prefer to think that monogamy results simply from intrasexual antagonism and the absence of social hierarchies in the population. The aggressive behavior is clearly advantageous and almost certainly innate, so I am sticking closer to the facts by relegating monogamy to a secondary effect rather than to a primary function.

It may be somewhat ambiguous to speak of the effective breeding size of a natural population, but the ratio between the effective size and the total number of potential breeders may be meaningful. The effective size might be visualized as the number of lizards that are producing offspring that survive to maturity. However, because some doubtless produce more than others, in an estimate of the effective size one must consider the variance in production of surviving offspring. This was done by Tinkle (1965b) who found that the effective size was about the same as the actual number of pairs of resident adults, indicating that each pair was producing about the same number of surviving offspring. In years in which natality was high and winter mortality low, competition and selection among the young were presumably increased. At certain times like these the young of some females were at an advantage and survived in more than random numbers, resulting in an effective breeding size that was lower than usual.

In conclusion, it appears that the utas are generally monogamous and random in their production of surviving offspring. If the figures on maximum emigration are brought into account, any tendency toward inbreeding that results from the low degree of movement and the formation of inter-sib 
mating pairs is compensated by dispersal into the study areas from adjacent populations. Finally, the readiness with which an adult male will court females other than its usual mate, coupled with the continual movements of males around their home range periphery, insures that every female will be fertilized should her usual mate be preyed upon.

There is so little information in the literature on breeding structure of lizard populations that I hesitate to make generalizations. However, one seems apparent and that is that females almost always outnumber males among adult lizards. This was demonstrated in this study as well as by Blair (1960), Harris (1964), and Hirth (1963).

It may also be true that a facultative type of monogamy may be more common than is generally thought. Lorenz (1966) records an observation on the South European Green Lizard (presumably Lacerta viridis) in his experimental enclosures. The males and females of Lacerta defend their territories only against other lizards of the same sex. Inasmuch as the territory sites are limited, he found that a pair of dominant males and females came to be inadvertently associated and copulated much more frequently with one another than with chance partners met at the territory bounclaries. The removal of one member of the pair resulted in fighting among the subordinates with the result that the most aggressive of those soon filled the vacancy. Harris (1964) documented 5 instances in which female Agama agama remained with their dominant males throughout the breeding season, producing three or four clutches of eggs each. There are often several females associated with a dominant male Agama, but all are submissive to the dominant female. In no instance was a dominant female observed to leave a dominant male, whereas desertions by subordinates were common. That this facultative monogamy did not last beyond one breeding season was owing to reshuffling of the population cluring the non-breeding season, so that a dominant male was with a different mate the next breeding season.

In such cases as these the advantage of monogamy seems clearly one of sexual selection. At the same time the social hierarchy allows maintenance of a high density, and presumably of a high reproductive success, and at the same time minimizes conflict.

\section{Size and Age Strugture in the Populations}

The relation of size to age in the populations of the study areas may be seen in Table 44 for those lizards marked at the approximate time of hatching. Only data for the summer are shown, and it is clear that the populations at this season are composed almost entirely of lizards that are either about one year old or are young of the year. A few second-year adults are also present. 
TABLE 44

Mean Ages of Lizards of Various Snout-Vent Lengths

Data based on lizards marked at hatching. Data restricted to the period June-August; all years and areas combined

\begin{tabular}{|c|c|c|c|c|}
\hline \multirow{2}{*}{$\begin{array}{l}\text { Snout-vent } \\
\mathrm{mm}\end{array}$} & \multicolumn{2}{|c|}{ Males } & \multicolumn{2}{|c|}{ Females } \\
\hline & $N$ & X age (days) & $\mathrm{N}$ & x age \\
\hline 20 & 7 & 0.0 & 7 & 0.0 \\
\hline 21 & 39 & 2.2 & 82 & 2.0 \\
\hline 22 & 143 & 1.4 & 180 & 1.6 \\
\hline 23 & 152 & 2.4 & 207 & 2.9 \\
\hline 24 & 45 & 8.8 & 69 & 10.1 \\
\hline 25 & 45 & 13.8 & 65 & 17.1 \\
\hline 26 & 55 & 16.8 & 65 & 18.7 \\
\hline 27 & 30 & 21.6 & 47 & 26.9 \\
\hline 28 & 25 & 23.1 & 51 & 28.9 \\
\hline 29 & 31 & 28.9 & 41 & 31.7 \\
\hline 30 & 19 & 35.3 & 35 & 37.3 \\
\hline 31 & 25 & 34.2 & 25 & 41.0 \\
\hline 32 & 13 & 32.7 & 17 & 43.7 \\
\hline 33 & 13 & 40.1 & 8 & 45.4 \\
\hline 34 & 13 & 44.9 & 8 & 44.4 \\
\hline 35 & 10 & 41.6 & 4 & 45.3 \\
\hline 36 & 7 & 46.6 & 0 & - \\
\hline 37 & 6 & 51.3 & 1 & 48.0 \\
\hline 38 & 5 & 46.6 & 1 & 50.0 \\
\hline 39 & 2 & 46.0 & 0 & - \\
\hline 40 & 0 & & 0 & \\
\hline 41 & 0 & & 0 & \\
\hline 42 & 0 & & 0 & \\
\hline 43 & 0 & & 3 & 348.3 \\
\hline 44 & 0 & & 7 & 353.7 \\
\hline 45 & () & & 19 & 346.2 \\
\hline 46 & 1 & 320.0 & 22 & 331.4 \\
\hline 47 & 2 & 285.5 & 13 & 356.2 \\
\hline 48 & 6 & 326.5 & 5 & 347.2 \\
\hline 49 & 2 & 304.0 & 0 & \\
\hline 50 & 3 & 308.0 & 0 & \\
\hline 51 & 9 & 372.4 & 0 & \\
\hline 52 & 10 & 351.3 & 0 & \\
\hline 53 & 3 & 357.0 & 0 & \\
\hline 54 & 2 & 377.0 & 0 & \\
\hline
\end{tabular}

The bimonthly distribution of size groups is shown in Figures 18 and 19 for males and females, respectively. The shift in size groups reflects the rapid rate of growth; young of the year and one-year-old age classes overlap by fall. In these figures there was no way of showing the precise ages of the 


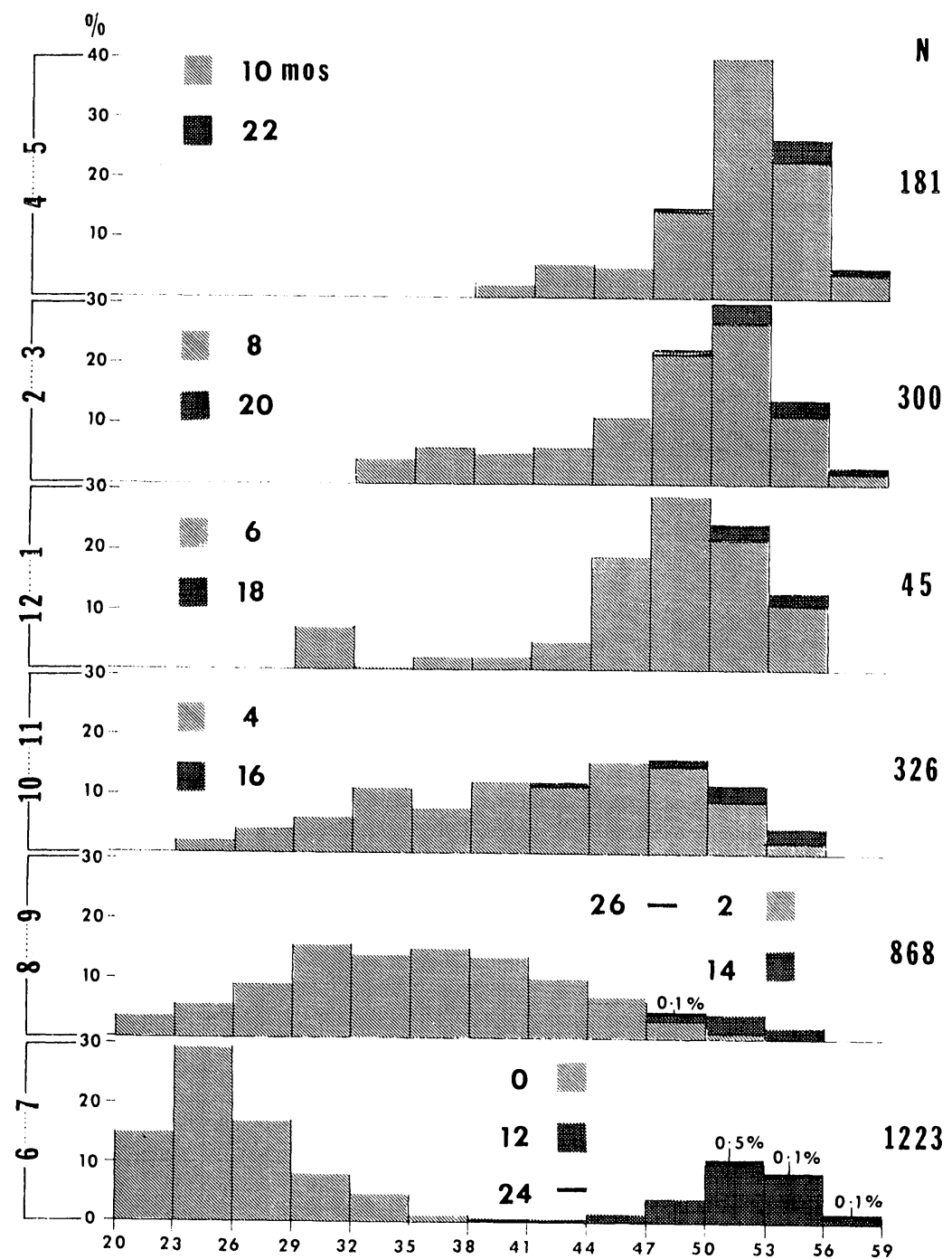

Fic. 18. Approximate age structure of males in a Texas uta population over a period of several years. Abscissa shows snout-vent length in millimeters. Ordinate shows months of year. The approximate ages of the size classes are indicated on the histogram. The percentages above some histograms are proportions of third-season adults. See text for further explanation.

animals composing the size classes, but arbitrary ages can be assigned fairly accurately as follows: most hatching occurs about July 1, so lizards in the August-September season (8-9 in the figures) would be either 2 or 14 months 


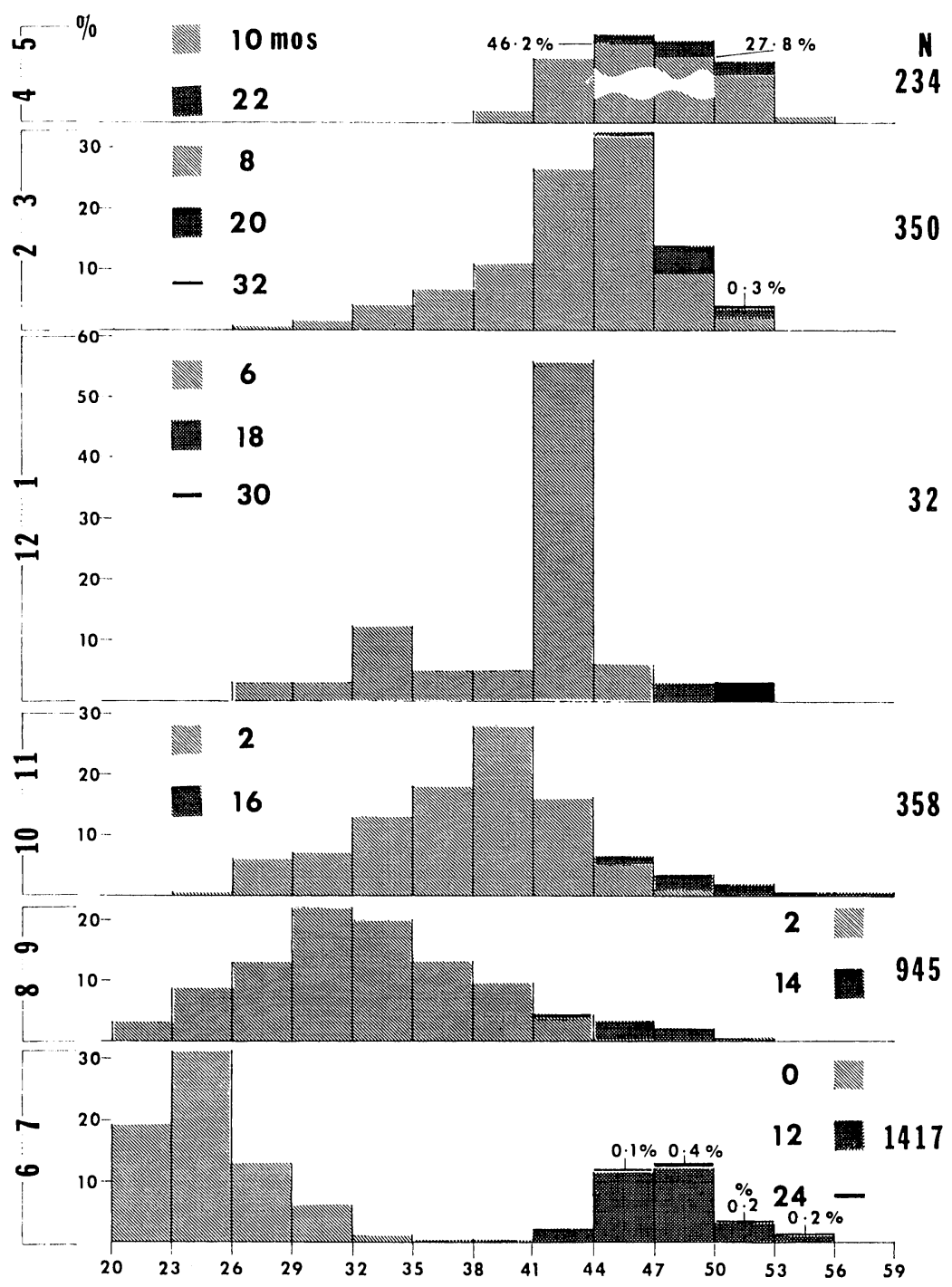

Fig. 19. Approximate age structure of females. Information same as in Figure 18.

old depending on whether they were young of the year or adults. Therefore, this figure also shows in a somewhat imprecise way the degree of overlap of the different age classes. Note that at no time of the year at which this population might be sampled would it be possible to separate the age classes on the basis of size. In the summer, the young of the year may be separated 
from the adults (see Table 44), but the one-year and two-year age classes are inseparable by size criteria.

Table 45 shows rather precisely the age composition of the Texas population at each of four seasons. This table shows in a striking way that the population of lizards is composed primarily of young of the year (over

TABLE 45

Age Distribution in the Texas Populations of Uta stansburiana at Four Seasons Years and areas combined. All figures are percentages

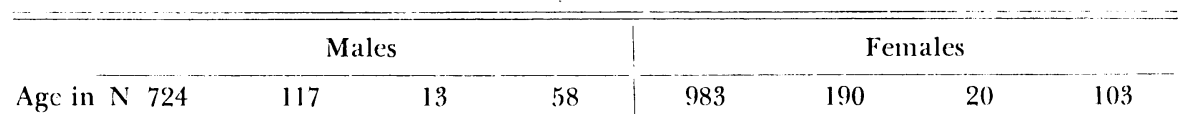

Days June-Aug. Sept.-Nov. Dec.-Feb. Mar.-May June-Aug. S pt.-Nov. Dec--Feb. Mar.-May

\begin{tabular}{rrrrrrrrr}
\hline 30 & 79 & 12 & - & - & 77 & 4 & - & - \\
60 & 15 & 13 & - & - & 16 & 12 & - & - \\
90 & 1 & 45 & - & - & .1 & 44 & - & - \\
120 & - & 17 & 8 & - & - & 25 & 10 & - \\
150 & - & 10 & 31 & - & - & 11 & 30 & - \\
180 & - & 1 & 31 & 5 & - & 3 & 10 & 3 \\
210 & - & - & 15 & 4 & - & - & 25 & 6 \\
240 & - & - & 8 & 16 & - & - & 25 & 19 \\
270 & - & - & - & 43 & .1 & - & - & 41 \\
300 & 1 & - & - & 16 & 2 & - & - & 10 \\
330 & 1 & - & - & 16 & 2 & - & - & 10 \\
360 & 1 & - & - & - & 3 & - & - & - \\
390 & 1 & 1 & - & - & 2 & - & - & - \\
420 & - & - & - & - & .2 & 2 & - & - \\
450 & - & - & - & - & .1 & 1 & - & - \\
480 & - & 1 & - & - & - & - & - & - \\
510 & - & - & - & - & - & 1 & - & - \\
540 & - & - & - & - & - & - & - & - \\
570 & - & - & - & - & - & - & - & - \\
600 & - & - & 8 & - & - & - & - & 1 \\
630 & - & - & - & 4 & - & - & - & - \\
660 & - & - & - & - & - & - & - & - \\
690 & - & - & - & - & .1 & - & - & 1 \\
\hline
\end{tabular}

90 per cent of the population). Some care must be exercised in interpreting this table. There is little doubt that the figures for the summer months accurately reflect the proportion of animals of different ages in the natural population. The small samples from December to February could not possibly reflect the proportion of different age groups in nature. Nevertheless there is no mistaking the fact that the age structure is a simple one- 
essentially one-year-old adults and their young, and this is of importance to population dynamics.

Table 46 shows the number of adults of known age, recorded each year from 1962-65; they were marked as young or were present as adults in more than one year. The number of second-year adults never exceeded 11 per cent; the average was 7 per cent. Only one lizard, a female, out of 581 adults was recorded in the population for three breeding seasons.

TABLE 46

Age Distribution of Adult Animals Handled Each Yfar on

Two Areas for Which the Age of the Animal Was Known All figures except total lizards are percentages

\begin{tabular}{ccccc}
\hline & $\begin{array}{c}\text { Total } \\
\text { lizards }\end{array}$ & $\begin{array}{c}\text { First year } \\
\text { adults }\end{array}$ & $\begin{array}{c}\text { Second year } \\
\text { adults }\end{array}$ & $\begin{array}{c}\text { Third year } \\
\text { adults }\end{array}$ \\
\hline 1962 & & & & \\
Area I & 86 & 94 & 6 & 0 \\
Area II & 73 & 90 & 10 & \\
1963 & & & & 0 \\
Area I & 42 & 90 & 10 & 0 \\
Area II & 62 & 89 & 11 & 0 \\
1964 & & & & 0 \\
Area I & 88 & 97 & 3 & 0 \\
Area II & 110 & 95 & 5 & 2 \\
1965 & & & & 02 \\
Area I & 55 & 93 & 7 & 0 \\
Area II & 65 & 92 & 7 & \\
Totals & 581 & 93 & & \\
\hline
\end{tabular}

Discussion of the Literature on Age Structure in Lizards.-The age structure must be known to understand the dynamics of natural populations. The reproductive rate of a population is understandable only in terms of the age structure. Much more frequent than careful analysis of age structure in populations have been reports of long-lived animals (e.g., Fitch, 1956a, of a 9-year-old Eumeces fasciatus). A case in point is a recent study by Tanner (1965) in which he stated:

"Our data on longevity in Uta does not agree with that recently published by Tinkle, McGregar [sic] and Dana (1962)." Actually, Tanner found that 6 of "over 100" utas marked in 1960 were alive in 1962. Thus, some utas live at least 3 years, but his data indicate a turnover of about 75 per 
cent of the adults, a turnover consistent with what I have found in some Uta populations (see section on comparative demography). Age structure will doubtless differ in different species and even in the same species in different parts of its range if environmental conditions are significantly different. Kramer (1946) in his studies of Lacerta sicula suggested that the age structures of adjacent island and mainland populations of this species were different. On the islands the lizards lived longer, had a lower reproductive rate, and approximately twice as long a generation time as populations on the adjacent mainland. Such considerations are important because they affect the rates at which genetic changes can take place in the populations.

There are about 10 studies in the literature in which some useful data on age structure have been obtained. In Sceloporus undulatus (Crenshaw, 1955), Anolis limifrons (Sexton et al., 1963), and Ameiva quadrilineata and Basiliscus vittatus (Hirth, 1963) there is a simple age structure like that of $U t a$, with essentially annual turnover of adults. In Uta stansburiana (Tanner, 1965), Sceloporus olitaceus (Blair, 1960), and Sceloporus occidentalis (Fitch, 1940) there is about 75 per cent annual turnover among adults. This reduced turnover is not always accompanied by a reduced reproductive rate inasmuch as that of $S$. olivaceus is higher than any other species. In Eumeces obsoletus (Fitch, 1955) and Sceloporus graciosus (Stebbins and Robinson, 1946; Stebbins, 1948) the age structure is more nearly balanced between young and old animals than in the preceding species. In the Eumeces, over a 5-year period adults comprised 43 per cent of the population; subadults, 26 per cent; yearlings, 26 per cent; and hatchlings only 5 per cent. In the Sceloporus, 16 per cent of the adults marked in 1942 were recorded in 1945 when they still comprised one-third of the adult population. Eight of 73 lizards in 1947 were marked in 1942. Even on a conservative basis, assuming that all of the 1942 animals had been yearlings, over 15 per cent lived to be four years of age and about half that many lived to be six. Never in this high-altitude population did young animals outnumber adults even if the yearling animals were considered young of the year.

Long-life expectancy occurs through decreased mortality of juveniles and adults. This decrease might be accomplished by parental care or might occur automatically in areas where interspecific competition was reduced. The evolution of a large body size or spinosity might reduce predator pressure and allow greater longevity of adults. An understanding of the factors involved in producing the obvious differences in age structure of lizard populations would be of great interest. 


\section{Population Density, Biomass, and Regulation of Numbers}

The fact that utas move short distances and that their normal movements are not easily interrupted by close observation made censusing of the animals by Lincoln Index method a fairly accurate procedure. Also, in the process of weighing lizards, repainting the young, and performing other operations, we had occasion to attempt to capture every lizard on the areas over a short period, usually 2-3 days. The total number removed on such occasions was consistently within 10 per cent of the Lincoln Index estimates.

During the summer and early fall, when the areas were worked intensively, we knew rather precisely how many animals were present at any particular time. The only problem was to decide which of the lizards captured were really using the study area to a significant extent and which were transients or marginal individuals. Therefore, I designated as residents those lizards that were captured at least three times within the study area; I have based density figures of adults on the number of resident lizards.

We have approached 100 per cent efficiency in registering the juvenal utas produced each year. Because of the large numbers it was rarely possible to be certain how many were present at a specified time or which were residents of the area. I have, therefore, relied almost entirely on Lincoln Index estimation of juvenile density. I have relied on it also for estimating numbers of adults at seasons other than summer and early fall, for we seldom have sufficient captures (except during the spring of some years) to determine which lizards were residents. Generally I could assume that an adult that was a resident in summer and spring was also a resident in fall and winter.

I have previously presented some data on density and biomass of utas (Tinkle, 1967). I now have more data, better refined, which make possible better estimates than those presented previously. I have determined more precisely the number of resident adults present at each season (Table 40, survivorship section). Table 47 summarizes the density estimates made on the two study areas over a period of several years. Density seldom varied by more than a factor of two on any one area in any year. The figures show clearly that density was fairly constant from March through June, but declined abruptly in August after a less precipitous drop in July. The density on the two study areas was usually about the same in each year, but area II was usually carrying more lizards than area $\mathrm{I}$.

The figures presented here based only upon known residents are somewhat at variance with those presented by Tinkle (1967) which indicated a mean density of 19 adults per acre from March to September.

Density on the study areas increases abruptly in late June or early July as recruitment of hatchlings begins. During the summer months I have available numerous index estimates of juveniles that are quite accurate and 
TABLE 47

Density (Resident Adults per Acre) on Two Study Areas in Six Years During the Breeding Season

Figures rounded to whole animals

\begin{tabular}{lcccccccc}
\hline \hline Year & Area & March & April & May & June & July & August & $\begin{array}{c}\text { Total residents } \\
\text { marked/acre }\end{array}$ \\
\hline 1960 & I & - & - & - & 11 & 10 & 5 & - \\
& II & - & - & - & - & - & - & - \\
1961 & I & - & - & - & 16 & 8 & 4 & - \\
& II & - & - & - & 22 & 11 & 7 & - \\
1962 & I & 18 & 18 & 13 & 14 & 9 & 5 & 22 \\
& II & 16 & 17 & 16 & 16 & 9 & 6 & 19 \\
1963 & I & 9 & 10 & 9 & 9 & 7 & 3 & 11 \\
& II & 11 & 12 & 14 & 14 & 9 & 7 & 15 \\
1964 & I & 17 & 17 & 17 & 18 & 13 & 8 & 20 \\
& II & 21 & 22 & 24 & 24 & 10 & 7 & 24 \\
$1965 *$ & I & 8 & 8 & 10 & 9 & - & - & 11 \\
& II & 8 & 8 & 12 & 14 & - & - & 14 \\
& Means & 14 & 14 & 14 & 15 & 10 & 6 & 17 \\
\hline
\end{tabular}

* Adults killed at end of June.

some, less accurate, for the fall months (Table 48). The figures for the two study areas and for different years are similar and the estimates of juvenile density never varied by more than a factor or two.

Biomass was calculated after simplifying assumptions were made, vi\%., that the average density of juveniles and adults is indicative of long-term trends, that each animal's weight in a particular month is near the population mean for that month, and for its size class, and that the sex ratio was practically 50:50. Biomass may then be calculated as the mean density multiplied by the mean weight of the lizards obtained from Tables 13 and 14 . The figures are certainly not exact, but they are accurate enough to indicate the trends (Table 49).

The trends in biomass are as reported by Tinkle (1967), but the figures are different. The average biomass is about 84 grams per acre, somewhat less than that calculated previously. Although there are negligible numbers of juveniles in the spring and negligible numbers of old adults in the fall and winter, there are enough to bring the mean figure to about 90 grams per acre.

Biomass is highest in the early fall when the young of the year are approaching adult size. During the winter a low of about 60 grams is reached. 
TABLE 48

Density of Juveniles on Two Study Areas Over a Thref-year Period

The figures are means per acre of several estimates or direct counts made over short periods of time (maximum, 3 days)

\begin{tabular}{ccccccc}
\hline Year & Area & June & July & August & Septcmber & October \\
\hline 1961 & I & 28 & 85 & 66 & 72 & 51 \\
& II & - & 81 & 75 & 72 & 54 \\
1962 & I & 24 & 60 & 58 & - & - \\
& II & 36 & 77 & 61 & - & 59 \\
1963 & I & 32 & 89 & 80 & 72 & - \\
& II & 29 & 119 & 100 & 98 & - \\
Mcans & & 30 & 85 & 73 & 79 & 55 \\
\hline
\end{tabular}

TABLE 49

Biomass of Juveniles and Adults Determined on a Thforetical Basis From thr. Figurfs Givin in Tables 47 and 48

\begin{tabular}{|c|c|c|c|c|c|c|c|}
\hline & $\begin{array}{l}\mathrm{x} \text { adult } \\
\text { density }\end{array}$ & $\begin{array}{l}\mathrm{x} \text { adult } \\
\text { weight }\end{array}$ & $\begin{array}{l}\text { Adult } \\
\text { biomass }\end{array}$ & $\begin{array}{c}\text { x juv. } \\
\text { density }\end{array}$ & $\begin{array}{l}x \text { juv. } \\
\text { weight }\end{array}$ & $\underset{\text { biomass }}{\text { Juv }}$ & $\begin{array}{c}\text { Total } \\
\text { biomass }\end{array}$ \\
\hline March & 14 & 4.30 & 60 & - & - & 一 & $60 \mathrm{gms}$ \\
\hline April & 14 & 4.30 & 60 & - & - & - & 60 \\
\hline May & 14 & 4.30 & 60 & - & - & - & 60 \\
\hline June & 15 & 3.89 & 58 & 30 & .69 & 21 & 79 \\
\hline July & 10 & 3.89 & 39 & 85 & .69 & 59 & 93 \\
\hline August & 6 & 3.89 & 23 & 73 & .69 & 50 & 74 \\
\hline September & - & - & - & 79 & 1.81 & 143 & 143 \\
\hline \multirow[t]{2}{*}{ October } & - & - & 一 & 55 & 1.81 & 100 & 100 \\
\hline & & & & & & \multicolumn{2}{|c|}{$\dddot{x}=84$ grams } \\
\hline
\end{tabular}

Like density, the biomass during the year varied by a factor of about two.

With the data now available we could probably estimate the secondary productivity of this species. However, knowledge of metabolic rates of utas under natural conditions is not available, but the metabolic rates are presumably low as are the energy demands for activity. I leave it for future herpetologists to measure the energy budget of the utas, but I think such a study will show that they are of minor importance in energy flow (D. R. Johnson, 1966). It has already been noted that the stomachs of utas, possibly filled twice a day, contain about 0.1 gram of food on the average, making a total of $3-5$ grams of insects consumed daily per acre in a population of average density. 
Remaining to be demonstrated is whether densities and biomasses estimated here actually exist. I have selected a few examples from the numerous occasions when attempts were made to capture and weigh as many lizards as possible on each area over a period of $1-2$ days (Table 50). Obviously, all lizards were not captured, so for this reason I have included Lincoln Inclex figures whenever they were available to indicate about what proportion of the animals were captured and weighed on each occasion.

These data are not in perfect agreement with the hypothetical data on biomass presented in Table 49, but there are several occasions (Table 50) when the number of lizards actually captured and weighed approached or exceeded the average density and biomass figures in Tables 48 and 49 . The

TABLE 50

Examples of KNown Densities and Weights of Lizards on tile Study Areas AT DIFFERENT SEASONS

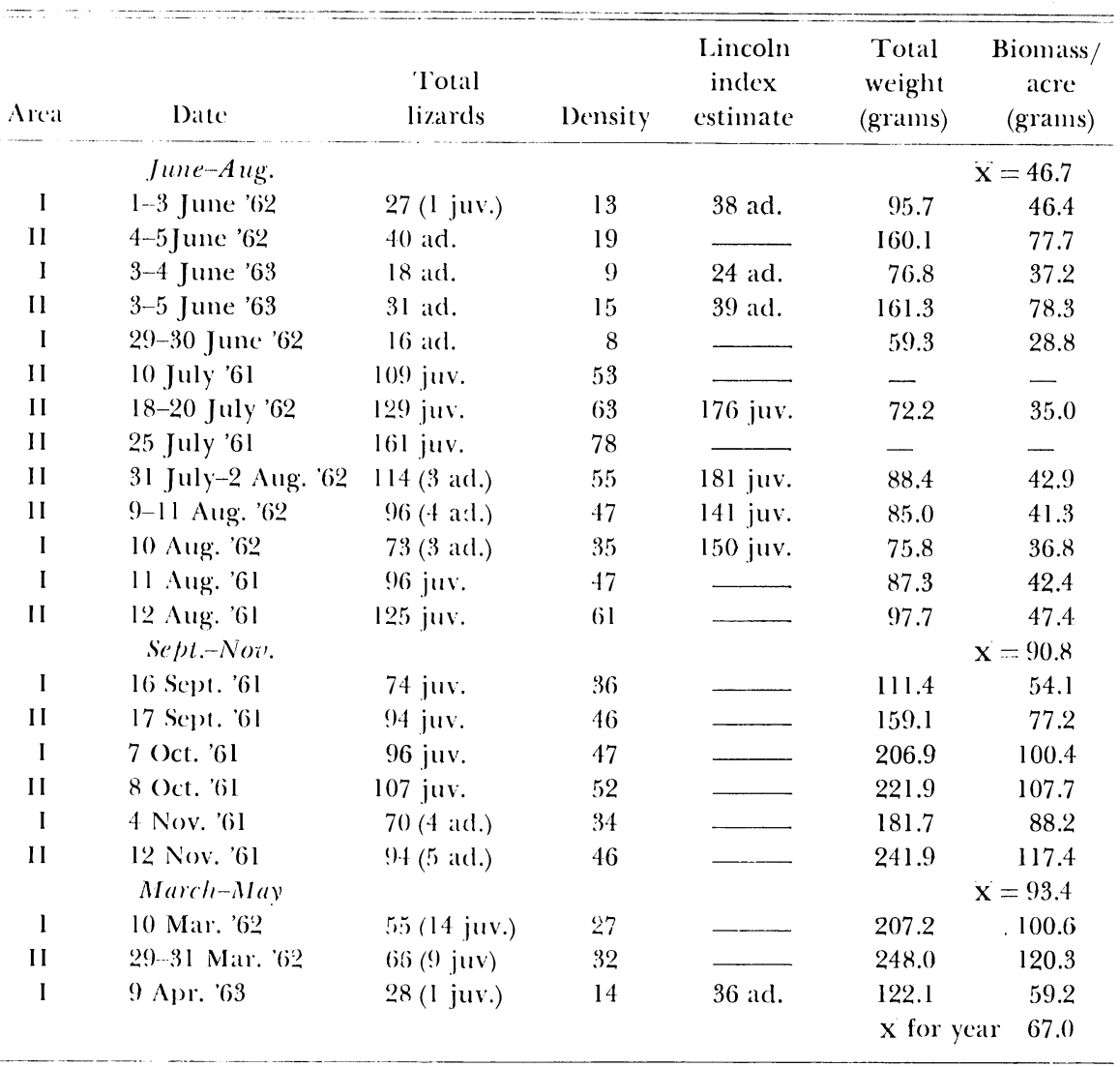


average weight of 67 grams prr acre (Table 50), based on samples that were probably never complete, compares favorably with the hypothetical mean of 84 grams per acre (Table 49).

The regulation of numbers in the populations is an interesting problem that probably cannot be solved without manipulation of field populations in enclosed areas, but some ideas can be presented.

The territorial behavior of the lizards cloubtless restricts density to some extent, but the available evidence from this study indicates that considerable contraction of territory size may occur at high densities. To the extent that aggressiveness is still maintained at such times, there will be a limit to the compressibility of territory size so that space would become limiting. On the other hand aggressiveness at very high densities may be sublued just as occurs in our laboratory populations. In such a case social hierarchies would be established which might act to prevent increasing numbers by restricting the breeding to animals dominant in the hierarchies.

As already noted, natality seems generally inversely related to population density, suggesting that density-dependent factors are operating, but this is not a very informative idea. There is little evidence of increased survivorship when natality is low or decreased survivorship when it is high, in other words, that survivorship is also density dependent.

Discussion of thl: Litiraturf: on Density and Biomass.-The data available are presented in Table 51. These data are difficult to compare because the estimates have, in some cases, been based on the total number of lizards captured without knowledge of which among them were residents.

Large species, as might be expected, have low densities. The highest densities have been recorded among tropical species. It is unfortunate, though, that so little data are available on biomass because this might allow more meaningful comparisons of species of very different sizes. Harris (1964), for example, reported a density of 36 per acre in Agama agama. He also presented clata on the mean weight of adults which can be used to estimate very roughly a biomass of about 2000 grams per acre in $A$ gama, which is many times the biomass of all species of lizards on my study areas.

Another factor making density comparisons difficult is the vertical climension in the home ranges of some lizards. The activity of Anolis limifrons, for example, is centered in trees.

The highest density reported for any lizard is that of 500 adult $\mathrm{Hemi}$ dactylus (Cagle, 1946a) in a 2400-square-foot area on Tinian Island in the Pacific. Assuming uniform dispersion over the surrounding area, a density of about 10,000 per acre is indicated.

Degenhardt (1966) provided some data based on the use of a refined 
TABLE 51

1)ata on Population Density and Biomass Avail.able from THE LITERATURE ON LIZARDS

\begin{tabular}{|c|c|c|c|}
\hline Species & $\begin{array}{l}\text { Density } \\
\text { per acre }\end{array}$ & $\begin{array}{l}\text { Biomass } \\
\text { per acre }\end{array}$ & Authority \\
\hline Sceloporus olivaceus & $17.8-25.2$ & $\longrightarrow$ & Blair (1960) \\
\hline Sceloporus undulatus & c. 70 & & Carpenter $(1959 a)$ \\
\hline Sceloporus undulatus & $\begin{array}{l}36 \text { ad.; } 112 \text { juv. } \\
\text { on one area; } 44\end{array}$ & & \\
\hline & juv. on 2 nd area & - & Cirenshaw (1955) \\
\hline Sceloporus graciosus & 1 & - & Stcbbins (1944) \\
\hline Basiliscus vittatus & $\begin{array}{c}6-11 \text { juveniles; } \\
2-4 \text { adults }\end{array}$ & 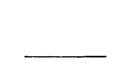 & Hirth (1963) \\
\hline Agama agama & $\begin{array}{l}7 \text { urban areas, } \\
36 \text { nat. habitat }\end{array}$ & 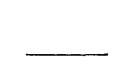 & Harris (1964) \\
\hline Anolis limifrons & $\begin{array}{l}250 \text { residents, } \\
600 \text { maximum }\end{array}$ & 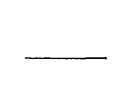 & $\begin{array}{l}\text { Heatwole and } \\
\text { Sexton (1966) }\end{array}$ \\
\hline Anolis limifroms & $\begin{array}{l}50-105 \text { depending } \\
\text { on area and season }\end{array}$ & & Sexton et al. (1963) \\
\hline Enmeces fasciatus & $\begin{array}{l}50-100 \text { in favor- } \\
\text { able habitat }\end{array}$ & $1 \mathrm{lb}$ & litch $(1954)$ \\
\hline Eumeces obsoletus & 6 & $\begin{array}{l}3 / 4 \text { lb. in } \\
\text { favorable } \\
\text { habitat }\end{array}$ & Fitch (1955) \\
\hline Eumeces egregius & 25 & 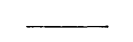 & Mount (1963) \\
\hline Cinemidophorus sexlineatus & $\begin{array}{l}100 \text { (very rough } \\
\text { estimate) }\end{array}$ & & Bellis (1964) \\
\hline Cinemidophorus sexlineatus & $\begin{array}{l}50-100 \text { on } 4900 \\
\text { sq. ft. area; very } \\
\text { rough estimate }\end{array}$ & — & Carpenter $(1959)$ \\
\hline Ameina quadrilineata & $\begin{array}{c}5.1-10 \text { juveniles } \\
7-16 \text { adults }\end{array}$ & & Hirth (1963) \\
\hline (ionalodes fuscus & 50 maximum & & $\begin{array}{l}\text { Heatwole and } \\
\text { Sexton (1966) }\end{array}$ \\
\hline Hemidactylus garmoti & $\begin{array}{c}500 \text { adults } / 2400 \\
\text { sq. ft. }\end{array}$ & & Caigle $(1964 a)$ \\
\hline
\end{tabular}

line transect method of estimating numbers. As interesting as the study may be in suggesting differences in relative abundance, it is still a crude means of obtaining density estimates.

\section{Effects of Radiation on the Population}

It became evident early in this study that the limited movements, ease of capture, and rapid turnover of utas made them an ideal subject for the study of the effects of radiation on a natural population, specifically upon 
the demographic properties. The radiation was carried out in 1962 using area I for the experiment and area II as a control. It was replicated in 1964 with area II serving as the experimental area.

Prior to radiation, laboratory studies were made to determine the closage required for sterilization and the lethal dose so that those administered in the field could be kept below these levels.

Dana and Tinkle (1965) demonstrated histologically that an x-ray dose as high as $500 \mathrm{r}$ caused only temporary sterility in males with nearly complete recovery in 36 clays. Dosages above $800 \mathrm{r}$ were evidently required for permanent sterility. The radiation dosage required to kill 50 per cent of an experimental group of lizards within 30 clays (LD 50/30) was 1000-1200 r. l)osages of $450 \mathrm{r}$ were used in both field experiments.

The most obvious effect of the racliation (see Tinkle, 1965a) was on natality (Table 36). After radiation of adults on area $I$ at the onset of the 1962 breeding season (March), the natality declined by almost 50 per cent over that of 1961. Natality in the control population (area II) also cleclined, but by less than 25 per cent. In the 1964 switchback experiment radiation was administered to adults of area II in March. The natality during the subsequent breeding season declined by 40 per cent over that of the previous year, but natality on the control area (area I) declined only 15 per cent. The clecline in natality was probably attributable, in part, to temporary sterilization of the adults. Some mutations may also have been produced that were lethal to the oflspring prior to hatching. No increase in the frequency of abnormalities among hatchlings was observed.

One consequence of ecological importance was the effectiveness of radiation in reducing natality, independent of adult density, and might be used in future field studies for this purpose.

Other effects of radiation were more subtle than that on natality and many must have occurred that were not detectable because of the nature of field data. For example, variations in growth rate were observed in this study. To separate effects of radiation from other environmental influences on growth rate would require more control over field conditions, larger samples of animals, and numerous replications of the experiments.

Throughout this study I have presented clata that may inclicate residual radiation effects, and some of these warrant further discussion. Some data could be selected from those presented on growth to indicate a lower growth rate among juveniles produced by parents that were irradiated in 1962 (area I). However, other data could be selected to show an increased rate, at least in females (Table 7); furthermore, similar data could be obtained from the control area. If radiation produced any effect on growth this was masked by normal variation in growth rates. 
Effects of radiation on movement seem clearly indirect. The low natality in the irradiated area in 1962 was not sufficiently compensated by increased immigration to avert a drop in clensity of nearly 50 per cent between 1962 and 1963. Mean recapture radii and mean distance between captures both increased on area I in 1963 compared with the previous year. These increased movements are correlated with decreased density, so are indirectly attributable to radiation. However, in 1965, no such correlation can be drawn; the density of adults was somewhat higher on the experimental area than on the control, but the mean recapture radius increased on both areas from 1964 to 1965. The mean distance between captures increased for adult males and females on the control area from 1964 to 1965, but declined somewhat in males and increased greatly in females on the experimental area. These variable results in the two experiments illustrate the difficulty of ascertaining which effects if any resulted from radiation, but indirect effects are at least indicated.

There was no indication in either experiment that the young from irradiated parents showed lower survivorship than young of the control animals. Survivorship was about the same on both areas in each of the experiments and was neither the highest nor the lowest observed in the several years of the study when survivorship estimates were not complicated by possible radiation effects.

The data on immigration likewise gave no hint of radiation effects. Although population density was greatly lowered on the experimental area in 1963, the evidence indicated that the proportion of immigrants among the resident breeders in that year was about the same on the experimental and control areas.

The sex ratio was not affected by radiation as Table 43 indicated, but other aspects of population structure evidently were (Tinkle, 1965a). The low natality on the experimental area in 1962 resulted in few surviving offspring. The variance in number of surviving offspring produced by each female parent was low. This was quite in contrast to the situation on the control area. Assuming that a differential in the production of surviving offspring is indicative of the differential in competitive advantage among the various female breeders, we can conclude that the normal process of natural selection was thwarted to some extent by the radiation.

In summary, radiation lowered natality which, in turn, resulted in a lower density of adults the following year. The lower density resulted in a second year of low natality. In addition, the effective population breeding size was altered by the low natality on the experimental area in 1962. These are the only clearly evident effects of radiation, though influence on the 
movements of individuals by the indirect effects of radiation on density was suspected.

Turner, Hoddenbach, and Lannom (1965), working with Uta stansburiana at the Nevada Test Site, found no variations in growth rates of lizards that could be attributed with certainty to the chronic irradiation given them in the field experiments.

\section{Comparative Demography of Uta}

One of the clistant objectives of my studies of the Texas populations was to predict what differences in demography might occur in that area of the range of 'Uta stansburiana where climatic conditions were quite different from those of Texas, for example, in the northern part of the range where winters are more rigorous and the growing seasons and reproductive seasons shorter. The demographic environment is an important component of the total selective pressures on individuals and deserves detailed comparisons. One might predict, for example, that northern lizards might have a lower birth rate because of the shorter reproductive season. Under such conditions maintenance of a constant population size would require a lower death rate than prevails in Texas. This would, in turn, lead to a difference in the age structure of the northern and Texas populations.

I chose an area in northwestern Colorado for such a study and decided to concentrate on only a few objectives. No attempt was made to study the populations in Colorado as intensively or as broadly as was done in Texas.

The stucly area was the same size as those used in Texas, and was located in Colorado National Monument, Mesa County, Colorado, very near the Utah border. A rather gross extrapolation of the comparative climatic conclitions between western Colorado and western Texas have been taken from Visher (1954) and are shown in Table 52. The figures are crucle, but the comparison leaves little doubt that the winters are more rigorous than in Texas and that the activity season for the utas is almost certainly shorter.

More precise data are available from long-term records kept at the weather station in Colorado National Monument about 3 miles from my study area, but at an elevation 2000 feet higher. The 25-year average (194064) snowfall was 41 inches, near the extrapolated figure in Table 52. The mean January minimum was $19^{\circ} \mathrm{F}$ and the mean maximum $37^{\circ} \mathrm{F}$. The mean annual precipitation was about 11 inches.

Discription of the Lizards and of the Study AREa.-The study area is probably not located in optimum habitat, which apparently occurs in the 
TABLE 52

A Comparison of Some Gross Chimatic Differences Between Western Colorado and Western Texas

Data extrapolated from Visher (1954)

\begin{tabular}{|c|c|c|}
\hline Itcm & Texas & Colorado \\
\hline Isotherm & $60^{\circ} \mathrm{F}$ & $50^{\circ} \mathrm{F}$ \\
\hline Gen. climatic classification & $\begin{array}{l}\text { Hot summer; } \\
\text { mild winter }\end{array}$ & $\begin{array}{l}\text { Short and not hot } \\
\text { summer; cold winter }\end{array}$ \\
\hline Gen. climatic region (Köppen) & Steple & Steppe \\
\hline Biotic Province (Dice) & $\begin{array}{l}\text { Boundary of Kansan } \\
\text { and Chihuahuan }\end{array}$ & Navahonian \\
\hline Normal precipitation & ca. 15 inches & ca. 12 inches \\
\hline Normal annual snowfall & cal. 6 inches & ca. 50 inches \\
\hline $\begin{array}{l}\text { Date of } 75 \text { per cent probability of } \\
\text { frost in fall }\end{array}$ & After Dec. 15 & Nov. $1-10$ \\
\hline Nomal per cent Oct. nights & & \\
\hline below freczing & 1 per cent & 40 per cent \\
\hline Normal no. of nights below freczing & ca. 90 & ca. 130 \\
\hline $\begin{array}{l}\text { Normal no. of days with temp. } \\
\text { continuously below freezing }\end{array}$ & ca. 4 & ca. 20 \\
\hline $\begin{array}{l}\text { Normal no. of days with temps. } \\
\text { of } 0^{\circ} \text { F or lower }\end{array}$ & .5 & 7 \\
\hline Normal no. of days with snow cover & cal. 3 & ca. 40 \\
\hline $\begin{array}{l}\text { Duration of season with little } \\
\text { or no plant growth }\end{array}$ & 30 & 150 \\
\hline Normal Jan. daily minimum & $30^{\circ} \mathrm{F}\left(\mathrm{X}=40^{\circ} \mathrm{F}\right)$ & $35^{\circ} \mathrm{F}\left(\mathrm{X}=20^{\circ} \mathrm{F}\right)$ \\
\hline Nommal Jan. daily maximum & $50^{\circ} \mathrm{F}$ & $35^{\circ} \mathrm{F}$ \\
\hline $\begin{array}{l}\text { Bate when normal daily temp. } \\
\text { rises above } 50^{\circ} \mathrm{F}\end{array}$ & Late Feb. & Early April \\
\hline $\begin{array}{l}\text { Date of } 75 \text { per cent probability of no } \\
\text { frost in spring } \\
\text { Normal length of frost-free season }\end{array}$ & $\begin{array}{l}\text { Mid-Feb. } \\
215 \text { days }\end{array}$ & $\begin{array}{l}\text { Mid-March } \\
175 \text { days }\end{array}$ \\
\hline
\end{tabular}

boulder strewn ravines. Such areas would be difficult to work; capture of juveniles, for example, would be extremely difficult. The area was, instead, laid out across some rocky arroyos and hillsides that are favorable habitat, but included about 50 per cent sagebrush flats in which utas were seldom found.

The appearance of the subspecies in Colorado (Pl. IV) (U. s. stansburiana) is quite different from that of the Texas race (U. s. stejnegeri). The Colorado lizards are a drab gray to brown with almost no dorsal markings except for the bands on the tail. Sexual dimorphism is minimal. Their reduced wariness, compared with the Texas lizards, made them easy to capture. The many differences in pattern, morphology, and behavior of these 
lizards suggest that the two races are behaving as good biological species, but I have seen obvious areas of intergradation between the two in southwestern Utah and such zones have been reported elsewhere by other authors. Either gene flow between the populations is reduced or selection pressures are strong to maintain such striking differences between the two races over the short distance across their area of overlap.

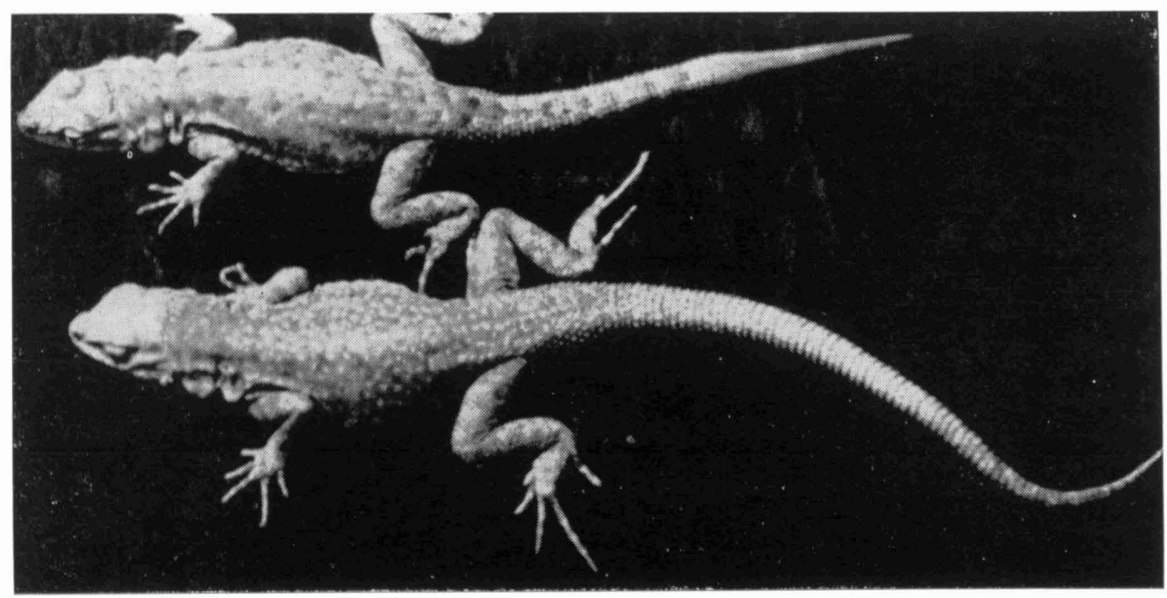

PLATE IV

Adult female (top) and adult male of Uta stansburiana stansburiana from Mesa County, Colorado. Note the reduced degree of dimorphism in pattern as compared with the Texas lizards. Photo by Gary Ferguson.

Reptile Associates on the Colorado Area.-Utas are numerically dominant on the study area, but several other species are present in fair numbers, and it is not so simple to judge their relative abundance as it was in Texas. Cnemidophorus tigris, Sceloporus undulatus, Cnemidophorus velox, Crotaphytus wislizeni, Crotaphytus collaris and Urosaurus ornatus are present in about that order of abundance. Sceloporus graciosus is extremely abundant in places near the study area, but was never captured within it.

Only one species of snake, Masticophis taeniatus, was seen in the study area, and it is fairly common there. Other snakes are doubtless present at times for they have been captured nearby. These include Pituophis catenifer, Crotalus viridis, Elaphe guttata, and Hypsiglena torquata.

Masticophis, Crotalus, and Hypsiglena are known to prey on lizards, as does the leopard lizard Crotaphytus wislizeni. All of the lizards on the area are insectivorous and, as such, represent potential competitors of the 
utas at some time in their ontogeny. The only records of predation on utas are: one marked uta removed from the stomach of a juvenile Masticophis and another from the stomach of a leopard lizard taken outside the study area.

The Reproductive Cycle of Colorado Utas.-The weakest part of my knowledge of reproduction of these lizards is the precise time of the year when enlargement of the ovarian follicles begins. My earliest sample is from April 8-9, 1966, when all of the females of adult size were in reproductive condition. However, only 5 per cent of them had oviducal eggs and none

TABLE 53

Reproductive Data on Uta stansburiana stansburiana from Mesa County, Colorado Figures shown are percentages: $c .1$. = corpora lutea; $\mathrm{N}=$ sample size

\begin{tabular}{|c|c|c|c|c|c|}
\hline \multirow[b]{2}{*}{$\begin{array}{l}\text { Date of } \\
\text { Sample }\end{array}$} & \multirow[b]{2}{*}{$\mathrm{N}$} & \multicolumn{3}{|c|}{ Females with } & \multirow[b]{2}{*}{ Juveniles } \\
\hline & & $\begin{array}{l}\text { eggs or } \\
\text { fresh c.l. }\end{array}$ & $\begin{array}{l}2-3 \mathrm{~mm} \\
\text { follicles }\end{array}$ & $\begin{array}{l}4-7 \mathrm{~mm} \\
\text { follicles }\end{array}$ & \\
\hline 11-13 May '63 & 46 & 33 & 14 & 55 & 7 \\
\hline 27 May '65 & 75 & 40 & 26 & 34 & 1 \\
\hline 11-12 June '65 & 50 & 60 & 14 & 28 & 0 \\
\hline 23-24 June '65 & 48 & 36 & 31 & 31 & 4 \\
\hline (9-10 July '65 & $47^{*}$ & 39 & 6 & 13 & 0 \\
\hline $22-23$ July '65 & $50+$ & 16 & 0 & 2 & () \\
\hline 5-6 Aug. '65 & $50+$ & 6 & 0 & 0 & 0 \\
\hline $8-9$ April '66 & 40 & 5 & 10 & 50 & 25 \\
\hline 11-13 May '66 & 46 & 33 & 14 & 55 & 7 \\
\hline 27-30 Мау '66 & 36 & 50 & 20 & 25 & 3 \\
\hline $7-8$ June '66 & 31 & 52 & 26 & 16 & 3 \\
\hline
\end{tabular}

* 40 per cent postreproductive.

+82 per cent postreproductive.

$\$ 100$ per cent postreproductive.

had corpora lutea, definite indications that they were laying their first clutch of the year. One-half of the females were postreproductive by midJuly, and 82 per cent by July 23, 1965. On the basis of this information I would say that the enlargement of the ovarian follicles commences about mid-March and ends about mid-July. Assuming that about one month is required for each clutch, there is sufficient time for each female to lay three clutches during the reproductive season. Nothing can be said at present about the factors that initiate or terminate the estrous cycles.

The actual data available on the reproductive cycle are shown in Table 53. One fact not shown in the table is that from one to 21 per cent of the 
animals in each sample had both recent corpora lutea and yolked follicles, providing proof for multiple clutches. Note that on May 27, sixty per cent of the females had yolked follicles; ovulation of these would be expected in the next two weeks. That this was the case can be seen from the sample of June 11-12 in which the majority had oviducal eggs. The next sample of June 24 showed the majority again with yolked follicles. Inasmuch as about one month elapsed between the May 27 and June 23-24 samples, in both of which the majority of females were in the same reproductive stage, this may be considered the average time between clutches.

The earliest sample available (April, 1966) contained about 25 per cent immature females compared with about 7 per cent in the early May samples. The first-clutch natality is probably considerably smaller than the theoretical maximum because of the presence of so many immature animals at the onset of the reproductive season.

Fat Storage by Colorado Lizards.-I weighed no fat bodies from Colorado lizards, but I measured the length of the right fat body in each female and noted its thickness. These data are shown below:

\begin{tabular}{lcc}
\multicolumn{1}{c}{ Date } & Mean length of fat body & Relative thickness \\
April $8-9,1966$ & $5.2 \mathrm{~mm}$ & Thin \\
May 11-13, 1966 & 3.3 & Thin \\
May 27, 1965 & 3.0 & Thin \\
June 11-12, 1965 & 2.8 & Thin \\
June 23-24, 1965 & 2.6 & Thin \\
July 9-10, 1965 & 2.8 & Thin \\
July 23-24, 1965 & 5.4 & Fairly thick \\
August 5-6, 1965 & 7.0 & Fairly thick
\end{tabular}

Seven adult females collected in September and October had a mean fat body length of $9.0 \mathrm{~mm}$, and the fat bodies were quite thick. All of these data indicate that increase in size of fat bodies is coincident with the cessation of reproduction and that the size of fat bodies in the fall is more than double that during the breeding season. Therefore, the fat bodies may be important in the reproduction of Colorado lizards just as was the case in Texas.

Reproductive Potential.-Some females were damaged when collected, so data are not available for all females in the samples. There are no reproductive females available after July, so only the period April-May and June-July can be compared with Texas clata for the same months.

The smallest sexually mature female was $36 \mathrm{~mm}$, but all of those $38 \mathrm{~mm}$ or above were mature; I have taken $37 \mathrm{~mm}$ as the average size at sexual maturity, considerably smaller than in the Texas lizards. This difference is 
presumably a genetic one because Texas lizards of $40 \mathrm{~mm}$ cannot be brought into estrous in the laboratory by experimental manipulation of the laboratory environment.

The average clutch size based on counts of yolked follicles, eggs, or corpora lutea in 256 females was 3.2, almost an egg less than in the Texas populations, but not so different when lizards of the same size from Texas and Colorado are compared. The mean clutch size based on 145 counts of follicles, 92 of eggs, and 19 of corpora lutea were 3.2, 3.3, and 3.1, respectively, so mean clutch size can be accurately determined by any one of the techniques. The mean clutch size for the three size groups considered is shown below:

$\begin{array}{lccc}\text { Size group } & 35-39 \mathrm{~mm} & 40-44 & 45-49 \\ \text { April-May } & 2.8(12) & 3.3(77) & 3.9(38) \\ \text { Junc-July } & 2.5(4) & 2.9(71) & 3.2(54) \\ \text { Mean and Total } & 2.7(16) & 3.1(148) & 3.5(92)\end{array}$

As in the Texas population there is an increase in the mean clutch size with increase in size of the females. The mean clutch size is almost one egg greater in the largest than in the smallest size class. The clutch size later in the reproductive season is smaller than in the early part, and this is not because the females comprising the late season samples are smaller. The smallest size class (35-39 mm) comprises 9 per cent of the April-May samples, only 3 per cent of those in June and July. The largest size class comprised 30 per cent of the April-May samples and 42 per cent in June and July.

The mean clutch size for 40-44- and 45-49-mm females is about the same in Texas and Colorado. There are no mature females in Texas in the 35-39-mm class and none in the 50-54-mm class in Colorado. Therefore, the small size of the Colorado lizards may be an important factor in the smaller clutch size in this population.

If each Colorado female laid 3 clutches of average size, which would seem to be the maximum number of clutches in the short breeding season, then the reproductive rate would be about 9 eggs per female per generation. However, this probably should be nearer 8 because of the large number of immature females in the population at the onset of the reproductive season. This estimate is smaller than the minimum of 12 eggs per female in Texas.

The first eggs were evidently laid in mid-April in 1966 inasmuch as none of the females collected on April 8-9 had laid recently, and only 2 contained oviducal eggs. We were not on the study area when the young lizards hatched in 1966, but in 1965 the first hatchlings appeared near the 
arca on July 23, in the area on July 25. Assuming the time of first egg-laying was about the same in both years, then a period of postdepositional development of nearly 100 days is indicated. This is about one month longer than in Texas. Whether the period of development is really this long or whether the first eggs laid simply do not hatch is not known, but the first alternative seems more likely.

The (irowth of Colorado Utas.-We made no concerted effort to measure growth rates, but some clata have accumulated from recaptures of juveniles. Because many of the recaptures were far apart chronologically the estimate of daily increment must be considered a minimum one. I have used only data involving more than $1 \mathrm{~mm}$ of growth and at least one week between recaptures. Growth records for 23 males and 23 lemales, all between the months of July and October, indicate a mean growth rate of $.21 \mathrm{~mm}$ per clay in males (.16-.43) and .18 in females (.08-.42). In Texas the rates for a comparable season were .22 and .19 for males and females, respectively. The growth rates in the two areas must be considered practically identical.

As in Texas, the lizards in Colorado showed essentially no growth during the reproductive season, but lizards that lived more than one season did show growth between the two seasons. For 13 adult males the growth after sexual maturity averaged $2.2 \mathrm{~mm}$; for 6 adult females, $1.8 \mathrm{~mm}$.

The rapid growth rate of the Colorado lizards suggests that there would be considerable overlap of age classes in size. Data on size groups present in the Colorado population are available for the months of May, June, July, August, and October from the study area; none of the lizards sampled for the reproductive study are included (Fig. 20). Considering the May-June graph as a single unit, 36 per cent of the adult animals in May-June, 1966, were young of the summer of 1965 . The largest size attained by these lizards was $47 \mathrm{~mm}$ in males, $46 \mathrm{~mm}$ in females. Thus, there is almost complete overlap of the age classes in size. For example, of the 44-mm lizards, 7 were yearlings and 12 were at least 2 years of age; of the $45-\mathrm{mm}, 7$ were yearlings and 17 were at least 2 years old. Age classes cannot be separated on the basis of size and the situation is more complicated in Colorado than in Texas because of the large number of 2-year-old adults in the Colorado populations.

Figure 20 shows that the July-August population is composed predominantly of juveniles which do not exceed $32 \mathrm{~mm}$ during this time whereas the smallest yearlings are $39 \mathrm{~mm}$. By October, some young of the summer have reached $41 \mathrm{~mm}$; the smallest adults at the same time are $43 \mathrm{~mm}$. Therelore, sometime during the late fall, certainly during the following spring, the age classes begin to overlap and some inclividuals can no longer be aged on the basis of size. 
Age at Maturity.-Females reach sexual maturity at $37 \mathrm{~mm}$ on the average. The exact size at maturity in males is not known from histological evidence, but is assumed to be about $42 \mathrm{~mm}$ on the basis of the size of breeding adults recorded on the study area. Some females reach the minimum size at maturity in about 90 days after hatching. The exact time in males is

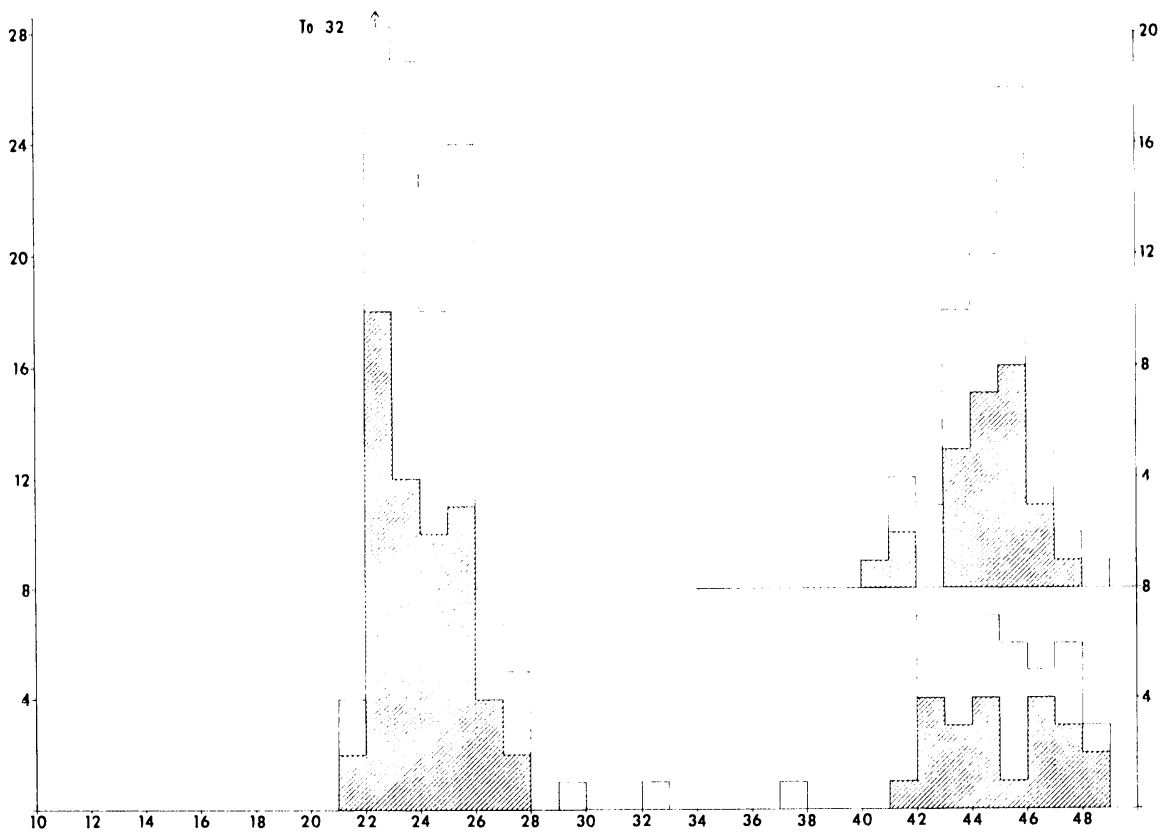

Fic: 20. Size groups present among marked utas on the Colorado study area for certain months when reliable data were available. Abscissa shows snout-vent length in millimeters; ordinate shows number of individuals. The left histogram is for July and August, 1965, not including the adults. The $33-\mathrm{mm}$ record belongs with this histogram. The right lower histogram is for May, 1966, and includes the $37-\mathrm{mm}$ individual. The right upper histogram is for June, 1965, and June, 1966. Solid areas are males, open areas females. Sec text for additional explanation and cliscussion.

not known, although some hatchling males marked in late July had reached $41 \mathrm{~mm}$ by early October, so some of them probably mature within three months also. The fact that samples collected in April for the study of reproduction contained 25 per cent immature females indicates that many late hatchlings clo not mature before the spring, approximately 9 months after hatching.

Some data from the marked lizards have a bearing on estimation of the age at maturity. Of those marked at hatching in 1965, or at least very near the 
time of hatching, 11 males and 11 females survived until October, at least, when the area was worked for the last time that year, but were not recorded on the area in 1966. These lizards had reached, by October, a mean length of $35.7 \mathrm{~mm}$ ( $\left.\begin{array}{l}\delta \\ \delta\end{array}\right)$ and $32.8 \mathrm{~mm}$ ( $q$ \& ), so were still well short of mature size. It might be argued that these lizards did not survive to maturity because they were not found in 1966 and that this was a group growing at a slower rate than the ones that clid survive. This is not the case, for all the lizards that did survive to the 1966 breeding season had been the same size in October as the non-surviving lizards. Nine males averaged $35.3 \mathrm{~mm}$ in length and 5 females averaged 32.8 . Twelve males and 11 females that were marked for the first time in ()ctober averaged 30.2 and 31.3, respectively. The mean size in October of young-of-the-year males, using all of the clata above, was 33.5 (22 records) and of females 32.2 (27 records).

The critical question is how many of these lizards would continue to grow after mid-October in Colorado and reach adult size prior to the onset of the reproductive season the following April. Our recapture data are not sufficient to answer the questions for the area was worked for the last time in 1965 in mid-October, and work was not resumed until late May of 1966. However, the size distribution of lizards collected for the reproductive study on April 8-9, 1966, provided an important clue. This sample was certainly biased in favor of larger lemales because of the purpose for which the collection was being made, so any estimate of the frequency of immature animals in the population made from the sample will be minimal. Even so, 10 of the 40 females in the sample were immature. Our survivorship data indicate that among the adult lizards, a third or more were two years old or older. Therefore, we may assume that about 25 of the 40 lizards collected were yearling animals and 10 of these were immature at the onset of the reproductive season. As stated previously, this is almost certainly a minimum estimate, so the proportion of the animals hatched in 1965 that had reached maturity at the start of the 1966 breeding season may have been only 50 per cent.

Therefore, even though the Colorado lizards mature when smaller, and have approximately the same growth rate as those in Texas, they are still not all able to reach maturity by the onset of the reproductive season because they hatch late in the summer and have a shorter growing season than those in Texas. These data will be discussed later in connection with the evolution of reproductive rates in these utas.

The Behavior of Ciolorado Utas.-Utas in Colorado are much less wary than those in Texas and use the assertive bobbing display much less frequently. Interactions between individuals are less often seen in casual 
observation than was true in Texas. During the summer of 1965 no interactions between individuals were observed.

From May 31-June 2, 1966, individual lizards on the Colorado study area were followed by 4 observers throughout the day. Similar procedures were carried out on June $8-9$ during the late evening and early morning.

Utas in this area do not become active as early as those in Texas. High bluffs to the east shade the study area until about 7:(0) A.M., and a high thin cloud cover is frequently present during the summer mornings. As a result of these factors and the cool early mornings, utas are not active until 8-9 A.M.

As in Texas, they spend most of the time basking and leeding opportunistically. During the midclle of the day, most of them seek shelter beneath rocks, but females are far more likely than males to be basking during the micllle of the day.

The nature of the landscape blocks many social interactions. Utas frequently pass in close proximity without seeing one another. It was largely on the basis of negative information on social interactions and on the basis of laboratory behavior that I had formed the opinion (Tinkle and Woodward, 1967) that the utas were not territorial and that this was one of the major reasons for the high degree of home range overlap on the stucly area.

To test the aggressiveness of the lizards we could not depend upon chance observation of the rare interactions. Non-resident males and females were caught outsicle the area, tied to long threads and introduced into the visual range of study-area residents. In this manner we found that lizards of both sexes do behave aggressively toward lizards of the same sex. We were also surprised to find that a male gave immediate indication of sex recognition clespite the very low degree of sexual dimorphism. When a resident male was confronted with a non-resident male, it always displayed immediate aggressive reactions, but immediately began courtship of a female.

There was little doubt among any of the observers that the degree of aggressiveness shown by these utas was less than that displayed by the Texas lizards. The resident seemed satisfied to drive the non-resiclent only a short distance away. They did not persist in their aggression once the non-resident retreated a short distance or displayed a submissive posture. Such behavior is suggestive of the existence of a social hierarchy, and I think that the available evidence suggests that such may exist. First, as many as 3 males may have closely congruent home ranges. Tinkle and Woodward, 1967, wrongly interpreted this as absence of territorial behavior; instead, the overlap is permitted by the weak territoriality and tolerance for other lizards that behave subordinately. Secondly, during the summer of 1966 we observed lizards which immediately ran beneath a rock or quickly retreated at the approach of a larger, dominant male even before they were challenged by 
him. Three encounters were observed between males of different ages; in each the older male was clearly dominant. Three encounters were seen between lizards of the same age class. Two of these were between females and in neither instance dicl one retreat even though one of the encounters resulted in vigorous fighting. The third was between two males of nearly iclentical size. One succeeded in chasing the other out of its area.

These clata are not a strong case for a social hierarchy, but they are about as good as that previously reported for natural populations. The fact that in all three cases of interactions between young and old males (all adults), the younger one retreated without even returning the challenge of the older is significant. This type of behavior was not observed in the rexas study.

This presumed hierarchical arrangement of the Colorado lizards comes about, in my view, from the greater overlap of age classes than occurs in Texas, and from the non-random distribution of good habitat in the area. The systcm, compared with a strict territorial one, allows higher densities to develop in times of high resource levels. The interesting question is whether regulation of numbers has also been achieved in such hierarchies by restriction of reproduction primarily to the dominant lizards. I cloubt that this occurs because all adult females appear to be reproductive during the breeding season.

The difference in clegree of aggression between lizards of the Texas and Colorado populations may have a genetic basis. In Texas a uta, generally, has a single chance to reproduce. In Colorado, a submissive individual, becausc of the longer life expectancy, has a greater opportunity to reproduce in another season. Perhaps uncler such circumstances selection in favor of aggression will be less rigorous.

Courtship and Copllation.-Twenty-two courtships, which were not staged by the observers, were observed, and none ended in copulations. Several copulations were observed between lizards in which a female selected for her receptivity was introduced by the observer to a resident male. The courtship and copulation by Colorado lizards in the laboratory was studied in cletail by one of my students (Ferguson, 1965) and the field and laboratory behavior appeared identical in every respect. The Colorado lizards do less circling of the female than those in Texas, they lick the females more frequently, copulation lasts much longer (a minute or more) and involves a dozen or more pelvic thrusts compared with half that number in Texas.

The female rejects the courting male by giving a shudder bob that is similar to the male courtship bob. This rejection mechanism seems quite effective in quickly discouraging the male. The rejection mechanism in 
Texas usually involves retreat of the female, but the male is not as readily discouraged by this behavior and may attempt courtship several times.

One of the apparently dominant (2-year-old) males courted 2 different lemales, one of which was also courted by a yearling male. Each of two other females was courted by two different males. One dominant male performed 16 courtships, or all but 6 of the total number observed. Even without a highly territorial system the dominant male may enjoy a reproductive advantage.

Home Ranges and Movements.-Home range was studied from recapture data, by tracking inclividual lizards and by calculation of the mean recapture radii. A comparison of these data for both Colorado and Texas lizards is presented in Table 54.

TABLE 54

Somf Comparative Data on Home-Range Size of l.izards in Colorado and Texas, Determined by 'Three Differfant Methods

All figures are in acres unless otherwise noted, and all are means

\begin{tabular}{lcccccc}
\hline & \multicolumn{2}{c}{ Texas } & \multicolumn{3}{c}{ Colorado } \\
\cline { 2 - 6 } \multicolumn{1}{c}{$\begin{array}{l}\text { Method of } \\
\text { Estimate }\end{array}$} & Males & Females & Males & Females & Males & Females \\
\hline Recaptures & .11 & .03 & .06 & .05 & .06 & .02 \\
Tracking & .21 & .05 & - & .07 & - & .02 \\
Probability density function & .49 & .15 & .27 & .23 & .38 & .09 \\
Recapture radlius (ft.) & 37.4 & 20.4 & 26.6 & 27.1 & 34.7 & 18.8 \\
\hline
\end{tabular}

Tinkle and Woodard, 1967, had noted from the 1965 data in Colorado that the recapture radii and computed home ranges for males and females were not significantly different. However, the 1966 data do not indicate this. The males in 1966 had significantly larger recapture radii and larger home ranges based upon recaptures and tracking than did females. This is the first instance in which the recapture radius failed to give consistent results, probably because of the short-term study in 1966 (2 weeks) compared with the long-term study in 1965. Never in the Texas population, in which the mean recapture radius was not influenced by the time over which captures were made, did the period of recaptures approach so short a time as two weeks. This may be too short a time to measure accurately the movements, particularly of the less conspicuous females.

Density differences between 1965 and 1966 may also be involved in the differences in home-range size, for there were 17 resident males and 18 
females in 1965 compared with 13 and 8, respectively, in 1966. These differences, however, will not fully explain the results, for females should have shown a larger increase in mean recapture radius than males. I'm afraid that my (Tinkle and Woodard, 1967) statement about the utility of the recapture radius was overly optimistic. I still believe it is the best available measure of relative movements, but a longer period of time than I suspected may be necessary to estimate it accurately.

Movement from the Hatching Site.-Essentially all young produced on the area in 1965 were marked, and some survived to become study-area residents in 1966 . The distance from the hatching site to the geometric center of the home range for the single female involved was 21 feet; for 4 males it averaged 110 feet (67-139). The data are too scant to make fruitful comparisons with the Texas lizards. However, it was clear that movement of young lizards far out of the study area was at a much higher frequency than in the Texas population. These clata will be presented in the section on emigration.

\section{Population Dynamics of Colorado Lizards}

Natality.-In 1965, effort was made to mark all young produced in the area. This was not completed by August, when the summer work was terminated, because all of the young had not hatched. I returned to the area in October to complete registration of the young; no new lizards were being found on the area when I left. The total number of young produced by the resident adults was assumed to be the number marked between July and October, viz., 128 (64 of $\delta$; 64 o $q$ ). The actual number produced was only about 7 per female or what might be expected from only two clutches of eggs, or three if many females were immature at the onset of the season.

The natality was lower than ever observed in the Texas population even after radiation of the adults. It is about one-half the average in Texas over several years. To maintain a stable population size, assuming an annual turnover of adults, at least two of the 7 young produced must survive to maturity. Data are available on both crude mortality of the young and on population turnover among the adults.

Survivorship.-Of all of the young marked in 1965, thirty-four are known to have survived to a mature size during the 1966 reproductive season. This figure of 20 per cent survivorship of young is only slightly higher than that recorded in Texas. However, there does appear to be a difference in the time at which most mortality occurred. Seventy-four of 128 young (58 per cent) survived at least to October. The mean age of the Colorado lizards would be about 10 weeks at the time the area was worked in October. Figure 
17 shows that only about half as many of the Texas young survive to this age. Therefore, the pattern of age-specific mortality is different for the Colorado and Texas lizards. The winter mortality is evidently quite high in Colorado, for few of the lizards handled in October were recaptured the lollowing spring as adults.

In 1965, fifty-nine adult lizards were marked, of which 13 were recovered in 1966, a crude adult survivorship of 22 per cent which is higher by twice than the adult survivorship observed in Texas over 5 generations.

Immigration and EMigration.-The same assumptions about immigrants were made as in the Texas population. (Of 93 young marked inside the stucly area boundaries, 12 emigrated (13 per cent). Of 33 aclults marked outside the area, 3 (9 per cent) moved into the area as residents. Seven of 21 (39 per cent) resident adults in 1966 were considered immigrants. These estimates are not greatly different from those for the Texas population.

One fact about emigration is strikingly different in the two populations. In the summer of 1966 we attempted to kill as many utas as possible within 200 yards of the study area. In doing so, we collected 10 distant emigrants from the study area, almost 10 per cent of the total young marked the previous year. Eight of the 10 were males that were between 107 and 690 feet from their last recorded 1965 capture point $(\overline{\mathrm{X}}=366$ feet $)$. The two lemales were recorded 110 and 190 feet away from their last 1965 capture points.

Not only is this a high proportion of distant emigrants, but the total of 10 exceeds the total number of such long distance movements recorded for the Texas lizards over a five-year period. Eight of the 10 were first-year aclults, reinforcing my contention that the greater overlap of age classes forces more subadult animals out of the population. It may seem paradoxical to attribute the development of social hierarchies to reduced aggression and at the same time attribute greater emigration to the overlap and consequent conflict between lizards of different ages. Some additional discussion of this point seems warranted. In Texals a lizard must reproduce during its first reproductive season or die without issue. Under such conditions selection woukl favor strong aggression. At the same time there would appear to be little advantage to a lizard leaving a certain area. In Colorado, a nonaggressive lizard may remain submissive to a dominant one in a social hierarchy, but live to breed during its second or third reproductive season. However, by emigrating it might be able to breed during its first season also. Perhaps there is a genetic basis for the phenotype of "disperser" which has a selective advantage under one demographic regime, but not in another.

Population Structurf.-The sex ratio of juveniles and adults was essentially 50:50. The ratio was exactly 50:50 among the young marked in 
1965. Of the 59 adults handled in 1966, thirty-two (54 per cent) were males; of 59 handled in 1965, the same proportion were females.

Excluding adult lizards that were marked for the first time in 1966, there were 46 adults of known age handled in the 1966 breeding season. Of these, 13 (28 per cent) were 2 nd-year adults. Of the 21 study area residents in 1966,15 were of known age and 5 of the 15 (33 per cent) were 2ncl-year adults. In no year clid the proportion of 2 nd year adults in the Texas population exceed 11 per cent.

Population Density and Biomass.-Tinkle and Woodward, 1967, have already presented data on these aspects of the Colorado population in 1965. Little can be added to the information on biomass, but some additional figures on clensity are available.

The Colorado lizards average considerably smaller than those in Texas with the result that the average adult biomass is about 40 grams to the acre compared with about 50 in Texas. However, as I have previously pointed out, the clensity of Colorado lizards is higher in optimum habitat; only about 50 per cent of the study area in Colorado supports a high clensity of utas.

In 1965, the clensity in the Colorado population was 17 resident adults per acre, compared with an overall average in Texas of about 14. In 1966, the density in the Colorado population was quite low with only 21 resident lizards or a density of about 10 per acre.

I have determined the density and biomass in only one other population of Uta, that being near Mercury, Nevada, in the summer of 1964. Over a period of 6 weeks, Donald Woodard and I recorded 29 utas on an area slightly larger than those used in Texas and Colorado. The density here was about 12 per acre and the biomass per acre about 34 grams. The Nevada habitat was in very dry desert and yet the density reached by utas there was not far below that recorded in far more productive habitats in other parts of its range.

Discission of (iomparative: Drmography.-With only about two-thirds turnover in adults annually, and with about 80 per cent crude mortality of young, the population size can be maintained at a stable level with each female producing only 7 young per year, i.e., with about one-half the reproductive rate required in Texas.

Whether the differences in the structure and dynamics of these populations have a genetic basis is a question that must be asked by someone interested in the evolutionary aspects of ecology. The answer is that both are probably involved, but I think that the differences in the environments of the two areas are primarily responsible for the differences in demography. 
The shorter activity season and lower temperatures in Colorado may result, indirectly, in a prolonged life expectancy which leads in turn to altered age structure, altered breeding structure, and possibly altered behavior.

It might be sufficient from the ecological point of view to end with the observation that the relatively low birth rate in the Colorado lizards balances a relatively low death rate compared with that in Texas. However, these are scarcely cause and effect relationships. The observed differences in reproductive rates call for an evolutionary explanation which I shall attempt to provide.

The clutch size in Colorado is smaller than in Texas. Because it is difficult to visualize selection for a lower clutch size, per se, another explanation of the difference must be sought. I have already pointed out that even with a smaller size at maturity nearly one-half of the young produced each year are immature by the onset of the reproductive season in the following spring. If these lizards in Colorado had to reach $42 \mathrm{~mm}$, the minimum size at maturity in Texas lizards, they might not reproduce at all during their first season.

Therefore, I think that selection has acted to favor a smaller size at maturity in the northern part of the range. Because this results in smaller females, it automatically results in smaller clutches, for it is practically universal among lizards for clutch size to be directly related to body size within the same species. All of this assumes that the difference in body size has a genetic basis and that the maturation at different sizes in the two populations, likewise, is genetically determined. Some support for the latter idea comes from our photoperiod experiments with the utas in which positive responses were never obtained from Texas lizards under any photoperiod or temperature regime if the lizards were smaller than the minimum size at maturity.

Numerous experiments need to be done. Transfer of lizards between the two areas would answer some questions as would comparison of the size at maturity in Texas and Colorado lizards that were raised in Colorado and Texas, respectively.

The fact remains that if selection has favored a smaller size at maturity it has resulted in a higher reproductive rate than would have been possible if the size at maturity were the same in the two populations. The northward distribution of this species must be limited at those points where the reproductive rate is not sufficiently high to prevent population fluctuations that occasionally or regularly go to zero.

It might fairly be asked why the clutch size of Texas lizards has not increased further. This would presumably necessitate an increase in body 
size or a reduction in egg size that might be inimical to survival. The former effect would result, presumably in greater competition with larger species. A larger body size might also delay the achievement of sexual maturity and result in a lowered reproductive rate.

A recent study (McCoy and Hoddenbach, 1966) on the clutch size of the lizard Cnemidophorus tigris was made in the same Colorado and Texas populations in which I studied Uta. C. tigris has larger and fewer clutches in Colorado than in Texas. These differences are not explicable on the basis of differences in egg size or body size in the two populations. They conclude that the single broodedness in Ciolorado is owing to the short growing season and absence of food for lizards emerging early from hibernation, and that the larger clutch size evolved as compensation for the climatically enforced single broodedness. Whatever the cause of the single broodedness, there is no necessity for linking clutch size with that phenomenon. I would think that larger clutches would be equally advantageous in a multi-brooded population. That the utas and the whiptails have evolved opposite geographic trends in clutch size is clear, but I think the reason for this is not related directly to the number of clutches produced.

\section{EPILOgue}

The demography of reptiles is still very poorly known. The majority of published papers on the subject contain little information of value. Comments in the literature on clutch size based on a very few individuals, on movements, on growth, and on longevity are of little interest because the data are too scant to make comparisons with populations of other species, or even to define those aspects of the populations that were purportedly measured.

The question must be asked, why are any thorough population studies of value? This can be answered as follows: 1. They provide quantitative data of value to the theoretical ecologist. 2. They suggest problems to the experimentalist which can be solved only by manipulating populations in the field or laboratory. 3. They are of interest to the evolutionary biologist because they provide data on such things as population size, population turnover, behavioral characteristics, and degree of movement which influence the course of evolution at the population level.

As I terminate this study, I am still left with a feeling of dissatisfaction; despite a wealth of descriptive information, the big problems still remain to be solved. However, I would not have been aware of some of them without the background of the long-term population study. Some of the problems remaining for which I hope to search for a solution are as follows: 
1. What regulates the population numbers of this species, and is the regulatory mechanism different in different parts of the range?

2. What are the adaptive values of the observed differences in sexual dimorphism, and behavioral patterns of the utas? What factors have influenced the reduction of sexual dimorphism in the northern utas? Have the same factors resulted in social hierarchies or are these simply byproducts of differences in population age structure?

3. What advantage accrues to monogamous animals? What would happen to lertility, natality, and survivorship under a system of forced polygamy? What would happen if the sex ratio were drastically altered in favor of females?

4. What part has the difference in coexistent species had on the ecology and evolution of the utas in different parts of their range?

5. What influence on population dynamics can actually be demonstrated through alteration of the population age structure?

I think such questions can be answered in a reasonable length of time with a dozen or more enclosed areas of about 1 acre each, in which breeding structure, predator levels, density, and other factors could be manipulated at the whim of the investigator. Such studies are feasible in a rapidly breeding species like uta which is quite immune to close observation and disturbance and amenable to laboratory studies. Most of the ecological and evolutionary problems that are important exist in utas and most of them can be investigated provided suitable field and laboratory facilities are available.

Over and above the major questions raised by this study of utas there is a need for much more data, descriptive though it may be, on reptile populations. This information can be obtained in a relatively short time provided the problem is properly approached. All juveniles and adults in selected populations must be marked, preferably for at least two generations, and their survivorship determined. This operation alone would provide much more useful data than is currently available for most reptile populations.

Finally, I would like to emphasize that I think at the termination of this lengthy study that more may be gained by manipulation of field populations of lizards than can ever be gained by post facto reasoning from descriptive data. Neverth sless, I feel that the studies of most reptile populations have simply not progressed to the point where such an approach is possible. Such relatively simple matters as reproductive rate and density under natural conditions are still unknown for the vast majority of species. 


\section{SUMMARY}

Nearly 13,000 captures of more than 3700 Uta stansburiana were compiled over a six-year period in populations of this lizard in Texas, Colorado, and Nevada, generally on study areas just over 2 acres in extent. The most intensive study was of the populations in western Texas where the purpose was to quantify as many aspects of the population ecology of this species as possible, and to use such information as a basis of predicting what differences in the biology of the species would exist in other parts of its range.

In Texas, utas lay at least three clutches of 4 eggs each compared with a maximum of three, of 3 eggs each, in Colorado. In both populations, clutches are larger in larger females and larger early in the season than late. The difference in clutch size has presumably come about by selection of a smaller size at maturity in the Colorado populations.

The onset of reproduction in the Texas populations has been shown in the laboratory to be brought about primarily by high temperatures, rather than by lengthened photoperiods. Further, the lizards are protected in Texas against unseasonal reproduction by a period in late fall and early winter when they are refractory to those factors that ordinarily initiate the estrous cycle.

The development of the first clutch of eggs in the spring has been shown experimentally to depend primarily upon utilization of the lipid reserve stored during the fall in the corpora adiposa of the females.

Both the time of initiation of breeding and the size of the clutch vary from year to year. The first is variable because of variations in temperature and sunlight in the springs of different years. The differences in clutch size are associated with differences in size structure of the populations in different years.

The time required for a female to procluce a clutch of eggs may vary from as little as 4 weeks to as long as 6-7, and is generally longer early in the reproductive season. About two months are required for the egg to hatch after it is laid, both in the field and in the laboratory. The mean weight of an egg at deposition is about .25 gram; a whole clutch of eggs may constitute 25-30 per cent of the body weight of a gravid female.

Over a period of 6 summers, hatchlings first appeared in the Texas population between June 17 and 23; in Colorado, they hatch one month later. Hatchlings in Texas have been recorded from June to October. The proportion of these surviving to maturity is about the same as the proportion hatching at each period of the reproductive season.

Sperm" stored in female utas in special oviducal receptacles are capable of fertilizing eggs for at least 81 days after isolation of a female from males. 
Hatchling utas grow at the rate of about $0.2 \mathrm{~mm}$ per day from June to September and at about half this rate in October and November. Rapid growth continues, usually, until sexual maturity is reached, on the average about 4 months after hatching, and almost always within 8 months. Growth of adults is almost negligible after sexual maturity.

During early growth utas shed their skin at about 3-week intervals. In the fall shedding occurs at 5-6-week intervals and ceases during the winter. During the breeding season, adults shed at intervals of 4-8 weeks.

In the first week of life, increase in weight is negligible. After this utas increase from a mean weight of 0.3 grams to about 1 gram within 30 days, to about 2 grams in 50 days. The greatest weights are attained by adults in the spring; some loss of weight occurs during the breeding season.

The tails of juvenal utas elongate about twice as fast as the body, i.e., at a rate of about $0.5 \mathrm{~mm}$ per day. If the tail is broken, the rate of growth of the remaining base is always less than the rate of the intact tail. Because regeneration occurs at the same rate as the growth of an unbroken tail, a broken tail actually grows faster than an unbroken one.

About 10 per cent of juveniles and 30 per cent of adults sampled outside the study area had broken tails. Little regeneration occurs the first 10 days following a break, during which time a callous forms. Regeneration of tails broken near the base is much faster than those broken distally; the reverse is true of the growth rate of the unbroken base. There is little difference in the rates of tail regeneration between juveniles and adults, but in adults the growth of the unbroken base is negligible. On the study areas, as many as 4 breaks have been incurred by a single individual and at least 1 break is the average; fewer than one-third of the adults on the study areas reached maturity without losing a tail at least once.

Utas are opportunistic insectivores; they feed throughout the year whenever temperatures are high enough for them to be active. Ants and small beetles comprise 50 per cent of the diet by volume; the total volume of food eaten per day is probably about 0.2 gram.

Six species of snakes and 3 of lizards are known predators on utas, but the proportion falling prey to these animals is unknown. Winter kill, mostly attributable to snowfall, may be as high as 25 per cent. Males are more often victims than females. About 3 per cent of the mortality to utas during these studies was attributable to the investigators themselves.

Abnormalities are rare in utas and were not increased by radiation of the lizards. Injuries are more common and utas have been observed to recover from even such serious ones as loss of an eye or a limb. About 3 per cent of the lizards handled in this study showed evidence of some abnormality or previous injury. 
Male and female utas are both territorial, but much more so in Texas than in Colorado. Both sexes perform push-up behavior, even in the absence of other lizards, but the function of this is unknown. During aggressive displays the back is strongly arched and the body compressed and tilted at an angle toward the adversary. During mating the male arches his back, circles the female, licks her, and, if not rejected, attempts copulation. The details of mating and copulation procedures are different in the Texas and Colorado populations. The aggressiveness by lizards of both sexes in Texas leads to a sort of quasi-monogamy. In the Colorado population the reduced aggressiveness evidently results in a social hierarchy in which the older adults are dominant over the yearling adults. Aggression is not limited to the adult utas, but becomes quite strong in the juveniles when they are about one-half grown; presumably it results in greater movement by them.

In the laboratory the behavior of utas is sharply altered. Aggression becomes reduced and courtship practically ceases. Instances of homosexual matings, never observed in the field, are fairly frequent.

The daily life of the utas is one of basking in morning and evening with intermittent feeding. During midday they retreat beneath the shade of plants or rocks, but almost never underground except in winter. Activity begins shortly after sunrise and continues until clark, when the lizards burrow into sand. The same activity pattern continues throughout the year, but is shortened during colder periods. It is also shorter in the Colorado lizards in the northeastern part of the range of the species.

The size of home range of utas has been estimated in three ways. These estimates vary from .10 to .49 acre in adult males and from .03 to .15 in adult females in Texas. Comparable estimates in Colorado are from .06 to .38 in males and .02 to .23 in adult females. There was no correlation between the estimated home-range size and the number of captures on which the estimate was based. The home range of juvenal utas less than $35 \mathrm{~mm}$ snout-vent length was only .003 acre (130 square feet). The mean recapture radius was found to be the most constant parameter useful for comparing degree of movement, but it is influenced by density and to some extent by the duration of time over which captures are made. The mean radius was about 37 feet for adult males and 20 for adult females in Texas. Similar figures were obtained for Colorado lizards. The average distance between captures was 51 feet in adult males, 27 in females; it was less than 15 feet for young lizards of both sexes.

After hatching, utas generally clisperse very little, the average being only 11 feet in young lizards, 60-70 in adult males, and 40-50 in adult 
females. The distance from the hatching site to the geometric center of the adult home range averaged 84 feet in males, 53 in females.

Utas are strongly heliothermic and maintain a body temperature near $36-38^{\circ}$ ( ) cluring the summer by behavioral thermoregulation. The period of maximum activity of the utas in summer corresponds closely with those times of the clay when the ambient temperatures are in the above range. The critical thermal maximum was about $43^{\circ} \mathrm{C}$, and only about 50 seconds are required for adult lizards to reach this thermal point in the open on a clear day in summer.

The natality in the Texas populations is high, about 15 young per lemale per year on the average. Survivorship of the hatchlings to maturity is rarely above 20 per cent and is somewhat higher in females than in males. The turnover in resident adults is about 90 per cent per year compared with $6(0) 7()$ per cent in Colorado where the reproductive rate of the lizard is about half that observed in Texas. The maximum longevity observed for any Texas uta actually marked at hatching was 100 weeks, but the average life expectancy at birth is only about 19 weeks. Only one lizard was handled during this study that had survived for three years.

Emigration and immigration by juveniles were low in both Texas and Colorado populations, probably not exceeding 20 per cent in any year. Immigration by adults was higher, possibly as high as 40 per cent in the Texas populations. Records of long-distance movements by emigrants from the study area comprised only 0.2 per cent of all lizards marked in the Texals population, but approached 10 per cent in the Colorado population where the greater overlap of age classes may force greater emigration through competitive interactions of the yearling adults with the surviving adults from the previous generation. In Texas, practically the entire breeding population is composed of animals hatched the preceding summer, animals less than a year old, whereas in Colorado about one-third of the breeding population is two years of age.

Population density varies from year to year, but not by more than a factor of two. The average adult density in the Texas population was about 14 resident adults per acre, but this declined to about 6 in August near the end of the reproductive season. The density of juveniles reached a high of about 85 per acre in July. The biomass represented by these figures averages 84 grams per acre. In Colorado, the density in two breeding seasons varied from 10 to 17 adult residents per acre with average biomass of adults (40 gms per acre) less than in Texas because of the small size of the Colorado lizards.

The effects of radiation administered in two different years to the resident adults in Texas were noted in a drastic fall in natality and a subse- 
quent lower density of resident adults the following year. Indirect effects on movements and growth through the effect on density were suspected, but not provable from the available data.

Experimental analysis will be required to answer the questions raised by this study concerning the regulation of numbers, the function of differences in breeding structure, and in behavior of the species in clifferent parts of its range. For such studies enclosed populations in which variables can be manipulated will be required.

The literature on lizard biology, which has been reviewed throughout this report, is painfully inadequate. Much more intensive studies of at least two generations in the life of the lizards seem required to broaden the base of factual knowledge concerning the demography of lizard populations. The demographic environment is extremely important as a major component of the total environment in which the selection of alternate phenotypes occurs in natural populations.

\section{ACKNOWLEDGMENTS}

To all students, too numerous to mention, that have participated at some time in some aspect of this study, I wish to express my appreciation not only for their physical effort, but for many discussions and ideas, some of which they may recognize in these pages.

Don McGregor, Don Woodard, Gerard Hoddenbach, James Platz and Norman Williams must be singled out for their dedication to the field program under living and working conditions that would, and did, discourage other inclivicluals. For their laboratory work on various aspects of the research on $U t a$, I wish to thank Sumner Dana, Garry Knopf, William Hahn, Louis Irwin, Orlando Cuellar, Gary Ferguson, and Ann Connor.

Other inclividuals who frequently participated in the research, often on a purely voluntary basis, deserve special acknowledgment. These include Dan McGregor, Jerry Gerald, Whit Gibbons, Royce Ballinger, Charles McKinney, Michael Sabath, and Garry Knopf.

I am deeply indebted to Chester Rowell of Texas Technological College for identification of plants from my study areas and for numerous photographs that he took at my request. My sincere appreciation is clue Earl Vest of Monahans, Texas, who made available to me an area of his ranch near Kermit, Texas, where my studies have been conducted. Dr. William Milstead of the University of Missouri at Kansas City kindly provided me with his unpublished data on feeding habits of $U t a$, that I have incorporated into this report.

I am thankful to many persons of Kermit, Texas, for their support of 
our work and for providing certain facilities and services to us. Among these, I am particularly indebted to Dave Sclair, Judge W. E. Cook, Fred Pearson, and Maud Green. Similarly, I wish to thank Superintendent Paul Ellis and his staff of Colorado National Monument for use of some land and facilities for our field studies there.

A study of this duration and intensity would not have been possible without research support. Different aspects of the research discussed here were supported by the U.S. Atomic Energy Commission (AT-40-1-2673) and the National Science Foundation (G-7143, G-15608, GB-1425).

Nelson G. Hairston read and criticized the entire manuscript. His suggestions resulted in many improvements. I am also grateful to L. B. Slobodkin for reading parts of the manuscript and to William H. Burt for editing the entire manuscript. Those errors of fact and judgment that remain are, however, the responsibility of the author.

John Tottenham of the Museum of Zoology converted my rough graphs into finished illustrations.

Finally, I would like to dedicate this treatise to my wife, Marjorie, who for many years endured the months of my absence in the field and yet continuously encouraged me; to my undergraduate and graduate students who devoted themselves unstintingly to the ofttimes arduous field work; and to Fred R. Cagle of Tulane University who gave me the incentive, and later the opportunity and training, to be a professional biologist.

\section{LITERATURE CITED}

Allred, D. M., D. E. Beck, ANd C. D. Jorgenson

1963 Biotic communities of the Nevada Test Site. Brigham Young Univ. Biol. Ser., 2:1-52.

Asplund, K. K., AND C. H. Lowf

1964 Reproductive cycles of the iguanid lizards Urosaurus ornatus and Uta stansburiana in Southeastern Arizona. Jour. Morph., 115:27-33.

Auffenberg, W., And W. W. Milstead

1965 Reptiles in the Quaternary of North America. In: The Quaternary of the United States. H. E. Wright and D. G. Frey, Eds.: 557-568. Princeton Univ. Press, Princeton, N.J.

BAKER, J. R.

1947 The seasons in a tropical rain forest. 6. Lizard (Emoia). Jour. Linn. Soc. (Zool.) 41:243.

BALlinger, R. E., And C. O. MCKinney

1967 Variation and polymorphism in the dorsal color pattern of Uta stansburiana stejnegeri. Amer. Midl. Nat., 77:476-483.

BANTA, B. H.

1962 Preliminary remarks upon the zoogeography of lizards inhabiting the Great Basin of the western United States. Wasmann Jour. Biol., 20:253-287. 
Bartholomew, G. A., Jr.

1950. The effects of artificially controlled temperatures and day length on gonadal development in a lizard Xantusia vigilis. Anat. Rec., 106:49-60.

1953 The modification by temperature of the photoperiodic control of gonadal development in the lizard Xantusia vigilis. Copeia, 49-50.

BARWICK, R. E.

1959 Life history of the common New Zealand skink Leiolopisma zelandica. Trans. Roy. Soc. N. Z., 86:331-380.

BARWICK, R. E., AND C. BRYANT

1966 Physiological and biochemical aspects of hibernation in the scincid lizard Egernia cunninghami (Gray, 1832). Physiol. Zool., 39:1-20.

BELLIS, E. D.

1964 A summer six-lined racerunner (Cnemidophorus sexlineatus) population in South Carolina. Herpetologica, 20:9-16.

BLAIR, W. F.

1960 The rusty lizard. A population study. Univ. Texas Press, Austin.

Bostic, D. L.

1966 A preliminary report of reproduction in the teiid lizard, Cnemidophorus hyperythrus beldingi. Herpetologica, 22:81-90.

BOYD, M. M. M.

1940 The structure of the ovary and the formation of the corpus luteum in Hoplodactylus maculatus Gray. Quart. Jour. Micros. Sci., 82:337-375.

BRATTSTROM, B. H.

1953 The amphibians and reptiles from Rancho La Brea. Tians. San Diego Soc. Nat. Hist., 11:365-392.

BRECKENRIDGE, W. J.

1943 The life history of the black-banded skink, Eumeces septentrionalis (Baird). Amer. Midl. Nat., 29:591-606.

Brown, E. E.

1956 Nests and young of the six-lined racerunner Cnemidophorus sexlineatus Linneaus. Jour. Elisha Mitchell Sci. Soc., 72:30-40.

Bustard, $\mathrm{H}$.

1963 Growth, sloughing, feeding, mating, gestation, life span and poor health of chameleons in captivity. Copeia, 704-706.

1964 Egg laying and incubation of the striped mountain lizard Pholidobolus montium (Teiidae) with notes on an incubator. Brit. Jour. Herp., 3:163-164.

1965 Observations on the life history and behavior of Chameleo hohneli Steindachner. Copeia, 401-409.

1966 Observations on the life history and behavior of Chameleo bitaeniatus Fischer. Herpetologica, 22:13-23.

Bustard, H., AND R. Hughes

1966 Gekkonid lizards: average ages derived from tail loss data. Science, 153:1670-1671.

CAGLe, F. R.

1946a A lizard population on Tinian. Copeia, 4-9.

$1946 b$ Tail loss and regeneration in a Pacific island gecko. Copeia, 45.

1948 A population of Carolina anole. Nat. Hist. Misc., 15:1-5.

1950 Notes on Holbrookia texana in Texas. Copeia, 230. 
Carpenter, C. C.

$1959 a$ A population of Sceloporus undulatus consobrinus in southcentral Oklahoma. Southwest: Nat., 4:110-111.

$1959 b$ A population of the six-lined racerunner (Cnemidophorus sexlineatus). Herpetologica, 15:81-86.

1960 a Parturition and behavior at birth of Yarrow's spiny lizard Sceloporus jarrovi. Herpetologica, 16:137.

$1960 b$ Reproduction in Oklahoma Sceloporus and Cnemidophorus. Herpetologica, 16:175-182.

1961 Patterns of social behavior of Merriam's canyon lizard (Sceloporus m. merriamiIguanidae). Southwest. Nat., 6:138-148.

1962 A comparison of the patterns of display of Urosaurus, Uta and Streptosaurus. Herpetologica, 18:145-152.

Carpenter, C. C., and G. Grubits, ili

1960 I) ominance shifts in the tree lizard (Urosaurus ornatus-Iguanidae). Southwest. Nat., 5:123-128.

1961 Time-motion study of a lizard. Ecology, 42:199-200.

ChaNiY, A. H., INI) R. E. GORDON

1954 Notes on a population of Sceloporus merriami. Tex. Jour. Sci., 6:78-82.

Cimapman, B. M., AND R. F. Chapman

1964 Olservations on the biology of the lizard Agama agama in Ghana. Proc. Zool. Soc. London, 143:121-132.

Churcil, G.

1962 The reproductive cycles of the Javanese house geckos Cosymbotus platyurus, Hemidactylus frenatus and Peropus mutilatus. Copeia, 262-269.

CIARKE, R. F.

1965) An ethological study of the iguanid lizard genera Callisaurus, Cophosaurus and Holbrookia. Emporia State Res. Stud., 13:1-66.

Ciole, I. C.

1954 The population consequences of life history phenomena. Quart. Rev. Biol., $29: 103-137$.

COOPRE, J. S.

1965 Notes on fertilisation, the incubation period and hybridisation in Lacerta. Brit. Jour. Herp., 3:218-220.

COWlis, R. B., AND C. M. BOgERT

19.4 A preliminary study of the thermal requirements of desert reptiles. Bull. Amer. Mus. Nat. Hist., 83:261-296.

Cirenshaw, J. W.

1955 The life history of the southern spiny lizard Sceloporus undulatus undulatus Latreille. Amer. Midl. Nat., 54:257-298.

Cuellar, O.

1966 Delayed fertilization in Ula stansburiana. Copeia, 549-551.

1966b Oviducal anatomy and sperm storage structures in lizards. Jour. Morph., 119: $7-20$.

DANA, S. W., AND D. W. TINKLE

1965 Effects of X-radiation on the testes of the lizard, Uta stansburiana stejnegeri. Int. Jour. Rad. Biol., 9:67-80. 
DANIEL, P. M.

1960 Growth and cyclic behavior of the West African lizard Agama agama africana. Copeia, 94-96.

\section{DAREVSKY, I.}

1957. Seasonal changes of fat bodies and gonads in some lizards of the Arax river valley in Armenia. Zoologichesini Zhurnal, 39:1209-1218.

DEGENHARDT, $W . \mathrm{G}$.

$1966 \Lambda$ method of counting some diurnal ground lizards of the genera Holbrookia and Cnemidophorus with results from the Big Bend National Park. Amer. Midl. Nat., 75:61-100.

DUTTA, S. K.

1944 Studies on the sexual cycle in the lizard, Hemidactylus flaviviridis (Rüppel). Univ. of Allahabad Stud., 8:57-153.

ETHERIDGis, R.

1964 The skeletal morphology and systematic relationships of sceloporine lizards. Copeia, 610-631.

Evans, L. T.

1938 a Cuban field studies on territoriality of the lizard, Anolis sagrei. Jour. Comp. Psychol., 25:97-125.

1938b Courtship behavior and sexual selection of Anolis. Ibid., 26:475-496.

1951 Field studies of the social behavior of the black lizard, Ctenosaura pectinata. Amer. Mus. Novit., 1493:1-26.

1961 Structure as related to behavior in the organization of populations in reptiles: In: Vertebrate Speciation, 148-178. Univ. of Tex. Press, Austin.

Ferguson, G. W.

$1966 a$ Releasers of courtship and territorial behavior in the side-blotched lizard Uta stansburiana. Anim. Behavior, 14:89-92.

1966b Effect of follicle-stimulating hormone and testosterone propionate on the reproduction of the side-blotched lizard, Uta stansburiana. Copeia, 495-497.

Firch, H. S.

1935 Natural history of the alligator lizards. Trans. Acad. Sci. St. Louis, 29:3-38.

$1940 \wedge$ field study of the growth and behavior of the fence lizard. Univ. Calif. Publ. 7ool., 44:151-172.

1954 Life history and ecology of the five-lined skink, Eumeces fasciatus. Univ. Kans. Publ. Mus. Nat. Hist., 8:1-156.

1955 Habits and adaptations of the Great Plains skink Eumeces obsoletus. Ecol. Monogr., 25:59-83.

1956a A ten-year-old skink? Herpetologica, 12:328.

1956b An ecological study of the collared lizard (Crotaphytus collaris). Univ. Kans. Publ. Mus. Nat. Hist., 8:213-274.

1958 Natural history of the six-lined racerunner (Cnemidophorus sexlineatus). Ibid., $11: 11-62$.

FrTCH, H. S., AND H. W. GREENE

1965 Breeding cycle in the ground skink, Lygosoma laterale. Ibid., 15:565-575.

Fox, W., AND H. C. DEssauer

1957 Photoperiodic stimulation of appetite and growth in the male lizard, Anolis carolinensis. Jour. Expt. Zool., 134:557-575.

1958 Response of the male reproductive system of lizards (Anolis carolinensis) to unnatural daylengths in different seasons. Biol. Bull., 115:421-439. 
FUKADA, H.

1965 Breeding habits of some Japanese reptiles. Bull. Kyoto Gakugei Univ. Ser. B, $27: 65-87$.

GivLer, J. P.

1922 Notes on the oecology and life history of the Texas horned lizard, Phrynosoma cornutum. Jour. Elisha Mitchell Sci. Soc., 37:130-137.

GoldberG, S. R., AND C. H. Lowe

1966 The reproductive cycle of the western whiptail lizard (Cnemidophorus tigris) in southern Arizona. Jour. Morph., 118:543-548.

HAHN, W. F.

1964 Seasonal changes in testicular and epididymal histology and spermatogenic rate in the lizard Uta stansburiana stejnegeri. Jour. Morph., 115:447-460.

Hahn, W. E., AND D. W. TINKLE

1965 Fat body cycling and experimental evidence for its adaptive significance to ovarian follicle development in the lizard Uta stansburiana. Jour. Expt. Zool., 158:79-86.

HaMLETt, G. W. D.

1952 Notes on breeding and reproduction in the lizard Anolis carolinensis. Copeia, 3-5.

HARRIS, V. A.

1964 The Life of the rainbow lizard. Hutchinson Tropical Monographs, Hutchinson and Co., Ltd. London.

HeATwole, H., ANd O. J. SeXton

1966 Herpetofaunal comparisons between two climatic zones in Panama. Amer. Midl. Nat., 75:45-60.

HirTh, H. F.

1963 The ccolngy of two lizards on a tropical beach. Ecol. Monogr., 33:83-112.

Hoddenbach, G. A.

1966 Reproduction in western Texas Cnemidophorus sexlineatus (Sauria:Teiidae). Copeia, 110-113.

HoTTON, N., III

1955 $A$ survey of adaptive relationships of dentition to diet in the North American Iguaniclae. Amer. Midl. Nat., 53:88-114.

HUNSAKER, D., II

1959 Birth and litter sizes of the blue spiny lizard Sceloporus cyanogenys. Copeia, 260.

1962 Ethological isolating mechanisms in the Sceloporus torquatus group of lizards. Evolution, 16:62-74.

InGER, R. F., AND B. GREFNBERG,

1966 Annual reproluctive patterns of lizards from a Borncan rain forest. Ecology, 47:1007-1021.

IRWIN, L. N.

1965 Diel activity and social interaction of the lizard Uta stansburiana stejnegeri. Copeia, 99-101.

JOHNSON, C.

1960 Reproductive cycles in females of the greater earless lizard Holbrookia texana. Copeia, 297-300.

JoHnson, D. R.

1966 Diet and estimated energy assimilation of three Colorado lizards. Amer. Midl. Nat., 76:504-509. 
JOHNSON, R. M.

1953 A contribution to the life history of the lizard Scincella laterale (Say). Tulane Stud. Zool., 1:11-26.

JORGENSON, C. O., AND W. W. TANNER

1963 The application of the density probability function to determine the home ranges of Uta stansburiana and Cnemidophorus tigris. Herpetologica, 19:105-115.

KeHL, R., AND C. CombescoT

1955 Reproduction in the Reptilia. In. The Comparative Physiology of Reproduction and the Effects of Sex Hormones in Vertebrates. Mem. Soc. Endocrin., 4:57-74.

KNOP', G. N.

1963 Sexual, geographical, and individual variation in three Texas populations of the lizard, Uta stansburiana stejnegeri. Amer. Midl. Nat., 70:74-89.

KNOWLTON, G. F.

1934 Lizards as a factor in the control of range insects. Jour. Econ. Entomol., 28:998-1004.

1936 Lizard digestion studies. Herpetologica, 1:9-10.

KNOWLTON, G. F., AND IE. W. ANTHON

1935 Uta stansburiana stansburiana (Baird and Girard). Copeia, 183.

KNOWLTON, G. F., AND W. L. ThOMAS

1936 lood habits of skull valley lizards. Copeia, 64-65.

KOISTEIN, F.

1938 Lin Beitrag zur Eierkunde und zur Fortpflanzung der Malaiischen Reptilien Bull. Raffles Mus., 14:81-167.

KRANIF, G.

1946 Veranderungen von Nachkommenziffer und Nachkommengrosse sowie der Altersverteilung von Inseleidechsen. Zeitschr. Naturforsch., 1:700-710.

LEWIS, 'T. H.

1951 The biology of Leiolopisma laterale (Say). Amer. Midl. Nat., 45:232-240.

Licht, P.

1964a The temperature dependence of myosin-adenosinetriphosphotase and alkaline phosphotase in lizards. Comp. Biochem. Physiol., 12:331-340.

$1964 b$ A comparative study of the thermal dependence of contractility in saurian skeletal muscle. Comp. Biochem. Physiol., 13:27-34.

1965 The relation between preferred body temperature and testicular heat sensitivity in lizards. Copeia, 428-436.

LORENZ, K.

1966 On aggression. Harcourt, Brace and World, Inc., New York, N.Y.

Lowe, C. H., JR.

1954 Normal field movements and growth rates of marked regal horned lizards Plirynosoma solare. Ecology, 35:420-421.

1955 A new subspecies of Urosaurus graciosus Hallowell with a discussion of relationships within and of the genus Urosaurus. Herpetologica, 11:96-101.

MAHENDRA, B. C.

1936 Contributions to the bionomics, anatomy, reproduction and development of the Indian house-gecko, Hemidactylus flaviviridis Rïppel. Part I. Proc. Indian Acad. Sci., 4:250-281. 
Marshall, A. J., AND R. HoOK

1960 The breeding biology of equatorial vertebrates: reproduction of the lizard Agama agama lionotus Boulenger at latitude $0^{\circ} 01^{\prime}$ N. Proc. Zool. Soc. London, 134:197-205.

MAYHEW, W. W.

1961 Photoperiodic response of female fringe-toed lizards. Science, 134:2104-2105.

$1963 a$ Reproduction in the granite spiny lizard, Sceloporus orcutti. Copeia, 144-152.

$1963 b$ Biology of the granite spiny lizard, Sceloporus orcutti. Amer. Midl. Nat., 69:310-327.

1964 Photoperiodic responses in three species of the lizard genus Uma. Herpetologica, 20:95-113.

1965 a Growth response to photoperiodic stimulation in the lizard Dipsosaurus dorsalis. Comp. Biochem. Physiol., 14:209-216.

1965b Reproduction in the sand-dwelling lizard Uma inornata. Herpetologica, 21:39-55.

1966a Reproduction in the arenicolous lizard Uma notata. Ecology, 47:9-18.

1966b Reproduction in the psammophilous lizard Uma scoparia. Copeia, 114-122.

McCoy, C. J., JR., ANd G. A. Hoddenbach

1966 Geographic variation in ovarian cycles and clutch size in Cnemidophorus tigris (Teiidae). Science, 154:1671-1672.

\section{McGinnis, S.}

1966 Scelotorus occidentalis: preferred body temperature of the western fence lizard. Science, 152:1090.

MCKinNEY, C. O., AND R. E. BALLinger

1966 Snake predators of lizards in western Texas. Southwest. Nat., 11:410-412.

MCNAB, B. K.

1963 A model of the energy budget of a wild mouse. Ecology, 44:521-532.

Miller, M. R.

1948 The seasonal histological changes occurring in the ovary, corpus luteum, and testis of the viviparous lizard, Xantusia vigilis. Univ. Calif. Publ. Zool., 47:197224.

1951 Some aspects of the life history of the yucca night lizard, Xantusia vigilis. Copeia, 114-120.

1959 The endocrine basis for reproductive adaptations in reptiles. In. Comparative Endocrinology (A. Gorbman, Ed.), 499-516. John Wiley and Sons, Inc., N. Y.

MiLsTEAD, W. W.

1959 Drift-fence trapping of lizards on the Black Gap Wildlife Management Area of southwestern Texas. Texas Jour. Sci., 11:150-157.

1961 Observations of the activities of small animals (Reptilia and Mammalia) on a quadrat in southwest Texas. Amer. Midl. Nat., 65:127-138.

Mittleman, M. B.

1942 A summary of the iguanid genus Urosaurus. Bull. Mus. Comp. Zool., 9:105-181.

Mount, R. H.

1963 The natural history of the red-tailed skink, Eumeces egregius Baird. Amcr. Midl. Nat., 70:356-385.

Mulaik, D. D.

1946 A comparative study of the urinogenital system of an oviparous and two ovoviviparous specics of the lizard genus Sceloporus. Bull. Univ. Utah, 37:1-24. 
Noble, G. K., AND H. T. BRAdi.eY

1933 The mating behavior of lizards: its bearing on the theory of sexual selection. Ann. N. Y. Acad. Sci., 35:25-100.

Panigel, M.

1956 Contribution I.'Eude de l'ovoviviparité chez les reptiles: gestation et parturition chez le Lézard vivipare Zootoca zivipara. Annales des Sciences Naturelles, 18:569668 .

PEARson, O. P.

1954 Habits of the lizard I.iolaemus multiformis multiformis at high altitudes in southern Peru. Copcia, 111-116.

RAND, A. S.

1964 Inverse relationship between temperature and shyness in the lizard Anolis lineatopus. Ecology, 45:863-864.

1965 On the frequency and extent of naturally occurring foot injuries in Tropidurus torquatus (Sauria:Iguanidac). Papeis Avulsos de Depto. Zool., 17:225-228.

REGAMEY, J.

1935 Les caracterès sexuels de Lézard (Lacerta agilis L.). Rev. Suisse Zool., 42:87-168.

ROLLINAT, R.

1934 La V'ie des Reptiles de la France Centrale. Librairic Delegrave, Paris.

SAVAGE, J. M.

1958 The iguanid lizard genera Urosaurus and Uta, with remarks on related groups. Zoologica, 43:41-54.

1960 Evolution of a peninsular herpetofauna. Syst. Zool., 9:184-212.

SCIMIDT-NIFISEN, K., AND W. R. DAW'SON

1964 Terrestrial animal in dry heat: desert reptiles. In. Handbook of Physiology (D.B. Dill, Ed.), 467-480. Amer. Physiol. Soc., Wash., D.C.

Sraton, O. J., H. Hfatwolf, and E. H. Meseth

1963 Seasonal population changes in the lizard, Anolis limifrons, in Panama. Amer. Midl. Nat., 69:482-491.

SMITH, H. M.

1946 Handbook of lizards. Comstock Publ. Co., Inc. Ithaca, N.Y.

SmITI, M.

1951 The British amphibians and reptiles. Collins, London.

STEBBins, R. C.

1914 Ficld notes on a lizard, the mountain swift, with special reference to territorial behavior. Ecology, 25:233-245.

1948 Additional observations on home ranges and longevity in the lizard Sceloporus graciosus. Copeia, 20-22.

STEBBins, R. C., AND H. B. ROBINSON

1946 Further analysis of a population of the lizard Sceloporus graciosus gracilis. Univ. Calif. Publ. Zool., 48:149-168.

STORR, G. M.

1965 The Amphibolurus maculatus species-group (Lacertilia, Agamidae) in western Australia. Jour. Roy. Soc. West. Australia, 48:45-54.

TANNER, W. W.

1957 A taxonomic and ecological study of the western skink (Eumeces skiltonianus). Great Basin Nat., 17:59-94. 
1965 A comparative population study of small vertebrates in the uranium areas of the Upper Colorado River basin of Utah. Brigham Young Univ. Sci. Bull., Biol. Ser., $7: 1-24$.

TElford, S. R., JR.

1959 A study of the sand skink, Neoseps reynoldsi Stejneger. Copeia, 110-119.

TINKLE, D. W.

1959 Observations on the lizards Cnemidophorus tigris, Cnemidophorus tessellatus and Crotaphytus u'islizeni. Southwest. Nat., 4:195-200.

1961 Population structure and reproduction in the lizard Uta stansburiana stejnegeri. Amer. Midl. Nat., 66:206-234.

1965 a Effects of radiation on the natality, density and breeding structure of a natural population of lizards, Ita stamsburiana. Health Phys., 11:1595-1599.

1965b Population structure and effective size of a lizard population. Evolution, 19:569573.

1967 Home range, density, dynamics and structure of a Texas population of the lizard Uta stansburiana. In: Lizard Ecology: A Symposium (W. W. Milstead, Ed.). Univ. Missouri Press: 5-29.

TinkLe, D. W., AND L. N. IRWIN

1965 Lizard reproduction: refractory period and response to warmth in Uta stansburiana females. Science, 148:1613-1614.

TinkLE, D. W., AND W. C. L.AWRENCF.

1956 Blowguns for reptile sampling. Southwest. Nat., 1:133-134.

Tinkle, D. W., D. McGregor, and S. Dana

1962 Hone range ecology of I'ta stansburiana stejnegeri. Ecology, 43:223-229.

TINKI.E, D. W., AND D. WOODARI

1967 Relative movements of lizards in natural populations as determined from reCapture radii. Ecology, 48:166-168.

Turner, F. B., G. A. Hodmfnibach, and J. R. Lannom, Jr.

1965 Growth of lizards in natural populations exposed to gamma irradiation. Health Phys., 11:1585-1593.

VISHER, S. S.

1954 Climatic atlas of the United States. Harvard Univ. Press.

WEEKFS, H. C.

1934 The corpus lutem in certain oviparous and viviparous reptiles. Proc. Linn. Soc. N.S.W., 59:380-391.

WILHOFT, D. C.

1963 Reproduction in the tropical Australian skink, Leiolopisma rhomboidalis. Amer. Midl. Nat., 70:442-461.

Wil.hOFT, D. C., ANI E. O. REITFR

1965 Sexual cycle of the lizard, Leiolopisma fuscum, a tropical Australian skink. Jour. Morph., 116:379-388.

WOODBURY, M., AND A. M. WOODBURY

1945 Life history studies of the sagebrush lizard Sceloporus g. graciosus with special reference to cycles in reproduction. Herpetologica, 2:175-196. 



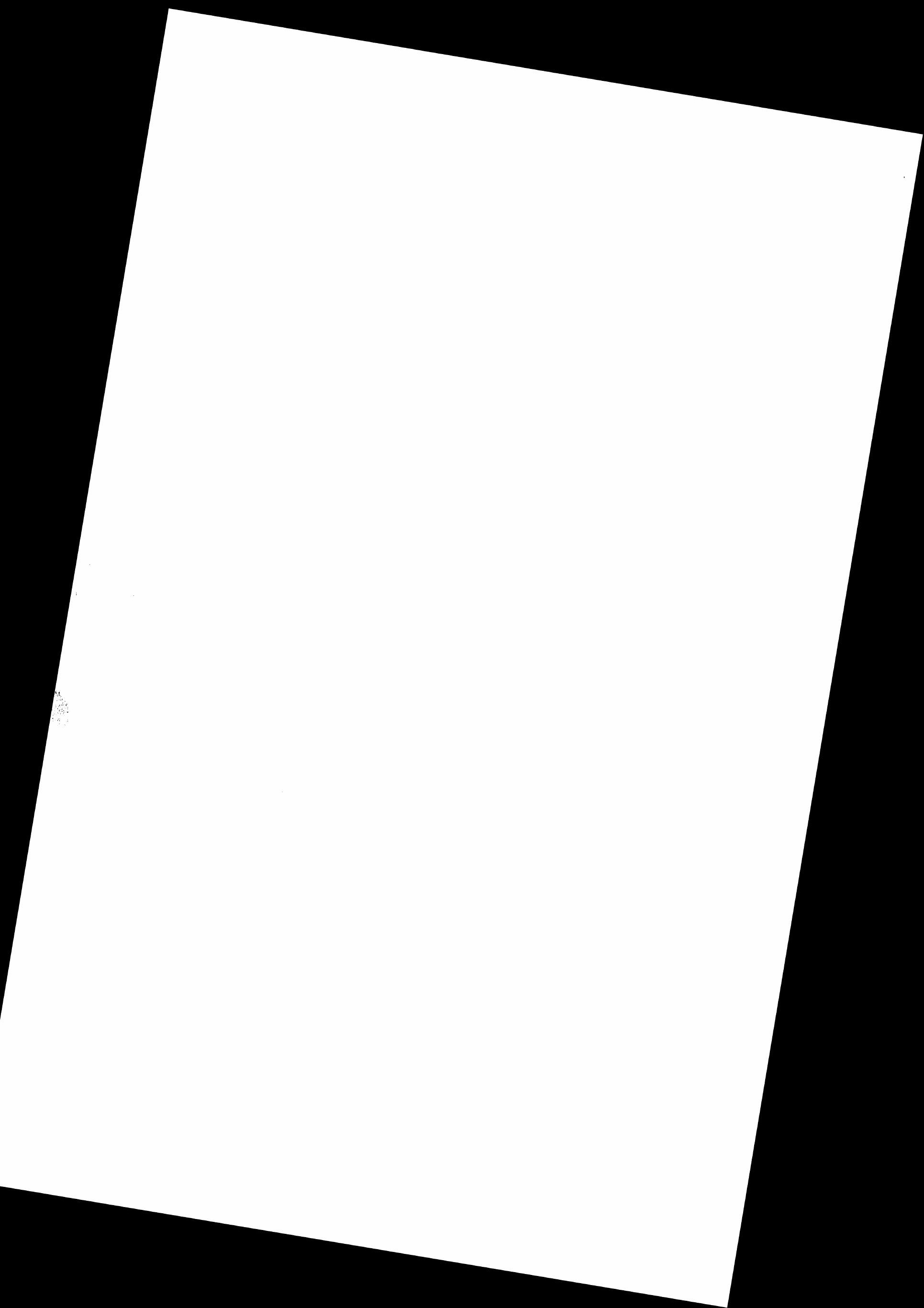


No. 101. A biogeography of reptiles and amphibians in the Gómez Farias Region, Tamaulipas, México. By Paul S. Martin. (1958) 102 pp., 7 pls., 7 figs.,

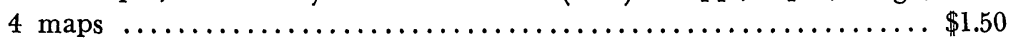

No. 110. Descriptions of tadpoles of Middle American frogs. By Priscilla Starrett. (1960) 38 pp., 1 pl., 33 figs. ........................... $\$ 1.10$

No. 111. A systematic study of the lizards of the deppei group (Genus Cnemidophorus) in México and Guatemala. By William E. Duellman and John Wellman. (1960) 80 pp., 1 pl., 16 figs. .................... $\$ 1.75$

No. 112. A Revision of the Ecuadorian Snakes of the Colubrid Genus Atractus. By Jay M. Savage. (1960) 86 pp., 11 figs. .................. $\$ 2.00$

No. 114. The Snakes of the Subfamily Dipsadinae. By James A. Peters. (1960)

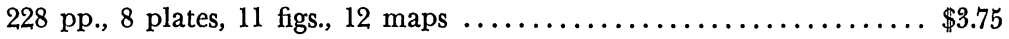

No. 122. A checklist of the herpetofauna of Guatemala. By L. C. StuART (1963)

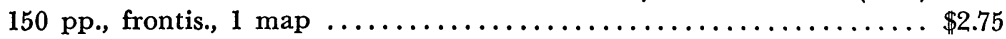

No. 128. Reptiles of Rancho Grande and Vicinity, Estado Aragua, Venezuela. By Frederick H. Test, Owen J. Sexton, and Harold Heatwole, (1966) 63 pp., 2 pls., 2 figs. ................................. $\$ 1.15$

No. 131. Intrageneric relationships among colubrid snakes of the genus Geophis Wagler. By Floyd L. Downs (1967) 193 pp., 23 figs. ............ $\$ 3.00$

No. 132. The life and demography of the side-blotched lizard, Uta stansburiana. By Donald W. Tinkle (1967) 182 pp., 4 pls., 20 figs. ............ $\$ 3.75$

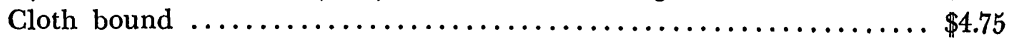


- 